Portland State University

PDXScholar

Fall 12-4-2018

\title{
Lone Wolves and Copycats: Assessing Policy and Infrastructure for Flood Hazard and Floodplain Management
}

Samantha L. Hamlin

Portland State University

Follow this and additional works at: https://pdxscholar.library.pdx.edu/open_access_etds

Part of the Environmental Sciences Commons, and the Geography Commons Let us know how access to this document benefits you.

\section{Recommended Citation}

Hamlin, Samantha L., "Lone Wolves and Copycats: Assessing Policy and Infrastructure for Flood Hazard and Floodplain Management" (2018). Dissertations and Theses. Paper 4654.

https://doi.org/10.15760/etd.6538

This Dissertation is brought to you for free and open access. It has been accepted for inclusion in Dissertations and Theses by an authorized administrator of PDXScholar. Please contact us if we can make this document more accessible: pdxscholar@pdx.edu. 
Lone Wolves and Copycats:

Assessing Policy and Infrastructure for

Flood Hazard and Floodplain Management

by

Samantha L. Hamlin

A dissertation submitted in partial fulfillment of the requirements for the degree of

\author{
Doctor of Philosophy \\ in \\ Environmental Sciences and Resources
}

Dissertation Committee:

Max Nielsen-Pincus, Chair

Randy Bluffstone

Heejun Chang

Alex Sager

Jennifer Allen

Portland State University 2018 
(C) 2018 Samantha L. Hamlin 


\begin{abstract}
To mitigate flood hazard, which affects millions of people every year, increasing numbers of communities are developing green infrastructure policies to not only mitigate the hazard, but to meet other community policy objectives, as green infrastructure is often cited for the multiple benefits it confers. To support the implementation of policies that help communities meet their policy objectives, however, it is imperative to understand how policy is innovated and adopted. To do so, I applied the internal determinants and regional diffusion models, what I refer to as the lone wolf and copycat models. In policy, a lone wolf innovates a policy to meet a specific, internal objective; this objective may include economic, environmental, or social needs. A copycat evaluates the efficacy of a policy in other municipalities before adopting it for its own use. Because infrastructure is one of the primary routes of implementing flood hazard and floodplain management policies, I developed a framework that describes the relationship between these two models. In this framework, a community may rely more heavily on either gray or green infrastructure, while also being more of a lone wolf or copycat in the ways in which it adopts policy.

Based on this framework, I analyzed four Oregon communities-Eugene, MiltonFreewater, Prineville, and Sherwood — that exemplify these different infrastructure and policy approaches. From this case study analysis, I developed several propositions to explain why each community pursued certain policies. I then expanded this research to floodplain administrators across the state, using a key informant questionnaire to capture the managerial and demographic characteristics that correlate with the adoption of green infrastructure in over 100 Oregon communities. I found that urbanization strongly correlated with the use of green infrastructure, as did a floodplain administrator having


professional experience with flooding, being knowledgeable about flood mitigation infrastructure, and talking more frequently to other floodplain administrators. Finally, I use my research framework for an in-depth case study of the internal determinants model. I focus on a community in the Portland metropolitan area, Sherwood, and a program the community developed in the early 1990s to protect extensive areas of open space, greenways, and floodplains to preserve a unique community identity. In pursuing these objectives, Sherwood spearheaded the creation of the Tualatin River National Wildlife Refuge, the first urban wildlife refuge in the country. 


\section{Dedication}

Dedicated to my father, Sam Franklin Hamlin.

A promise made is a promise kept. 


\section{Acknowledgements}

First and foremost, I am grateful for the guidance and support of my advisor, Max Nielsen-Pincus. He not only provided the scholarly engagement I needed for embarking on this new journey, his encouragement, engagement, and humor helped make the trip a bit less weary. I am also indebted to the remaining members of my dissertation committee, who enthusiastically supported my interdisciplinary research in all its guises. This includes Randy Bluffstone, who graciously agreed to serve in this capacity and patiently explained some statistical analyses when my reach exceeded my grasp. This also includes Alex Sager, my resident philosopher, who introduced me to political ecology, theories of justice and value, and the moral philosophy of economic analysis.

I wouldn't have had the opportunity to pursue interdisciplinary research without my committee member Heejun Chang, who sponsored my application to the National Science Foundation Integrative Graduate Education and Research Traineeship program in Ecosystem Services in Urbanizing Regions —aka IGERT. This sponsorship set me on a path that shaped (and will continue to shape) my intellectual development. It was as a new IGERT that I began to find my footing as an interdisciplinarian. With the continued support of our IGERT PIs, Dave Ervin, Darrell Brown, and Elise Granek, as well as other IGERT faculty, and my other 'Gerts, I not only found my footing, I found my path.

IGERT faculty Alan Yeakley deserves special recognition for bringing me on board the Blue-Green Cities research initiative. Through this project, I developed an interest in urban flood mitigation and green infrastructure, spent time at the University of Cambridge, worked in China studying sponge cities, and traveled to London for the first time - all in all, 
a fruitful experience. He has continued to support my intellectual pursuits and is a highlyvalued mentor.

I would also like to thank Fletcher Beaudoin at the Institute for Sustainable Solutions. Our work created the opportunity to expand my research into a topic that at the time, was novel for me: flooding and floodplain management. Bobby Cochran and Nicole Maness at the Willamette Partnership furthered this research, and I am indebted to Bobby who simply asked me to "say yes" to working with them.

Finally, while I dedicate this dissertation to my father, who did not live to see its completion, I would like to acknowledge mi Madre, who has supported me in more ways than one, to finish this degree. 
Table of Contents

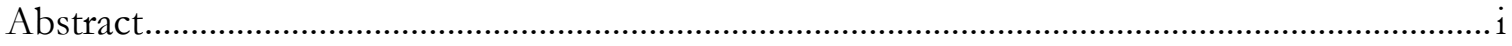

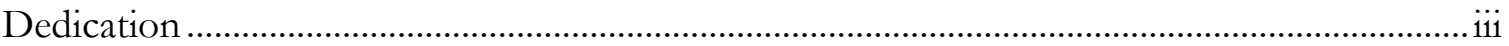

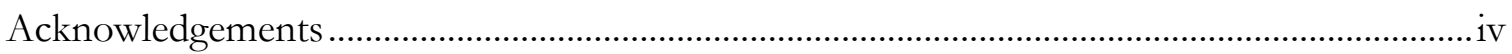

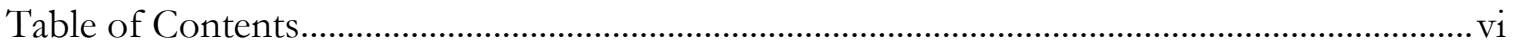

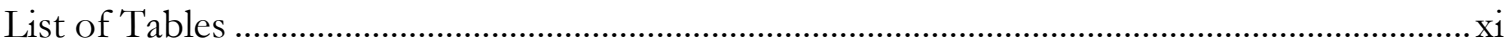

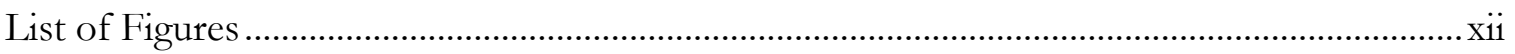

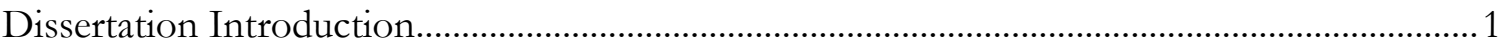

Chapter One: From gray copycats to green wolves: Assessing policy and infrastructure for flood hazard and floodplain management ..................................................................................

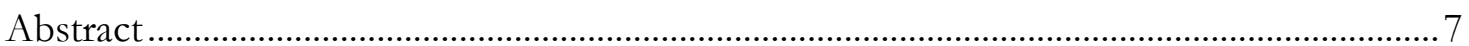

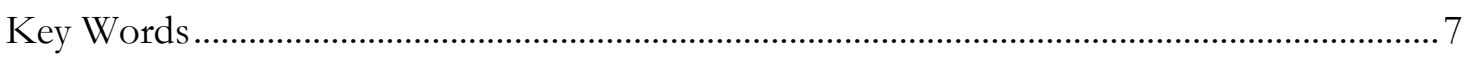

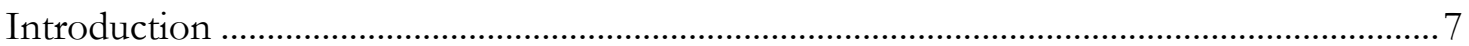

Flood Control Policy and Floodplain Management...........................................................10

Why Do Communities Adopt Green Infrastructure for Flood Hazard and Floodplain

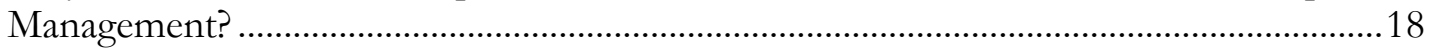

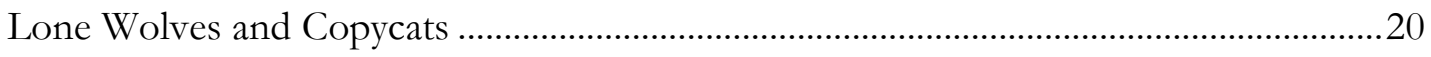

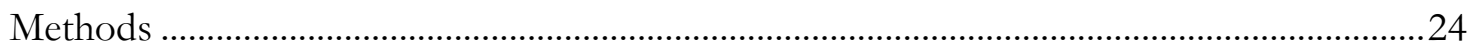

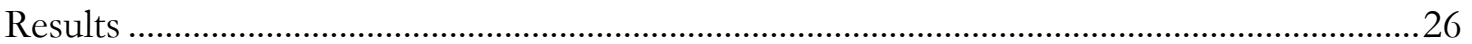

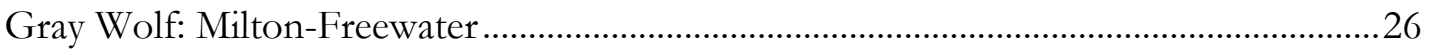

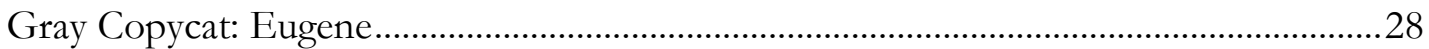

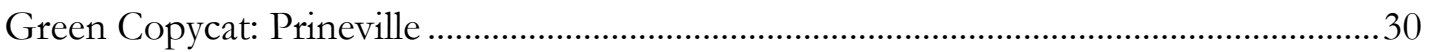

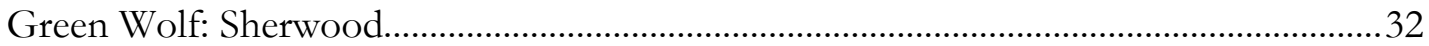

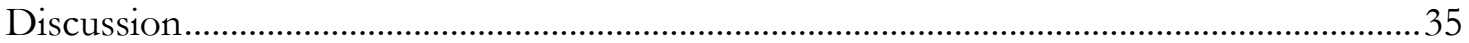

Proposition 1: A historical legacy can constrain future policy decisions. ...........................35

Proposition 2: Communities can circumvent the historical legacy of past decisions and

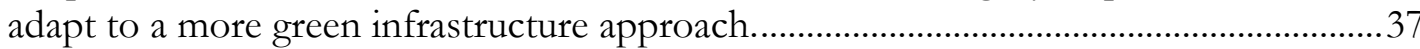

Proposition 3: Meeting regulatory requirements and improving economic competitiveness can complement floodplain protection......................................................38

Proposition 4: Innovative green infrastructure policy is likely to involve social rationale like community identity in addition to basic stormwater management or floodplain management objectives.

Proposition 5: A community can be a lone wolf and a copycat within the same policy process.

Conclusion 
Chapter Two: Green infrastructure for flood hazard and floodplain management: A survey

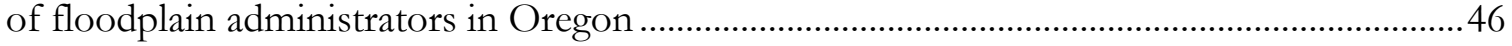

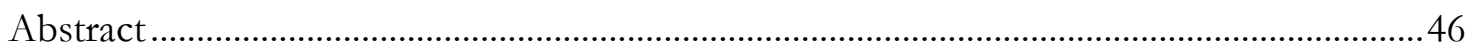

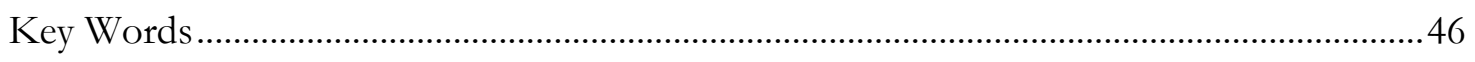

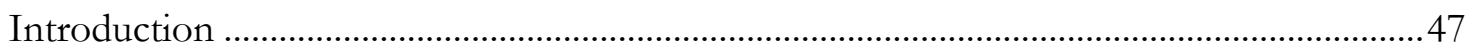

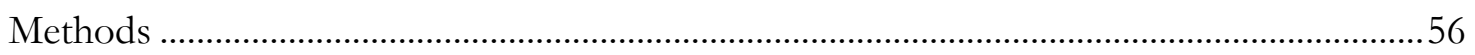

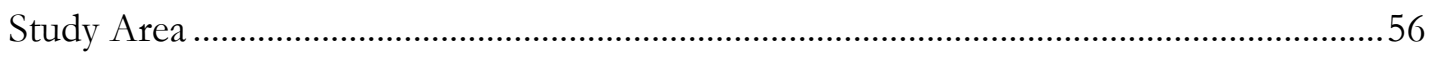

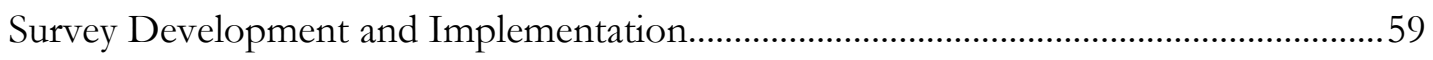

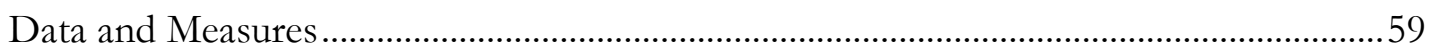

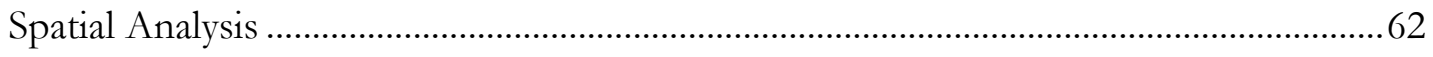

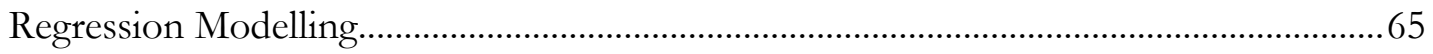

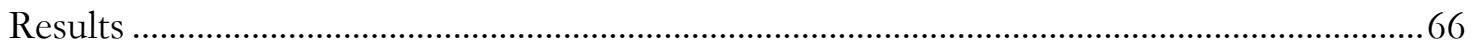

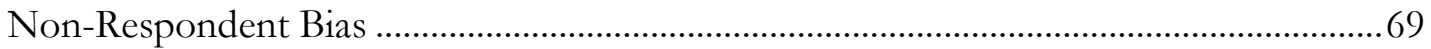

Green Infrastructure Composite Index ...................................................................................69

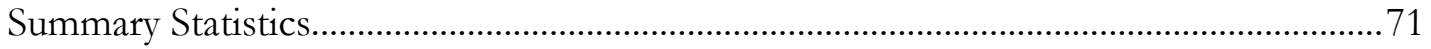

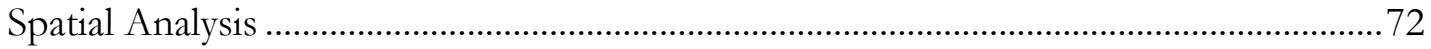

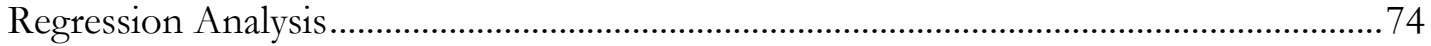

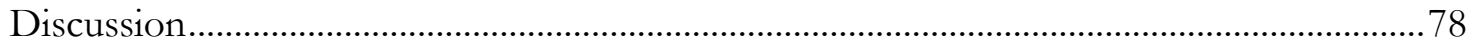

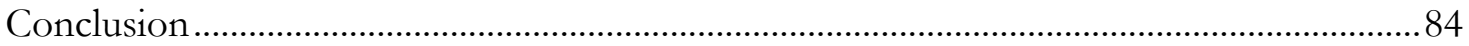

Chapter Three: Community identity, green infrastructure, and flood hazard mitigation: The novel case of the nation's first urban National Wildlife Refuge..................................................86

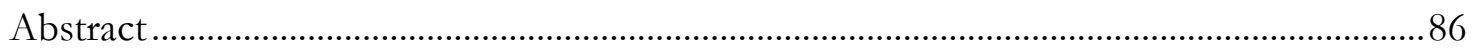

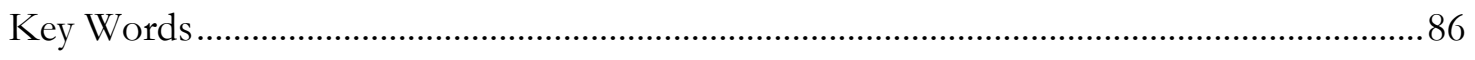

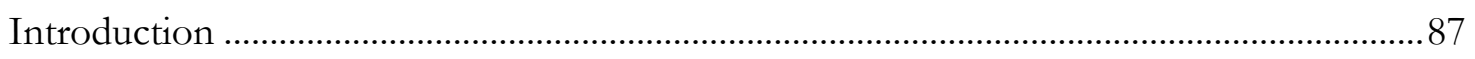

Internal Determinants and Policy Innovation and Adoption.............................................8

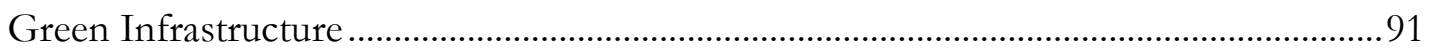

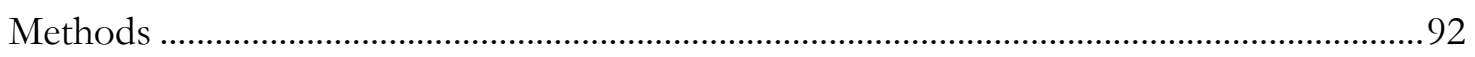

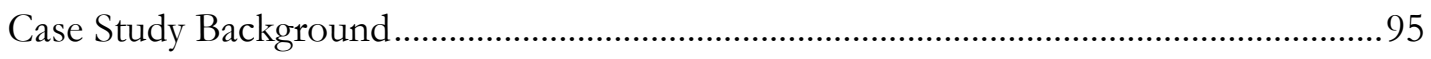

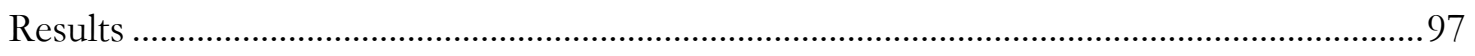

Sherwood Floodplain and Open Space Protection Program ..........................................97

Creation of the Tualatin River National Wildlife Refuge .................................................... 102

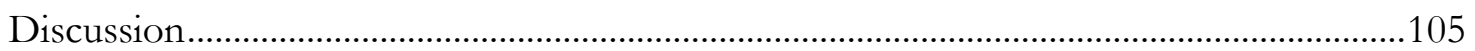

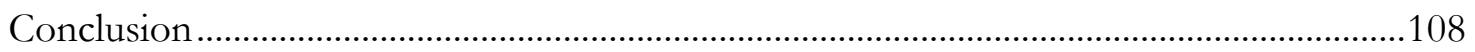

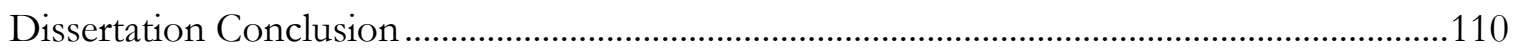




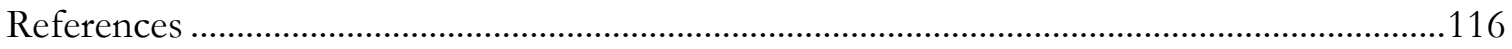

Appendix A: Survey Summary Report.........................................................................134

Executive Summary ………………………………………………………………...134

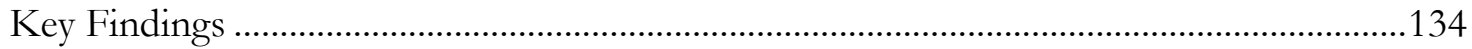

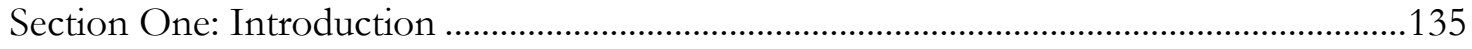

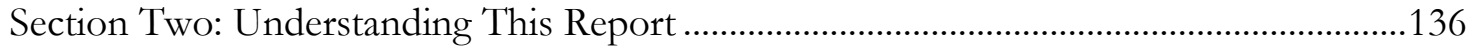

Frequently Used Abbreviations......................................................................................139

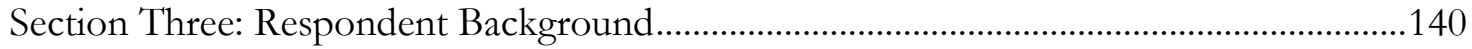

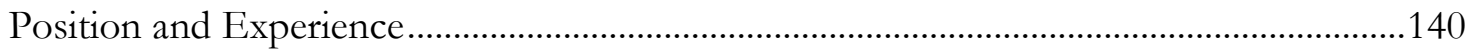

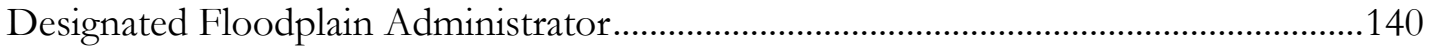

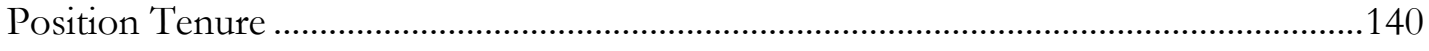

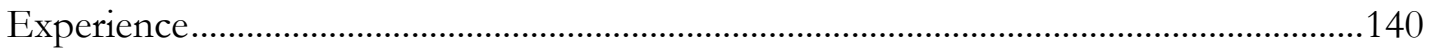

Floodplain Manager Certification ……………………………………………………....140

Professional Membership.......................................................................................... 140

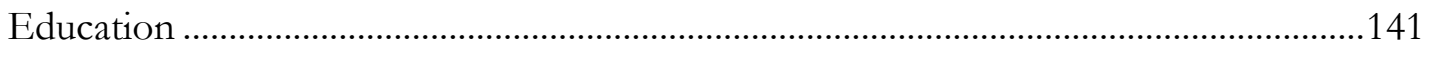

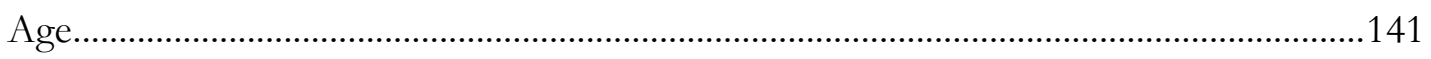

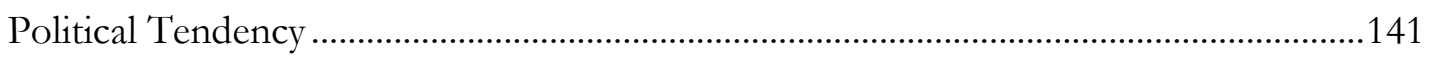

Participation and Knowledge...................................................................................142

Flood Hazard and Floodplain Management Activities......................................................142

Flood Hazard and Floodplain Management Knowledge ..................................................143

Section Four: Community History and Experience with Flooding .....................................144

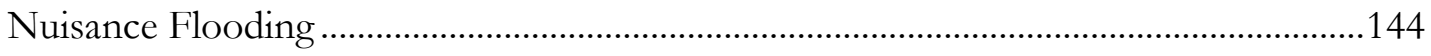

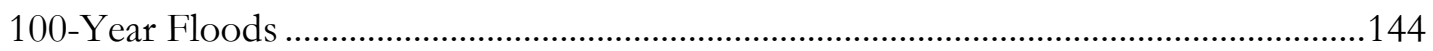

Federal Flood Disaster Declarations .................................................................................146

Section Five: Community Flood Hazard and Floodplain Policy Development .................148

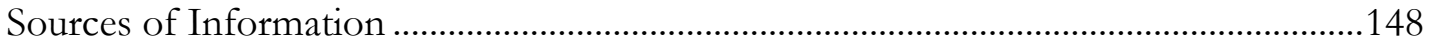

Flood Management Plans................................................................................................148

Talking to Other Communities ..................................................................................149

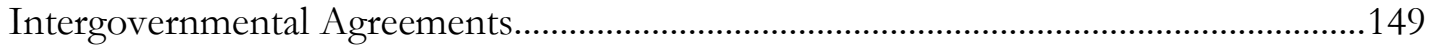

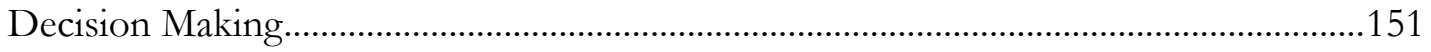

Section Six: Community Infrastructure and Policy ……………………………………...152

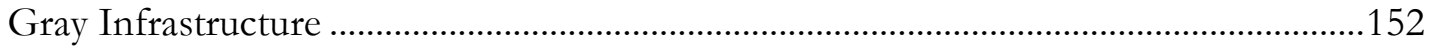

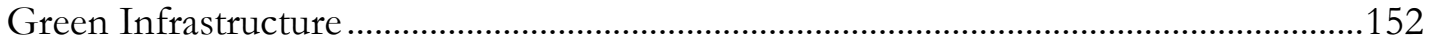

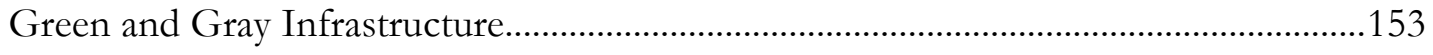

viii 
Green / Gray Infrastructure Index ............................................................................154

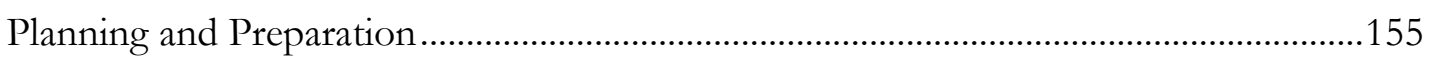

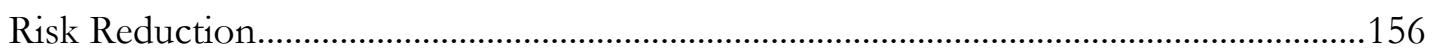

Education and Public Awareness.....................................................................................157

Emergency Management Improvements...................................................................158

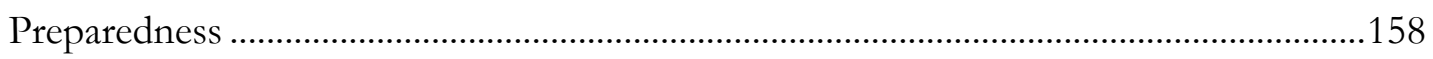

Section Seven: Beliefs and Attitudes About Flood Hazard and Floodplain Management

Flood Hazard and Floodplain Management Benefits...................................................160

Green Infrastructure Beliefs .............................................................................................161

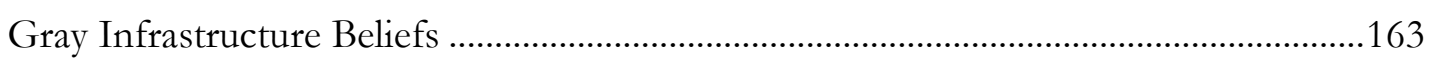

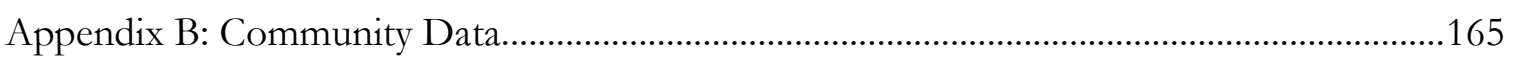

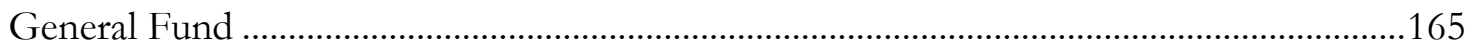

Income and Unemployment …………………………………………………………...165

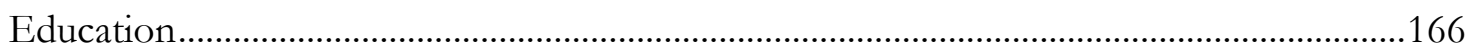

Appendix C: Additional Survey Responses...........................................................................168

Flood Hazard and Floodplain Management Activities and Knowledge .............................168

Flood Hazard and Floodplain Management Activities ....................................................168

Flood Hazard and Floodplain Management Knowledge ..................................................168

Communities Exemplifying Good Management ................................................................169

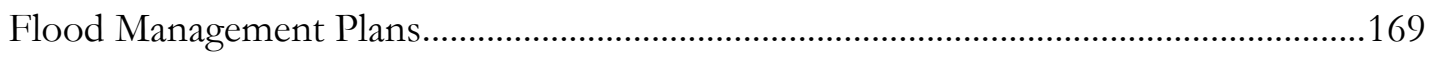

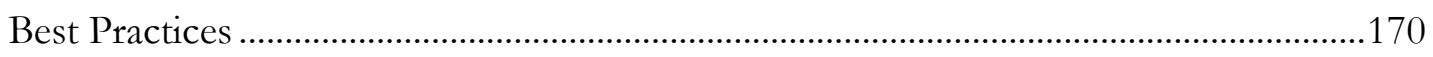

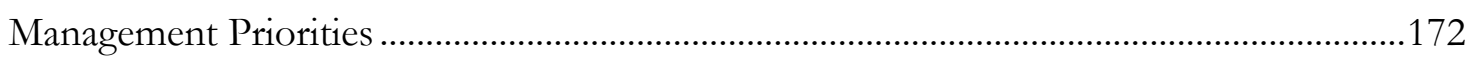

Improving Development and Zoning.......................................................................172

Improving Stormwater Management ........................................................................172

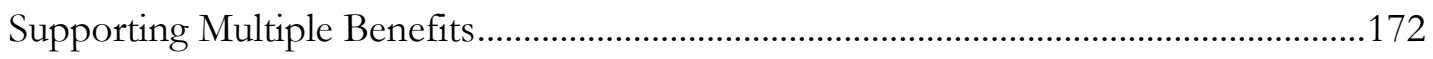

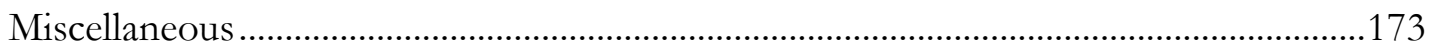

Green Infrastructure and Native Fish ....................................................................... 174

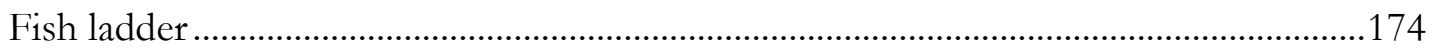

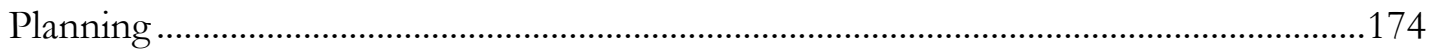

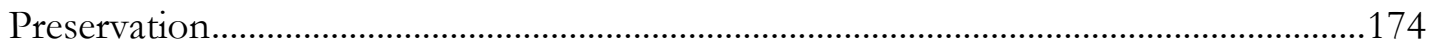

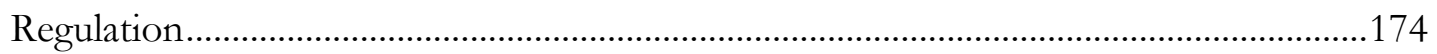

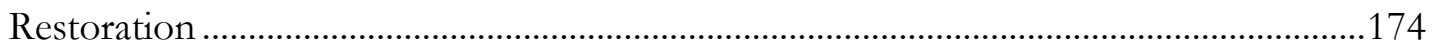

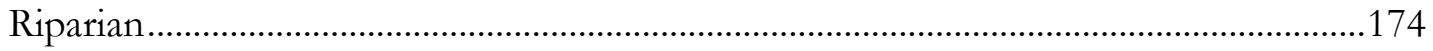




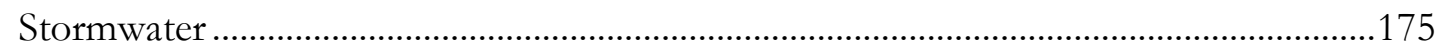

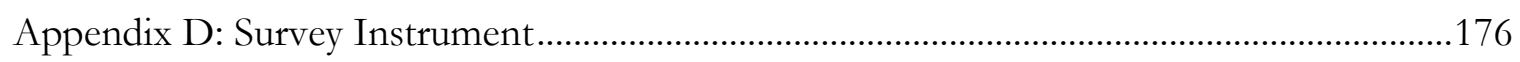




\section{List of Tables}

Table 1. The professional association of interviewees in each of the case study communities: Eugene, Milton-Freewater, Prineville, and Sherwood. Respondent numbers are included for references within the text.

Table 2. Hypotheses on the characteristics that may positively influence the adoption of green infrastructure adoption for flood risk and floodplain management. ...............................56

Table 3. Variable names and descriptions for Poisson and OLS regression analysis.

Table 4. Survey inventory questions for the dependent variable Green Infrastructure, with percentage of affirmative answers and Cronbach's alpha....

Table 5. Summary statistics for the dependent and independent variables. The range and mean are presented for integer data, and proportions are presented for categorical data. .....71 Table 6. Documents used for archival analysis of Sherwood's floodplain protection program and the creation of the Tualatin River National Wildlife Refuge. 


\section{List of Figures}

Figure 1. A spectrum of green to gray infrastructure for flood hazard and floodplain management. The green end of the spectrum includes more ecologically-based infrastructures such as preserved wetlands and floodplains, as well as stream and floodplain restoration. Vegetated bioswales, while still considered green infrastructure, are typically highly engineered and contain concrete or similar materials. The gray end of the spectrum includes weirs, which sit directly in rivers to moderate streamflow; levees, which may be earthen or concrete; and dams and other flood control structures.

Figure 2. A conceptual framework for the interaction of gray and green infrastructure with the internal determinants (i.e., lone wolf) and regional diffusion (i.e., copycat) models. The lone wolf and copycat model are on the $y$-axis, and infrastructure type is on the $x$-axis. The interaction of these two dimensions of flood hazard and floodplain management create four archetypes: The gray copycat, green copycat, green wolf, and gray wolf. Each of these describes a different approach to flood hazard and floodplain management, based on infrastructure used and mode of policy adoption.

Figure 3. Oregon topography, showing the range of different land covers, including extensive forest, agriculture, and scrublands. The most heavily urbanized areas are in the western and northwestern part of the state; these areas are also heavily agricultural. The darker shades in the western part of the state indicate lower elevations compared to the higher elevations in the eastern part of the state.

Figure 4. Flood-prone communities and the 1\% annual flood zone (formerly called the 100year floodplain) in Oregon. Survey respondents are noted with red circles, while nonrespondents are noted with dark blue diamonds.

Figure 5. The types of gray and green infrastructure respondent communities are using for flood hazard and floodplain management. This includes large-scale green infrastructure such as wetland or floodplain preservation and stream or floodplain restoration as well as smallscale green infrastructure such as vegetated bioswales, in addition to large-scale gray infrastructure such as dams or levees and smaller gray infrastructures such as build flood control channels. Regardless of scale, green infrastructure was reported as being used more than gray infrastructure for flood hazard and floodplain management.

Figure 6. Histogram of the distribution of the dependent variable, green infrastructure. Values for this variable range from zero to nine, with approximately $10 \%$ of communities reporting that no green infrastructure was being used.

Figure 7. Local Getis-Ord spatial autocorrelation analysis. Hot spots with high values of green infrastructure adoption are found in the Portland metropolitan area. Cold spots with lower values of green infrastructure adoption are primarily in the eastern part of the state. 72

Figure 8. Bivariate Local Indicators of Spatial Association analysis of green infrastructure and MMSA. High - high values found primarily in northwestern Oregon indicate high values of green infrastructure in urban areas. The low - high values interspersed with these indicate urban areas with low amounts of green infrastructure. Low - low areas, found primarily in eastern Oregon, indicate rural areas with low values for green infrastructure, while a couple of high - low spots show rural areas with higher amounts of green infrastructure..................74 Figure 9. The City of Sherwood and the Tualatin River National Wildlife Refuge in the southwestern Portland metropolitan area. 
Figure 10. The City of Sherwood and the Portland Metropolitan area. The Tualatin River and its tributaries, Cedar and Rock Creeks are visible, as well as the acquired and approved boundaries of the Tualatin River National Wildlife Refuge........................................................97 


\section{Dissertation Introduction}

In 2007, the Great Coastal Gale landed in Oregon, Washington, and British

Columbia. At 2:30 p.m. on December 1, the Nehalem River, which runs through the town of Vernonia in northwest Oregon, was running at 153 cubic feet per second. Twenty-four hours later, it was up to 1,130 cubic feet per second. Another 24 hours later, on December 3, the Nehalem River discharged at 17,600 cubic feet per second (U.S. Geological Survey Water Data Support Team 2016b). The river was in major flood stage, with its highest recorded crest, 19.10 feet (National Weather Service 2016b). It inundated the small town, flooding homes and business in up to five feet of water, engulfing vehicles, and wiping out roads and communication. The entire town was cut off until the National Guard arrived, evacuating more than $15 \%$ of residents in boats and rafts; almost a third of the town residents sought shelter with the Red Cross (Crombie 2007, December 4).

Forty miles to the southeast, Milwaukie, a suburb in southeastern Portland, was also getting hit the by Great Coastal Gale. At 4:30 p.m. on December 1, Johnson Creek, a tributary of the Willamette River that runs through heavily populated East Portland, was discharging at 111 cubic feet per second. After 24 hours, it had almost tripled, to 331 cubic feet per second. And 24 hours after that, Johnson Creek ran at 1,990 cubic feet per second (U.S. Geological Survey Water Data Support Team 2016a). Johnson Creek was also in flood stage and crested at 11.90 feet (National Weather Service 2016a). As it rose, streets flooded and several intersections were closed, "but for the most part, homeowners and businesses weren't affected much” (Learn 2007, December 3).

What is different about these two cities, so close together and hit by the same storm, but affected so differently? Precipitation levels differed between Vernonia and Milwaukie, 
but not as substantially as the impacts: approximately 6.74 inches outside of Vernonia versus 4.94 inches in the Milwaukie area (National Centers for Environmental Information 2016). Both cities are vulnerable to flooding based on the amount paid in National Flood Insurance Program (NFIP) claims (Oregon Department of Land Conservation and Development 2015). How did the same storm with similar precipitation levels in the same region slow the morning commute in one place but require a National Guard evacuation in another? One critical difference is that almost half of Vernonia, $42 \%$, is located within the 100 -year floodplain (Oregon Partnership for Disaster Resilience 2012).

Weather-related disasters have caused $90 \%$ of natural disasters in the past twenty years, and flooding was responsible for approximately half of those disasters (Centre for Research on the Epidemiology of Disasters and United Nations Office for Disaster Risk Reduction 2015). As the most common natural disaster in the world, flooding is also the leading cause of fatalities from natural disasters (Doocy, Daniels, Murray, and Kirsch 2013). The United Nations notes two specific factors that play a critical role in determining flood hazard: population growth and "uncontrolled building on floodplains" (p. 5; Centre for Research on the Epidemiology of Disasters and United Nations Office for Disaster Risk Reduction 2015). As population increases, so too does urbanization, development, and deforestation; individually each factor increases flood hazard, but taken in concert, there is a risk of catastrophic loss because of flooding (Doocy, Daniels, Murray, and Kirsch 2013). Coupled with these contributing factors is climate change. The Intergovernmental Panel on Climate Change forecasts that climate change will very likely cause an increase of heavy precipitation events and flooding in most areas of the world (Bates, Kundzewicz, Wu, and Palutikof 2008). Indeed, a global analysis of the frequency of 'great floods' - that is, floods 
with large discharges (exceeding a 100-year event) in large basins (greater than $200,000 \mathrm{~km}^{2}$ ) found that not only did the frequency of great floods increase substantially in the twentieth century, but climate models suggest that this trend will continue (Milly, Wetherald, Dunne, and Delworth 2002).

Gray infrastructure projects such as dams and levees have been engineered to protect against flood hazard. Graf (2001) estimated that the US has constructed more than 80,000 dams, many of them at least partially for flood control. Levees, unlike dams, which are also used for irrigation, recreation, and other activities, are constructed solely for flood control. The U.S. Army Corps of Engineers (USACE) estimates that there are approximately 30,000 miles of levees in the US; they are, on average, 55 years old (U.S. Army Corps of Engineers 2018), a legacy of the decades-long 'levees-only' policy of the USACE (Randolph 2018; U.S. Army Corps of Engineers 2017b).

As flood hazard increases, however, communities are looking for other solutions to mitigate flooding, including green infrastructure and ecosystem-based approaches such as wetland and floodplain protection (Kabisch, Frantzeskaki, Pauleit, Naumann, Davis, Artmann, Haase, Knapp, Korn, Stadler, Zaunberger, and Bonn 2016; Wenger 2015). Green infrastructure is a term that captures a wide range of approaches to sustainable land use and water resource management, and is often used for stormwater management and flood mitigation (Hansen and Pauleit 2014; Tzoulas, Korpela, Venn, Yli-Pelkonen, Kaźmierczak, Niemela, and James 2007). Benedict and McMahon (2006) define green infrastructure as "an interconnected network of natural areas and other spaces that conserves natural ecosystem values and functions, sustains clean air and water, and provides a wide array of benefits to 
people and wildlife. Used in this context, green infrastructure is the ecological framework for environmental, social, and economic health—in short, our natural life-support system.”

Green infrastructure is often implemented for the ancillary benefits it confers (Tayouga and Gagné 2016). These benefits may include air and water quality improvement, increased biodiversity, carbon sequestration, flood mitigation, and recreation (Benedict and McMahon 2006). In the case of floodplains as green infrastructure, there are numerous benefits to be realized, in addition to flood mitigation, including groundwater recharge, wildlife habitat, and aesthetic and cultural values (Brauman, Daily, Duarte, and Mooney 2007). The multiple benefits of green infrastructure, as well as cost savings over the life of the infrastructure (Talberth, Gray, Yonavjak, and Gartner 2013), are two reasons communities may choose to adopt green infrastructure.

The use of green infrastructure is a policy decision, balancing local planning objectives with regional needs and regulatory requirements. Why some communities adopt policies earlier than others has been the subject of extensive research into policy diffusion, starting with Walker's Walker (1969) seminal article, which adapted the theory of the diffusion of innovations (Rogers 1962) to policy. Initially, the policy diffusion literature investigated how policy innovations were diffusing between communities: was it simply a function of proximity, or were there factors that predisposed a community to the adoption of innovation? Walker (1969) noted that a policy innovation was simply a policy that was new to the community adopting it, an argument that has continued throughout policy diffusion literature. Berry and Berry (1990) eventually expanded the research on policy diffusion, however, developing the regional diffusion and internal determinants models to explain the innovation and diffusion of policy adoption. 
The internal determinants model describes a community that innovates a policy to meet because of internal social, political, or economic characteristics. In order to meet a policy objective, the community develops and implements a policy that meets its specific goals. The regional diffusion model describes a community that adopts a policy after observing its implementation in a neighboring community (Berry and Berry 2014). In this way, the community is able to observe the consequences of a policy to determine if it is a good fit-in other words, other communities function as "policy laboratories" (Matisoff 2008). Berry and Berry (2014)posit that this spread of policy occurs regionally-either between adjacent or proximal communities—because of similar regulatory environments and sociopolitical pressures.

This dissertation investigates the factors that drive communities to adopt green infrastructure for flood hazard and floodplain management. A research framework flows from this, in which I analyze the interaction between the internal determinants and regional diffusion models and the use of gray and green infrastructure. I argue in this dissertation that while there are extensive socioecological benefits to be provided by green infrastructure, it is often indirect factors that primarily drive its adoption. That is, while green infrastructure may be adopted to meet, for example, stormwater management requirements, the choice to do so is often driven by social and institutional factors unrelated to green infrastructure itself.

In the first chapter, I review the literature on flood hazard and floodplain management, the use of gray and green infrastructure for flood mitigation, and modes of policy adoption. I apply this research to four municipal case studies in Oregon to enhance my understanding of the different approaches communities may take for managing flood hazard and floodplains. Through the literature and the case studies, I develop several 
propositions to describe the underlying rationale for infrastructure and policy adoption. These propositions are not meant to be testable hypotheses, but rather ways of framing flood hazard and floodplain management within the two dimensions of gray and green infrastructure and the internal determinants and regional diffusion models.

In Chapter Two, I report on the results of a key informant questionnaire to Oregon floodplain administrators to develop hypotheses to explain the likelihood of a municipality adopting green infrastructure. This chapter tests several different characteristics often associated with innovation adoption, including managerial, organizational, and demographic characteristics, as well as a spatial analysis to investigate the regional diffusion model.

In Chapter Three I perform an in-depth case study analysis of the policy process for a floodplain protection program that supported the creation of the first urban National Wildlife Refuge in the nation. In this chapter I examine the horizontal and vertical governance coordination, as well as the strong local leadership to maintain a distinct community identity, that made this possible.

The dissertation conclusion reviews primary findings from each chapter and how they fit together, as well as final thoughts on future directions for research on green infrastructure for flood hazard and floodplain management.

The appendices include a report that was created to summarize the data from the key informant questionnaire. To provide more context to the findings, I summarized the data based on the size of the community. The appendix also includes a copy of the survey instrument. 


\title{
Chapter One: From gray copycats to green wolves: Assessing policy and infrastructure for flood hazard and floodplain management
}

\begin{abstract}
Flooding has affected well over two billion people. While gray infrastructure like levees and dams has traditionally been used to mitigate this hazard, many communities are looking for other approaches to augment or even replace some of these structural solutions. Propelled by the regulatory support for green infrastructure approaches for stormwater management—which incorporate vegetation into the design—some of these communities are also looking to green infrastructure for flood hazard and floodplain management. This research uses case study analysis to evaluate how these policies are evolving in place and diffusing through policy networks by applying the internal determinants and regional diffusion models. Based on these case studies, I develop several propositions as a way of focusing my findings on the community objectives and policy processes for flood hazard and floodplain management. These findings contribute to the literature on policy innovation and adoption, and further elucidate the nuances of these models in explaining flood hazard and floodplain management.
\end{abstract}

\section{Key Words}

Flooding, floodplain management, internal determinants, regional diffusion, gray infrastructure, green infrastructure

\section{Introduction}

Flooding is the most damaging natural disaster in the world today (Opperman, Galloway, Fargione, Mount, Richter, and Secchi 2009). Flooding has numerous impacts, including loss of life, property damage, and loss of livestock and crops; flood-related 
malnutrition and water-borne illness are also common (Centre for Research on the Epidemiology of Disasters and United Nations Office for Disaster Risk Reduction 2015; Office of the Queensland Chief Scientist 2011). Extensive infrastructure damage may also result from flooding, resulting in a lack of clean drinking water and wastewater treatment, as well as limited access to electricity, communication, education, health care, and transportation (Office of the Queensland Chief Scientist 2011). Flooding caused over 170,000 deaths globally between 1975-2000 (University of Sheffield Social and Spatial Inequalities Group and Newman 2006) and 2.3 billion people were affected between 1995 and 2015 at an economic cost of over US\$650 billion (Centre for Research on the Epidemiology of Disasters and United Nations Office for Disaster Risk Reduction 2015). In recent research on the countries most impacted by flooding, the United States (US) ranked eighteenth, largely because of economic costs (World Resources Institute 2015); fatalities in the US are significantly fewer than in other parts of the world-approximately 100 annually (Centers for Disease Control and Prevention 2014).

There are, however, also substantial benefits from flooding. Floods increase connectivity between rivers and the land, enhancing aquatic and riparian habitats, inundating wetlands, and recharging groundwater (Opperman, Luster, McKenney, Roberts, and Meadows 2010). Numerous fish and plant species also rely on flooding for breeding, dispersal, and migration (Office of the Queensland Chief Scientist 2011; Opperman, Luster, McKenney, Roberts, and Meadows 2010; Postel and Carpenter 1997). Flooding deposits nutrient-rich soil for agricultural production as floodwaters recede (Postel and Carpenter 1997). These ecological effects from flooding may provide several ecosystem services, such as increased fish production, improved recreation areas, improved water availability, and 
enhanced soil productivity (Brauman, Daily, Duarte, and Mooney 2007; Opperman, Luster, McKenney, Roberts, and Meadows 2010).

Policy to address flood hazard and floodplain management aims to balance the tension between flood disasters and beneficial floodplain management. In the United States, federal policies such as the numerous Flood Control Acts and the National Flood Insurance Act granted federal authority to the U.S. Army Corps of Engineers (USACE) to manage flood hazard and created programs like the National Flood Insurance Program (NFIP). State and local governments also have policies and programs that affect flood hazard and floodplain management policy, including land use regulations (Burby 2005; Burby, Deyle, Godschalk, and Olshansky 2000). Several states have statewide land use planning systems that address natural hazards like flooding (e.g., California, North Carolina, and Oregon; Burby 2005). Oregon, for example, has nineteen statewide planning goals with guidelines for both land use planning and areas subject to natural hazards (Oregon Department of Land Conservation and Development 2010). In addition, some metropolitan areas also have regional governments that oversee local planning and land use (Oregon Metro 2016; Regional Plan Association 2017). The Metro regional government for Oregon's Portland Metropolitan area oversees planning for a network of open space and natural areas, including floodplains, within its jurisdiction of three counties and 24 cities (Oregon Metro 1992).

Governance of flood hazard and floodplain management also contributes to decisions about the types of infrastructure communities rely on to balance the tensions between the benefits and costs of flooding. Traditionally, gray infrastructure such as weirs, dams, and levees has been used to mitigate flooding, either by retaining floodwater during periods of inundation, or to move it off the landscape as quickly as possible (Graf 2001; 
Wenger 2015). For instance, St. Louis, Missouri is one of many cities that rely on an extensive levee system along the Mississippi River to control flooding, and the repair and enlargement of these levees has enabled the city to increase development along the river (Belt 1975; Pinter 2005; U.S. Army Corps of Engineers 2016). Green infrastructure is often used for stormwater management, but may also be used for flood mitigation relying on natural vegetation and soil properties to slow the entry of water into the hydrological system (Benedict and McMahon 2006). In addition to providing hydrologic benefits, green infrastructure may also provide benefits to water quality improvement, wildlife habitat, recreation, and other human values (Benedict and McMahon 2006).

This paper aims to investigate why some municipalities adopt more comprehensive green infrastructure programs and policies than others. To do so, I begin by reviewing the history of municipally-oriented flood control policy and the emergence of green infrastructure and natural area preservation as a floodplain and flood hazard management strategy and alternative to gray infrastructure, and the different models of policy adoption important to answering this question. In addition, I use several case studies from the state of Oregon, USA to illustrate different influences on green infrastructure adoption and to develop a series of propositions that help explain why some communities develop approaches to floodplain and flood hazard management that are disproportionately dependent on green infrastructure, while others continue to reinvest in grey solutions. Flood Control Policy and Floodplain Management

Flood hazard and floodplain management in the US are regulated by several federal policies. The first federal flood control regulations were a series of Flood Control Acts that funded flood control projects in different areas of the country, as well as granted authority to 
the USACE to oversee flood control projects as a federal activity (Arnold 1988). Most of these USACE flood control projects constructed gray infrastructure, such as the 3,500 miles of levees and dikes protecting cities and agriculture throughout the Mississippi River Basin (U.S. Army Corps of Engineers 2016). This authority has shaped much of the country's topography, especially in cities where flood control projects removed some of the most obvious disincentives to settling and developing floodplains.

One of the prevailing regulations for flood hazard and floodplain management is the NFIP administered by the Federal Emergency Management Agency (FEMA). The National Flood Insurance Act of 1968 created the NFIP while also encouraging state and local governments to create policy that would minimize flood damage in vulnerable areas (Office of the General Counsel 1997). FEMA crafts some of the most important policy for flood hazard and floodplain management through the NFIP. The vast majority $(85 \%)$ of flood insurance in the US is underwritten by the NFIP, not private insurers (Lehmann 2018, March 18) because of the high risk. Unlike most insurance, in which risk is balanced against the premiums, flood damages are considered so variable and extreme that many private insurance companies are unwilling to underwrite policies (Burby 2001; Michel-Kerjan 2010). The NFIP covers many properties where private insurance would not be available. However, the NFIP requires that participating municipalities meet or exceed minimum standards and requirements, which primarily regulate development in defined floodplain areas (Federal Emergency Management Agency 2005). The NFIP also reflects the effects of the many Flood Control Acts by removing insurance NFIP standards and requirements from floodplains protected by levees managed by the USACE and other entities (Pinter 2005). Burby (2006) refers to the tension created by programs like the NFIP and the government's 
flood control authorities as the paradoxes of government disaster policy. On the one hand, the 'safe development paradox,' develops from the federal government trying to make hazardous areas safer-for example, by building levees and then removing insurance requirements-but actually substantially increasing the potential for catastrophic losses and property damage should those levees fail. On the other hand, although the local residents bear the brunt of these catastrophes, local officials — incentivized by safe development— do not pay sufficient attention to policies that would limit their vulnerability creating the 'local government paradox' (Burby 2006). For example, despite being devastated by the Mississippi River flooding in 1993, St. Louis extensively developed previously flooded areas in the decade that followed (Pinter 2005).

Since 1978, the NFIP has received over $\$ 67$ billion in insured claims (Federal Emergency Management Agency 2018d). Although the majority of claims are from Texas and Louisiana, every state in the country has experienced flooding issues. Oregon, the study area for the case studies in this paper, has had approximately $\$ 1$ billion in NFIP claims (Federal Emergency Management Agency 2018d). Costs in addition to NFIP claims include damaged infrastructure, crop loss and decreased food production, community displacement, and health impacts (Mallakpour and Villarini 2015). Catastrophic events can increase these costs substantially: Hurricane Katrina was estimated to cost over $\$ 140$ billion (Burton and Hicks 2005) and Hurricanes Harvey and Irma each had an economic cost between $\$ 42$ and \$65 billion (Stupak 2017, October 2).

Increasingly, however, municipalities are relying on green infrastructure such as open space and floodplain protection to mitigate flooding (Brody and Highfield 2013). While open space can include any area free from development (Kline 2006), floodplains are a specific 
type of open space. Floodplains are the low-lying lands adjacent to rivers and streams that are predictably inundated with flood waters of varying depths, and are an interface between terrestrial and aquatic environments (Junk and Welcomme 1990; Tockner and Stanford 2002). During periods of high precipitation and snow melt, functioning floodplains store excess water, temporarily slowing its entry into the hydrological system. After inundation periods, water is slowly released from storage, thereby reducing hazardous flooding and simultaneously recharging groundwater (Tockner and Stanford 2002). The benefits of functioning floodplains are limited or unrealized in systems that have been developed or highly modified; vegetation removal, channelization, paving, dikes, and levees alter the topography and make these areas more susceptible to hazardous flooding (Office of the Queensland Chief Scientist 2011). Although open space protection is not new to planners (Bengston, Fletcher, and Nelson 2004), specifically tailoring open space protections toward floodplain protection for flood mitigation is a relatively innovative approach to managing flood hazard. In the early 1990s policy in the US started focusing on protecting open space, greenways, and floodplains explicitly for flood mitigation (Brody and Highfield 2013). Floodplain protection as a strategy for flood hazard management recognizes the flood mitigation benefits of well-functioning floodplains, and seeks to either preserve them, or enhance them by removing structures or other limits to floodplain function. Protecting floodplains not only increases the water storage capacity of the floodplains, but also decreases the property that is vulnerable to damage (Brody and Highfield 2013), in addition to providing a variety of other social and ecological benefits.

In the US, public policy typically uses the $1 \%$ flood to demarcate the difference between a regulated and unregulated floodplain. Formerly called the 100-year flood, which 
would inundate a given area known as the 100-year floodplain, this is the flood volume that has a $1 \%$ chance of occurring in a given year. The $1 \%$ flood area is commonly denoted as the special flood hazard area. Other floods volumes and areas, such as a bankfull flood or the 500-year flood may have important hydrological and ecological significance, but in the US, the special flood hazard area has particular significant to floodplain and flood hazard management in the US.

The majority of flood hazard and floodplain management policy in the US is focused on preparing for and mitigating flood damage. Recognizing that there are benefits from flooding and floodplains, though, the Clean Water Act (CWA) directly supports floodplain management for the benefits provided by functioning floodplains. The CWA regulates water pollution, including physical alterations to aquatic environments (Section 404), which is particularly salient for flood hazard and floodplain management. Jointly administered by the U.S. Army Corps of Engineers (USACE) and the U.S. Environmental Protection Agency (EPA), Section 404 regulates the discharge of dredge and fill material into waterways. In 1977, President Jimmy Carter cited Section 404 when he issued Executive Order 11988 that floodplains shouldn't be occupied or modified, nor should agencies, either directly or indirectly, support development in floodplains whenever there was a practicable alternative (President Jimmy Carter and U.S. Environmental Protection Agency 1977).

Ten years later, the 1987 amendments to the CWA expanded the National Pollutant Discharge Elimination System (NPDES) permitting requirements to include stormwater discharges from municipal separate storm sewer systems to control the amount of polluted stormwater entering waterways, often through combined sewer overflow systems (U.S. Environmental Protection Agency 2018b). These amendments have resulted in a strong 
incentive for green infrastructure approaches to flood hazard and floodplain management because of the need to reduce stormwater pollution for NPDES permitting. Since 2007, the EPA has released a set of policy memos explicitly supporting the use of green infrastructure for NPDES permits and combined sewer overflow system management (U.S.

Environmental Protection Agency 2017).

\section{Gray and Green Infrastructure}

Stormwater management and flood mitigation infrastructures are typically defined on a spectrum of gray to green infrastructure (Figure 1; modified from Davies, MacFarlane, McGloin, and Roe 2006). Gray infrastructure is used to move water off the landscape as
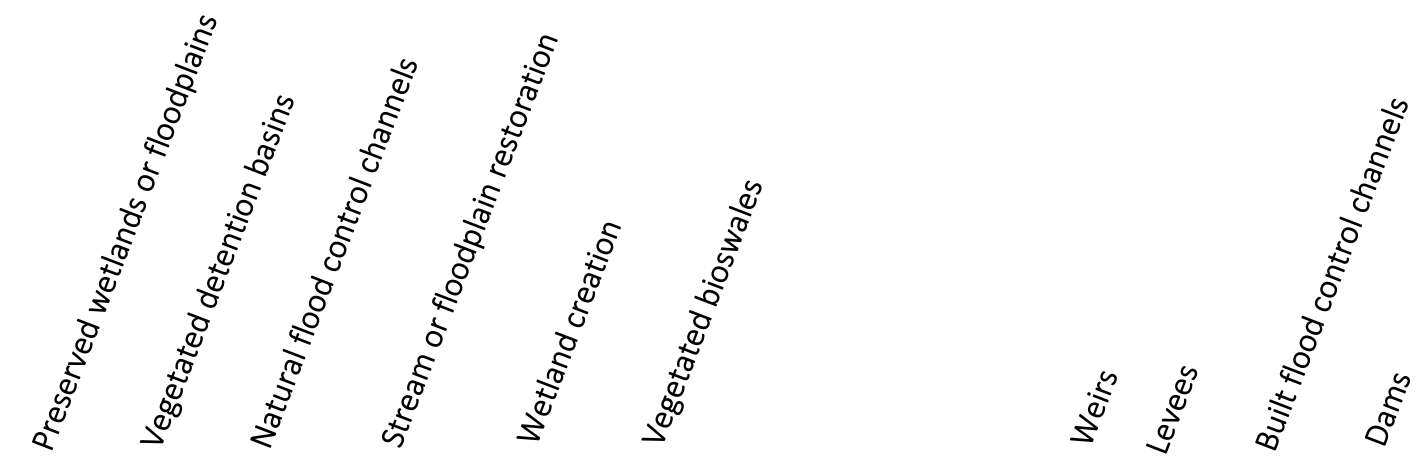

Figure 1. A spectrum of green to gray infrastructure for flood hazard and floodplain management. The green end of the spectrum includes more ecologically-based infrastructures such as preserved wetlands and floodplains, as well as stream and floodplain restoration. Vegetated bioswales, while still considered green infrastructure, are typically highly engineered and contain concrete or similar materials. The gray end of the spectrum includes weirs, which sit directly in rivers to moderate streamflow; levees, which may be earthen or concrete; and dams and other flood control structures.

quickly as possible: combined sewer overflow systems contain stormwater runoff, levees hold floodwater back during periods of inundation, and dams are frequently designed to stabilize the hydrological system against seasonal variability (Graf 2001; Holloway, Strickland 
Jr, Gerrard, and Firger 2014). Even though levees often increase flow velocity, channelization, and upstream flooding, they are commonly used for flood control (Criss and Shock 2001; Heine and Pinter 2012); for example, the National Levee Database, which tracks USACE and non-USACE maintained levees, currently records almost 30,000 miles of levees in the US (U.S. Army Corps of Engineers 2018). There is a continued legacy of using gray infrastructure for flood prevention and flood control, as institutions and public perspectives toward flooding were formed when this engineered approach to controlling floods was prevalent (Lennon, Scott, and O'Neill 2014).

Another type of gray infrastructure that influences flood hazard is impervious surfaces. As population increases in an area, so does development, which increases the amount of impervious surface like roads, parking lots, and buildings. When it rains, water can no longer infiltrate the ground to be held in the soil and slowly released to streams; instead, this rain becomes stormwater runoff and either enters surface drainage systems or runs directly into streams and other waterbodies (Walsh, Roy, Feminella, Cottingham, Groffman, and Morgan II 2005). In addition, development typically requires the conversion of open space such as agricultural and forestlands, which further lessens water infiltration. This increase in surface water runoff and streamflow velocities, coupled with impeded water infiltration and storage, substantially alters hydrological systems and increases flood vulnerability and severity (Brody, Zahran, Highfield, Grover, and Vedlitz 2008).

Green infrastructure may be used to mitigate stormwater runoff or flood hazard. When used for stormwater management, green infrastructure aims to control stormwater at the source by using facilities such as vegetated bioswales and detention basins (U.S. Environmental Protection Agency 2000). Green infrastructure is most often used for 
stormwater management because the biggest regulatory push has come from the EPA, which began "strongly encouraging" its use in 2007 for stormwater and nonpoint source pollution (Grumbles 2007, March 5). In keeping with its institutional mandate, the EPA now defines green infrastructure as "a comprehensive approach to water quality protection defined by a range of natural and built systems that can occur at the regional, community, and site scales" (U.S. Environmental Protection Agency 2010:2). The definition I use in this paper comes courtesy of Benedict and McMahon (2006), which incorporates different scales and functions for green infrastructure:

We define [green infrastructure] as an interconnected network of natural areas and other spaces that conserves natural ecosystem values and functions, sustains clean air and water, and provides a wide array of benefits to people and wildlife. Used in this context, green infrastructure is the ecological framework for environmental, social, and economic health - in short, our natural life-support system (Benedict and McMahon 2006:1).

Regardless of application, the concept of green infrastructure as a nature-based solution underscores definitions of green infrastructure; the function and scale of the infrastructure often determines the definition that is used (Allen 2012; Koc, Osmond, and Peters 2017). For instance, the definition used by the EPA works well when using vegetated bioswales to manage stormwater; the EPA's definition does not work so well when crafting policy to widen riparian buffers for downstream flood mitigation. As a nature-based solution, there are frequently ancillary benefits conferred by green infrastructure beyond their designated function, including air and water quality improvement, carbon sequestration, and habitat provisioning (Tayouga and Gagné 2016; Thorne, Lawson, Ozawa, Hamlin, and Smith 2018), as well as improved physical and mental health, enhanced community cohesion, and aesthetic values (Thorne, Lawson, Ozawa, Hamlin, and Smith 2018). The term itself continues to evolve as it is used in different applications, in different contexts, and at 
different scales (Koc, Osmond, and Peters 2017; McDonald, Allen, Benedict, and O'Connor 2005; Tayouga and Gagné 2016).

Why Do Communities Adopt Green Infrastructure for Flood Hazard and Floodplain Management?

Municipalities typically have agency over stormwater management systems, as well as open space protection and development within their boundaries. Why some communities rely more of grey infrastructure while others heavily invest in green infrastructure is the primary question invoked by my dissertation. Over the last several decades the types of infrastructure and policy available to manage floodplains and flood hazard has changed dramatically. In many municipalities there is a strong historical legacy of dams, dikes, levees, weirs, and other hardened gray infrastructure used for flood control. However, recognizing the limits of gray infrastructure and potential for catastrophic failure (e.g., Hurricanes Katrina and Sandy), some municipalities have employed other solutions.

I examined policy innovation and adoption to help explain the characteristics correlating to or predicting the adoption of policy. Infrastructure may have been selected decades ago in a community, but as historical legacies age, current decision-making continues. As new policy is adopted, implementation of selected strategies for flood hazard and floodplain management begins, including (re)investing in different types of infrastructure. To understand the approaches to community floodplain and flood hazard management, I examine the factors that may influence infrastructure policy choices. With green infrastructure use increasing, some research has applied policy diffusion and adoption to green infrastructure to help understand what influences the implementation of green infrastructure for floodplain and flood hazard management. Although much research 
focuses on the barriers, I highlight the characteristics that enable green infrastructure adoption.

Policy Innovation and Adoption

Policy research generally describes two models for analyzing policy innovation and adoption at the municipal level: the internal determinants model and the regional diffusion model (Berry and Berry 2014). These models are based on Rogers' seminal work, Diffusion of Innovations (1962), which was soon applied to policy diffusion (Walker 1969). For an innovation to be successful, community leaders and residents need to be receptive, perceiving the innovation as beneficial (Bassett and Shandas 2010). A policy innovation refers to a policy that is new to the community adopting and implementing it (Berry and Berry 2014; Damanpour 1987; Walker 1969). As Damanpour later stated, "Innovation does not occur when a new idea is generated, but rather when that new idea is put into use.... Organizations adopt innovation in order to maintain or enhance their performance. Innovations cannot influence performance until they have been actually used" (Damanpour 1987:676). Berry and Berry modified policy diffusion, creating the internal determinants model and regional diffusion model, which emphasize the dual influences of local character and nearby communities in policy adoption and diffusion (1990). The internal determinants model, or, for simplicity, the lone wolf model, describes policy innovators and frames policy innovation and adoption as a function of internal economic, political, or social factors (Berry and Berry 2014). The regional diffusion model, or copycat model, describes policy adoption as a clustered, regional phenomenon, in which innovation spreads between communities through policy networks (Bassett and Shandas 2010; Berry and Berry 2014; Walker 1969)_i.e., communities view neighboring communities "as laboratories for policy experimentation" 
(Matisoff 2008:535). There are several mechanisms that facilitate regional diffusion, including learning, imitation, normative pressure, coercion, and competition. For example, regional diffusion via competition occurs when a municipality decides to adopt a policy to be more competitive with other municipalities, either by gaining an economic advantage, or by preventing other municipalities from gaining an economic advantage (Berry and Berry 2014). Policy innovation and adoption is often described with the internal determinants and regional diffusion models, but they are not mutually exclusive. Berry and Berry (2014) posit that policy adoption may be a function of both internal determinants and regional diffusion, and Newmark (2002) hypothesized that these two models exist on a continuum.

\section{Lone Wolves and Copycats}

Given that gray and green infrastructure exist on a continuum, as do the lone wolf and copycat models, I propose that they can be arrayed as orthogonal dimensions of flood hazard and floodplain management (Figure 2). I use this framework to develop propositions that help explain floodplain and flood hazard policymaking. Municipal policy processes occur in a certain place, at a certain time, for a specific purpose, and it is to be expected that while any given policy process can be arrayed on these orthogonal dimensions, a community as a whole is more complex and may not fit neatly into one of these quadrants.

A gray copycat describes a traditional approach to flood hazard management, using gray infrastructure like hardened flood control channels and levees, as the USACE built in many communities around the country. A green copycat is a case indicative of the spread of green infrastructure between communities for stormwater management, as well as flood hazard and floodplain management. A green lone wolf (hereafter referred to as a green wolf) describes innovative communities that adopt green infrastructure because they believe the 
potential benefits in meeting internal planning objectives outweigh the risks. A gray wolf describes a case in which an innovative approach is being implemented to use hardened infrastructure for flood hazard and floodplain management.

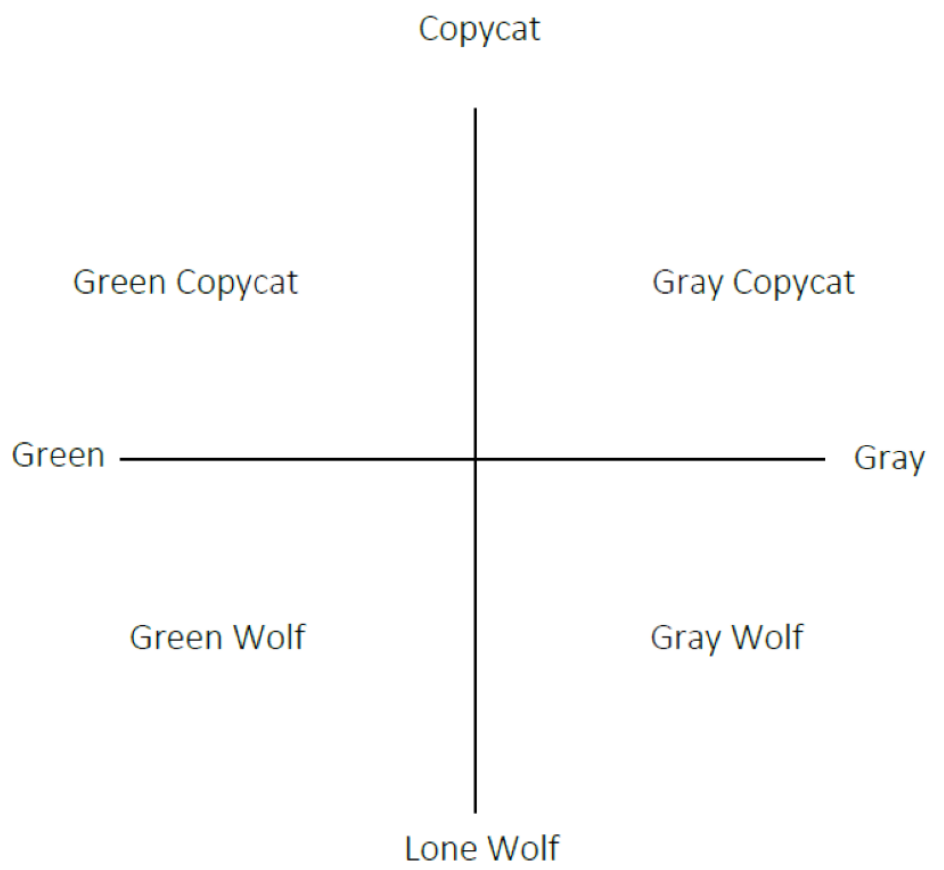

Figure 2. A conceptual framework for the interaction of gray and green infrastructure with the internal determinants (i.e., lone wolf) and regional diffusion (i.e., copycat) models. The lone wolf and copycat model are on the $y$-axis, and infrastructure type is on the $x$-axis. The interaction of these two dimensions of flood hazard and floodplain management create four archetypes: The gray copycat, green copycat, green wolf, and gray wolf. Each of these describes a different approach to flood hazard and floodplain management, based on infrastructure used and mode of policy adoption.

Researchers have attempted to determine which characteristics correlate with the adoption of innovation in a community, analyzing policies ranging from technological innovation in public libraries (Damanpour 1987) and state lottery adoption (Berry and Berry 1990) to climate change (Matisoff 2008; Sharp, Daley, and Lynch 2011) and stormwater management (Carlet 2015; White and Boswell 2007). Broadly speaking, adoption of policy innovations may be related to managerial (e.g., manager's age or professional membership), organizational (e.g., size of municipal government and its financial resources), and 
demographic (e.g., city size or per capita income) characteristics. Baldridge and Burnham (1975) argued that individual characteristics are important when an individual is the innovation adopter; if an organization is the innovation adopter, however, organizational characteristics are more important. No unanimous predictor of innovative policy adoption has been identified, and some authors have failed to identify clear trends between policy types and adoption predictors. This is unsurprising, given earlier conclusions by Damanpour (1987), who clarified that when we refer to policy innovation and adoption, all innovations are not equal, nor are the processes by which innovation are adopted.

All of these characteristics — managerial, organizational, and demographic — have one commonality: they are aspatial. Diffusion of innovation theory, however, posits spatial diffusion. Walker argued that if the theory is correct, there should be regional clustering; he did find such a pattern, albeit not as neatly as expected (1969). When Berry and Berry developed their internal determinant and regional diffusion models, they hypothesized that the likelihood of the lottery policy being adopted would be positively related to the number of neighboring states who had already adopted a state lottery (1990). The authors later developed a more nuanced theory related to diffusion through space, arguing that spatial diffusion does not have to be defined solely by adjacency, but instead might be through membership in a collective region (Berry and Berry 2014). Like other factors, there have been mixed results for regional proximity and regional diffusion, but in recent research on climate change policy in cities and counties, proximity was one of the most significant drivers predicting the adoption of climate protection agreements (Yi, Feiock, and Berry 2017). There are two primary explanations for the mechanisms of regional diffusion. It may be that governments within the same region have similar economic, environmental, and 
social issues, and are responding to similar demands and influences, creating the perfect ‘policy laboratory' for observation and potential adoption (Berry and Berry 2014). Another explanation is more bottom-up: when residents or municipal leadership become aware of a new policy or program in other communities, they may begin to think of it as a legitimate state responsibility, and demand the same for their own community: "Once a program has gained the stamp of legitimacy, it has a momentum of its own” (Walker 1969:890).

Much of the research on the adoption of green infrastructure conforms to previous research on policy innovation and adoption. For example, Carlet (2015) analyzed the adoption of green stormwater infrastructure using technology acceptance theory, organizational theory, and diffusion of innovation theory. She found that a manager's attitudes and age had a significant effect on the likelihood of adopting green infrastructure (Carlet 2015). A recent literature review identified six major socioecological factors that influence the adoption of green infrastructure: ecosystem services provisioning, education, financial incentives, planning recommendations, laws and policies, and coordination among actors (Tayouga and Gagné 2016). Coordination among actors clearly dovetails with the regional diffusion model; it is described as "knowledge diffusion among groups in a coordinated network" (Tayouga and Gagné 2016:9).

While the use of green infrastructure continues to expand, there are numerous barriers to its implementation. In a national survey by the Clean Water American Alliance, respondents identified numerous technical and physical, legal and regulatory, community and institutional, and financial barriers to the adoption of green infrastructure (Abhold, Loken, and Grumbles 2011). These barriers included restrictive definitions of green infrastructure, rigid municipal codes and ordinances, lack of funding or data on maintenance costs, and lack 
of public support or private leadership (Abhold, Loken, and Grumbles 2011). Later research on urban flood hazard management in Portland, Oregon also identified a lack of political will, leadership, and vision as challenges to implementing blue-green infrastructure for practitioners (Thorne, Lawson, Ozawa, Hamlin, and Smith 2018). Brown and Farrelly (2009) also analyzed the barriers to adoption of sustainable urban water management. After reviewing 53 studies, the authors concluded that socio-institutional barriers, rather than technological barriers, are the main impediment to the adoption of sustainable urban water management systems The barriers the authors identified included limits of regulation, insufficient resources, poor organizational commitment, path dependency, lack of political and public will, and limited community engagement (Brown and Farrelly 2009). Many of these community and socio-institutional barriers are not concrete, often involving perceptions and attitudes that can be extremely challenging to overcome (Abhold, Loken, and Grumbles 2011; Brown and Farrelly 2009; Carlet 2015).

\section{Methods}

To understand the types of infrastructure currently being used for municipal flood hazard management, how existing infrastructure was selected, and how current policy decisions were being made, I developed case studies using four Oregon municipalities. Each case study was selected based on preliminary research that indicated case study communities were good examples of innovative policy decisions about either gray or green infrastructure for floodplain and flood hazard management. To develop each case study, I visited each case study community for one to three days, interviewed and interacted with local floodplain managers, kept field notes, and augmented my observations with literature designed to elaborate on the major observations made in each case study. 
I used an informal descriptive case study format to write each of the four cases (Yin 2014). The descriptive format allowed me to take propositions based on findings from the literature and illustrate the strengths and weaknesses of each proposition as observed in real examples. The four selected Oregon communities_Eugene, Milton-Freewater, Prineville, and Sherwood — were examples of different approaches to flood hazard and floodplain management, relying on gray or green infrastructure, as either lone wolves or copycats.

Before visiting each community, I contacted key informants, requested interviews, and also requested recommendations for others to interview. For each community, I completed a document review and site visit, during which I completed semi-structured interviews with one or more key informants and a tour of the community's streams and floodplains, flood and floodplain management infrastructure, and other relevant features. I interviewed 24 key informants among the four communities: one in Eugene, three in MiltonFreewater, seven in Prineville, and thirteen in Sherwood (Table 1). All but three of these interviews were recorded and transcribed; for those that were not recorded due to interviewee preference or technical difficulties, I took notes and transcribed the content of the interview within 24 hours. I used the interview notes and transcriptions, as well as document analysis, to develop a case description that provide richness to the literature-based propositions about lone wolves and copycats adopting green and grey infrastructure policy for floodplain and flood hazard management. 
Table 1. The professional association of interviewees in each of the case study communities: Eugene, Milton-Freewater, Prineville, and Sherwood. Respondent numbers are included for references within the text.

\begin{tabular}{lll}
\hline Community & Professional Association & Respondent \\
\hline Eugene & Consultant and retired City of Eugene & 1 \\
Milton-Freewater & Water Control District & 2 \\
& City of Milton-Freewater & 3 \\
Prineville & Watershed Council & 4 \\
& Watershed Council & 5 \\
& City of Prineville & 6 \\
& City of Prineville & 7 \\
& City of Prineville & 8 \\
City of Prineville & 9 \\
Oregon Department of Fish and Wildlife & 10 \\
& Oregon Department of Transportation & 11 \\
& Metro regional government & 12 \\
& Metro regional government & 13 \\
& City of Sherwood & 14 \\
& Retired City of Sherwood & 15 \\
& Retired City of Sherwood & 16 \\
& Retired City of Tigard & 17 \\
& Friends of the Tualatin River National Wildlife Refuge & 18 \\
& Clean Water Services & 19 \\
U.S. Fish and Wildlife Service & 20 \\
Retired U.S. Fish and Wildlife Service & 21 \\
Retired U.S. Fish and Wildlife Service & 22 \\
Retired U.S. Fish and Wildlife Service & 23 \\
Retired U.S. Fish and Wildlife Service & 24 \\
\hline
\end{tabular}

\section{Results}

\section{Gray Wolf: Milton-Freewater}

Milton-Freewater, Oregon manages flood hazard and floodplains with a strong historical legacy of gray infrastructure. A small town of 7,070 people in northeastern Oregon (Portland State University College of Urban \& Public Affairs 2017), Milton-Freewater sits less than two miles from the Washington State border, and is adjacent to the Walla Walla River. In 1951 the USACE began building extensive levees along the Walla Walla River where it runs through the town: 4.2 miles of levees on the east side of the river and 5.3 miles 
of levees on the west side of the river (U.S. Army Corps of Engineers 2010a; U.S. Army Corps of Engineers 2010b; U.S. Army Corps of Engineers 2010c; U.S. Army Corps of Engineers 2010d). Levees maintenance is the jurisdiction of the Milton-Freewater Water Control District, whose annual revenue wasn't sufficient to maintain, much less repair, the levees. The Water Control District estimated the need for approximately $\$ 75,000$ annually for levee maintenance and repair; however, revenues were only about $\$ 24,000$, which was primarily used for vegetation removal per USACE requirements (Respondent 2). The Water Control District placed a bond initiative on the ballot two different times to raise money to repair the levees, but failed both times (Respondent 2). Then, in 2006, the USACE classified the levees' condition as "unacceptable," meaning they were no longer considered viable for flood control (Oregon Solutions 2009). For Milton-Freewater, an "unacceptable" rating meant that large portions of the town were no longer protected by levees, and without protection, these portions of Milton-Freewater would, after over 50 years, be considered part of the special flood hazard zone and require flood insurance (Committee on Levees and the National Flood Insurance Program Improving Policies and Practices, Water Science and Technology Board, and Division of Earth and Life Studies 2013; Pinter 2005). The impact of the unacceptable rating would require many residents and private property owners to start purchasing flood insurance through the NFIP. Community leaders decided that the trajectory created by the degraded levee system was unacceptable and instead developed an effort to raise the money— $\$ 4.1$ million—required to repair 5.5 miles of levees as required by the USACE. A bond initiative was placed on the ballot for a third time, and with marketing support from Blue Mountain Community College, it passed:

It was just great to see a community that's been struggling to pass school bonds [pass the levee bond]. It's just a depressed community. There used to 
be a lot of packing houses here, vegetable canning, fruit packing - and a lot of that industry is gone. There's a lot of unemployment, a lot of older people that don't want to pay new taxes. To get the community to agree to tax itself was a real challenge (Respondent 4).

Repair of the Walla Walla River levees in Milton-Freewater fulfilled FEMA's

requirements to exempt the areas protected by the levees from the special flood hazard zone. In the City News of Milton-Freewater, a quarterly newsletter for Milton-Freewater, the City Manager announced, "Yes, it's true! We are out of the flood zone!" (Hall 2013; Oregon Solutions 2009). While the costs of levee repair were extensive, for many people the increase in annual property taxes was considerably less than a potential increase in flood insurance premiums (Respondent 4). The Water Control District considered the regulatory relief worth the expense. One interviewee commented that interacting with the USACE was preferable to interacting with FEMA: "They mapped the floodplain up on a hill. FEMA has their head where the sun don't shine" (Respondent 2). Given the historical legacy of levees being used for flood control, continuing their use is not innovative-a small community raising over $\$ 4$ million to repair them is. The Milton-Freewater Water Control District went on to win an award for engineering excellence for their work (Anderson Perry \& Associates 2016).

\section{Gray Copycat: Eugene}

After Portland, Eugene is the second largest city in Oregon, at approximately 155,000 people (U.S. Census Bureau 2016b). Located in Oregon's Willamette Valley, the Willamette River runs through the northeastern part of the City. In the western part of Eugene, Amazon Creek drains over 21 square miles_almost half of the City's land area (U.S. Census Bureau 2017)—eventually entering Fern Ridge Reservoir to the west of the city before draining to the Willamette through the Long Tom River. The extensive gray infrastructure built by the USACE in Eugene, Oregon describes a gray copycat that is 
nonetheless moving toward green. In 1946, following years of flooding, the U.S. Army Corps of Engineers channelized and reinforced large portions of Amazon Creek, including a 1.75-mile concrete trapezoidal flood control channel (City of Eugene 2016). This approach to flood mitigation was common at the time, with the USACE engineering extensive gray infrastructure in many communities (Arnold 1988).

Over the intervening decades, the city has developed around and adjacent to Amazon Creek. In 2002, the City of Eugene and the Long Tom Watershed Council partnered with several other agencies to restore portions of Amazon Creek, including planting native vegetation, protecting the headwaters, and remeandering the stream where possible (Long Tom Watershed Council 2002; Schneider 2013). Portions of the concrete flood control channel have been cut out to create a 'green pipe,' a vegetated channel for water conveyance (Respondent 1). The efforts by the city were part of a larger restoration project, the West Eugene Wetlands Plan, which sought to balance wetland restoration in west Eugene with economic development (City of Eugene and Lane Council of Governments 2004). Developed by the West Eugene Wetlands Partnership (now the Rivers to Ridges Partnership), the project used land acquisition, levee setbacks, habitat restoration, community engagement, and environmental education to protect 3,000 acres of wetlands and uplands along 12,000 linear stream feet (Cooperative Conservation America 2017; Respondent 1). The complex now includes the Meadowlark Prairie, Bertelsen Nature Park, and the Tsal Luk-wah 'River of Grass' Wet Prairie Remnant, all of which adjoin Amazon Creek (City of Eugene 2006; City of Eugene n.d.). Initial work began in the Meadowlark Prairie with levee setbacks, which reconnect the creek to its floodplain, while still providing flood protection (City of Eugene 2006). The main driver for this project was the discovery 
that some of the best remaining wet prairies in the Willamette Valley were in the heart of Eugene's industrial area and the community sought to protect these while supporting sound economic development and educational and recreational opportunities (City of Eugene and Lane Council of Governments 2004; Cooperative Conservation America 2017).

This extensive restoration highlights that a gray copycat may shift toward adopting innovative policy more indicative of a green wolf. However, even though these aspects of Eugene's green infrastructure and floodplain management policy are indicative of a green wolf, policy is substantially constrained in areas of the city that have developed along the built flood control channels. While restoration and levee setbacks were possible along undeveloped sections of Amazon Creek, "the concrete channel is the one exception to that. It's all urbanized right up to the edge of the concrete.... You're not going to remove [that development] — it'd be hundreds of houses and businesses to actually go back and bring that to a more natural system" (Respondent 1$)$.

\section{Green Copycat: Prineville}

Prineville, Oregon sits in central Oregon's high desert with the Crooked River running directly through town. Prineville has a population of approximately 10,000 people (Portland State University College of Urban \& Public Affairs 2017). In 2005, city leaders recognized that Prineville's wastewater treatment plant was had reached its design capacity and that an upgraded facility was needed (Anderson Perry \& Associates 2010). At the time, the City of Prineville contracted with outside engineering firms for facility plans; it was one of these plans that focused on constructing a wastewater treatment plant (Respondent 6). As the Chief Engineer stated, the facility plan basically said, "Prineville, you're going to become a big city, and lagoons are something little cities do. You need to look at a mechanical 
treatment process" (Rulseh 2018). The City supported the construction of a new mechanical wastewater treatment plant, at a cost of $\$ 62$ million, in order to meet future needs and support continued economic development. System development charges, fees used to cover the costs of capital improvements needed to support residential and commercial development, would undoubtedly increase. The mayor at the time said, "We knew our rates would skyrocket. If we had to raise our system development charge fees, we couldn't be competitive with the rest of Central Oregon for new business and new homes" (Kent 2015). The increase in system development charges was substantial. System development charges (SDCs) for a new homes increased from $\$ 3,800$ to $\$ 9,147$; monthly sewer rates also tripled (Rulseh 2018). By 2008, in response to the increased costs, the City was considering alternatives to mechanical treatment, including constructed wetlands at a cost of approximately $\$ 9$ million, that would also create ancillary benefits such as park space, recreation, and water storage (Chaney 2010; Kent 2015). After preliminary analysis to determine the ecological and hydrological impact of building the wetlands, the project was approved, costing only $\$ 7.7$ million, which was reduced to $\$ 4.75$ million due to the City receiving several grants (Rulseh 2018). The groundbreaking ceremony celebrating the completion of the 120-acre Crooked River Wetlands Complex was Earth Day, April 22, 2016 (City of Prineville 2016). The City Engineer noted the impact on system development charges as support for the project:

We were drastically higher than any of our neighboring communities. It was tough if you wanted to come to Prineville and build a home. And imagine if you wanted to build a manufacturing facility that would have an impact on our treatment plant equivalent to 100 homes. That became a real hindrance to economic development. The City Council said, 'This wastewater treatment plant is breaking our back—we can’t afford this plan’ (Rulseh 2018). 
While constructing wetlands for water treatment isn't new-the EPA published seventeen case studies on the subject in 1993 (U.S. Environmental Protection Agency 1993)_Prineville borrowed the idea from one community in particular, clearly illustrating the regional diffusion model. The Chief Engineer noted that in their research, they discovered a community in eastern Oregon, La Grande, that was releasing treated effluent into a wetland managed for wildlife by the Oregon Department of Fish and Wildlife (Oregon Department of Fish and Wildlife 2008; Rulseh 2018). This solution addressed the water treatment needs of the community while revitalizing an important wetland (Oregon Department of Fish and Wildlife 2008). “The wetland was starved for water, and [La Grande] essentially negotiated a contract to provide its effluent to the wetland. We investigated that and started doing due diligence to determine if we could construct our own wetlands" (Rulseh 2018). The choice to construct wetlands adjacent to the Crooked River to meet the Prineville's regulatory and economic objectives, as well as environmental goals, illustrates a community that looked to its neighbors, such as La Grande, Oregon, to find a successful policy that could be used for its own objectives and available resources. Regional diffusion in this case was spurred by the need to regain competitive standing in the economically growing region of central Oregon.

\section{Green Wolf: Sherwood}

In 1990, the Sherwood, Oregon was home to approximately 3,100 people on the southwestern outskirts of the Portland Metropolitan Area. Since then, the population has increased to 19,350 in 2017 - a 500\% growth rate (Portland State University College of Urban \& Public Affairs 2017). The Tualatin River, a tributary of the Willamette River in northwestern Oregon, runs directly north of town, and two tributaries of the Tualatin River, 
Cedar and Rock Creeks, run directly through Sherwood. In anticipation of increasing population growth impacts, community leaders in the early 1990s started to address the impacts of growth in their municipal planning. To protect the many natural features of the community, the city of Sherwood codified planning objectives that included goals to "achieve the maximum preservation of natural features" and to "minimize the adverse effects of human activity on the natural environment" (City of Sherwood 1991a). The city identified 476 acres as open space (19\% of the city); 424 of those acres were designated as wetlands, floodplains, and other significant natural areas (City of Sherwood 1994). To preserve these areas, the city began a project to acquire and protect floodplains using three different economic and regulatory incentives: outright purchase, density transfer, and SDC credits. Within a five-year period, $\sim 335$ acres of floodplain had been protected, laying the groundwork for the federal creation of the Tualatin River National Wildlife Refuge (Respondent 15). Sherwood was one of the initial sponsors of the creation of the refuge, and a Sherwood couple donated 12 acres of land to demonstrate local commitment to Congress (Respondent 15). Initial plans for the refuge ended at the city's edge; however, because the city had focused its efforts on protecting the floodplains of a tributary of the Tualatin River, the U.S. Fish and Wildlife Service was ultimately persuaded to extend the boundary of a newly designated National Wildlife Refuge to include the municipal floodplain, making it part of the 1,238-ha refuge (Respondents 15, 21, and 22).

Sherwood sought to protect community identity by protecting its natural amenities. Engaged city staff and citizens wanted to maintain a community identity that was separate from Portland and other neighboring cities (Respondents 15, 21, 23, and 24):

[A community leader] was heavily involved...in trying to preserve wetlands, floodplains, other natural areas. Then there were other people in the 
community who were also interested in natural areas, and people who were trying to differentiate Sherwood as a community from the whole rest of the metropolitan area, instead of just making it another neighborhood or nameless suburb.... One of the ways they wanted to do it was providing a green buffer between Sherwood and the rest of the metro area (Respondent 24).

The City of Sherwood considered the creation of the Refuge an excellent solution to protecting open space and floodplains, and preserve a unique community identity in perpetuity (Respondents 1 and 9). Doing so required engagement between the Sherwood municipal government, especially the Planning Department, as well as local farmers, and the USFWS. Local farmers owned much of the land that the USFWS would be approaching to purchase for the Refuge. Land acquisition for the Refuge required landowner buy in (Respondent 11). There was initially some trepidation on the part of farmers about dealing with USFWS; these concerns were largely put to rest, however, when a member of a prominent farming family returned from Idaho to talk to local farmers about his personal experience with the USFWS:

Unbeknownst to [the USFWS] was [he] had some interactions with the Fish and Wildlife Service quite a few years before on a small hydroelectric project in Idaho. There were several agencies involved, [including] the Federal Energy Regulatory Commission, there was the State of Idaho Fish and Game..., the Fish and Wildlife Service, and there were some others. He was pretty unhappy with most of the agencies-[he] felt they were jerking him around, except for the Fish and Wildlife Service.... He felt they treated him fairly.... When he came to the meeting [about the creation of the Refuge], [he] stood up and said in front of all the other farmers there, he says, "I had this experience with the Fish and Wildlife Service in Idaho. They'll treat you fairly, they're not going to jerk you around, they're not going to speak with forked tongues, you can trust them, don't worry about it." Any opposition or skepticism that was on the part of the [agricultural] community dissipated because of [him] (Respondent 11)

Sherwood protected greenways, open space, and floodplains in order to preserve a unique community identity. This focus on community identity not only shaped local 
planning and management, but also helped shape federal policy in the creation of the Tualatin River National Wildlife Refuge and exemplifies the importance of internal social motivations in the guidance of a green wolf.

\section{Discussion}

The four Oregon case studies_Eugene, Milton-Freewater, Prineville, and Sherwood-represent four different policy processes for flood hazard and floodplain management. There is a wide range of gray and green infrastructure being used in each community, either the result of contemporary policy decisions (e.g., the West Eugene Wetlands Plan) or the historical legacy of USACE-designed gray infrastructure (e.g., the levees in Milton-Freewater). These case studies were developed based on two primary themes from the literature: the use of gray and green infrastructure for stormwater and flood hazard and floodplain management, and the internal determinants and regional diffusion models for policy adoption.

From the four case studies I developed five propositions to discuss my findings. These propositions were developed as a way of focusing my findings on the community objectives and policy processes for flood hazard and floodplain management. The thread connecting these propositions is goal of flood hazard and floodplain management. Each community demonstrated varied reasons for selecting their approach towards that goal and the intent of the propositions is to make sense of that variability.

Proposition 1: A historical legacy can constrain future policy decisions.

Past policy decisions can set a community on a path that may be extremely difficult to change. Path dependence-i.e., "What happened at an earlier point in time will affect the possible outcomes of a sequence of events occurring at a later point in time" (Selbmann 
2015:2) — can be seen in each community in this analysis. Sherwood's policy decisions helped create a national wildlife refuge within its city limits. Prineville has foregone the construction of a wastewater treatment plant and has instead created extensive treatment wetlands. Built flood control channels in Eugene continue to be maintained to protect the extensive urban development that relies on this protection. The construction of levees for flood control in Milton-Freewater in the 1950s continues to steer current flood control policies.

Milton-Freewater, in particular, exemplifies a more focused definition of path dependency: "Structures, which emerged in a curious historical initial configuration, subsequently tend to reproduce themselves" (Selbmann 2015:2). Starting in the 1860s, the USACE had a 'levees only' policy for flood control that lasted for several decades (U.S. Army Corps of Engineers 2017b). Even after the policy itself was abandoned, thousands of miles of levees continued to be constructed, often in concert with flood diversion channels and spillways (Maass 1951; Randolph 2018). The passage of the 1936 FCA, granting authority to the USACE to manage and engineer federal flood control projects, coupled with the 1944 FCA, which authorized a multipurpose approach to water management, "put the Corps firmly into the reservoir construction business" (U.S. Army Corps of Engineers 2017c). Following World War II, the construction of multipurpose projects by USACE, which typically included hydropower dams, levees, and flood control channels, expanded considerably (U.S. Army Corps of Engineers 2017c). The National Flood Insurance Act of 1968 was designed to address the ramifications of these policies, which created a culture and a policy landscape in which it was considered safe to develop and live in floodplains protected by this flood control infrastructure (King 2012). Communities continued to grow and develop, often extensively in the floodplain, around, and up to, levees and flood control 
channels. The passage of the National Flood Control Act, and the NFIP provision that areas behind levees are not in the regulatory floodplain, have created a strong historical legacy and path dependency in flood hazard and floodplain management: Decisions made decades ago continue to steer current and future decisions, as seen in the case studies of Milton-

Freewater and Eugene.

Proposition 2: Communities can circumvent the historical legacy of past decisions and adapt to a more green infrastructure approach.

The historical legacy of some infrastructures has been documented to create a path dependency in a community (Park, Seager, Rao, Convertino, and Linkov 2013).

Communities with gray infrastructure designed and constructed decades ago have evolved with the legacy of the goal to control flooding and keep people and property safe so that development could continue. Many communities with this historical legacy of gray infrastructure have developed around it, making it extremely difficult to try to use natural approaches like green infrastructure for floodplain management (Park, Seager, Rao, Convertino, and Linkov 2013).

The City of Eugene demonstrates, however, that even within the confines of hardened infrastructure, policy can be used to increase ecological connectivity, restore habitat, provide environmental education, and improve recreational opportunities (Cooperative Conservation America 2017). When wetlands were identified in the City's industrial area they were considered problematic, as they have a propensity to flood and need to be filled if the area is going to be developed (City of Eugene and Lane Council of Governments 2004). This perception was not unique to Eugene, as wetlands are frequently filled to make way for development or agricultural production (Zedler and Kercher 2005). The West Eugene Wetlands Plan, however, documents a shift in how wetlands were 
perceived in the City. After extensive research and wetland inventories, the City determined that not all wetlands are created equal. Some were fully-functioning wetlands and wet prairie grasslands, while other wetland areas were lacking the biota and abiotic characteristics needed for full functioning. Characterizing wetlands in terms of function allowed the City to determine their suitability for economic development or other community objectives. Lowfunctioning wetlands were deemed appropriate for continued economic development that wouldn't substantially impact wetlands habitat and connectivity. Fully-functioning wetlands were considered more suited for preservation to fulfill other planning goals such as stormwater runoff treatment and water quality improvement, flood mitigation, and recreational opportunities, as well as habitat and biodiversity protection (City of Eugene and Lane Council of Governments 2004). Shifting the focus from wetlands as a land use problem to be overcome for economic development to a feature with amenity value helped Eugene circumvent the historical legacy of gray infrastructure within the community.

Proposition 3: Meeting regulatory requirements and improving economic competitiveness can complement floodplain protection.

There has often been a tension between environmental protection and economic development (Arrow, Bolin, Costanza, Dasgupta, Folke, Holling, Jansson, Simon, Mäler, Perrings, and Pimentel 1995). Increasingly, however, particularly with the advent of environmental economics, this tension has been called into question (Carson 2010). Berry and Berry (2014) posit that competition is one of the routes fostering regional diffusion. When the policies in question are both environmental (water quality regulation) and economic (system development charges and municipal competition), there is the potential for economic goals to foster environmental improvement. The case of Prineville illustrates this complementary relationship. By leveraging the cost-effectiveness of constructed 
wetlands versus constructing a new wastewater treatment plant, the community was able to improve water quality and its ability to compete with neighboring communities, while providing recreational opportunities and environmental education.

An earlier, notable example is the protection of the Catskill and Delaware Watersheds for source drinking water protection for New York City. The Safe Drinking Water Act of 1974 requires public water systems to protect drinking water and drinking water sources. There are numerous provisions in the Act, including actions related to minimizing contaminants, as well as cost-benefit analyses of drinking water standards (U.S. Environmental Protection Agency 2016). To meet these regulatory requirements, a memorandum of agreement was negotiated in 1997 between New York City, rural upland communities, New York State, environmental groups, and the Environmental Protection Agency. This agreement created an exemption from having to build a water filtration plant to meet the requirements of the Safe Drinking Water Act in exchange for protecting water quality through watershed protection. The economic benefit was clear: land acquisition for watershed protection was estimated to cost approximately $\$ 500$ million, as opposed to the estimated \$3-8 billion (plus annual operating costs) for a water filtration plant (Mehaffey, Nash, Wade, Ebert, Jones, and Rager 2005). Since then, New York has spent more than $\$ 1.6$ billion to maintain the necessary watershed protection, rather than build a water filtration plant, now estimated to cost more than $\$ 10$ billion, in addition to over $\$ 100$ million in annual operating costs (Hu 2018). The Commissioner of New York City's Department of Environmental Protection noted that building such a filtration plant would be "the largest capital project that the city has ever taken on," and water bills would increase significantly to cover the costs (Hu 2018), concerns Prineville later echoed. Similarly, New York City 
recognizes the additional benefits this program confers, including flood mitigation and carbon footprint reduction (Lloyd and Licata 2015). New York City now considers their source watershed protection program one piece of a green infrastructure approach to make New York City "the most resilient, equitable, and sustainable city in the world" (New York City 2018).

These communities adopted programs to not only meet Clean Water Act and Safe Drinking Water Act regulatory requirements for water quality, but to do so in a way that was less costly and accrued additional benefits, such as recreation and education in Prineville, or flood mitigation and greenhouse gas reduction in New York. Programs that protect riparian areas, floodplains, and watersheds were largely adopted because of the economic benefits and avoided costs they provided, demonstrating how environmental and economic goals can be complementary rather than oppositional.

Proposition 4: Innovative green infrastructure policy is likely to involve social rationale like community identity in addition to basic stormwater management or floodplain management objectives.

The literature on the use of green infrastructure has emphasized that the barriers to its adoption are not technical, but rather social, political, and institutional in nature (Abhold, Loken, and Grumbles 2011; Brown and Farrelly 2009; Brown 2005; O'Donnell, Lamond, and Thorne 2017). Correspondingly, I propose that social considerations, such as maintaining community identity or preserving natural heritage values, are the linchpin for generating support for the use of green infrastructure.

The connection between community identity and the perception and value of greenspace and other environmental amenities within a community is well documented. Arnberger and Eder (2012) found a significant effect between greenspace and community 
attachment. Research in Texas found that community identity is a significant component of quality of life, and greenway trails were one of the major contributors to pride in the community and community identity (Shafer, Lee, and Turner 2000). Swanwick (2009) discussed the positive relationship between sustainable land management and community identity. A review of the connections between green infrastructure, ecosystem health, and human health identified four aspects of public health: socio-economic, community, physical, and psychological (Tzoulas, Korpela, Venn, Yli-Pelkonen, Kaźmierczak, Niemela, and James 2007). In addition to defining terms, this review created a conceptual framework of the interactions between these three aspects of socioecological systems. Green infrastructure was specifically defined to include many functional types of infrastructure at multiple scales, which included green corridors; open, standing water; and running water. Of the four aspects of human health, the importance of community identity in community health was highlighted as a significant contributor to individual well-being (Tzoulas, Korpela, Venn, YliPelkonen, Kaźmierczak, Niemela, and James 2007). In a later review of human interactions with urban outdoor environments, the authors found extensive support for a positive relationship between the physical environment and community attachment, and that the enhancement of urban greenways may not only enhance recreational opportunities, but aesthetic values and community identity, as well (Matsuoka and Kaplan 2008). The common thread between these studies is the directionality: environmental amenities, greenspace, or green infrastructure positively shape community identity. Research by Stewart, Liebert, and Larkin (2004) confirmed those findings of a connection between the environmental landscape and community identity, but also concluded that community identity has the potential to shape the environmental landscape, or a vision for landscape change. 
My research expands on this work, illustrating the vital role that social rationales can play in shaping the physical landscape. Sherwood, Oregon illustrates the critical role that a seemingly tangential objective like a desire to maintain a distinct community identity can play in policy processes for flood hazard and floodplain management. Eugene also illustrates the importance of social rationale in determining water resource management objectives. Even within the literal confines of the historical legacy of a concrete flood control channel, the desire to balance economic development with improved environmental protection and community livability led to an innovative project like the West Eugene Wetlands Plan and restoration of sections of the heavily channelized Amazon Creek.

Proposition 5: A community can be a lone wolf and a copycat within the same policy process.

Damanpour (1987) argued that "failure to distinguish between various types of innovations [and] failure to consider adoption of innovations as a multistage process with multiple outcomes" (p. 675) were two of the main reasons for instability in research on the theory of policy innovation. In other words, while my research ostensibly focused on one policy arena_flood hazard and floodplain management— there may be distinctions within the flood hazard and floodplain management policy process that are representative of both a lone wolf and a copycat.

Portland, Oregon exemplifies a city that innovated a green infrastructure policy while simultaneously engineering gray stormwater management infrastructure indicative of a copycat. In 1994, Portland signed an Amended Stipulation and Final Order to decrease the frequency of combined sewer overflow (CSO) events into the Willamette River, the number of which were in violation of the 1987 nonpoint source pollution amendments to the CWA (Oregon Department of Environmental Quality 2010). This 'Big Pipe’ project, as it was 
called, built two pipes, one on either side of the Willamette River, to direct all but the largest CSOs to wastewater treatment plants. Each pipe is several miles long and 14-22 feet in diameter, and additional treatment facilities and pump stations were built to accommodate the increased load. While construction on the Big Pipe was being completed, the City adopted the Cornerstone Projects, the first in their green infrastructure program, to retain stormwater at the source, thereby reducing the amount of stormwater in the combined sewer system (Oregon Department of Environmental Quality 2010). In 2007 Portland expanded its green infrastructure use with its 'Green Streets' program, which promoted and mandated the use of on-site stormwater management facilities in public and private development (City of Portland Bureau of Environmental Services 2018). With capital assets valued at over $\$ 400$ million (City of Portland 2015), the City now "has one of the most mature and comprehensive green infrastructure programs in the country" (U.S. Environmental Protection Agency 2010:53). This program includes site-specific green infrastructure (e.g. bioswales and downspout disconnection) as well as a willing seller program that has acquired over 250 acres of the Johnson Creek floodplain (Johnson Creek Watershed Council 2012).

Each community in this research also demonstrate multiple outcomes in their flood hazard and floodplain management policy. While Prineville constructed wetlands, it is also heavily reliant on the upstream Ochoco and Bowman Dams for flood control. Similarly, while Sherwood has protected floodplains within the city, they are also somewhat reliant on the Scoggins Dam upstream of the Tualatin River, which substantially reduces flood stage along the Tualatin River (Linenberger 2000). Milton-Freewater relies extensively on levees for flood control and on its own initiative to leverage multiple funding opportunities for reinvestment in its gray infrastructure. While areas of Amazon Creek in Eugene are 
constrained by a built flood control channel, Eugene has introduced green infrastructure design into planning for economic development and habitat protection. In other words, a community may be both a lone wolf and a copycat within their flood hazard and floodplain management policy.

I also discovered that it was not only lone wolf communities that had lone wolves. Each community—regardless of how I initially categorized it—had its own lone wolf, a champion for its floodplain and flood hazard management strategies. Sherwood had a lone wolf that launched a floodplain protection program and collaborative effort to create the Tualatin River National Wildlife Refuge. Prineville and Eugene each had local municipal employees that spearheaded, respectively, the construction of wastewater treatment wetlands or wet prairie and wetland protection. Milton-Freewater had a local volunteer that directed the maintenance of their flood control levees — and focused the community on reinvesting and pursuing a continued relationship with the USACE instead of FEMA.

While different community types and policy processes were evaluated to develop the propositions, there are limitations to the conclusions that can be drawn from this research. One of the primary limitations of this research—and the reason why I frame my interpretation as propositions rather than hypotheses-is not only the limited number of case studies used to develop this research, but the limited number of interviews in each case study. While there were thirteen interviews for Sherwood, there was only one for Eugene. Further, because of my research question, I focused on practitioners for my interviews, but this overlooks the role that local residents and citizen groups may play in the policy process. 


\section{Conclusion}

I presented five propositions to explain many of the different reasons that local policy processes for flood hazard and floodplain management may vary. First, as was seen in each community, a historical legacy can create a path dependency that constrains future policy decisions. However, communities can circumvent this historical legacy, potentially integrating green infrastructure into the policy process, while still maintaining necessary built infrastructure to protect people and property that rely on it. A community can also circumvent the policy dichotomy of economic development versus environmental protection and improvement, fulfilling both objectives simultaneously with the same project. Developing innovative green infrastructure policy is, however, likely to involve a social rationale, in addition to regulatory or economic reasons for stormwater and floodplain management. Finally, while a community's policy process can be described with the research framework I’ve developed, policy development and implementation are nuanced processes, and communities can exhibit both lone wolf and copycat properties within the same process. These propositions are a way of framing the character of different policy decisions. The propositions emerged out of the literature and were exhibited in each of four case studies that highlighted different examples of infrastructure use and policy adoption, what I term green and gray wolves or copycats.

I contribute to the body of literature on policy innovation and the adoption of green infrastructure, illustrating successful processes that relied on economic, environmental, and social motives for green infrastructure adoption. 


\title{
Chapter Two: Green infrastructure for flood hazard and floodplain management: A survey of floodplain administrators in Oregon
}

\author{
Abstract \\ The high risk and cost of flooding has led to extensive engineering of environmental \\ and social systems as communities attempt to reduce the impacts on those living in the \\ floodplain while still meeting environmental and economic goals. In the United States, there \\ is a historical legacy of using built infrastructure to meet these needs, thereby supporting \\ development in the floodplain and dictating future policy decisions. As this legacy evolves, \\ communities are challenged to adapt approaches that protect people and property from \\ flood hazard while still meeting other planning objectives; green infrastructure is increasingly \\ seen as one solution to meeting these multiple objectives. I used a key informant \\ questionnaire of Oregon floodplain administrators to determine the factors associated with \\ the use of green infrastructure, especially for flood hazard and floodplain management, and \\ to the extent to which regional diffusion may be affecting the use of green infrastructure in \\ these jurisdictions. Through regression and spatial analysis, I was able to elucidate some of \\ these managerial and regional diffusion characteristics, such as knowledge of flood \\ mitigation infrastructure, professional experience with flooding, and how often floodplain \\ administrators talk to their colleagues in other communities.
}

\section{Key Words}

Regional diffusion, green infrastructure, policy adoption, Oregon municipalities, key informant questionnaire, spatial analysis 


\section{Introduction}

Flooding is widely recognized as the most damaging natural disaster in the world (Centre for Research on the Epidemiology of Disasters and United Nations Office for Disaster Risk Reduction 2015; Opperman, Galloway, Fargione, Mount, Richter, and Secchi 2009). Recent research assessed the global impacts of flooding over a thirty-year period (1980-2009) and found that, on average, floods killed 17,000, injured 12,000, and affected more than 90 million people every year (Doocy, Daniels, Murray, and Kirsch 2013). Research on the economic impact of flooding over a twenty-year period (1995-2015) found that flooding cost over US\$662 billion (Centre for Research on the Epidemiology of Disasters and United Nations Office for Disaster Risk Reduction 2015). While countries in Asia are the most impacted by flooding, the United States ranks eighteenth in the world for the average number of people affected by flooding annually (World Resources Institute 2015).

There are two primary types of infrastructure to manage this flood hazard: gray and green. At its simplest, gray infrastructure for flood management is the hard, engineered components of a system such as built flood control channels, weirs, levees, or dams. Gray infrastructure is designed to quickly transport water off the landscape and reduce peak flows during high precipitation events (Opperman, Galloway, Fargione, Mount, Richter, and Secchi 2009). While green infrastructure may also be engineered, it typically uses vegetation, open space, and other mechanisms that mimic a more natural hydrology (Schifman, Herrmann, Shuster, Ossola, Garmestani, and Hopton 2017). Green infrastructure includes small-scale features such as vegetated bioswales for stormwater management and large-scale features such as constructed wetlands and floodplain preservation for flood mitigation 
(Benedict and McMahon 2006). In addition, green infrastructure is often implemented to provide benefits beyond stormwater and flood hazard management; these include carbon sequestration, improved air and water quality, increased wildlife habitat and biodiversity, and recreation (Tzoulas, Korpela, Venn, Yli-Pelkonen, Kaźmierczak, Niemela, and James 2007).

United States' policy to address and mitigate flood hazards started in 1917 with the passage of a series of Flood Control Acts (FCA); the majority of these Acts were authorizing specific flood control projects following major flood events. The 1936 FCA was more expansive, however, and granted federal authority to the U.S. Army Corps of Engineers (USACE) for building civil engineering flood control projects such as dams and levees. While this policy largely set the course for infrastructure development used for flood mitigation, there are two other important policies: The National Flood Insurance Act of 1968, which created the National Flood Insurance Program (NFIP), and the Flood Disaster Protection Act of 1973. The latter mandated the purchase of flood insurance for properties located within the special flood hazard area (SFHA) for properties constructed or acquired with federally-backed loans (Federal Emergency Management Agency 2018c).

The NFIP is critically important for flood hazard and floodplain management in the United States because of the dependency between an individual property owner and the Federal Emergency Management Agency (FEMA). The vast majority of flood insurance is underwritten by FEMA through the NFIP, not by private insurers. Flood insurance is only available to an individual, however, if the community in which they reside is part of the NFIP, and to be a part of the NFIP, there are numerous regulatory requirements that the community must meet—building and zoning standards that not only protect property in the SFHA, but also assurance that development does not elevate flood hazard elsewhere. 
In 1990, the Community Rating System (CRS) was developed and implemented by FEMA as an incentive for communities to go beyond the NFIP requirements for floodplain management. The CRS is comprised of eighteen floodplain management and public information activities that a community can elect to implement, and each action is worth a number of points. Participating communities are assigned a rank, based on the total number of CRS points awarded, ranging from Class 1 (the highest) to Class 10 (the lowest). NFIP participants in CRS-ranked communities received a discount on their flood insurance premiums as an immediate incentive for community participation. Long-term, however, the entire community benefits from decreased human casualties and property damage (Zahran, Brody, Highfield, and Vedlitz 2010). Many types of activities are eligible for CRS credit, from public information activities, to dam and levee safety programs, with many of these activities focused on nonstructural projects, such as open space preservation (i.e., guaranteeing that currently vacant floodplain parcels will be kept free from development) and the acquisition and relocation of flood-prone buildings out of the floodplain.

As the FCAs demonstrate, many regions rely on gray infrastructure to control flooding and protect people and property. Policies such as the NFIP Act were then crafted with the understanding that communities had developed, and were continuing to develop, in the floodplains. However, as flooding continues to periodically devastate communities and the importance of healthy functioning floodplains has become clearer (Kiedrzyńska, Kiedrzyński, and Zalewski 2015; Opperman, Galloway, Fargione, Mount, Richter, and Secchi 2009; Opperman, Luster, McKenney, Roberts, and Meadows 2010), agencies and communities are looking for other approaches to mitigate flood hazard. As some of the CRS-eligible activities indicate, this includes incorporating green infrastructure into 
floodplain and flood hazard management. At a small scale, green infrastructure is principally used for stormwater management. At larger scales, however, green infrastructure may include open space, riparian buffers, or protected floodplain, extending its functionality to flood mitigation and floodplain management. This conception of open space as green infrastructure gained traction with Benedict and McMahon's (2006) definition of green infrastructure as "an interconnected network of natural areas and other open spaces that conserves natural ecosystem values and functions, sustains clean air and water, and provides a wide array of benefits to people and wildlife" (p. 1). A recent review of green infrastructure typologies reflects these different types and scales of green infrastructure: Koc et al. (2017) identified four main categories of green infrastructure: tree canopy, vertical greenery systems, green roofs, and green open spaces. Amongst other land use types, greenways, vegetated wetlands, ecological buffers, and waterbodies and waterside areas were identified as green open space (Koc, Osmond, and Peters 2017).

Floodplain preservation may be identified and used as green infrastructure because of the numerous ecological and socioeconomic benefits that well-functioning floodplains provide. During periods of high precipitation and snow melt, floodplains store excess water, temporarily slowing its entry into the hydrological system. After these inundations periods, water is slowly released from storage, thereby reducing flooding and simultaneously recharging groundwater (Amoros and Bornette 2002; Brauman, Daily, Duarte, and Mooney 2007). In addition to this flood mitigation and groundwater recharge, floodplains may also improve air quality (Brauman, Daily, Duarte, and Mooney 2007) and water quality (Brauman, Daily, Duarte, and Mooney 2007; Kiedrzyńska, Kiedrzyński, and Zalewski 2015; Tockner and Stanford 2002), provide fish and wildlife habitat (Kiedrzyńska, Kiedrzyński, and 
Zalewski 2015; Opperman, Luster, McKenney, Roberts, and Meadows 2010; Postel and Carpenter 1997), increase biodiversity in estuarine systems (Brauman, Daily, Duarte, and Mooney 2007; Kiedrzyńska, Kiedrzyński, and Zalewski 2015; Opperman, Luster, McKenney, Roberts, and Meadows 2010; Tockner and Stanford 2002), provide aesthetic and cultural values (Brauman, Daily, Duarte, and Mooney 2007; Kiedrzyńska, Kiedrzyński, and Zalewski 2015; Tockner and Stanford 2002), and provide areas to recreate (Kiedrzyńska, Kiedrzyński, and Zalewski 2015; Tockner and Stanford 2002). A community may also value floodplains for economic development and transportation and navigation (Jackson, Carpenter, Dahm, McKnight, Naiman, Postel, and Running 2001). How a community selects and prioritizes these values_-some of which may conflict—guides the adoption of community policy and management for floodplains and flood hazard.

The efficacy of gray infrastructure for flood control and floodwater retention to protect people and property in the floodplain is often undermined by the "scale of vulnerability and the complexity of flooding causes" (Lennon, Scott, and O'Neill 2014:746). Many communities are therefore integrating flood mitigation and adaptation into their planning — what has been called "Making Room for the River"— to increase community resilience to flooding rather than attempting to prevent flooding (Cho 2011, June 7; Lennon, Scott, and O'Neill 2014; Missouri Coalition for the Environment 2015; Rijke, van Herk, Zevenbergen, and Ashley 2012). A noteworthy example of this is in The Netherlands, which relies on gray infrastructure like dikes and groynes for flood protection. The Room for the River Directive was adopted to improve flood mitigation and floodplain management by removing obstacles from the floodplain (e.g., bridge removal), relocating and setting dikes back, and increasing water storage (Rijke, van Herk, Zevenbergen, and Ashley 2012). 
Another example is the willing seller program in Portland Oregon, which acquired and removed properties in the Johnson Creek floodplain to restore and remeander the creek and reconnect the floodplain (City of Portland Bureau of Environmental Services 2008). Through these projects, communities are able to realize multiple benefits from their infrastructure management.

Policy innovation and adoption research provides an excellent framework to analyze how communities choose local policies and infrastructures to use for flood hazard and floodplain management. Berry and Berry adopted Rogers' seminal work on the diffusion of innovation (1962) for policy research to examine the innovation of policy and its diffusion through policy networks (Berry and Berry 1990; Berry and Berry 2014). Within this framework, green infrastructure is considered a policy innovation because of its relative newness when compared to gray infrastructure, and because a policy innovation is understood to mean new to the community in question (Berry and Berry 2014; Lundblad 2003). Empirical research on the paths and barriers to the adoption of green infrastructure as an innovative policy is nascent, but draws heavily on earlier research into the general characteristics of innovation in government planning (Daley and Garand 2005; Damanpour 1991; Damanpour and Schneider 2009; Godwin and Schroedel 2000; Kearney, Feldman, and Scavo 2000; Matisoff 2008; Simmons and Elkins 2004). Drawing heavily on Damanpour's (1991) pioneering work on organization innovation, Kearney et al. (2000) analyze government reinvention by city managers, describing a local willingness to adopt governance innovations as a function of managerial, organizational, fiscal, and community characteristics. 
Managerial characteristics such as age, total years of experience, length of tenure in the current position, the amount of formal education, political orientation, and membership in the relevant professional organization may all contribute to the probability of a community adopting an innovation (Damanpour and Schneider 2009; Kearney, Feldman, and Scavo 2000). It is not only these easily-identified managerial characteristics, however, that have predictive power in the adoption of innovations. In their research on the barriers to adopting green infrastructure, Abhold et al. (2011) found that having previous experience with green infrastructure corresponded with a more positive attitude toward its continued use. Carlet (2015) found that managers with a positive attitude toward green stormwater infrastructure may result in a greater likelihood of green stormwater infrastructure being adopted within the community, a finding in line with a broad body of literature on the relationship between attitude and behavior (Ajzen 1991; Ajzen 2002; Frambach and Schillewaert 2002).

Other factors may predict the likelihood of green infrastructure adoption, however. One of the primary organizational characteristics thought to contribute to the willingness of an organization to adopt an innovation is the size of the organization. If an organization has the capacity to invest the necessary resources and tap into the necessary technical expertise, it is more likely to adopt an innovation than a smaller organization without this capacity. A simple way of characterizing this is via the size of the municipal government workforce or the number of full-time employees in the organization (Brudney, Hebert, and Wright 1999; Damanpour and Schneider 2009; Kearney, Feldman, and Scavo 2000).

Fiscal characteristics may relate both to the local municipal government, as well as the community as a whole, which are often tightly coupled. For instance, both per capita 
revenue for a community (primarily collected from property taxes, permit sales, and fees), as well as per capita income, have been found to have a positive effect on the likelihood of adopting policy innovation (Damanpour and Schneider 2009; Kearney, Feldman, and Scavo 2000; Krause 2011; Matisoff 2008). These fiscal characteristics also may have a strong correlation with other community characteristics, such as the population size of the community.

Community characteristics have been analyzed extensively as factors contributing to the adoption of innovative policy. Most significant is the size of the community, including characteristics such as population size, population growth, and degree of urbanization (e.g., metropolitan and micropolitan statistical areas) (Burby and May 1998; Damanpour and Schneider 2009; Kearney, Feldman, and Scavo 2000; Krause 2011; Shipan and Volden 2008). Previous research has also found that communities with more liberal citizens tend to be more willing to adopt innovative approaches and policies such as climate change and antismoking policies (Matisoff 2008; Shipan and Volden 2008).

In adapting Rogers' theory of the diffusion of innovation, Berry and Berry not only described the innovation of a policy, but its dissemination to other communities (1990). In Berry and Berry's adaptation framework, the internal determinants model describes policy innovators and frames policy innovation and adoption as a function of internal economic, political, or social factors (2014). In contrast, the regional diffusion model describes those who wait to adopt policy, and frames policy innovation as a clustered, regional phenomenon, in which an innovation spreads through policy networks across communities (Bassett and Shandas 2010; Berry and Berry 2014). In the regional diffusion model, "[communities] view neighboring [communities] as laboratories for policy experimentation” (Matisoff 
2008:535)— that is, policy adoption occurs only after observing the effects when a neighboring community adopts the policy. Policy diffusion happens at the regional scale, spreading between communities through policy networks (Berry and Berry 2014). Berry and Berry's (2014) regional diffusion model situates communities within a policy network and describes another potential determinant of the adoption of green infrastructure in a community.

This research aims to expand on the current literature of both policy and green infrastructure adoption at the community level. Specifically, I evaluate the extent to which green infrastructure is being used in the many flood-prone municipal jurisdictions of Oregon, to elucidate my two primary research questions: What factors correlate with the use of green infrastructure, especially for flood hazard and floodplain management, and to what extent is regional diffusion affecting the use of green infrastructure in these jurisdictions? Based on previous research, I formulated three hypotheses incorporating managerial and regional diffusion characteristics that that would positively influence the adoption of green infrastructure (Table 2). To test these hypotheses, I conducted a survey of floodplain managers in communities across the state of Oregon. I next describe my data collection and analytical methods before providing results and discussing the nuances the data suggest about my hypotheses. 
Table 2. Hypotheses on the characteristics that may positively influence the adoption of green infrastructure adoption for flood risk and floodplain management.

\begin{tabular}{|c|c|c|}
\hline Hypothesis & Variables & Citation \\
\hline $\begin{array}{l}\text { H1: Having more professional experience } \\
\text { with } 100 \text {-year flood events, and } \\
\text { being more knowledgeable about the } \\
\text { history of flooding in the community } \\
\text { will positively correlate with the } \\
\text { adoption of green infrastructure. }\end{array}$ & $\begin{array}{l}\text { Flood experience } \\
\text { Flood history }\end{array}$ & $\begin{array}{l}\text { (Damanpour 1987; } \\
\text { Damanpour and Schneider } \\
\text { 2006; Damanpour and } \\
\text { Schneider 2009; Kearney, } \\
\text { Feldman, and Scavo 2000) }\end{array}$ \\
\hline $\begin{array}{l}\text { H2: Talking to other communities' } \\
\text { floodplain administrator, and reading } \\
\text { other communities' flood } \\
\text { management plans, will positively } \\
\text { correlate with the adoption of green } \\
\text { infrastructure. }\end{array}$ & $\begin{array}{l}\text { Frequency } \\
\text { Plans }\end{array}$ & $\begin{array}{l}\text { (Berry and Berry 2014; } \\
\text { Damanpour and Schneider } \\
\text { 2009; Walker 1969) }\end{array}$ \\
\hline $\begin{array}{l}\text { H3: Being more knowledgeable about } \\
\text { flood mitigation infrastructure, and } \\
\text { having previous experience as a } \\
\text { floodplain administrator will } \\
\text { positively correlate with the adoption } \\
\text { of green infrastructure. }\end{array}$ & $\begin{array}{l}\text { Infrastructure } \\
\text { Previous FPA }\end{array}$ & $\begin{array}{l}\text { (Abhold, Loken, and } \\
\text { Grumbles 2011; Carlet } \\
\text { 2015; Damanpour 1987; } \\
\text { Damanpour and Schneider } \\
\text { 2006) }\end{array}$ \\
\hline
\end{tabular}

\section{Methods}

$\underline{\text { Study Area }}$

Oregon was selected as the study area because of its topography, flood history, and land use planning. Oregon's topography is heterogeneous, with coastal and inland areas, urban and rural development, and extensive forests and agricultural production, providing an opportunity to examine flood response in communities of differing contexts (Figure 3). 


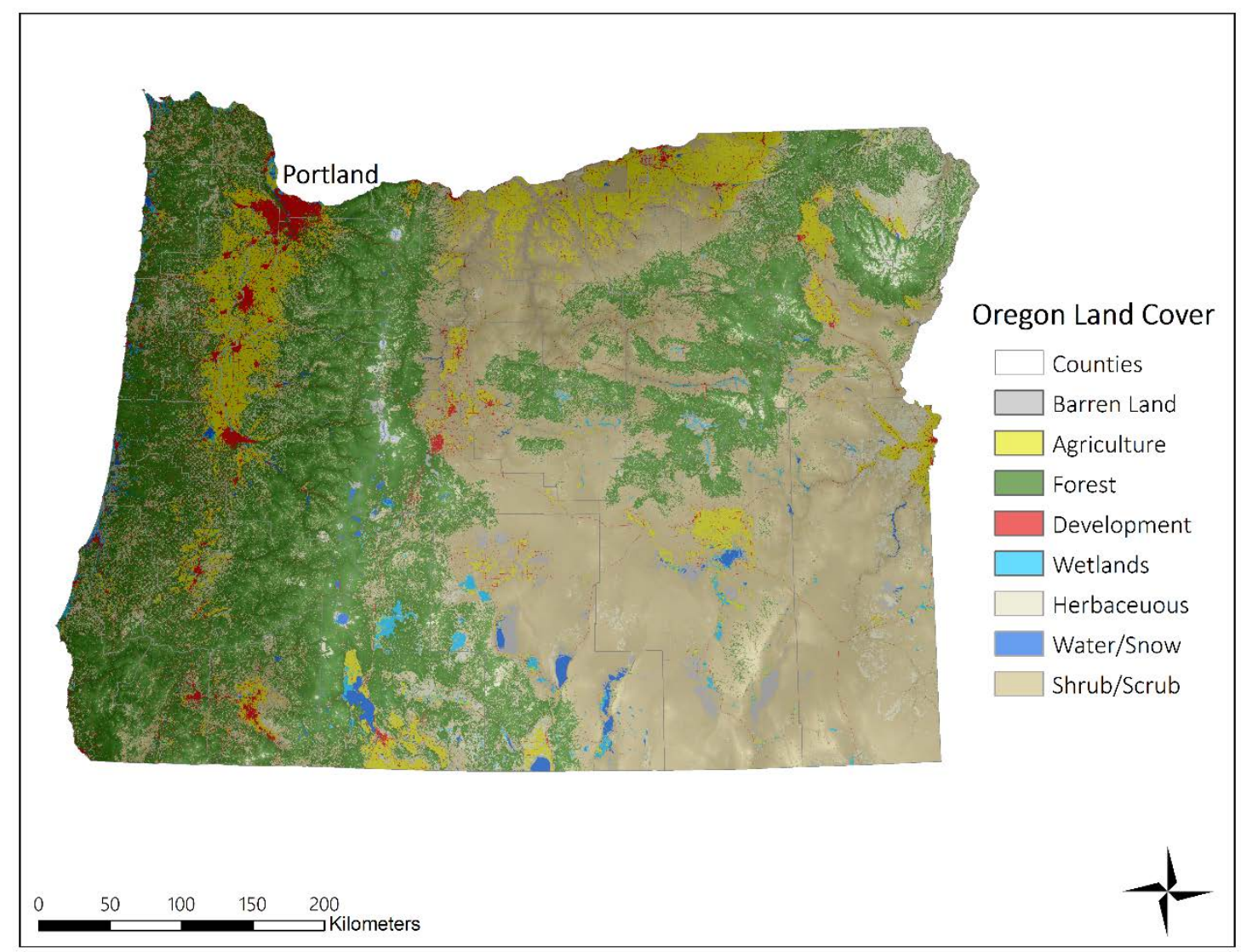

Figure 3. Oregon topography, showing the range of different land covers, including extensive forest, agriculture, and scrublands. The most heavily urbanized areas are in the western and northwestern part of the state; these areas are also heavily agricultural. The darker shades in the western part of the state indicate lower elevations compared to the higher elevations in the eastern part of the state.

Across these different landscapes, the state has a long history of flooding, with major riverine or coastal floods occurring regularly since at least the mid-1800s; the deadliest natural disaster in Oregon's recorded history was a 1903 flood in the town of Heppner, which killed almost 250 people (National Weather Service n.d.). Since 1955, there have been 23 major flood disaster declarations, with over $\$ 135$ million in FEMA payouts since 2005 (Federal Emergency Management Agency 2018b; Oregon Department of Land Conservation and Development 2015). The last flood to affect most of the state-27 of 36 counties — was in 1996, when eight people were killed and resulting damages were estimated 
at approximately $\$ 280$ million (Oregon Department of Land Conservation and Development 2015).

Oregon's land use planning history provides excellent context for examining the use of green infrastructure and open space for flood mitigation. In 1973, Oregon adopted nineteen statewide land use planning goals (Oregon Department of Land Conservation and Development 2010). Cities and counties are required to develop comprehensive plans to meet these planning goals, which include several goals salient to open space and flood hazard and floodplain management: Goal 5 for natural resources, scenic and historic areas, and open spaces; Goal 7 for areas subject to natural disaster and hazards; and Goal 17 for coastal shorelands. Amongst other objectives, Goal 5 mandates the conservation of open spaces for current and future use. This is reiterated in the natural hazards mitigation planning goal, which instructs local government to consider the benefits of preserving "natural hazard areas as open space," including measures similar to CRS activities that exceed NFIP requirements for floodplain management. These objectives are again reiterated in the coastal shorelands planning goal, which explicitly states that as part of the comprehensive planning process, floodplain management "should be expanded beyond the minimal considerations necessary to comply with the $[\mathrm{NFIP}]$ and the requirements of the Flood Disaster Protection Act of 1973." These objectives are again reflected in Goal 5, which mandates that "stream flow and water levels should be protected and managed at a level adequate for fish, wildlife, pollution abatement, recreation, aesthetics, and agriculture," all benefits of functioning floodplains (Brauman, Daily, Duarte, and Mooney 2007; Oregon Department of Land Conservation and Development 2010). 


\section{Survey Development and Implementation}

Survey data for this research were collected through a web-based key informant questionnaire completed by designated floodplain administrators in Oregon. There are 262 communities in Oregon that are part of the NFIP: 223 cities and towns, all 36 counties, and three tribal nations. To be part of the NFIP, a community must have a designated floodplain administrator as a point of contact with FEMA; this may be a municipal government position (e.g., a planner or city recorder) or the community may use an outside contractor. Designated floodplain administrators were the key informants for this survey; because there are questions related to the diffusion of policy between communities, only administrators from the cities and towns were contacted. Recruitment of key informants occurred up to six times between July to December 2017, which included an initial email with a link to the online survey, followed by up to five phone calls, and further emails when requested. Questions were a mix of open- and closed-ended questions, including yes/no, multiple choice, and Likert-type response questions, grouped into several sections: respondent background, community flood history, beliefs about community flood risk and floodplain policy development, an inventory of community infrastructure and policies, and beliefs and attitudes regarding infrastructure and flood hazard and floodplain management priorities.

\section{$\underline{\text { Data and Measures }}$}

Independent variables were created from publicly-available community data such as population and demographic characteristics. I used two population variables: the 2017 population of the community and population growth between 2000 and 2017 (i.e., Population and PopGrowth) (Portland State University College of Urban \& Public Affairs 
2017). There were two variables capturing education attainment: the percent of the community that holds a bachelor's degree (Bachelor) and the percent of the community that hold a graduate or professional degree (GradProf). (U.S. Census Bureau 2016b). I also included three employment and economic variables: the percent of the community that work as government employees (Government), community per capita income (Income), and unemployment rate (Unemployment) (U.S. Census Bureau 2016b). The final variable was the degree of urbanization — whether the community was in a Census-designated metropolitan statistical area (greater than 50,000 people), micropolitan statistical area (greater than 10,000 people but fewer than 50,000 people), or neither (U.S. Census Bureau 2018); MMSA, the variable for statistical areas, was coded 2 for metropolitan, 1 for micropolitan, and 0 for neither.

I then performed a Poisson and Ordinary Least Squares (OLS) regression for hypothesis testing, incorporating significant variables from the logistic regression to control for response bias. The dependent variable for the Poisson and OLS regressions was created from the inventory of community infrastructure and policies section of the survey. In this section, respondents were asked a series of yes/no questions regarding the types of green infrastructure, gray infrastructure, planning and preparation activities, risk reduction activities, public awareness activities, and emergency management improvements their community has adopted. Answers were scored 0 (no) or 1 (yes). The dependent variable, green infrastructure, was a sum of the scores from ten of the inventory items specifically related to green infrastructure. Berry and Berry (2014) note that while this approach has limitations, it is appropriate if the focus of the research is specific, rather than a large-scale analysis of adopting innovative policy. 
In addition to the significant variables from the logistic regression, six independent variables were created from the key informant questionnaire (Table 3). The respondents' knowledge of and experience with flooding was measured with three variables. The first was labeled Flood Experience and was measured as the number of 100-year flood events the respondent had experienced divided by their length of tenure with as the floodplain administrator. The remaining two variables for knowledge about flooding were created from two Likert-scale questions, including one on the respondent's knowledge of flooding in the community (Flood History) and another regarding flood mitigation infrastructure (Infrastructure); responses ranged from not at all knowledgeable (0) to extremely knowledgeable (4). Previous professional experience with flood hazard and floodplain management planning was measured with a yes (1) / no (0) question to determine if they had previously worked as a floodplain administrator (FPA) in other community (Previous FPA). Regional diffusion potential was measured with two questions. The first asked how often the respondent reported talking to other FPAs, ranging from more than once a week to less than once a year (Frequency). The second question asked respondents to answer yes (1) or no (1) about whether they had read other communities' flood management plans (Plans). 
Table 3. Variable names and descriptions for Poisson and OLS regression analysis.

\begin{tabular}{|c|c|c|}
\hline Variable name & Variable description & Source \\
\hline Bachelor & Percent of population with bachelor degree & U.S. Census \\
\hline Flood experience & $\begin{array}{l}\text { Number of 100-year floods during respondent's tenure, divided by } \\
\text { tenure }\end{array}$ & Survey \\
\hline Flood history & How knowledgeable respondent is on flooding in their community & Survey \\
\hline Frequency & How often respondent talks to other floodplain administrators & Survey \\
\hline GradProf & Percent of population with graduate or professional degree & U.S. Census \\
\hline Infrastructure & How knowledgeable respondent is on flood mitigation infrastructure & Survey \\
\hline MMSA & $\begin{array}{l}\text { Metropolitan (MMSA=2), micropolitan }(M M S A=1) \text {, or neither } \\
(M M S A=0) \text { designation }\end{array}$ & U.S. Census \\
\hline Plans & Respondent has read other communities' flood management plans & Survey \\
\hline Previous FPA & Respondent previously worked as a floodplain administrator & Survey \\
\hline Unemployment & Unemployment rate in community & U.S. Census \\
\hline
\end{tabular}

Spatial Analysis

After testing whether a spatial error model was appropriate, and finding that the residuals did not exhibit spatial autocorrelation, I conducted several other spatial analyses to better understand how green infrastructure was varying through space, and what variables in the regression were correlated with the spatial patterns of use of green infrastructure. To evaluate whether a community is more likely to adopt green infrastructure if its neighbors have already adopted it, and determine if there is correlation between green infrastructure and urbanization (i.e., MMSA), I used GeoDa 1.12.1.131 to calculate Moran's I (I), local Getis-Ord $\left(G_{i}^{*}\right)$, and bivariate Local Indicators of Spatial Association (LISA). Spatial autocorrelation tests whether a variable (e.g., green infrastructure) is correlated with itself in space-e.g., are similar values clustering together within the study area. Global spatial autocorrelation analyzes whether spatial autocorrelation exists in the study area; local spatial autocorrelation determines where within the study area spatial autocorrelation is occurring. The bivariate LISA, also known as the local Moran's I, is a local analysis of the correlation between two variables across space. 
The Moran's I statistic is given as:

$$
I=\frac{N \sum_{i=1}^{n} \sum_{j=1}^{n} w_{i j}\left(x_{i}-\bar{x}\right)\left(x_{j}-\bar{x}\right)}{\left(\sum_{i=1}^{n} \sum_{j=1}^{n} w_{i j}\right) \sum_{i=1}^{n}\left(x_{i}-\bar{x}\right)^{2}}
$$

where $\mathrm{N}$ is the number of observations, $\overline{\mathrm{x}}$ is the mean of the variable, $\mathrm{x}_{\mathrm{i}}$ is the variable value at a given location $i, x_{j}$ is the variable value at location $j$, and $w_{i j}$ is the spatial weights matrix defining the neighbor relation between points $\mathrm{i}$ and $\mathrm{j}$. I used an inverse distance weights matrix to define the neighbor relationship (Stakhovych and Bijmolt 2009). Moran's I calculates the extent that a variable covaries across space. If $x_{i}$ and $x_{j}$ are on the same side of the mean, then I is positive, denoting positive spatial autocorrelation, or clustering. If $x_{i}$ and $\mathrm{x}_{\mathrm{j}}$ are each on different sides of the mean, then I is negative, denoting negative spatial autocorrelation, or dispersion. I used GeoDa to test for significance using both a z-score and a Monte Carlo simulation with 9,999 permutations. The observed pattern is compared against expected patterns under the null hypothesis that the data are randomly distributed in the study area to generate a pseudo p-value.

I used the local Getis-Ord statistic to determine where clustering occurred in the study area. Getis-Ord can determine not only clustering, but also areas of low values clustering together (cold spots) and areas of high values clustering together (hot spots). The local Getis-Ord statistic is given as:

$$
G_{i}^{*}=\frac{\sum_{j} w_{i j} x_{j}}{\sum_{j} x_{j}}
$$

where $G_{i}^{*}$ is the local Getis-Ord statistic at a given location $\mathrm{i}, \mathrm{x}_{\mathrm{j}}$ is the variable value at location, $\mathrm{j}$, and $\mathrm{w}_{\mathrm{ij}}$ is the spatial weights matrix defining the neighbor relation between points 
$i$ and $j$ (Getis and Ord 1992). Again, I used an inverse distance weights matrix to define the neighbor relationship (Stakhovych and Bijmolt 2009), and GeoDa to test for significance with a Monte Carlo simulation based on 9,999 permutations. The local Getis-Ord statistic is the ratio of a point and all its neighbor values, as defined by the weights matrix, to the sum of all values in the study area. $G_{i}^{*}$ will be high where high values cluster and low where low values cluster.

I used bivariate LISA to evaluate potential correlation between green infrastructure and $M M S A$. Previous research has found innovation adoption to be more prevalent in urban areas (Damanpour and Schneider 2009; Godwin and Schroedel 2000; Hwang and Gray 1991; Shipan and Volden 2006; Walker 1969; Yi, Feiock, and Berry 2017); the bivariate LISA will allow me to see to what extent these two variables correlate across space. Bivariate LISA analyzes the correlation between one variable (e.g., adoption of green infrastructure) and the spatial lag of another variable (e.g., MMSA) in neighboring areas; the formula is given as:

$$
I_{i}=z_{i} \sum_{j} w_{i j} z_{j}
$$

where $\mathrm{I}_{\mathrm{i}}$ is the local Moran's I statistic, $z_{\mathrm{i}}$ is the $\mathrm{z}$-score for the first variable at location $i, z_{\mathrm{j}}$ is the $z$-score for the second variable at location $j$, and $\mathrm{w}_{\mathrm{ij}}$ is the spatial weights matrix (Anselin 1995). Because the bivariate LISA is evaluating the correlation of one variable with the spatial lag of a second variable, it is always the first variable at location $i$ and the second variable at location $j$. To be consistent, I again used an inverse distance weights matrix. This statistic returns four types of results: High - high, low - low, low - high, and high - low. The first term refers to the relative value of the first variable (in this case, green infrastructure) in that location, and the second term refers to the relative value of the second 
variable (i.e., MMSA) in surrounding locations. Thus, hot - hot, or hot spot, indicates a high value for green infrastructure and a high MMSA value (i.e., an urban area). Low - low, or cold spot, indicates a low green infrastructure value, and a low MMSA value. Low - high indicates a low green infrastructure value and a high MMSA value, while high - low is the reverse.

\section{$\underline{\text { Regression Modelling }}$}

To test for response bias, I first performed a logistic regression predicting differences between respondents and non-respondents. The logistic regression tested to see if there were significant trends describing questionnaire respondent and nonrespondent communities. The dependent variable was categorical—whether or not the community's floodplain administrator responded to the survey.

I used IBM SPSS 25 to perform both a quasi-Poisson and OLS regression for evaluating which factors correlate with the adoption of green infrastructure. Poisson regression is used when the dependent variable is count data, while OLS assumes the dependent variable is, or approximates, continuous data. The dependent variable in this analysis, green infrastructure, is a sum of the types of green infrastructure being used in a community for flood hazard and floodplain management. I used a quasi-Poisson specification due to the dependent variable being overdispersed; rather than assuming the mean and variance in the dependent variable are equal, as Poisson regression does, quasiPoisson regression estimates the dispersion parameter from the data. The diagnostics and coefficients remain the same, but the statistical inference is adjusted for overdispersion in quasi-Poisson regression, or what some call Poisson with robust standard errors (Zeileis, Kleiber, and Jackman 2008). To control for response bias, significant variables from the 
non-response logistic regression were included. I compared these results to those of an OLS regression. Since the dependent variable was bounded at zero, which is contrary to the assumptions of an OLS model, I also examined the frequency of non-zero predicted values from the OLS to determine its suitability.

\section{Results}

I identified 225 flood prone communities in Oregon based on participation in the NFPA. The questionnaire was administered to the municipal floodplain administrator for each community, and was focused on municipal flood hazard and floodplain management. Twenty-four communities were deemed ineligible because the county manages their floodplains; I was also unable to contact floodplain administrators for 43 communities either because I could not find contact information for them or because community staff could not identify their floodplain administrator. Thus, the sample included 158 administrators; 38 of these did not participate, typically stating that flooding was not an issue for their community, that they did not have the resources to complete the survey, or that they were uncomfortable participating. Thirteen completed less than $50 \%$ of the questionnaire, the a priori threshold I decided on to define incomplete and unusable responses. The final response rate was $68 \%$ and included the 107 responses that were at least 50\% complete (Figure 4). 


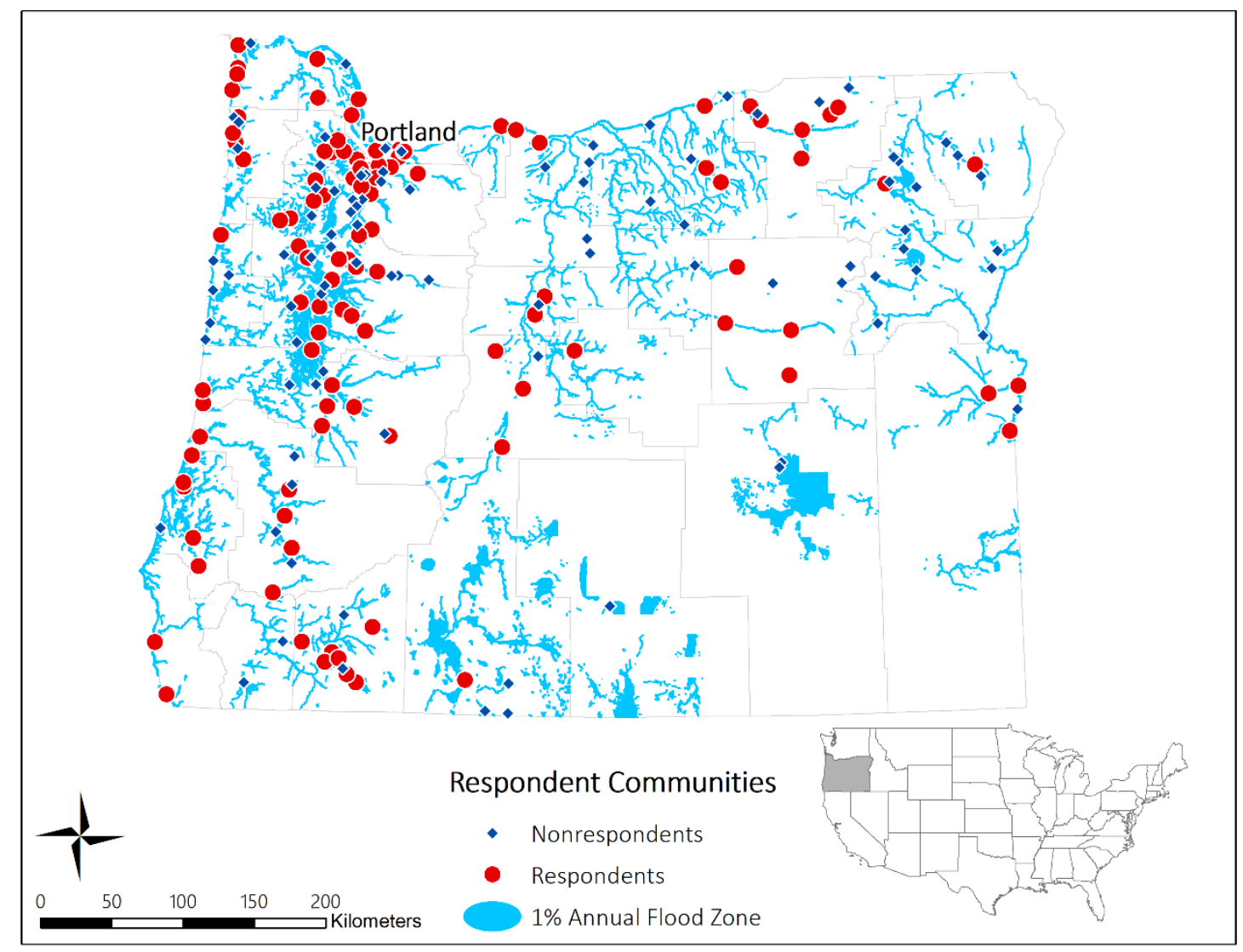

Figure 4. Flood-prone communities and the $1 \%$ annual flood zone (formerly called the 100-year floodplain) in Oregon. Survey respondents are noted with red circles, while nonrespondents are noted with dark blue diamonds.

Respondents tended to be from communities with a population greater than 2,500. Over half of the respondents were at least 50 years old (56\%) and had completed at least a bachelor degree $($ bachelor degree $=41 \%$, master degree $=35 \%$ ). Overall, respondents reported more commonly using green infrastructure than gray infrastructure for flood hazard and floodplain management (Figure 5). 


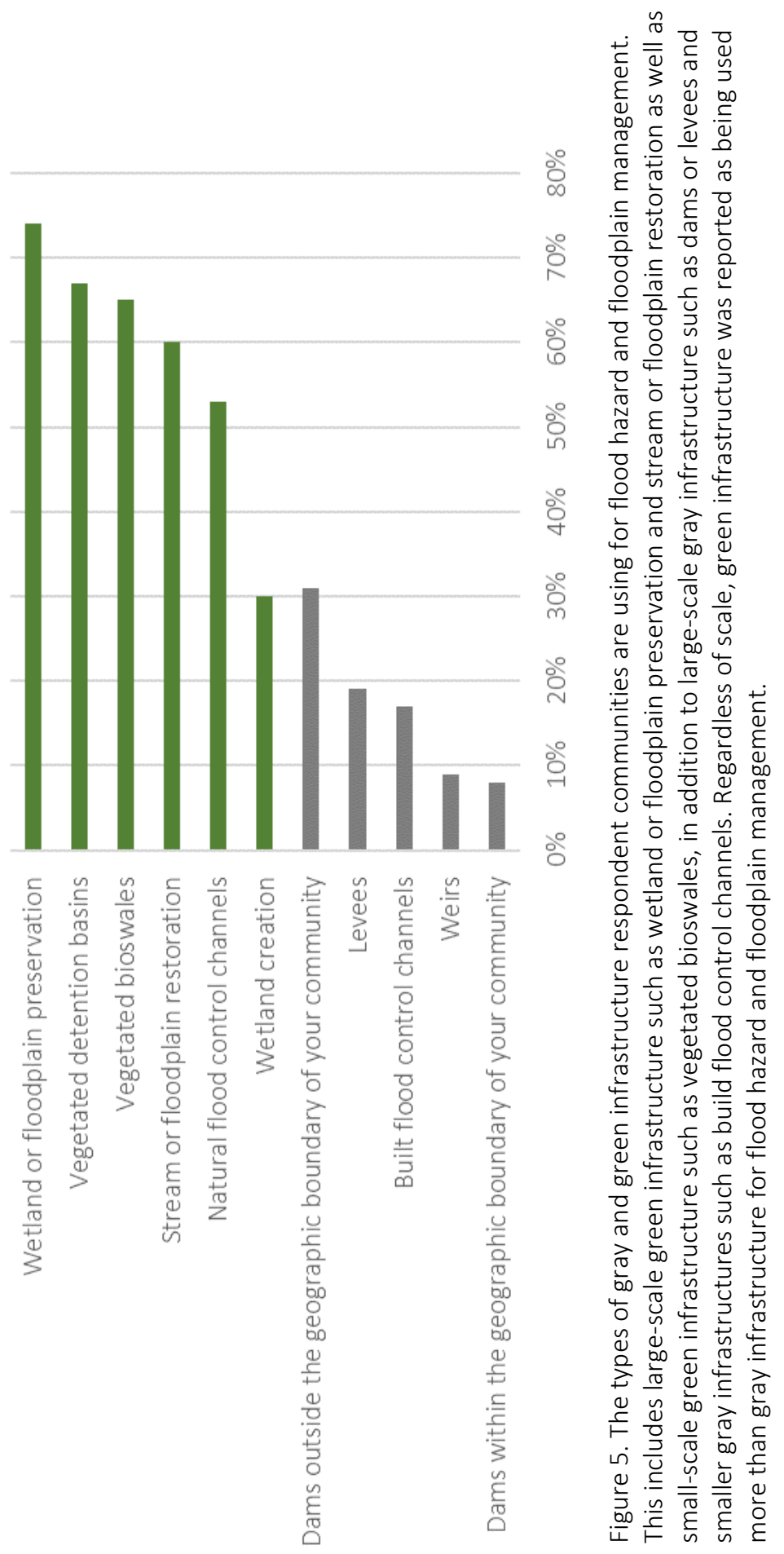




\section{$\underline{\text { Non-Respondent Bias }}$}

To evaluate whether the final sample was biased towards certain types of communities a logistic regression was performed on whether the community floodplain administrator replied to the questionnaire or not. To evaluate potential response bias across all of the communities, I classified the 43 communities that I was unable to contact and the thirteen incomplete responses as nonrespondents, as well as the 38 nonrespondents. The result was 107 respondents and 93 nonrespondents.

There were three significant variables predicting survey response in the logistic regression $(\alpha=0.10)$ : Bachelor, GradProf, and Unemployment; in addition, because MMSA was marginally significant $(\mathrm{p}=0.107)$, I decided to control for it in the quasi-Poisson and OLS regressions to ensure that I was addressing response bias. Communities with higher percentages of the population with college degrees and higher unemployment rates were more likely to respond.

\section{Green Infrastructure Composite Index}

The dependent variable, green infrastructure, was created as a composite index from the questionnaire data. This variable was the sum of ten yes/no answers from the survey about which types of green infrastructure their community relies on, which meant that values potentially ranged between zero and ten; the mean was 3.87 (standard deviation $=2.60$ ). 
Cronbach's alpha was 0.82 for green infrastructure, which denotes good internal consistency

(Table 4). Twelve communities reported using no green infrastructure (Figure 6).

Table 4. Survey inventory questions for the dependent variable Green Infrastructure, with percentage of affirmative answers and Cronbach's alpha.

\begin{tabular}{lccc}
\hline $\begin{array}{l}\text { Does your community rely on the following types of } \\
\text { infrastructure, or has it undertaken any of the following } \\
\text { activities? }\end{array}$ & $\begin{array}{c}\text { Percentage of } \\
\text { yes answers }\end{array}$ & $\begin{array}{c}\text { Cronbach's } \\
\text { alpha }\end{array}$ & $\mathrm{n}$ \\
\hline $\begin{array}{l}\text { Green Infrastructure variable } \\
\text { Wetland or floodplain preservation }\end{array}$ & $74 \%$ & 0.82 & 97 \\
$\quad$ Vegetated detention basins & $67 \%$ & & 93 \\
$\quad$ Vegetated bioswales & $65 \%$ & 97 \\
$\quad$ Stream or floodplain restoration & $60 \%$ & 93 \\
$\quad$ Natural flood control channels & $53 \%$ & 89 \\
Required compensatory storage in the floodplain & $33 \%$ & 88 \\
$\quad$ Wetland creation & $30 \%$ & 83 \\
$\quad$ Established a stream buffer code that exceeds county & & 89 \\
$\quad$ requirements & $28 \%$ & \\
$\quad \begin{array}{l}\text { Acquired and/or relocated flood-prone buildings out of } \\
\text { the floodplain }\end{array}$ & $16 \%$ & 98 \\
Required that currently vacant floodplain parcels will & & \\
$\quad$ be kept free from development & $11 \%$ & \\
\hline
\end{tabular}

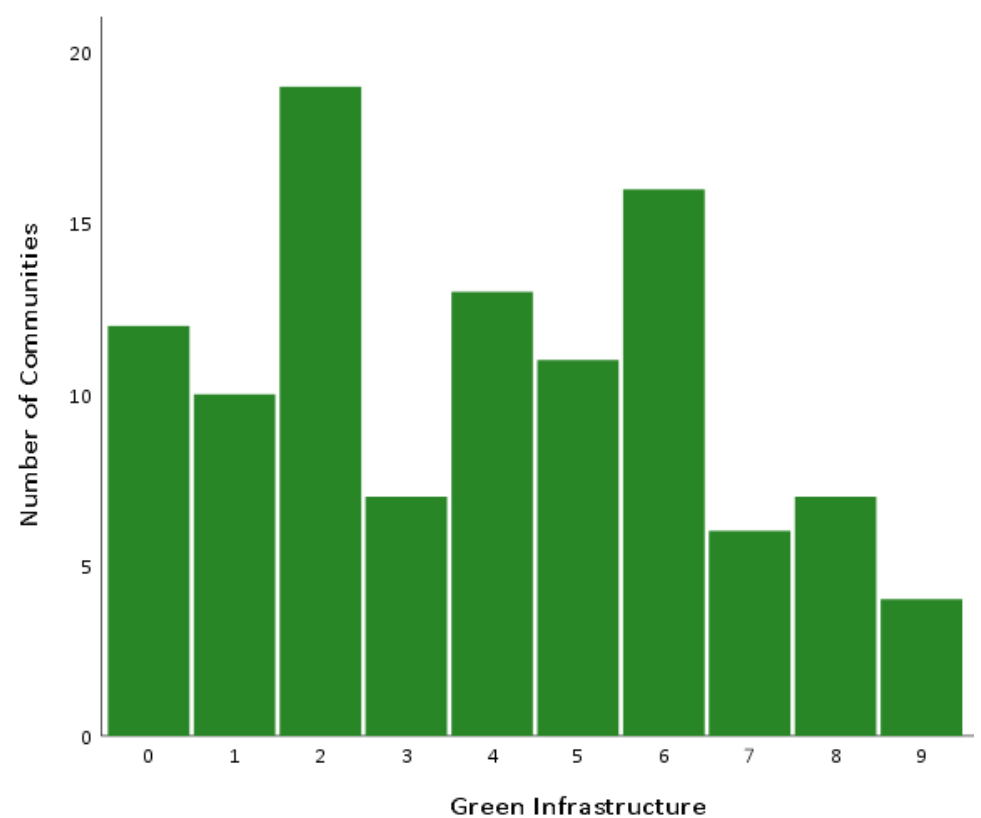

Figure 6. Histogram of the distribution of the dependent variable, green infrastructure. Values for this variable range from zero to nine, with approximately $10 \%$ of communities reporting that no green infrastructure was being used. 


\section{$\underline{\text { Summary Statistics }}$}

Flood experience — that is, the number of 100-year floods during the respondent's tenure, divided by the length of their tenure, ranged between zero and two with a mean of 0.11 (Table 5). The high score of two would be indicative of a respondent who had experienced, for example, two 100-year flood events within a one-year period, or four 100year flood events in a two-year period. The mean indicates a respondent who had experienced one 100-year flood in ten years or so. The two knowledge variables-Flood History and Infrastructure — each ranged between one and five, with five being extremely

Table 5. Summary statistics for the dependent and independent variables. The range and mean are presented for integer data, and proportions are presented for categorical data.

\begin{tabular}{lccc}
\hline & Range & Mean & Proportion \\
\hline $\begin{array}{l}\text { Dependent variable } \\
\text { Green infrastructure } \\
\text { Independent variables } \\
\text { Flood experience }\end{array}$ & $0-9$ & 3.87 & \\
Flood history & $0-2$ & & \\
Frequency & $1-5$ & 0.11 & \\
Infrastructure & $0-5$ & 3.71 & \\
Plan & $1-5$ & 1.83 & \\
$\quad$ No & & 2.76 & \\
$\quad$ Yes & & & $76.9 \%$ \\
Previous FPA & & & $23.1 \%$ \\
No & & & \\
$\quad$ Yes & & & \\
\end{tabular}

knowledgeable. On average, people reported being relatively more knowledgeable of the history of flooding in their community $(\overline{\mathrm{x}}=3.71$, or somewhat to very knowledgeable) than of flood mitigation infrastructure their community relies on $(\overline{\mathrm{x}}=2.76$, or slightly to somewhat knowledgeable). Frequency — the frequency respondents spoke with other administrators — ranged from zero to five with a mean of 1.83 , indicating that, on average, people talk to other administrators approximately once a year. The majority of respondents 
do not read other communities' flood management plans $(76.9 \%)$, nor have they previously worked as a floodplain administrator in another community $(76.6 \%)$.

\section{$\underline{\text { Spatial Analysis }}$}

Moran's I for the dependent variable, green infrastructure, was significant $(I=0.25$, $z=6.02$ pseudo $p$-value $<0.001)$, indicating significant positive spatial autocorrelation. The local Getis-Ord detected clustering throughout the study area. There were hot spots in the northwestern part of the state, primarily in the Portland metropolitan area. There were also cold spots, primarily in the eastern part of the state (Figure 7).

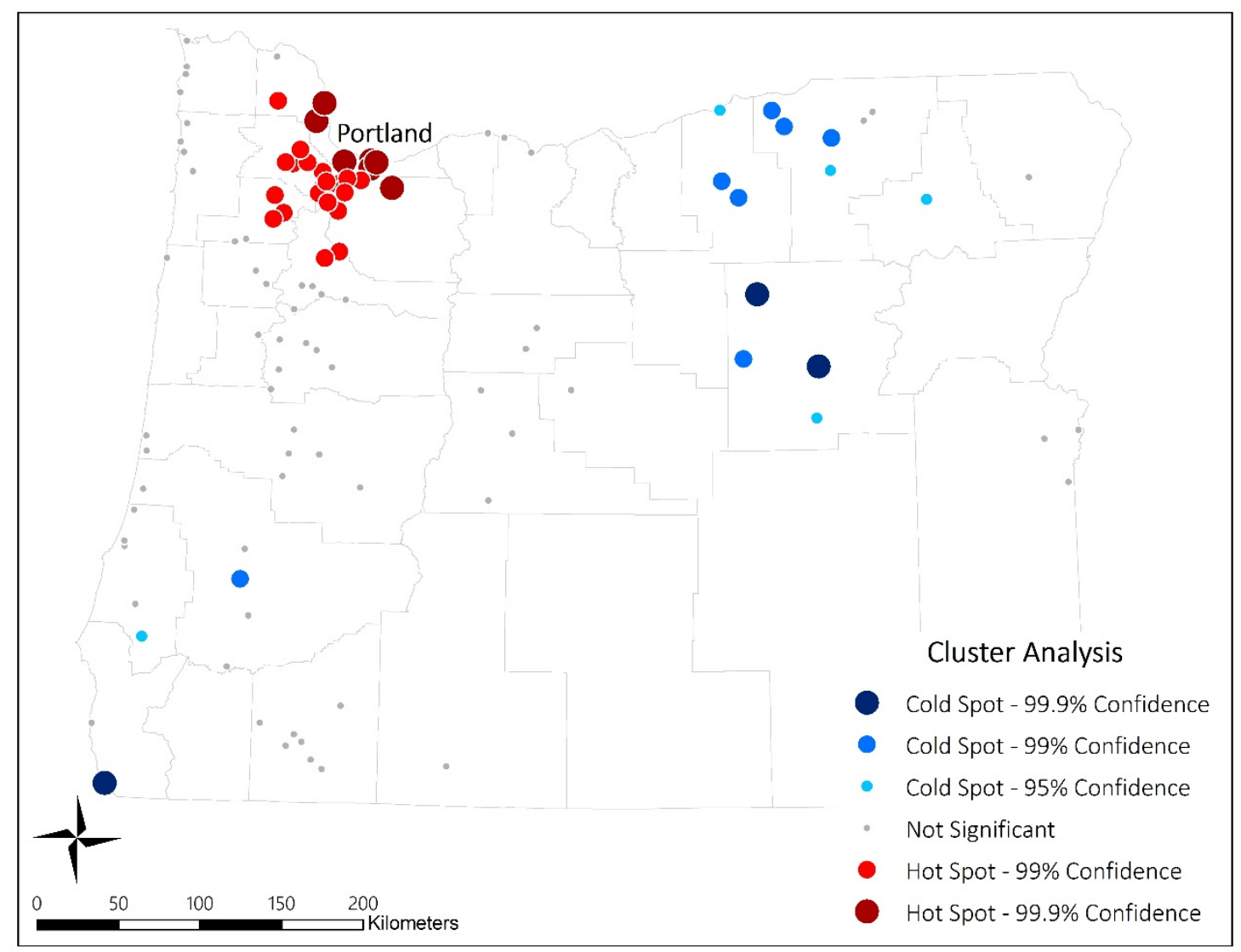

Figure 7. Local Getis-Ord spatial autocorrelation analysis. Hot spots with high values of green infrastructure adoption are found in the Portland metropolitan area. Cold spots with lower values of green infrastructure adoption are primarily in the eastern part of the state. 
I used a bivariate LISA to evaluate spatial correlation between green infrastructure and MMSA. By definition, MMSA should be spatially autocorrelated, because these are areas with a high population density surrounded by closely-integrated, populous areas (U.S. Census Bureau and Federal Register 2010); this supposition was confirmed by the global Moran's I $(\mathrm{I}=0.61$, pseudo p-value $<0.001)$. While there are hot spots in northwestern Oregon, there are also numerous low - high values, that is, urban areas with low amounts of green infrastructure. Eastern Oregon, as well as the northern coast, has several low spotslow amounts of green infrastructure in rural areas. There are a few high - low spots in these areas too, indicating rural areas using more green infrastructure than neighboring communities (Figure 8). 


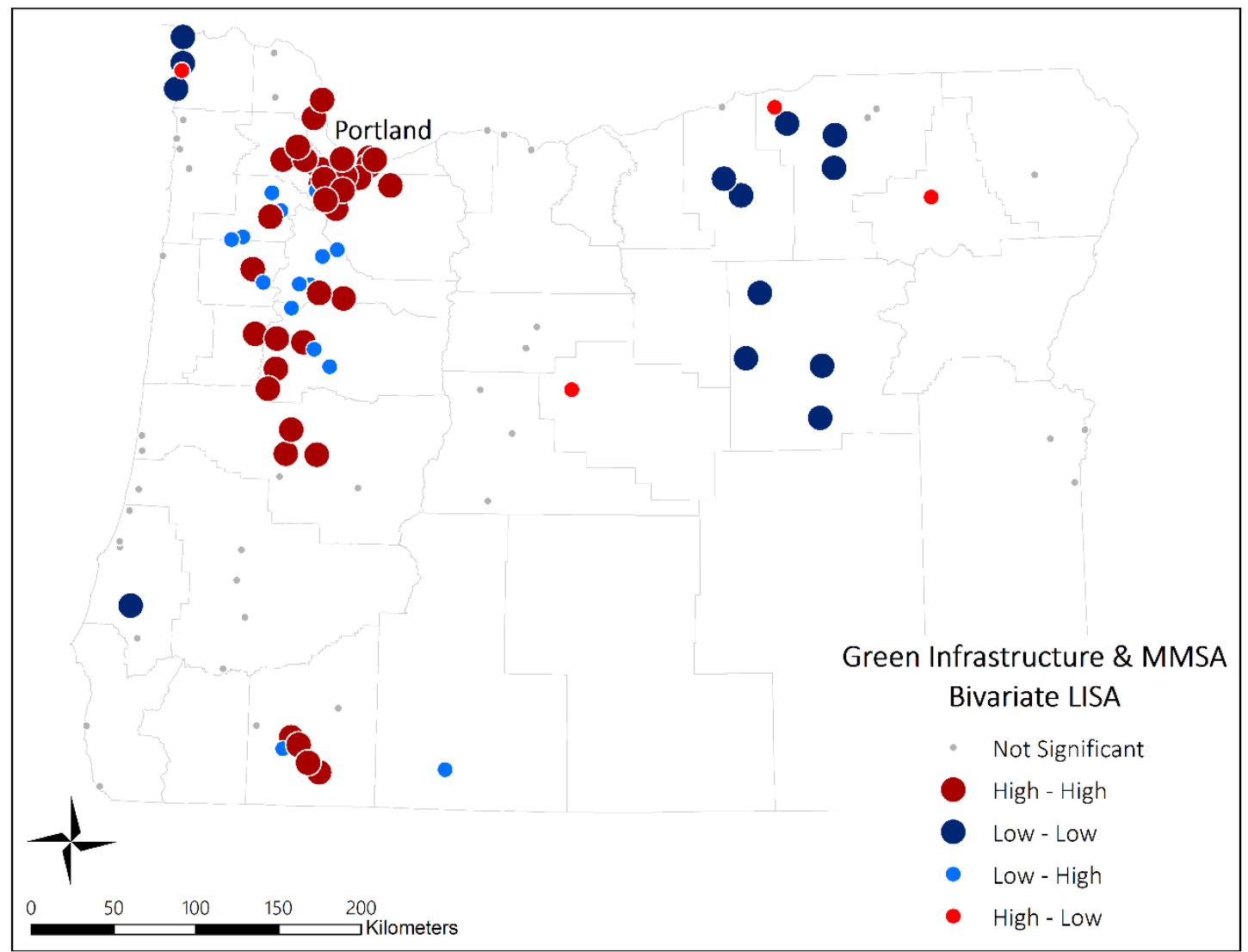

Figure 8. Bivariate Local Indicators of Spatial Association analysis of green infrastructure and MMSA. High high values found primarily in northwestern Oregon indicate high values of green infrastructure in urban areas. The low - high values interspersed with these indicate urban areas with low amounts of green infrastructure. Low - low areas, found primarily in eastern Oregon, indicate rural areas with low values for green infrastructure, while a couple of high - low spots show rural areas with higher amounts of green infrastructure.

\section{$\underline{\text { Regression Analysis }}$}

I first ran a quasi-Poisson regression (i.e., Poisson with robust standard errors) to account for the overdispersion in the Pearson chi-square diagnostic $\left(\chi^{2}=1.31\right)$ (Table 6$)$. Quasi-Poisson estimates a dispersion parameter used to improve coefficient standard errors and improve statistical inference. Three variables were significant $(\alpha=0.05)$ : Flood Experience, Infrastructure, and MMSA. A fourth variable, Plans, was borderline significant, but did not meet the alpha cutoff value $(\alpha=0.107)$. The model was significant, with a 
likelihood ratio $\chi^{2}$ of approximately $71(\mathrm{p}<0.001)$ and Akaike Information Criterion (AIC) of approximately 370 .

Before analyzing the OLS model, I used GeoDa to analyze the regression model for spatial autocorrelation that would be better addressed with a spatial regression model. The goal was to examine whether there was spatial variation in the Poisson regression error term in order to identify potential omitted variables that may be commonly associated with communities in specific areas. This is done by using Moran's I to test for significant spatial autocorrelation in the error term; a significant Moran's I indicates that spatial regression would fit the data with less bias. Moran's I was not significant, however, so I did not use spatial regression $(I=0.17, \mathrm{p}>0.10)$.

I then completed an OLS model, and diagnostics indicated that the model was significant $(\mathrm{F}=5.46, \mathrm{p}<0.001)$ and explained approximately $35 \%$ of the variance $\left(\mathrm{R}^{2}=\right.$ 0.35) (Table 6). The AIC was approximately 140. All but one of the predicted values for the OLS were positive, ranging from 0.04 to 7.60 (the exception was one value of -0.55), indicating that the OLS regression results were suitable for interpreting the data. Like the quasi-Poisson, the model included four variables to account for response bias, two variables address the regional diffusion theory, and four variables address factors other than regional diffusion that may correlate with the use of green infrastructure. Of these ten variables, the same three variables that were significant in the Quasi-Poisson regression were significant in the OLS regression: Flood Experience, Infrastructure, and MMSA. Frequency was also marginally significant $(\alpha=0.10)$ with a positive coefficient. Flood experience was the number of 100-year flood events the respondent had experienced during their tenure divided by their tenure. The coefficient on Flood Experience was positive and highly significant $(\mathrm{p}<0.01)$, 
indicating that if the administrator experienced more 100-year floods during their tenure, there also tended to be more green infrastructure in that community. Knowledge of infrastructure (the infrastructure variable) was also positive and highly significant, indicating that respondents who considered themselves highly knowledgeable about flood mitigation infrastructure tended to be in communities with higher amounts of green infrastructure. Urbanization (i.e., MMSA — whether a community is in a metropolitan, micropolitan, or rural area) was also highly significant, with the largest standardized coefficient (standardized $\beta=$ $0.40, \mathrm{p}<0.001)$. This positive coefficient indicates a correlation between increasing urbanization and an increased amount of green infrastructure being used. Two factors I hypothesized would be correlated with the use of green infrastructure in a communityknowledge of flood history in the community, and previous experience as a floodplain administrator-were not significant. 
Table 6. Model coefficients and diagnostics for the Quasi-Poisson and OLS regressions. The control variables are those variables that had a significant effect in the logistic regression evaluating response bias. Hypothesized variables were created from the questionnaire to evaluate which characteristics correlate with the adoption of green infrastructure. Standardized coefficients are in parentheses.

\begin{tabular}{|c|c|c|}
\hline & $\begin{array}{c}\text { Quasi-Poisson model } \\
\text { coefficients }\end{array}$ & OLS model coefficients \\
\hline & Wald $\chi^{2}$ & $B$ \\
\hline \multicolumn{3}{|l|}{ Control variables } \\
\hline Bachelor & 1.70 & $7.57(0.22)$ \\
\hline GradProf & 1.63 & $-9.40(-0.22)$ \\
\hline MMSA & $32.02 * * *$ & $1.56(0.40)^{* * *}$ \\
\hline Unemployment & 0.53 & $12.30(0.10)$ \\
\hline \multicolumn{3}{|l|}{ Hypothesized variables } \\
\hline Flood experience & $16.64 * * *$ & $2.60(0.28)^{* *}$ \\
\hline Flood history & 0.55 & $-0.370(-0.11)$ \\
\hline Frequency & 2.32 & $0.43(0.18)^{\ddagger}$ \\
\hline Infrastructure & $7.18^{* *}$ & $0.96(0.34)^{* *}$ \\
\hline Plans & 2.60 & $0.81(0.13)$ \\
\hline Previous FPA & 0.02 & $-0.08(-0.13)$ \\
\hline Likelihood ratio $x^{2}$ & $71.02 * * *$ & \\
\hline$F$ & & $5.46 * * *$ \\
\hline AIC & 370.04 & 139.28 \\
\hline Adjusted $R^{2}$ & & 0.35 \\
\hline
\end{tabular}

Significance levels: ${ }^{\ddagger}(<0.10),{ }^{*}(<0.05),{ }^{* *}(<0.01),{ }^{* * *}(<0.001)$.

Communities in which administrators talk to other administrators more frequently also have more green infrastructure. My second research question focused on the role of regional diffusion in the use of green infrastructure across Oregon municipalities, so I used two variables that I thought would best capture those mechanisms: the frequency floodplain administrators talk to other administrators (frequency variable), as well as whether or not an administrator has read other communities' flood management plans (plans variable). The richness of community use of green infrastructure may be influenced by the frequency administrators talk to other administrators or the likelihood that administrators read other communities' plans and obtain knowledge from other communities. The relationship was positive, indicating that communities in which administrators talk to other administrators more frequently also have more green infrastructure. 


\section{Discussion}

I had two primary research questions: First, what factors correlate with the use of green infrastructure, especially for flood hazard and floodplain management, and, second, to what extent is regional diffusion affecting the use of green infrastructure in these jurisdictions? This research contributes to, and expands on, the literature assessing the adoption of innovative policy and practice for green infrastructure development. Recent research in this area has largely focused on small-scale green infrastructure, such as for stormwater management (e.g., Abhold, Loken, and Grumbles 2011; Carlet 2015), and I sought to build on this earlier work in two ways. First, applying other definitions of green infrastructure (e.g., Benedict and McMahon 2006; Tayouga and Gagné 2016) to include features such as open space and floodplains sheds light on the ways in which planners and policymakers are conceiving of both green infrastructure and flood hazard and floodplain management. Second, I further explored the applicability of the regional diffusion model not only with spatial analysis but also by including variables that identified how often FPAs talk to other administrators or read other flood management plans.

Prior to these analyses, I performed logistic regression to determine response bias in the questionnaire, which I could then control for in the quasi-Poisson and OLS regression. There were 81 communities that were nonrespondents or that I was simply unable to contact, and I wanted to determine (and control for) any significant differences between nonrespondents and respondents in the quasi-Poisson and OLS regressions. The logistic regression identified three significant community demographic characteristics influencing the likelihood of responding to the survey, including the percent of the population with a bachelor's or graduate/professional degree and the unemployment rate in the community. 
Previous research has found that education can be a significant contributor to response bias in surveys (Sills and Song 2002); these results indicate that the education level of the community itself may be influencing the likelihood of a key informant responding to a survey. Unexpectedly, however, the attainment of a bachelor's degree had a negative influence on the likelihood of responding to the survey, while communities with greater proportions of residents that had attained graduate or professional degrees had a positive effect-more research is needed before making such a conclusion. Community unemployment rate had a negative effect on survey responses, which may indicate that hard times within the community translates to a lack of resources for community administrators to participate in a voluntary survey. Although the degree of urbanization was only marginally significant to response bias; I opted to control for urbanization in the regressions based on previous research that indicated its importance (Damanpour and Schneider 2009; Hwang and Gray 1991; Ormrod 1990; Sharp, Daley, and Lynch 2011; Walker 1969).

The dependent variable, green infrastructure, was structured as a count variable (a sum of $1 \mathrm{~s}$ and $0 \mathrm{~s})$; for this reason, I performed a Poisson regression with robust standard errors to account for overdispersion in the model. However, I was not ultimately interested in an exact determination of the number of green infrastructures being used, but more in relative richness of green infrastructure strategies within a community. Further, while this variable consists of discrete, non-negative integers, I propose that, similar to sales price or income, it approximates a continuous variable for this analysis. Moreover, the two models provided very similar results. The same variables were significant with the same directionality, and the AIC diagnostic for model comparison indicated that the OLS model fit the data better than the Poisson model (Poisson AIC = 370 vs. OLS AIC = 139). Lastly, 
the OLS model performed well: fewer than one percent of predictions are outside the range of the observed data, and it is more interpretable in determining the marginal effect of an independent variable on the dependent variables. For these reasons, I focus my interpretation on the OLS model.

There were two factors that, in practice, would likely be tightly coupled: previous experience with flooding and knowledge of infrastructure; i.e., experience with the problem, and solutions for addressing it. The former-in which a manager has more extensive experience with flooding — had a positive effect on the adoption of green infrastructure. Including this factor was somewhat novel—previous research has largely focused on a managers' expertise with the policy innovation itself, not the impetus for developing such a policy. Typically, managerial tenure is included to address experience, and is frequently found to be a significant factor in innovation adoption (Damanpour and Schneider 2006; Damanpour and Schneider 2009; Kearney, Feldman, and Scavo 2000). Tenure is often included as one of several managerial characteristics such as age and formal education as an approach to capture experience, insight, and professional judgment (Baldridge and Burnham 1975). However, got the purpose of understanding disaster policy innovation, the frequency of experience with the disaster over one's tenure may be an important predictor. The latter-knowledge of flood mitigation infrastructures - is more in line with previous research, which has included variables regarding a manager's attitudes and perceptions of an innovation such as green infrastructure. For instance, Carlet (2015) used several theoretical frameworks, including the technological acceptance model, as well as the diffusion of innovation model, to analyze the effect of managerial perspectives and attitudes on the adoption of green stormwater infrastructure. In her analysis, she discussed the positive 
influence that knowledge of green infrastructure would likely have on the perceived ease of use of green infrastructure, thereby increasing the likelihood of adoption (Carlet 2015). More recently, O’Donnell et al. (2017) analyzed the barriers to adopting blue-green infrastructure and found the second most important barrier to be a lack of knowledge. This research differed, however, in that I asked not about green infrastructure, but about flood mitigation infrastructure, implying that this knowledge, which may include both gray and green infrastructure, is correlated with the adoption of green infrastructure adoption in a community.

Communities in which administrators talk to other administrators more frequently and that have read other community plans were also somewhat more likely to employ more green infrastructure strategies. This finding supports the occurrence of regional diffusion, as well as earlier research by Damanpour and Schneider (2006). A positive correlation between the frequency with which managers are talking to each other and the number of types of green infrastructure used in itself is not conclusive of a causal relationship, but it does support the notion of regional diffusion where communities look to other communities to be laboratories for policy innovation. Additionally, Damanpour and Schneider's (2006) work included nine different models exploring the phases of innovation adoption in organizations; external communication was highly significant in each model. The authors hypothesized that communicating with other managers can improve their knowledge not only of environmental events, but of potential solutions for addressing these events. In effect, talking to other managers allows a manager to explore what Matisoff (2008) referred to as a "policy laboratory." 
Urbanization is an important factor in policy diffusion research, and may be included as a hypothesis in its own right (e.g., Walker 1969), or as a control (e.g., Damanpour and Schneider 2006; Damanpour and Schneider 2009). In this research, while urbanization was an extremely important factor in the OLS — a finding with extensive support in the literature-it was also important in the spatial analysis. Urbanization has frequently been found to strongly correlate with the adoption of innovative policies because those communities may have more capacity and resources, as well as a "higher density of information linkages" especially in dense metropolitan areas (Damanpour and Schneider 2006:218). This was borne out in the local spatial analysis to determine if urbanization and use of green infrastructure had a strong spatial association with each other, which they did. High values of green infrastructure were found in the Portland metropolitan area, with lower values observed in rural eastern Oregon. Notably, I also performed local spatial analysis with green infrastructure and factors other than urbanization and did not observe the robust pattern that was observed when green infrastructure was coupled with urbanization. Because of the strong association between urbanization and green infrastructure use, I included urbanization in the regression analysis, which not only controlled for that bias among survey respondents, but also controlled for the spatial variation in green infrastructure, giving me spatially-independent residuals. In other words, I captured variation in the dependent variable that was both managerially related and spatially related.

Policy diffuses through a network to neighboring communities, likely after observing successful implementation and outcomes elsewhere. This is supported not only by the local spatial analysis, finding hotspots of green infrastructure in the Portland metropolitan area, but also because of the positive correlation between green infrastructure use and how often 
managers talk to other managers, a mechanism of regional diffusion. The regional diffusion model as developed by Berry and Berry (2014) is inherently spatial— the authors reference proximity being one of the factors that influences the diffusion of policy through networks to neighboring communities. Because frequency of communication between policymakers is an obvious mechanism for policy to diffuse, leveraging this could be an important institutional strategy for encouraging the use of green infrastructure. Currently, the EPA strongly encourages the use of green infrastructure to meet requirements of the CWA, and in 2014 created the Green Infrastructure Collaborative with other federal agencies, nongovernmental organizations, academic institutions, and the private sector to support this mission (U.S. Environmental Protection Agency 2018a). Recreating this at a smaller scale, perhaps at the state or regional level, is one way to reach smaller, more rural communities that, while perhaps interested in implementing more green infrastructure, lack the resources or knowledge represented by a larger collaborative.

My research findings largely support previous research in the fields of policy adoption and green infrastructure use. Increased knowledge regarding flood mitigation infrastructure positively correlated with the use of green infrastructure. Recent research by Carlet (2015), found a strong correlation between manager beliefs and green infrastructure adoption for stormwater management. In her research, perceptions related to the ease of use, usefulness, and internal readiness were strong predictors of whether green infrastructure was being adopted by the community or not. Some of these attitudes and perceptions may very well be captured by the infrastructure variable in this analysis. Future research using a similar questionnaire to elucidate the use of green infrastructure for flood hazard and floodplain management could parse this question to get at these nuances; for example, what 
personal experience does the respondent have with gray infrastructure or green infrastructure, and when was their flood mitigation infrastructure constructed?

There are, however, some caveats to these findings. For example, I developed an overall index of the types of green infrastructure used in different communities. However, some communities may employ certain types of green infrastructure (e.g., small-scale stormwater features) for different reasons that attempting large-scale floodplain restoration. Disaggregating the green infrastructure concept may help to highlight motivations for employing different strategies. For instance, this variable contains all questionnaire inventory items that describe green infrastructure (see Appendices A and B). Factor analysis or principal components analysis could separate this variable to determine if the size, scale, or function of the infrastructure affects the degree to which it is implemented and the rationale for doing so, a critical need for future research. My questionnaire also did not address the extensiveness of green infrastructure in a community; for example, if a community has one bioswale, that would be treated the same as a community that had a bioswale on every block. My results therefore focus on the diversity of different approaches to green infrastructure a community employs rather than the richness of green infrastructure in the community.

\section{Conclusion}

Through the use of a key informant questionnaire, and regression and spatial analysis, my research uncovered several factors that positively influenced the use of green infrastructure for stormwater, flood hazard, and floodplain management in municipalities across Oregon. Confirming previous research, new policy like green infrastructure development was strongly associated with urbanization, and was a source of respondent bias potentially due to the higher salience of the topic in municipalities that were more likely to 
have experience with green infrastructure. Professional experience with 100-year floods, a high degree of knowledge regarding flood mitigation infrastructure, and the frequency a floodplain administrator speaks to other administrators also positively correlated with the use of green infrastructure in a community. It is these last two factors that create the opportunity for intervention to increase the use of green infrastructure within a community. Creating an open forum for administrators to increase their awareness not only about flood hazard, but also about flood mitigation infrastructure, as well as share policy successes (and failures) with colleagues would create an excellent opportunity to further advance the use of green infrastructure for stormwater and flood hazard and floodplain management. 


\title{
Chapter Three: Community identity, green infrastructure, and flood hazard mitigation: The novel case of the nation's first urban National Wildlife Refuge
}

\author{
Abstract \\ In the early 1990s, Sherwood, Oregon, was a small town on the outskirts of the \\ Portland metropolitan area. Expecting increasing population pressure from Portland, and \\ wanting to protect what they felt was a unique community identity, Sherwood started taking \\ steps to mitigate the impacts of population growth. To protect the many natural features of \\ the community, the city of Sherwood codified planning objectives that included goals to \\ "achieve the maximum preservation of natural features" and to "minimize the adverse \\ effects of human activity on the natural environment." The city identified 476 acres as open \\ space (what was then $19 \%$ of the city); 424 of those acres were designated as wetlands, \\ floodplains, and other significant natural areas. The town implemented a policy to protect \\ those natural areas and maintain their unique identity by using three different economic and \\ regulatory incentives: outright purchase, density transfer, and system development charges \\ (SDC) credits. Within a five-year period, $\sim 335$ acres of floodplain had been protected. \\ Sherwood's floodplain protection program laid the groundwork for the creation of the first \\ urban wildlife refuge, the Tualatin River National Wildlife Refuge. With this case study, I \\ was able to explore the rationale for both the protection of these greenways, as well as the \\ creation of the Refuge, and how these lessons may be applied elsewhere.
}

\section{Key Words}

Floodplain protection, internal determinants, green infrastructure, urban wildlife refuge, Tualatin River National Wildlife Refuge 


\section{Introduction}

Sherwood, Oregon, is a historically agricultural community located on the periphery of the greater Portland Metropolitan Area (Figure 10). In the early 1990s, pressure from urban growth and increased population from neighboring Portland challenged Sherwood's leaders to consider how the city could shape growth and minimize the negative impacts of building in the city's undeveloped floodplain. Doing so would help meet 1970s regulatory

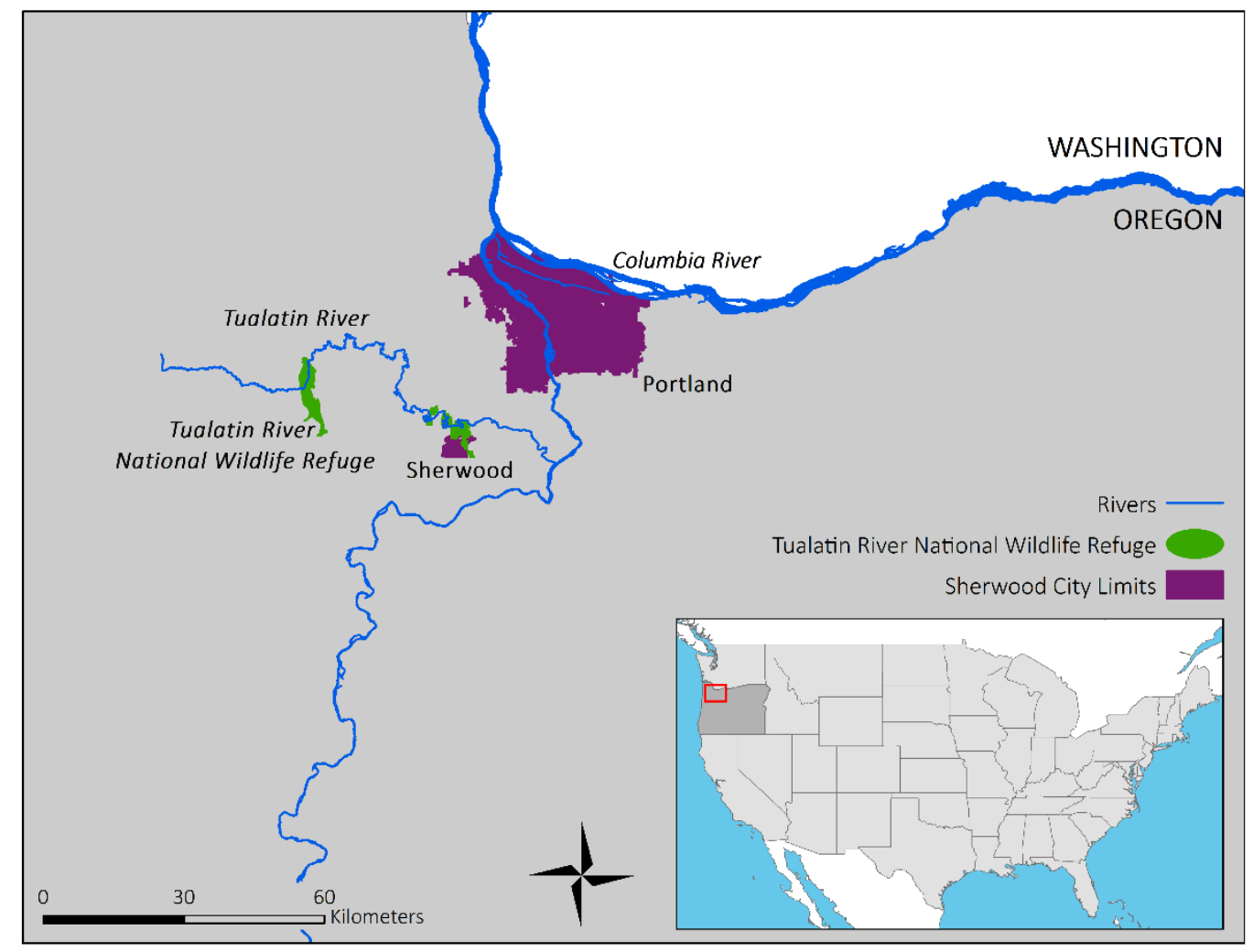

Figure 9. The City of Sherwood and the Tualatin River National Wildlife Refuge in the southwestern Portland metropolitan area.

requirements designed by the state of Oregon to manage growth cohesively through comprehensive plans. In the course of developing Sherwood's comprehensive plan, an unexpected outcome emerged-Sherwood leaders helped create one of the nation's first urban wildlife refuges while simultaneously minimizing future risks to the built environment 
from flood hazard. The question underlying this chapter is how Oregon's two decades-old land use planning law resulted in the recognition of Sherwood's natural green infrastructure and the creation of a nationally-protected wildlife refuge. In doing so, I explore how cities adopt natural resource policies and protect resources like urban floodplains, an increasingly important topic as cities around the country and globe struggle to manage imperiled and fragmented floodplain habitat. This paper presents a case study of an Oregon community leveraging coordination across different scales of government and stakeholders to meet local objectives and state-mandated planning goals, in an open space and floodplain preservation program.

Communities that are intersected by streams, rivers, and floodplains rely on policy to balance local planning objectives with state, federal, and other priorities. Local objectives typically include issues like hazard mitigation, economic development, water quality and habitat protection, and open space preservation, which are supported or constrained by federal policies such as the Clean Water Act and National Flood Insurance Program (Freitag, Bolton, Westerlund, and Clark 2009). Observing the difficulties of meeting these federal regulations related to clean water and flood hazards, while also wanting to encourage the growth and vitality of local communities, Oregon developed nineteen statewide planning goals in the early 1970s, focused on land use planning; natural resources, scenic and historic areas, and open spaces; and areas subject to natural hazards, among others. Cities and counties are required to develop comprehensive plans addressing these planning goals that are implemented in local policy (Oregon Department of Land Conservation and Development 2010). Doing so requires not only coordinating vertically between local and state government, as well as regional governments, but also horizontally between potentially 
conflicting goals within the local community (Miller and Demir 2007). How do cities navigate vertical and horizontal coordination challenges in the context of floodplain and flood hazard management and how is this task resolved when local objectives create relatively few examples of other cities to emulate? These are the questions I ask in my examination of Sherwood, Oregon's pursuit of a floodplain preservation program that resulted in the establishment of the Tualatin River National Wildlife Refuge, hereafter referred to as the Refuge.

To answer these questions, I introduce two complementary themes: (1) The internal determinants model of policy innovation and adoption, and (2) green infrastructure for flood hazard and floodplain management. I use these two themes-which were developed more extensively in Chapter One-throughout the paper to describe the case of Sherwood and develop a framework for assessing similar policy processes in other Oregon cities.

\section{Internal Determinants and Policy Innovation and Adoption}

The internal determinants model describes a community that pioneers the innovation and adoption of policy or management strategies to meet their own economic, social, or political needs (Berry and Berry 2014). The internal determinants and regional diffusion models are widely used for analyzing policy making (Berry and Berry 2014). The regional diffusion model is based on earlier research on policy diffusion (Walker 1969), which Berry and Berry (1990) paired with a new model — the internal determinants model—-to explain the innovation and spread of a policy between local communities. For simplicity, I use the term lone-wolf to depict the internal determinants model.

One driver for policy innovation in flood hazard and floodplain management is a desire to maintain a distinct community identity. Previous research has found that a desire to 
protect the natural environment as part of community identity may be a powerful driver in open space protection policy. McMillan and Chavis (1986) defined a sense of community as having four dimensions: membership, influence, integration and fulfillment of needs, and shared emotional connection. As Kim and Kaplan (2004) note, however, this framework defining community identity was not designed to consider or integrate conceptions of the physical or natural environment. Separate research has addressed the phenomenon of attachment to place or community, however, which bridges the gap to a sense of community that is rooted in place (Hummon 1992; Mesch and Manor 1998; Nielsen-Pincus, Hall, Force, and Wulfhorst 2010; Trentelman 2009). Community identity incorporates these ideas as personal or public identification with a geographically-bounded community that has its own character (Kim and Kaplan 2004).

This geographic-boundedness of community identity is often enhanced by open spaces and natural features, and this embeddedness of open space and natural amenities into community identity often drives a community to preserve these spaces (Kim and Kaplan 2004; Kline 2006; Swim, Zawadzki, Cundiff, and Lord 2014; Tzoulas, Korpela, Venn, YliPelkonen, Kaźmierczak, Niemela, and James 2007). Kline (2006) examined the economic rationale for open space preservation and found that as open space in a community decreases and its marginal value increases, so too does public demand. Swim et al. (2014) found that strong environmental identity (identifying with nature) and place identity (identifying with their township) predicted the willingness to pay more for open space preservation. Furthermore, people with these two identities were more likely to rank open space as important, but especially important to preserving community identity (Swim, Zawadzki, Cundiff, and Lord 2014). 


\section{Green Infrastructure}

Green infrastructure is one type of infrastructure that may be used for flood hazard and floodplain management. Green infrastructure can be used for small-scale stormwater management (e.g., rain gardens, green rooves, bioswales), or for flood hazard and floodplain management utilizing the natural hydrologic values of open space and natural areas (Allen 2012; Benedict and McMahon 2006). The municipal use of large-scale green infrastructure such as open space and natural areas for flood hazard and floodplain management in the US is relatively recent; Brody and Highfield (2013) note that the explicit use of open space protection for flood mitigation wasn't observed until the 1990s.

Green infrastructure, and the protection of open space for flood mitigation can accrue multiple ecological and socioeconomic benefits (Benedict and McMahon 2006; Brauman, Daily, Duarte, and Mooney 2007). Floodplains protected through open space preservation provide fish and wildlife habitat, increased biodiversity, improved water quality, recreational opportunities, and aesthetic and cultural values (Bengston, Fletcher, and Nelson 2004). Floodplains additionally provide flood risk mitigation through natural storage capacity, and groundwater recharge (Brauman, Daily, Duarte, and Mooney 2007; Opperman, Galloway, Fargione, Mount, Richter, and Secchi 2009; Postel and Carpenter 1997).

Merging the two themes (i.e., policy innovation and adoption, and grey and green infrastructure) provides a framework for understanding local policy choices for floodplain and flood hazard management. For example, I use the term green wolf to describe a community that independently pursues green infrastructure (see Chapter 1). In this chapter, I illustrate in depth why the green wolf concept is represented by Sherwood's approach to flood hazard and floodplain management. Further, community identity is an important 
factor that drove Sherwood's independent push to be a green wolf. I rely on two primary

observations to support my case: (1) Sherwood's protection of its open space, greenways, and floodplains through the establishment of a National Wildlife Refuge, and (2) the internal planning objectives and lack of nearby municipalities taking a similar innovative policy approach in the early 1990s. Given these observations, I evaluated what policy decisions Sherwood leaders and stakeholder made, why Sherwood adopted these 'green wolf policies, and what can be generalized from Sherwood's experience for other communities with similar planning objectives.

\section{Methods}

I used an embedded single-case design for this case study (Yin 2014). The case focuses on two primary embedded units of analysis including the City of Sherwood and the Refuge. I used three primary sources of data, which were analyzed using a pattern matching technique (Yin 2014): semi-structured interviews, document analysis, and site visits.

Several supporting documents were examined for a wide range of salient information, including community descriptions, policy objectives and descriptions, mechanisms for policy implementation, and agency and institutional rationale in decision making (Table 6).

Table 6. Documents used for archival analysis of Sherwood's floodplain protection program and the creation of the Tualatin River National Wildlife Refuge

\begin{tabular}{ll}
\hline Document title & Citation \\
\hline Sherwood Comprehensive Plan, part 2 & (City of Sherwood 1991b) \\
Sherwood Comprehensive Plan, part 3 & (City of Sherwood 1995) \\
Washington County Comprehensive Plan, vol. II & (Washington County Planning Commission 1993) \\
Metropolitan Greenspaces Master Plan & (Oregon Metro 1992) \\
Urban National Wildlife Refuge policy & (U.S. Fish and Wildlife Service 1991) \\
USFWS Environmental Assessment & (Harrison 1992) \\
\hline
\end{tabular}


Thirteen people were interviewed during two time periods: one person, a retired municipal employee, was interviewed six times between February 2015 and February 2016. During the last interview, this participant suggested other people for possible interviews; these were conducted between October 2016 and February 2017. I continued using the snowball sampling method and solicited recommendations for other interviewees during each interview. Interviewees were selected from several professional organizations from different levels of government and from non-governmental organizations (Table 7).

Table 7. The professional association of each interviewee regarding the Sherwood floodplain protection program and creation of the Tualatin River National Wildlife Refuge. Respondent numbers are included for references within the text.

\begin{tabular}{ll}
\hline Respondent association & Interviewee number \\
\hline Retired Sherwood municipal & 2 \\
Retired Sherwood municipal & 3 \\
Retired U.S. Fish and Wildlife & 4 \\
Retired Tigard municipal & 5 \\
Sherwood municipal & 6 \\
Metro regional government & 7 \\
Metro regional government & 8 \\
Clean Water Services & 9 \\
U.S. Fish and Wildlife & 10 \\
Friends of the Tualatin River National Wildlife Refuge & 11 \\
Retired U.S. Fish and Wildlife & 12 \\
Retired U.S. Fish and Wildlife & 13 \\
Retired U.S. Fish and Wildlife & \\
\hline
\end{tabular}

Interviewees were selected because they were either involved with planning Sherwood's open space and floodplain protection program or creating the Refuge. The interviews were semi-structured with open-ended questions, allowing respondents to reply to specific questions while still sharing their own perspective and any other information they considered salient. 
Ten of the interviews were recorded and transcribed. I had technical difficulties for two of the interviews, and one interview took place during a site visit, making recording unwieldy; for these interviews, I took field notes and transcribed unrecorded interviews immediately following the interview. The transcriptions were coded using QDA Miner Lite software. The analysis was based on preliminary research that Sherwood's green wolf policy for floodplain and flood hazard management were driven by its internal planning objectives and the lack of relevant nearby examples of similar policy to draw on. Prior to analysis, I created a codebook to capture main themes and patterns in the interviews, documents, and site visits (Table 8).

Table 8. Code tree with main stem and detailed codes used to analyze interview data.

\begin{tabular}{ll}
\hline Code Family Main Stem & Code \\
\hline Flooding & Flood hazard \\
Policy & Croodplain management \\
& Infrastructure \\
& Tradeoffs \\
& Achievements \\
Refuge & Challenges \\
& Creation \\
& Friends of the Refuge \\
& Funding and acquisition \\
Riverkeepers \\
Community identity \\
Concerns \\
Floodplain natural area protection \\
Local policy \\
Planning goals \\
Successes \\
Policy and political will \\
Urban refuges \\
Background, policy, and funding \\
Quotation \\
\hline
\end{tabular}




\section{Case Study Background}

In the early 1990s, Sherwood, Oregon, was a rapidly urbanizing satellite of the Portland Metropolitan area in northwestern Oregon. Sherwood remains a relatively small community, at 1,165 ha and approximately 19,350 people (Portland State University College of Urban \& Public Affairs 2017), but its population growth rate since 1990 dwarfs that of Oregon as a whole. Between 1990 and 2017, Oregon's population increased by approximately 46 percent, while Sherwood's population growth was approximately $526 \%$ (Portland State University College of Urban \& Public Affairs 2017; U.S. Census Bureau 1990).

Sherwood's demographics reflect not only a rapidly-growing city, but an economically-advantaged city as well. Compared to the City of Portland, Sherwood has substantially lower unemployment $(3.5 \%$ versus $5.2 \%)$ and poverty $(3.3 \%$ versus $16.9 \%)$, in addition to substantially higher median income $(\$ 86,111$ versus $\$ 58,423)$ (U.S. Census Bureau 2016b). Nonetheless, in 2006, the city prioritized economic development with the Economic Development Strategy, and re-prioritized economic development again in 2013 (City of Sherwood n.d.). The vision statement for the Economic Development Strategy declares that the city will:

Provide jobs for our residents by building on our assets and developing the necessary infrastructure to retain existing businesses and support new businesses. Economic development will also be supported by maintaining our livability and character as a clean, healthy, and vibrant suburban community where one can work, play, live, shop, and do business (p. 1; City of Sherwood 2006).

Although increasingly urbanized, Sherwood has significant environmental resources and natural assets that contribute to community livability and character, as well as its community identity. The largest of these is the Tonquin Scabland Geologic Area, a 67-ha 
basalt uplift area created by the Glacial Lake Missoula Floods during the last Ice Age (City of Sherwood 2009; Oregon Metro 2013). Sherwood also contains over seven hectares of public parks, a ponderosa pine forest of almost three hectares (relatively rare for western Oregon), portions of the Chehalem Mountains, Cedar and Rock Creeks (tributaries of the Tualatin River), the Onion Flat floodplains, and portions of the 549-ha Tualatin River National Wildlife Refuge (Figure 8; City of Sherwood 2009; Oregon Metro 2013; U.S. Fish and Wildlife Service 2006).

The Refuge is an urban wildlife refuge created in 1992 and managed by the U.S. Fish and Wildlife Service (USFWS). National wildlife refuges are created to protect wildlife habitat (particularly for migrating birds) and to provide specific types of wildlife-dependent recreation: hunting, fishing, wildlife observation, wildlife photography, environmental education, and environmental interpretation (U.S. Fish and Wildlife Service 1997). The Refuge is located in the southwestern portion of the Portland Metropolitan area and, like most wildlife refuges, has two demarcations — the project boundary that has been approved for acquisition, and the actual acquisition. The Refuge is 549 hectares, with another 689 hectares approved for future acquisition (Figure 11; Tualatin River National Wildlife Refuge 2015). The Refuge straddles approximately eight miles of the Tualatin River, mainly to the north and northwest of Sherwood, but also encompassing a large portion of the Rock Creek floodplain within the Sherwood urban growth boundary, as well as the Onion Flat floodplain (Figure 10; Harrison 1992).

As part of the Portland Metropolitan area, Sherwood is subject to multiple levels of governance. In addition to the city, county (Washington County), state, and federal government, the Portland Metropolitan area has a regional governing body, Metro, that 


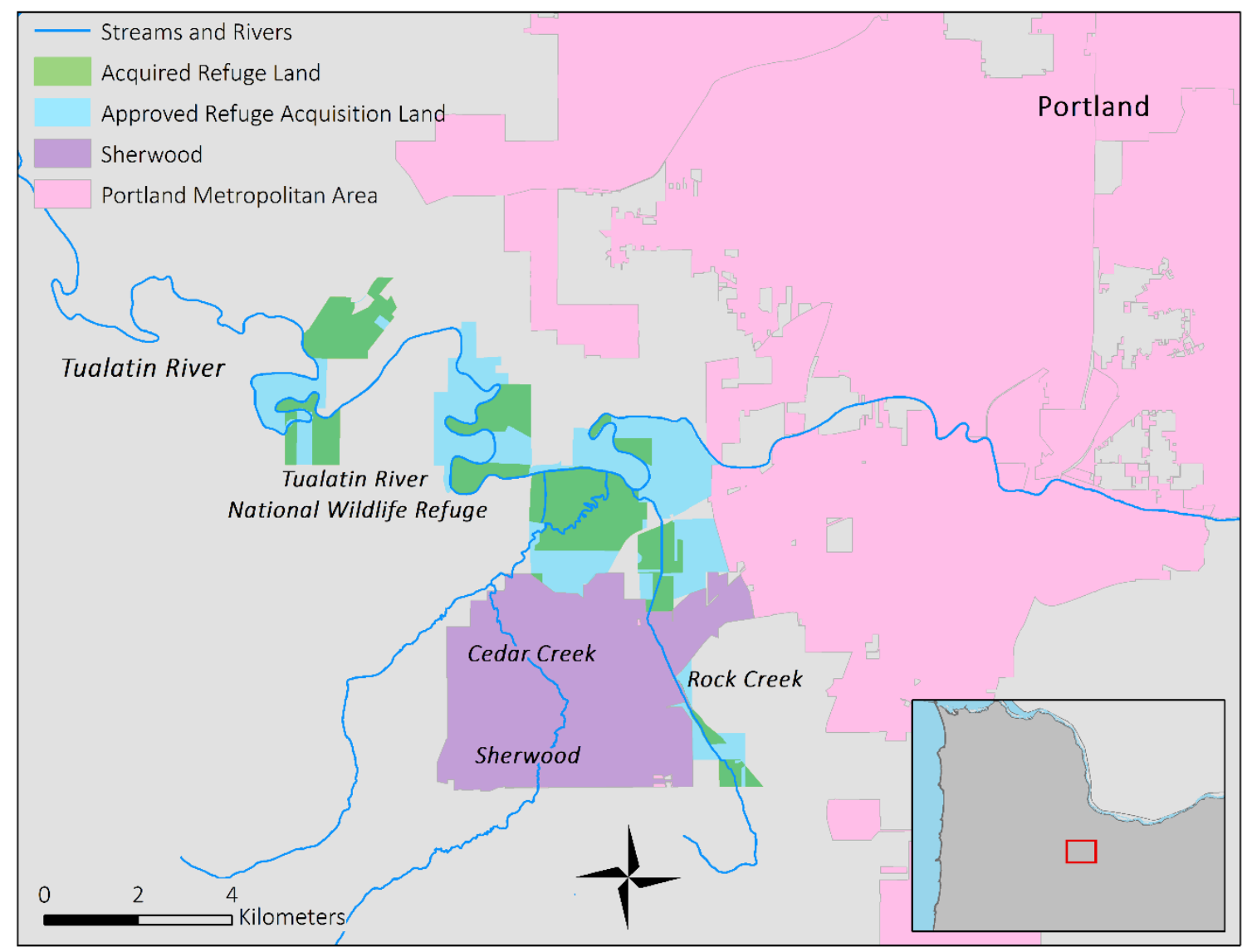

Figure 10. The City of Sherwood and the Portland Metropolitan area. The Tualatin River and its tributaries, Cedar and Rock Creeks are visible, as well as the acquired and approved boundaries of the Tualatin River National Wildlife Refuge.

oversees regional planning and services, particularly related to parks, recreation, and land use for municipalities in the metropolitan area.

\section{Results}

\section{$\underline{\text { Sherwood Floodplain and Open Space Protection Program }}$}

In 1991, with the environmental amenities in the community, and the prescient expectation of strong growth pressure- "Everybody knew growth was coming" (Respondent 2) — the city started taking steps in their comprehensive planning to mitigate the pressure. Their first policy goal was "to adopt and implement a growth management policy which will accommodate growth consistent with growth limits, desired population 
densities, land carrying capacity, environmental quality, and livability" (p. 3-2; City of Sherwood 1991b). Eight strategies were identified to meet this goal, including a policy objective to "achieve the maximum preservation of natural features" (p. 3-2; City of Sherwood 1991b). Other policies included growth management coordination with Washington County government to ensure the "conservation of a needed amount of open space” (p. 3-8; City of Sherwood 1991b). This policy for growth management translated directly into land management, which included a policy goal to "minimize the adverse effects of human activity on the natural environment" (p. 4-10; City of Sherwood 1991b).

Sherwood's Parks Master Plan identified 193 ha as open space, greenways, and floodplains — almost $20 \%$ of the area within the city's urban growth boundary—and designated 172 of those hectares for wetlands, greenways, and "significant natural areas" (City of Sherwood 1994). The city used three mechanisms to achieve their policy goals of maximizing the preservation of natural features and open space and minimizing adverse impacts on the natural environment from human activity. To protect and acquire open space, floodplains, and greenways from developers wanting to develop parcels containing a portion of these areas, Sherwood used system development charge (SDC) credits, density transfer, and outright purchase, or a mix of all three. SDCs are fees owed to the city by developers to fund the infrastructure improvements that are needed to meet increased demand. Sherwood originally had three types of SDC credits to offer to developers: parks, stormwater, and water supply. The park SDC credit applied to residential development only-industrial and commercial lands were not eligible for receiving a park SDC credit. In this instance, dedicating a natural area, wetland, or floodplain to the city would make the developer eligible for a park SDC credit (Respondent 1). After the city switched from 
groundwater to a regional water supply, the water supply SDC credit was no longer available, leaving the stormwater SDC credit as the main SDC credit mechanism for open space protection (Respondent 1). Stormwater SDC credits were available to developers that met green infrastructure standards developed by the local wastewater treatment utility, Clean Water Services. While Sherwood still relied on a groundwater water supply system, any mechanism that "scrubbed runoff" was eligible for a stormwater SDC credit (Respondent 1). Density transfer was another mechanism used by Sherwood in the protection and acquisition of open spaces. Density transfer was mainly used in planned unit developments by allowing a developer to increase density in a subdivision if the development also protected greenway or floodplain areas; in exchange for the increased density allowance, the developer would transfer ownership for the greenspace to the city. Outright purchase was the third and most used mechanism used by Sherwood to acquire greenspace and floodplains. Sherwood offered $\$ 5,000$ per acre of greenspace, and while developers were welcome to get their own appraisal, the incentive was sufficiently powerful that, "no one ever did so" (Respondent 1). With these three mechanisms, the city acquired and protected approximately $90 \%$ of the targeted greenways and floodplains in five years (Respondent 1).

At the time, flooding was not a major concern in Sherwood (Respondent 2), although it was in neighboring communities (Respondent 4). Even though there are two creeks running directly through Sherwood and the city is also in close proximity to the Tualatin River, the most recent flood at the time was the Christmas Flood of 1964-1965, which affected large portions of the western United States, although the Tualatin River was affected less than in other areas (Waananen, Harris, and Williams 1971). During Sherwood's 
efforts to protect its floodplain areas, there was a major flood event on the Willamette River that impacted some neighboring communities.

The 1996 flood was a major indicator to [our community] that it, like all other communities, needed to be concerned about flooding.... The 1996 flood...was incredibly high.... There were picnic tables and port-o-potties that were taken downstream from Cook Park. It was totally underwater. That was a wakeup call to the extent of flooding that could take place with a major event like that (Respondent 4).

While neighboring communities downstream on the Tualatin River were severely impacted by the 1996 flood, Sherwood, was not (U.S. Army Corps of Engineers 2017a). Flooding was not a concern: "We really have very few storm issues and a lot of that is because we have such open space. We just don't have issues with our floodplain. We have a really wide floodplain and it's pretty good.... There are some little issues and pockets, but for the most part we don't have flooding issues" (Respondent 5).

While natural hazards are mentioned in the comprehensive plan, as required for state land use planning, hazard reduction was not the primary objective of the city's greenway and floodplain protection program. As the comprehensive plan stated, protecting open space and natural amenities was done to preserve the natural environment and livability of the community (City of Sherwood 1991b). Further, the comprehensive plan also stated that "The planning process must involve specific steps to identify community design objectives which best enhance community identity and quality of life. Careful attention to site design can result in the protection of natural and man-made features which contribute to the community's identity" (City of Sherwood 1991b:4-58). The city's focus on maintaining environmental quality and livability was a natural extension of community concerns. In addition to municipal staff, 
Who were trying to preserve wetlands, floodplains, other natural areas, there were other people in the community who were also interested in natural areas, and people who were trying to differentiate Sherwood as a community from the whole rest of the metropolitan area instead of just making it just another neighborhood of a nameless suburb (Respondent 3).

This desire to differentiate and preserve a unique community identity was a consistent theme in the interviews:

The community recognized that Portland was growing outward and [Sherwood] was much more rural. There was quality of life, of value around rural lands, more open spaces, green spaces-if you want to call them green spaces - that they wanted to maintain (Respondent 9).

Sherwood was concerned about maintaining their community identity. At the time, they were still separate from Portland and they wanted to keep a separate community identity. I don't know who the founding fathers were who had this idea, but it stuck (Respondent 13).

I think [Sherwood's floodplain and open space protection program] was really driven by community values more than product line problems or some stormwater requirement or anything like that. I think that's why it was successful. They wanted to create, I hate the term of community distinction, because that is what some people call planning efforts. They wanted to create something different (Respondent 8).

One interviewee stated that Sherwood successfully met this objective:

[Sherwood has] been ranked a number of times in the top most livable communities in various magazines and things like that. Part of that is that open space protection that we have and the trails and all that stuff. I think that kind of creates that community identity. Again, it just is what makes Sherwood, Sherwood. I don't know that people would necessarily associate it with the Refuge, but they associate that open space and natural areas (Respondent 5).

One ramification of this success is that the protected open space and other natural areas are embedded in many peoples' identification with Sherwood, as well as their expectations for future growth. In current planning processes that will likely expand development westward, residents have voiced their expectations of continued preservation of open space and natural amenities, which the municipality may not be able to achieve to 
the same extent: 'We'll still be able to protect the floodplains, but I feel like it seems like it's more than just the floodplain area in Sherwood that's protected in open space" (Respondent 5). This outcome is not entirely unexpected, given the focus of the planning department and local residents on protecting floodplains, wetlands, and other natural areas. A potential solution to protect greenways and floodplains in such a way as to "provide a green buffer between Sherwood and the rest of the metro area" began gaining municipal and community support in the form of a national wildlife refuge (Respondent 3).

\section{Creation of the Tualatin River National Wildlife Refuge}

While Sherwood was pursuing a program of floodplain protection for community identity, the USFWS had drafted an urban wildlife refuge policy prioritizing wildlife habitat protection in urban areas via the creation of wildlife refuges. The mission of the National Wildlife Refuge System at the time was "to provide, preserve, restore, and manage a national network of lands and waters to meet society's needs for areas where the widest possible spectrum of benefits associated with wildlife and wildlands is enhanced and made available to the public" (U.S. Fish and Wildlife Service 1991). There were six 'wildlife-dependent' public uses available for National Wildlife Refuges: hunting, fishing, wildlife observation, wildlife photography, environmental education, and environmental interpretation (Respondent 3). To support the mission of the National Wildlife Refuge System in urban areas, the USFWS chose to acquire land for Refuges in areas that were in or adjacent to metropolitan statistical areas. There were several goals in addition to the mission in this urban refuge policy, including adequacy of habitat corridors and buffer areas, and creating partnerships with local government and citizens (U.S. Fish and Wildlife Service 1991). The Tualatin River National Wildlife Refuge was created in 1992, after the USFWS had looked 
throughout the Portland-Vancouver metropolitan area for a suitable site (Respondent 2). There are currently fourteen wildlife refuges that are considered urban, but many of these became urban as increased development surrounded them; the Tualatin River National Wildlife Refuge was the first refuge created from scratch following the urban wildlife refuge policy (U.S. Fish and Wildlife Service 2015, September 16).

The idea of urban wildlife refuges was not unanimously well received by USFWS staff-" [some staff] said, these dinky refuges and these urban refuges, we don't want them" (Respondent 12), but there were other factors supporting the creation of the Refuge besides the new urban wildlife refuge policy. The idea for the Refuge itself started in Sherwood's planning department and quickly gained traction with Sherwood citizens: "The push did not come from [the] Fish and Wildlife Service... The push came from the citizenry"

(Respondent 2). Indeed, at the time, "The City of Sherwood was trying to do something to distinguish themselves from the rest of the urban sprawl... They didn't want to get absorbed into [neighboring communities]. [The USFWS] presented the idea about buying a big park there to separate them from [their neighbor] — they thought that was wonderful" (Respondent 11). Further, while Sherwood leaders continued to support the creation of the Refuge, even going to Washington D.C. to lobby for the funding to create the Refuge, it was a local Sherwood couple that donated the first twelve acres of land that would make the Refuge eligible for congressional funding (Respondents 1 and 2). One of the first purchases by the USFWS was from a local citizen who sold a parcel along Rock Creek, on the edge of the urban growth boundary; this purchase resulted in the Refuge continuing into the City of Sherwood (Respondents 12 and 13). The expansion of the Refuge acquisition boundarythe land the USFWS was approved to acquire- into Sherwood's urban growth boundary 
aligned with the attitude Sherwood residents had toward the Refuge: 'It's the only refuge I know where we drew the acquisition boundary, opened it up to public comment, and had many people say that it wasn't big enough. That never happens. So, they went back to the drawing board and expanded the boundary. Almost doubled the size of the Refuge” (Respondent 13).

Neighboring municipalities, however, did not take the same interests as Sherwood in the creation of the Refuge. The Metro charter was being written in the early 1990s, and the Metropolitan Greenspaces Master Plan was adopted in 1992, which laid out a vision for creating a regional system of open space, green space, trails, and natural areas, for people and wildlife in the Portland-Vancouver metropolitan area (Oregon Metro 1992). Without a completed masterplan during the refuge creation, Metro's involvement in the creation of the Refuge was limited and coordination around the acquisition of open spaces between the USFWS and Metro was causing some challenges. Metro was conducting land acquisition in the area, seeking to fulfill its mission, which created tension with the USFWS, as there was occasionally competition for the same parcel of land. "You don't want two public agencies competing with one another for land acquisition. The seller loves it because they want to get the best price, but it's not good for anyone else" (Respondent 13). This tension led to a somewhat adversarial relationship with Metro (Respondents 7,8, and 13). Coordination has since improved (Respondents 7 and 8). No other communities took such a clear interest in the creation and implementation of the Refuge. One downstream neighboring community that is intersected by the floodplain opted to be involved by mostly staying informed, but had limited operational involvement in the creation of the Refuge (Respondent 13). Several other nearby communities, while located in the Tualatin River Watershed, did not have a 
vested interest as they were not intersected by the floodplain of the Tualatin River or its tributaries.

In addition to fulfilling the six goals of a national wildlife refuge, downstream communities, especially Sherwood, realized flood mitigation benefits from the establishment of this Refuge:

...Imagine what this [area] would look like if this [Refuge] wasn't here. You just have to look up the hill to see this encroaching [development]—it's suburbanized, all this building. This would all be developed, this would be strip malls, this would be a shopping center, this would be housing, apartments. There would be no place for this water to go. People don't realize [the economic impact the Refuge] has-how much money these areas, this catch basin of water, has saved the City of Sherwood (Respondent 9).

Sherwood's protected floodplains and the nation's first urban wildlife refuge were a culmination of internal social, environmental, and political motivations within the City of Sherwood, coupled with vertical coordination across local, regional, and federal agencies. "I also think for Sherwood, and the Friends of the Refuge, and this floodplain here, there's just so much of the story as a case study right here, but thinking about what it's growing into, it's a pilot for the country now" (Respondent 9).

\section{Discussion}

The City of Sherwood successfully implemented policy to protect open space, greenways, and floodplains within the community, eventually protecting more than 150 hectares-over $15 \%$ of the current city area, and contributed to the establishment of a National Wildlife Refuge that further shapes floodplain and flood hazard management in the city. I initially hypothesized that local planning goals around flood mitigation would explain Sherwood's adoption of this green infrastructure approach to flood hazard and floodplain management. My findings, however, point to a more complex policy landscape. Many 
interviewees reported that the primary catalyst for preserving open space was the preservation of a distinct community identity. Sherwood's Comprehensive Plan highlights the importance of maintaining its identity for planning and growth.: "Sherwood is more than an assemblage of buildings, street and utilities, and places of work, residence, leisure, and meeting. The identity of Sherwood is determined by its natural setting, how its land use activities fit into that setting, and what people see, feel, smell, or hear as they participate in the life of the community" (p. 4-58; City of Sherwood 1991b). The importance of community identity to Sherwood was also extremely influential in the creation of the Refuge. Sherwood's investment in creating the first urban national wildlife refuge supported two of the objectives of the USFWS: to not only create an urban wildlife refuge, but to do so through close collaboration with local communities (U.S. Fish and Wildlife Service 1991). This collaboration allowed Sherwood and the USFWS to meet their own goals in part by supporting each other's goals.

The term green wolf applies not just to the City of Sherwood; an individual champion was key to this lone wolf pursuit of green infrastructure. Multiple interviewees commented on the important role of a now retired city planner in driving local planning efforts and coordinating with the USFWS and others-even going to Washington D.C. to lobby Congress - to support the creation of this Refuge. Echoing a point made by many interviewees, while the Refuge was a federal creation, it would not have happened without the work of this green wolf. This importance of a local champion to achieve policy objectives supports earlier research that the lack of leadership and community buy-in are substantial barriers to the adoption of green infrastructure (Thorne, Lawson, Ozawa, 
Hamlin, and Smith 2018). My research goes further and supports the inverse-having a local champion and community support encourages the adoption of green infrastructure policies.

Brown and Farrelly (2009) reviewed 53 papers on the use of sustainable integrated urban water management and identified twelve types of barriers to the adoption and implementation of sustainable water management policies, finding that these impediments tend to be socio-institutional, rather than technological. One of the most prevalent barriers the authors identified was limited community engagement, empowerment, and participation (Brown and Farrelly 2009). Sherwood exemplifies the opposite, as a community that did not experience substantial barriers and demonstrated extensive community engagement in the creation of the Refuge and implementing floodplain and open space protection programs. Brown and Farrelly (2009), however, were not able to identify strategies to overcome socioinstitutional barriers. More recently, O’Donnell et al. (2017) identified barriers to the adoption of blue-green infrastructure, including a reluctance to support novel approaches for management or to change current practice. To overcome this barrier, local leadership's willingness to support novel policy and management is important for the adoption of green infrastructure. Indeed, respondents to O’Donnell et al.'s (2017) survey identified improved education and awareness, as well as community engagement and communication as the most important strategies for overcoming barriers to the adoption of green infrastructure. By the early 1990s Sherwood had already distinguished itself as a green wolf through its horizontal coordination of a local floodplain and open space protection program. Sherwood's vertical coordination with USFWS and other governments to support the creation of the nation's first urban National Wildlife Refuge further supports that distinction, while creating an 
example of the success that may occur from mitigating socio-institutional or socio-political barriers in policy adoption.

While the Sherwood case does present a model for communities interested in pursuing green infrastructure, there are important limitations. Twenty-five years after the designation of the Refuge and Sherwood's acquisition of floodplain properties, I was not able to find key informants that may have provided a contrarian view of Sherwood's approach. Further, the focus on community identity, exemplified in Sherwood, may not be the only pathway to becoming a green wolf in policy process for adopting flood hazard and floodplain management strategies. While previous research has found community identity to be a potent influence in adopting policies to protect floodplains and open space (Kline 2006; Swim, Zawadzki, Cundiff, and Lord 2014), additional models may also be possible. In-depth research addressing other internal determinants of floodplain policy may provide other motivations, and contrast with other approaches based on regional diffusion of policy innovations can further enhance our understanding of policy processes for green infrastructure adoption.

\section{Conclusion}

My research clearly articulates how one community fits the distinction as a green wolf - a community that innovatively leveraged horizontal and vertical governance coordination to protect green infrastructure and a distinct community identity. While open space preservation is not new, this is a novel case of the culmination of social motivations, community engagement, and agency cooperation to achieve a unique outcome for floodplain management and flood hazard mitigation. While novel, there are strategies that can be applied in other municipalities: the importance of community education, engagement, and 
local leadership, as well as the importance of agency cooperation. Further, Sherwood leveraged a regulatory requirement-Oregon state land use planning and open space protection requirements- to meet their own internal goals focused on maintaining a distinct community identity in the midst of a growing metropolitan region. 


\section{Dissertation Conclusion}

This research applies policy analysis to flood hazard and floodplain management, creating a framework that is used to inform several case study analyses, as well as a key informant questionnaire of floodplain administrators. Much of the policy for flood hazard and floodplain management occurs at the federal level, via Flood Control Acts, the National Flood Insurance Program, and the Clean Water Act. However, communities are the locus of practice for managing floodplain and flood hazard. Focusing on communities in Oregon allowed me to evaluate management approaches across communities with diverse social, political, and environmental contexts that are still functioning within the same federal and state regulatory environment.

My research framework focused on two interacting dimensions of flood hazard and floodplain management: policy innovation and adoption, and infrastructure. I first explore policy research on the adoption of policy using two complementary models, the internal determinants and regional diffusion models. The internal determinants model, what I came to call the lone wolf model, describes a community that innovates a policy to meet a specific internal need. The regional diffusion model, or copycat model, describes a community that treats other communities as policy laboratories, adopting innovative policy that has been applied in other municipalities before diffusing through policy networks to other municipalities. One of the crucial policies in flood hazard and floodplain management is the type of infrastructure that will be used to not only mitigate flooding, but to meet other community objectives, as well as regulatory requirements. I was therefore able to apply the lone wolf and copycat models to the adoption of a relatively innovative policy-green infrastructure development (Figure 2). This framework allowed me to develop several 
models of flood hazard and floodplain management approaches. This includes a gray copycat that continues to rely on gray infrastructure for flood control, as a result of historical legacy from extensive engineering by the USACE; a green copycat that chose to adopt green infrastructure after observing the successful implementation elsewhere; a gray wolf that required innovation to manage its gray infrastructure; and a green wolf that adopted green infrastructure as means of maintaining community identity.

I used this framework in Chapter One to investigate four Oregon communities that I considered as examples of these four models, including Eugene (gray copycat), Prineville (green copycat), Milton-Freewater (gray wolf), and Sherwood (green wolf). I used case study analysis to apply this framework and develop propositions about the rationale driving communities to pursue different management approaches. Briefly, I proposed that while a historical legacy can constrain future policy decisions (Proposition 1), a community may be able to circumvent such a historical legacy to adopt more green infrastructure (Proposition 2). I also proposed that different goals such as meeting regulatory requirements and improving economic competitiveness can complement floodplain protection (Proposition 3). I further proposed that adopting green infrastructure policy is likely to involve a social rationale (e.g., desire to protect a distinct community identity) in addition to water resource management objectives (Proposition 4). My final proposition connected directly back to my research framework, positing that a community can be a lone wolf and a copycat within the same policy process (Proposition 5). Using this conceptual framework grounded and focused my research, creating the structure to focus my analysis on those characteristics that create these archetypes, whether it's a gray or green, copycat or wolf. What I discovered from these case studies was that the policy processes were not only complex, but were frequently 
addressing needs and objectives I had not initially accounted for, such as community identity or regulatory relief.

I used what I learned in the first chapter-especially the discovery of those more nuanced objectives - to operationalize my research framework with a key informant questionnaire of floodplain administrators across the state. This questionnaire allowed me to collect data from over 100 communities, evaluating the role not only of managerial and internal community characteristics, but also regional diffusion characteristics, on the adoption of green infrastructure for flood hazard and floodplain management. My findings indicated that administrators that reported being knowledgeable about flood mitigation infrastructure, that had professional experience with flooding, and talked more frequently to other floodplain administrators often worked in communities with a more diverse suite of green infrastructure. Furthermore, while many of these communities were urban-a common finding in the policy adoption literature-this was not a universal trend; there were numerous urban communities that were using very little green infrastructure and some rural communities that used more green infrastructure than expected. This indicates that while urbanization may strongly correlate with the adoption and implementation of innovative policy like green infrastructure, there are other factors to consider, such as managerial or organizational attributes. I evaluated other factors (e.g., knowledge of flood mitigation infrastructure) and their relationship with the adoption of green infrastructure using spatial analysis_ — a straightforward way of identifying regional diffusion amongst neighbors—but there were no clear spatial trends that would serve to describe the mechanisms of regional diffusion. My research does, however, serve to expand the literature on green infrastructure, 
which in regulation is often described solely in terms of stormwater management because of the nonpoint source amendments to the CWA.

After developing my conceptual framework and propositions, which I then operationalized with the key informant questionnaire, I focused on one community to explore what drove it to adopt a substantial green infrastructure approach to flood hazard and floodplain management nearly three decades ago without other examples to look towards and earn itself the distinction of a green wolf. The final chapter used an in-depth case study method to understand what drove the internal determinants model within this community. The City of Sherwood was indicative of a green wolf because of its early adoption of policies that protected extensive natural areas, including floodplains, wetlands, and greenways. While focused on these riparian areas and floodplains, flood mitigation was not the sole or primary motivating objective of these policies-instead the motivation was to maintain a unique community identity. The internal determinants model describes a community that develops a policy to meet a specific internal objective-whether it is economic, environmental, or social. As a lone wolf, Sherwood was developing policy to protect natural assets and environmental amenities to meet other social objectives. Furthermore, it was not only the community itself that could be considered a lone wolf-an individual was critical. In this case, a now retired city planner drove the political will and leadership to implement these policies, and successfully collaborate with a federal agency and other governments to support the development of the first urban national wildlife refuge in the country. The desire of Sherwood to differentiate itself from its neighboring communities —including a physical separation with open space and floodplains_-complemented the 
needs of the USFWS to collaborate with a local community to create the first urban wildlife refuge.

I began with a precise research framework to define what type of infrastructure was being used for flood hazard and floodplain management, and how that policy was being innovated, diffused, and adopted. I quickly learned that not only is this a more complex endeavor than I had envisioned, but that there was also more ambiguity in the policy process than I had envisioned. Because my research methods such as interview and survey questions were based on this precise conception of floodplain management, policy adoption, and infrastructure, the data I collected sometimes failed to explain the complexities I uncovered. Future research incorporating more explicit exploration of policy objectives and implementation would allow for more stable hypothesis testing in understanding policy.

A final note on a limitation and contribution of this research: while I take care to differentiate between green infrastructure for stormwater management and for flood hazard and floodplain management, this differentiation is sometimes watered down. Regardless of function, green infrastructure includes vegetation and attempts to mimic natural hydrology. However, regulatory requirements are substantially different, as is the scale of these infrastructures. While community objectives (e.g., community identity preservation or improved water quality) may drive many different scales of green infrastructure adoption, space may constrain their use. In the questionnaire, while numerous scales and functions of green infrastructure are included, my analysis aggregated them together. Disaggregating these scales and functions would allow me to more precisely determine what drives a community to adopt green infrastructure for flood hazard and floodplain management versus for stormwater management. Nevertheless, to the best of my knowledge, this is some of the first 
research that specifically applies the internal determinants and regional diffusion models to policy for floodplain management and flood mitigation. 


\section{References}

Abhold, Kristyn, Lorraine Loken, and Ben Grumbles. 2011. "Barriers and gateways to green infrastructure." Clean Water America Alliance. http://uswateralliance.org/resources/publications, Washington, D.C.

Ajzen, Icek. 1991. "The theory of planned behavior." Organizational behavior and human decision processes 50:179-211.

—. 2002. "Perceived behavioral control, self-efficacy, locus of control, and the theory of planned behavior." Journal of Applied Social Psychology 32:665-683.

Allen, William L. 2012. "Environmental reviews and case studies: Advancing green infrastructure at all scales: From landscape to site." Environmental Practice 14:17-25.

Amoros, C. and G. Bornette. 2002. "Connectivity and biocomplexity in waterbodies of riverine floodplains." Freshwater Biology 47:761-776.

Anderson Perry \& Associates, Inc. 2010. "City of Prineville, Oregon: Wastewater facilities plan update." La Grande, OR.

https://www.cityofprineville.com/sites/default/files/fileattachments/community d evelopment/page/2637/prineville wwfp update.pdf.

—. 2016. "Milton-Freewater levee project wins engineering excellence award." Walla Walla, WA. http://www.andersonperry.com/milton-freewater-levee-project-winsengineering-excellence-award/.

Anselin, Luc. 1995. "Local Indicators of Spatial Association-LISA." Geographical Analysis 27:93-115.

Arnberger, Arne and Renate Eder. 2012. "The influence of green space on community attachment of urban and suburban residents." Urban Forestry \& Urban Greening 11:4149.

Arnold, Joseph L. 1988. "The evolution of the 1936 Flood Control Act." Washington, D.C. U.S. Army Corps of Engineers. http://www.publications.usace.army.mil/Portals/76/Publications/EngineerPamphle ts/EP 870-1-29.pdf.

Arrow, Kenneth, Bert Bolin, Robert Costanza, Partha Dasgupta, Carl Folke, C. S. Holling, Bengt-Owe Jansson, Levin Simon, Karl-Göran Mäler, Charles Perrings, and David Pimentel. 1995. "Economic growth, carrying capacity, and the environment." Science 268:520-521. 
Baldridge, J. Victor and Robert A. Burnham. 1975. "Organizational innovation: Individual, organizational, and environmental impacts." Administrative Science Quarterly 20:165176.

Bassett, Ellen and Vivek Shandas. 2010. "Innovation and climate action planning." Journal of the American Planning Association 76:435-450.

Bates, Bryson, Zbigniew W. Kundzewicz, Shaohong Wu, and Jean Palutikof. 2008. "Climate change and water." Geneva, Switzerland.

http://www.ipcc.ch/publications and data/publications and data technical paper s.shtml.

Belt, C. B. 1975. "The 1973 flood and man's constriction of the Mississippi River." Science 189:681-684.

Benedict, Mark A. and Edward T. McMahon. 2006. Green Infrastructure: Linking Landscapes and Communities. Washington, D.C.: Island Press.

Bengston, David N., Jennifer O. Fletcher, and Kristen C. Nelson. 2004. "Public policies for managing urban growth and protecting open space: Policy instruments and lessons learned in the United States." Landscape and Urban Planning 69:271-286.

Berry, Frances Stokes and William D. Berry. 1990. "State lottery adoptions as policy innovations: An event history analysis." The American Political Science Review 84:395415.

- 2014. "Innovation and Diffusion Models in Policy Research." in Theories of the Policy Process, edited by P. A. Sabatier and C. M. Weible. Boulder, CO: Westview Press.

Brauman, K. A., G. C. Daily, T. K. Duarte, and H. A. Mooney. 2007. "The nature and value of ecosystem services: An overview highlighting hydrologic services." Annual Review of Environment and Resources 32:67-98.

Brody, Samuel D. and Wesley E. Highfield. 2013. "Open space protection and flood mitigation: A national study." Land Use Policy 32:89-95.

Brody, Samuel D., Sammy Zahran, Wesley E. Highfield, Himanshu Grover, and Arnold Vedlitz. 2008. "Identifying the impact of the built environment on flood damage in Texas." Disasters 32:1-18.

Brown, R. R. and M. A. Farrelly. 2009. "Delivering sustainable urban water management: A review of the hurdles we face." Water Science \& Technology 59:839-846.

Brown, Rebekah R. 2005. "Impediments to integrated urban stormwater management: The need for institutional reform." Environmental Management 36:455-468. 
Brudney, Jeffrey L., F. Ted Hebert, and Deil S. Wright. 1999. "Reinventing government in the American states: Measuring and explaining administrative reform." Public Administration Review 59:19-30.

Burby, Raymond J. 2001. "Flood insurance and floodplain management: The U.S. experience." Global Environmental Change Part B: Environmental Hazards 3:111-122.

—. 2005. "Have state comprehensive planning mandates reduced insured losses from natural disasters?" Natural Hazards Review 6:67-81.

-. 2006. "Hurricane Katrina and the paradoxes of government disaster policy: Bringing about wise governmental decisions for hazardous areas." The Annals of the American Academy of Political and Social Science 604:171-191.

Burby, Raymond J., Robert E. Deyle, David R. Godschalk, and Robert B. Olshansky. 2000. "Creating hazard resilient communities through land-use planning." Natural Hazards Review 1:99.

Burby, Raymond J. and Peter J. May. 1998. "Intergovernmental environmental planning: Addressing the commitment conundrum." Journal of Environmental Planning and Management 41:95-110.

Burton, Mark L. and Michael J. Hicks. 2005. "Hurricane Katrina: Preliminary estimates of commercial and public sector damages." Marshall University. Huntington, WV. http://citeseerx.ist.psu.edu/viewdoc/download?doi=10.1.1.318.7580\&rep=rep1\&ty $\mathrm{pe}=\mathrm{pdf}$.

Carlet, Fanny. 2015. "Understanding attitudes toward adoption of green infrastructure: A case study of US municipal officials." Environmental Science \& Policy 51:65-76.

Carson, Richard T. 2010. "The environmental Kuznets curve: Seeking empirical regularity and theoretical structure." Review of Environmental Economics \& Policy 4:3-23.

Centers for Disease Control and Prevention. 2014. "Precipitation extremes: Heavy rainfall, flooding, and droughts." Washington, D.C. http://www.cdc.gov/climateandhealth/effects/precipitation extremes.htm.

Centre for Research on the Epidemiology of Disasters and United Nations Office for Disaster Risk Reduction. 2015. "The human cost of weather-related disasters 19952015." Geneva, Switzerland. https://www.unisdr.org/we/inform/publications/46796.

Chaney, Jason. 2010. "City to hold meeting on updated wastewater facility plan." in Central Oregonian. Prineville, OR.

https://pamplinmedia.com/component/content/article?id=183963. 
Cho, Renee. 2011, June 7. "Making Room for Rivers: A different approach to flood control." in State of the Planet, edited by Earth Institute. New York, NY: Columbia University.

City of Eugene. 2006. "West Eugene wetlands guide." Eugene, OR. https://www.eugeneor.gov/647/West-Eugene-Wetlands.

-. 2016. "Land and water in West Eugene." Eugene, OR. https://www.eugeneor.gov/1764/Land-and-Water-in-West-Eugene.

—. n.d. "West Eugene wetlands." Eugene, OR. https://www.eugene-or.gov/647/WestEugene-Wetlands.

City of Eugene and Lane Council of Governments. 2004. "West Eugene Wetlands Plan." Eugene, OR. https://www.eugene-or.gov/1766/West-Eugene-Wetlands-Plan.

City of Portland. 2015. "Citywide assets report: Status and best practices." Portland, OR. https://www.portlandoregon.gov/cbo/article/567961.

City of Portland Bureau of Environmental Services. 2008. "Johnson Creek land acquisition partnership and implementation strategy." Portland, OR. https://www.portlandoregon.gov/bes/article/214366.

—. 2018. "Green streets." Portland, OR. https://www.portlandoregon.gov/bes/45386.

City of Prineville. 2016. "Wetlands groundbreaking ceremony set for April 22, 2016." Prineville, OR. http://www.cityofprineville.com/newsroom/page/wetlandsgroundbreaking-ceremony-set-april-22-2016.

City of Sherwood. 1991a. "Sherwood Comprehensive Plan Part 2: Sherwood Community Development Plan." Sherwood, OR. Available from University of Oregon Local \& Regional Documents Archive. https://scholarsbank.uoregon.edu/xmlui/handle/1794/9071.

—. 1991b. "Sherwood Comprehensive Plan: Part 2: Sherwood Community Development Plan." Sherwood, OR.

—. 1994. "Greenway and natural area preservation program." Sherwood, OR.

—. 1995. "Sherwood Comprehensive Plan: Part 3: Zoning and Community Development Code." Sherwood, OR.

—. 2006. "Economic development strategy: Final report." Sherwood, OR. https://www.sherwoodoregon.gov/economicdevelopment/page/about-economicdevelopment. 
—. 2009. "Comprehensive Plan II: Chapter five: Environmental resources, open spaces, and natural resources inventory." Sherwood, OR.

http://www.sherwoodoregon.gov/planning/page/comprehensive-plan-ii.

—. n.d. "About economic development." Sherwood, OR.

https://www.sherwoodoregon.gov/economicdevelopment/page/about-economicdevelopment.

Committee on Levees and the National Flood Insurance Program Improving Policies and Practices, Water Science and Technology Board, and Division of Earth and Life Studies. 2013. Levees and the National Flood Insurance Program: Improving Policies and Practices. Washington, D.C.: National Academies Press.

Cooperative Conservation America. 2017. "West Eugene Wetlands Partnership: Urban wetlands spark community conservation." Falmouth, ME.

http://www.cooperativeconservation.org/viewproject.aspx?id=26.

Criss, Robert E. and Everett L. Shock. 2001. "Flood enhancement through flood control." Geology 29:875-878.

Crombie, Noelle. 2007, December 4. "Hundreds evacuated from flood-ravaged Vernonia." in The Oregonian. Portland, OR.

http://www.oregonlive.com/weather/index.ssf/2007/12/hundreds evacuated fro m floodr.html.

Daley, Dorothy M. and James C. Garand. 2005. "Horizontal diffusion, vertical diffusion, and internal pressure in state environmental policymaking, 1989-1998." American Politics Research 33:615-644.

Damanpour, Fariborz. 1987. "The adoption of technological, administrative, and ancillary innovations: Impact of organizational factors." Journal of Management 13:675-688.

—. 1991. "Organizational innovation: A meta-analysis of effects of determinants and moderators." The Academy of Management Journal 34:555-590.

Damanpour, Fariborz and Marguerite Schneider. 2006. "Phases of the adoption of innovation in organizations: Effects of environment, organization and top managers." British Journal of Management 17:215-236.

—. 2009. "Characteristics of innovation and innovation adoption in public organizations: Assessing the role of managers." Journal of Public Administration Research and Theory 19:495-522.

Davies, C., R. MacFarlane, C. McGloin, and M. Roe. 2006. "Green infrastructure planning guide ", Newcastle, UK. 
http://www.greeninfrastructurenw.co.uk/resources/North East Green Infrastruct ure Planning Guide.pdf.

Doocy, Shannon, Amy Daniels, Sarah Murray, and Thomas D. Kirsch. 2013. "The human impact of floods: A historical review of events 1980-2009 and systematic literature review." PLoS Currents 5:ecurrents.dis.f4deb457904936b07c09daa98ee8171a.

Federal Emergency Management Agency. 2005. "National Flood Insurance Program (NFIP) floodplain management requirements: A study guide and desk reference for local officials." Washington, D.C. Available from the Association of State Floodplain Managers. http://www.floods.org/ace-files/documentlibrary/CFMExam/FEMA 480 Complete.pdf.

—. 2018a. "Community status book report: Oregon communities participating in the National Flood Program." Washington, D.C. https://www.fema.gov/national-floodinsurance-program-community-status-book.

—. 2018b. "Disaster declarations for Oregon." Washington, D.C. https://www.fema.gov/disasters/grid/state-tribal-government/88.

—. 2018c. "Floodplain management requirements." Washington, D.C. https://www.fema.gov/floodplain-management-requirements.

—. 2018d. "Policy and claim statistics for flood insurance: Claim information by state." Washington, D.C. https://bsa.nfipstat.fema.gov/reports/1040.htm.

Frambach, Ruud T. and Niels Schillewaert. 2002. "Organizational innovation adoption: A multi-level framework of determinants and opportunities for future research." Journal of Business Research 55:163-176.

Freitag, Bob, Susan Bolton, Frank Westerlund, and J.L.S. Clark. 2009. Floodplain Management: A New Approach for a New Era. Washington, D.C.: Island Press.

Getis, Arthur and J. K. Ord. 1992. "The analysis of spatial association by use of distance statistics." Geographical Analysis 24:189-206.

Godwin, Marcia L. and Jean Reith Schroedel. 2000. "Policy diffusion and strategies for promoting policy change: Evidence from California local gun control ordinances." Policy Studies Journal 28:760-776.

Graf, William L. 2001. "Damage control: Restoring the physical integrity of America's rivers." Annals of the Association of American Geographers 91:1-27.

Grumbles, Benjamin H. 2007, March 5. "Memo: Using green infrastructure to protect water quality in stormwater, CSO, nonpoint source, and other water programs." U.S. 
Environmental Protection Agency. Washington, D.C. https://www.epa.gov/greeninfrastructure/integrating-green-infrastructure-federal-regulatory-programs.

Hall, Linda. 2013. "We are out of the flood zone!". Milton-Freewater, OR.: City News of Milton-Freewater. http://www.mfcity.com/sites/mfcity.com/files/File/news/fall13newsletter.pdf.

Hansen, Rieke and Stephan Pauleit. 2014. "From multifunctionality to multiple ecosystem services? A conceptual framework for multifunctionality in green infrastructure planning for urban areas." AMBIO 43:516-529.

Harrison, Ben. 1992. "Environmental assessment: Tualatin River National Wildlife Refuge." Department of the Interior: U.S. Fish and Wildlife Service, Region 1, Portland, OR.

Heine, Reuben A. and Nicholas Pinter. 2012. "Levee effects upon flood levels: An empirical assessment." Hydrological Processes 26:3225-3240.

Holloway, Caswell F., Carter H. Strickland Jr, Michael B. Gerrard, and Daniel M. Firger. 2014. "Solving the CSO conundrum: Green infrastructure and the unfulfilled promise of federal-municipal cooperation." Harvard Environmental Law Review 38:335370.

Hu, Winnie. 2018. "A billion-dollar investment in New York's water." in The New York Times. New York, NY. https://www.nytimes.com/2018/01/18/nyregion/new-york-citywater-filtration.html.

Hummon, David M. 1992. "Community Attachment: Local Sentiment and Sense of Place." in Place Attachment, edited by I. Altman and S. M. Low. New York: Plenum.

Hwang, Sung-Don and Virginia Gray. 1991. "External limits and internal determinants of state public policy." Western Political Quarterly 44:277-298.

Jackson, Robert B., Stephen R. Carpenter, Clifford N. Dahm, Diane M. McKnight, Robert J. Naiman, Sandra L. Postel, and Steven W. Running. 2001. "Water in a changing world." Ecological Applications 11:1027-1045.

Johnson Creek Watershed Council. 2012. "Johnson Creek acquisition strategy: Investing in a natural area network." Milwaukie, OR. http://jcwc.org/wpcontent/uploads/2012/01/JC-ACQUISITION-PLAN-2012-web.pdf.

Junk, W.J. and R.L. Welcomme. 1990. "Floodplains." in Wetlands and Shallow Continental Water Bodies, edited by B. C. Patten, S. E. Joergensen, and H. Dumont. The Hague, The Netherlands: SPB Academic Publishers.

Kabisch, Nadja, Niki Frantzeskaki, Stephan Pauleit, Sandra Naumann, McKenna Davis, Martina Artmann, Dagmar Haase, Sonja Knapp, Horst Korn, Jutta Stadler, Karin 
Zaunberger, and Aletta Bonn. 2016. "Nature-based solutions to climate change mitigation and adaptation in urban areas: Perspectives on indicators, knowledge gaps, barriers, and opportunities for action." Ecology and Society 21.

Kearney, Richard C., Barry M. Feldman, and Carmine P. F. Scavo. 2000. "Reinventing government: City manager attitudes and actions." Public Administration Review 60:535548.

Kent, Kandra. 2015. "Not a waste: Prineville plans cost-saving wetland project." Bend, OR. http://www.ktvz.com/news/not-a-waste-prinevile-plans-costsaving-wetlandproject/36353702: KTVZ.com.

Kiedrzyńska, Edyta, Marcin Kiedrzyński, and Maciej Zalewski. 2015. "Sustainable floodplain management for flood prevention and water quality improvement." Natural Hazards 76:955-977.

Kim, Joongsub and Rachel Kaplan. 2004. "Physical and psychological factors in sense of community: New urbanist Kentlands and nearby Orchard Village." Environment and Behavior 36:313-340.

King, Rawle O. 2012. "National Flood Insurance Program: Background, challenges, and financial status." Washington, D.C. Congressional Research Service. http://www.pennyhill.com/jmsfileseller/docs/R40650.pdf.

Kline, Jeffrey D. 2006. "Public demand for preserving local open space." Society \& Natural Resources 19:645-659.

Koc, Carlos Bartesaghi, Paul Osmond, and Alan Peters. 2017. "Towards a comprehensive green infrastructure typology: A systematic review of approaches, methods and typologies." Urban Ecosystems 20:15-35.

Krause, Rachel M. 2011. "Policy innovation, intergovernmental relations, and the adoption of climate protection initiatives by U.S. cities." Journal of Urban Affairs 33:45-60.

Learn, Scott. 2007, December 3. "Flooding throws wrench into Portland area's plans: Storm slows commuters on the west side." in The Oregonian. Portland, OR. http://blog.oregonlive.com/breakingnews/2007/12/flooding throws wrench in p ort.html.

Lehmann, Ray 2018, March 18. "Private flood insurance market is getting bigger, more competitive, less profitable." Insurance Journal.

Lennon, Mick, Mark Scott, and Eoin O'Neill. 2014. "Urban design and adapting to flood risk: The role of green infrastructure." Journal of Urban Design 19:745-758. 
Linenberger, Toni Rae. 2000. "Tualatin Project." Bureau of Reclamation, Washington D.C. https://www.usbr.gov/projects/index.php?id=411.

Lloyd, Emily and Angela Licata. 2015. "One New York City: One Water: Sustainable water management for New York City's people and environment." New York, NY. www.nyc.gov/html/dep/pdf/climate/one-nyc-one-water.pdf.

Long Tom Watershed Council. 2002. "Amazon Creek restoration in West Eugene." Eugene, OR. http://www.longtom.org/project/amazon-creek-restoration-in-west-eugene/.

Lundblad, Jennifer P. 2003. "A review and critique of Rogers' diffusion of innovation theory as it applies to organizations." Organization Development Journal 21:50-64.

Maass, Arthur. 1951. Muddy Waters: The Army Engineers and the Nation's Rivers. Cambridge, MA: Harvard University Press.

Mallakpour, Iman and Gabriele Villarini. 2015. "The changing nature of flooding across the central United States." Nature Climate Change 5:250-254.

Matisoff, Daniel C. 2008. "The adoption of state climate change policies and renewable portfolio standards: Regional diffusion or internal determinants?" Review of Policy Research 25:527-546.

Matsuoka, Rodney H. and Rachel Kaplan. 2008. "People needs in the urban landscape: Analysis of Landscape And Urban Planning contributions." Landscape and Urban Planning 84:7-19.

McDonald, L., W. Allen, M. Benedict, and K. O'Connor. 2005. "Green infrastructure plan evaluation frameworks." Journal of Conservation Planning 1:12-43.

McMillan, David W. and David M. Chavis. 1986. "Sense of community: A definition and theory." Journal of Community Psychology 14:6-23.

Mehaffey, M. H., M. S. Nash, T. G. Wade, D. W. Ebert, K. B. Jones, and A. Rager. 2005. "Linking land cover and water quality in New York City's water supply watersheds." Environmental Monitoring \& Assessment 107:29-44.

Mesch, Gustavo S. and Orit Manor. 1998. "Social ties, environmental perception, and local attachment." Environment and Behavior 30:504-519.

Michel-Kerjan, Erwann O. 2010. "Catastrophe economics: The National Flood Insurance Program." The Journal of Economic Perspectives 24:165-186.

Miller, Hugh T. and Tansu Demir. 2007. "Policy Communities." in Handbook of Public Policy Analysis: Theory, Politics and Methods, edited by F. Fischer, G. J. Miller, and M. S. Sidney. Boca Raton, FL: CRC Press. 
Milly, P. C. D., R. T. Wetherald, K. A. Dunne, and T. L. Delworth. 2002. "Increasing risk of great floods in a changing climate." Nature 415:514-517.

Missouri Coalition for the Environment. 2015. "Making Room for the River." St. Louis, MO. http://moenvironment.org/23-wetlands-floodplain-and-river/61-missourifloodplain-issues.

National Centers for Environmental Information. 2016. "Climate data online." Washington, D.C.: National Oceanic and Atmospheric Administration. http://www.ncdc.noaa.gov/cdo-web/.

National Weather Service. 2016a. "Advanced Hydrologic Prediction Service: Johnson Creek near Sycamore hydrograph." Washington, D.C.: National Oceanic and Atmospheric Adminstration.

http://water.weather.gov/ahps2/hydrograph.php?wfo=pqr\&gage $=$ syco3.

—. 2016b. "Advanced Hydrologic Prediction Service: Nehalem River near Vernonia hydrograph." Washington, D.C.: National Oceanic and Atmospheric Adminstration. http://water.weather.gov/ahps2/hydrograph.php?wfo=pqr\&gage=veno3.

—. n.d. "Oregon's top 10 weather events of 1900s." Portland, OR. https://www.wrh.noaa.gov/pqr/paststorms/index.php\#top1.

New York City. 2018. "OneNYC." New York, NY. https://onenyc.cityofnewyork.us/plan/.

Newmark, Adam J. 2002. "An integrated approach to policy transfer and diffusion." Review of Policy Research 19:151-178.

Nielsen-Pincus, Max, Troy Hall, Jo Ellen Force, and J. D. Wulfhorst. 2010. "Sociodemographic effects on place bonding." Journal of Environmental Psychology 30:443-454.

O'Donnell, E. C., J. E. Lamond, and C. R. Thorne. 2017. "Recognising barriers to implementation of Blue-Green Infrastructure: A Newcastle case study." Urban Water Journal 14:964-971.

Office of the General Counsel. 1997. "The National Flood Insurance Act of 1968, as amended, and the Flood Disaster Protection Act of 1973, as amended." in 42 U.S.C. 4001. Federal Emergency Management Agency. Washington, D.C. https://www.fema.gov/media-library/assets/documents/7277.

Office of the Queensland Chief Scientist. 2011. "Understanding floods: Questions and answers." Queensland Government. The State of Queensland, AU. http://www.chiefscientist.qld.gov.au/images/documents/chiefscientist/pubs/floods Lunderstanding-floods full colour.pdf. 
Opperman, Jeffrey J., Gerald E. Galloway, Joseph Fargione, Jeffrey F. Mount, Brian D. Richter, and Silvia Secchi. 2009. "Sustainable floodplains through large-scale reconnection to rivers." Science 326:1487-1488.

Opperman, Jeffrey J., Ryan Luster, Bruce A. McKenney, Michael Roberts, and Amanda Wrona Meadows. 2010. "Ecologically functional floodplains: Connectivity, flow regime, and scale." Journal of the American Water Resources Association 46:211-226.

Oregon Department of Environmental Quality. 2010. "Portland combined sewer overflow (CSO) management fact sheet." Portland, OR. http://www.deq.state.or.us/about/eqc/agendas/attachments/2010dec/HAttmntsCSO.pdf.

Oregon Department of Fish and Wildlife. 2008. "Ladd Marsh Wildlife Area management plan." Salem, OR. https://www.dfw.state.or.us/wildlife/management plans/wildlife areas/docs/LM WA $\% 20$ Management $\% 20 \mathrm{Plan} \% 20$ April $\% 202008$.pdf.

Oregon Department of Land Conservation and Development. 2001. "Oregon's statewide planning goals and guidelines: Goal 7: Areas subject to natural hazards." Salem, OR. http://www.oregon.gov/lcd/pages/goals.aspx.

—. 2010. "Oregon's statewide planning goals \& guidelines." Salem, OR. http://www.oregon.gov/lcd/pages/goals.aspx.

—. 2015. "Oregon natural hazards mitigation plan." Salem, OR. https://www.oregon.gov/LCD/HAZ/docs/2015ORNHMP/2015ORNHMPAppr oved/Approved 2015ORNHMP.pdf.

Oregon Metro. 1992. "Metropolitan Greenspaces Master Plan." Portland, OR. http://www.oregonmetro.gov/metropolitan-greenspaces-master-plan.

—. 2013. "Ice Age Tonquin Trail: Connecting the cities of Wilsonville, Tualatin, and Sherwood in Oregon: Master plan." Portland, OR. http://www.oregonmetro.gov/ice-age-tonquin-trail-master-plan.

—. 2016. "What is Metro?". Portland, OR. http://www.oregonmetro.gov/regionalleadership/what-metro.

Oregon Partnership for Disaster Resilience. 2012. "State of Oregon Natural Hazards Mitigation Plan: A report for Oregon Emergency Management." Salem, OR. Oregon Department of Land and Conservation Development. www.oregon.gov/LCD/HAZ/docs/OR NHMP 2012.pdf. 
Oregon Secretary of State. 2018. "Local government audit report search." Salem, OR. https://secure.sos.state.or.us/muni/public.do.

Oregon Solutions. 2009. "Milton-Freewater Oregon Solutions Levee Project." Portland, OR. http://orsolutions.org/osproject/milton-freewater-levee.

Ormrod, Richard K. 1990. "Local context and innovation diffusion in a well-connected world." Economic Geography 66:109-122.

Park, J., T. P. Seager, P. S. C. Rao, M. Convertino, and I. Linkov. 2013. "Integrating risk and resilience approaches to catastrophe management in engineering systems." Risk Analysis 33:356-367.

Pinter, Nicholas. 2005. "One step forward, two steps back on U.S. floodplains." Science 308:207-208.

Portland State University College of Urban \& Public Affairs. 2017. "Certified population estimates." Portland, OR: Population Research Center. https://www.pdx.edu/prc/population-reports-estimates.

Postel, Sandra and Stephen Carpenter. 1997. "Freshwater Ecosystem Services." in Nature's Services: Societal Dependence on Natural Ecosystems, edited by G. C. Daily. Washington, D.C.: Island Press.

President Jimmy Carter and U.S. Environmental Protection Agency. 1977. "Section 404 of the Clean Water Act: Floodplain management." Washington, D.C. https://www.epa.gov/cwa-404/floodplain-management.

Randolph, Ned. 2018. "River activism, "levees-only," and the Great Mississippi Flood of 1927." Media and Communication 6:43-51.

Regional Plan Association. 2017. "The fourth regional plan for the New York - New Jersey Connecticut Metropolitan Area: Making the region work for all of us." New York, NY. http:// fourthplan.org/download-the-plan.

Rijke, Jeroen, Sebastiaan van Herk, Chris Zevenbergen, and Richard Ashley. 2012. "Room for the River: Delivering integrated river basin management in the Netherlands." International Journal of River Basin Management 10:369-382.

Rogers, Everett M. 1962. Diffusion of Innovations. New York, NY: Free Press.

Rose, Joseph. February 5, 2016. "Remembering Oregon's epic 1996 flood: 20 years ago." in The Oregonian. Portland, OR. http://www.oregonlive.com/history/2016/02/oregon flood of 199620 years.ht $\underline{\mathrm{ml}}$. 
Rulseh, Ted J. 2018. "An Oregon city saves $\$ 55$ million with a natural approach to wastewater treatment." Treatment Plant Operator, April 2018.

Schifman, L. A., D. L. Herrmann, W. D. Shuster, A. Ossola, A. Garmestani, and M. E. Hopton. 2017. "Situating green infrastructure in context: A framework for adaptive socio-hydrology in cities." Water Resources Research 53:10139-10154.

Schneider, Amy. 2013. "The trouble with tributaries: Restoring the uban Amazon." in Eugene Weekly. Eugene, OR. http://www.eugeneweekly.com/20130620/lead-story/troubletributaries.

Selbmann, Kirsten. 2015. "Explanation of genesis, continuity and change of policy: Analytical framework." Innovative Energy \& Research 4:1-9.

Shafer, C. Scott, Bong Koo Lee, and Shawn Turner. 2000. "A tale of three greenway trails: User perceptions related to quality of life." Landscape and Urban Planning 49:163-178.

Sharp, Elaine B., Dorothy M. Daley, and Michael S. Lynch. 2011. "Understanding local adoption and implementation of climate change mitigation policy." Urban Affairs Review 47:433-457.

Shipan, Charles R. and Craig Volden. 2006. "Bottom-up federalism: The diffusion of antismoking policies from U.S. cities to states." American Journal of Political Science 50:825-843.

—. 2008. "The mechanisms of policy diffusion." American Journal of Political Science 52:840857.

Sills, Stephen J. and Chunyan Song. 2002. "Innovations in survey research: An application of web-based surveys." 20:22-30.

Simmons, Beth A. and Zachary Elkins. 2004. "The globalization of liberalization: Policy diffusion in the international political economy." The American Political Science Review 98:171-189.

Stakhovych, Stanislav and Tammo H. A. Bijmolt. 2009. "Specification of spatial models: A simulation study on weights matrices." Papers in Regional Science 88:389-408.

Stewart, William P., Derek Liebert, and Kevin W. Larkin. 2004. "Community identities as visions for landscape change." Landscape and Urban Planning 69:315-334.

Stupak, Jeffrey M. 2017, October 2. "Economic impact of Hurricanes Harvey and Irma." Federation of American Scientists. Washington, D.C. https://fas.org/sgp/crs/misc/IN10793.pdf. 
Swanwick, Carys. 2009. "Society's attitudes to and preferences for land and landscape." Land Use Policy 26:S62-S75.

Swim, Janet K., Stephanie J. Zawadzki, Jessica L. Cundiff, and Bruce Lord. 2014. "Environmental identity and community support for the preservation of open space." Human Ecology Review 20:133-155.

Talberth, John, Erin Gray, Logan Yonavjak, and Todd Gartner. 2013. "Green versus gray: Nature's solutions to infrastructure demands." Solutions 4:40-47.

Tayouga, Sarah J. and Sara A. Gagné. 2016. "The socio-ecological factors that influence the adoption of green infrastructure." Sustainability 8:1277-1293.

Thorne, C. R., E. C. Lawson, C. Ozawa, S. L. Hamlin, and L. A. Smith. 2018. "Overcoming uncertainty and barriers to adoption of Blue-Green Infrastructure for urban flood risk management." Journal of Flood Risk Management 11:S960-S972.

Tockner, Klement and Jack A. Stanford. 2002. "Riverine flood plains: Present state and future trends." Environmental Conservation 29:308-330.

Trentelman, Carla Koons. 2009. "Place attachment and community attachment: A primer grounded in the lived experience of a community sociologist." Society \& Natural Resources 22:191-210.

Tualatin River National Wildlife Refuge. 2015. "Rhythyms of the Refuge: Open your eyes to wildlife: An educator's guide to Tualatin River National Wildlife Refuge." Sherwood, OR. http://www.fws.gov/tualatinriver/documents/final.TWR Intro 002.pdf.

Tzoulas, Konstantinos, Kalevi Korpela, Stephen Venn, Vesa Yli-Pelkonen, Aleksandra Kaźmierczak, Jari Niemela, and Philip James. 2007. "Promoting ecosystem and human health in urban areas using green infrastructure: A literature review."

Landscape and Urban Planning 81:167-178.

U.S. Army Corps of Engineers. 2010a. "Periodic inspection report: Project: MiltonFreewater flood reduction project: System P." Milton-Freewater Water Control District. http://mfwcd.com/index.php/mfwcd-history, Washington, D.C. .

—. 2010b. "Periodic inspection report: Project: Milton-Freewater flood reduction project: System Q." Milton-Freewater Water Control District. http://mfwcd.com/index.php/mfwcd-history, Washington, D.C. .

—. 2010c. "Periodic inspection report: Project: Milton-Freewater flood reduction project: System R." Milton-Freewater Water Control District. http://mfwcd.com/index.php/mfwcd-history, Washington, D.C. . 
—. 2010d. "Periodic inspection report: Project: Milton-Freewater flood reduction project: System S." Milton-Freewater Water Control District.

http://mfwcd.com/index.php/mfwcd-history, Washington, D.C. .

—. 2016. "Mississippi Valley Division: Levee systems." Washington, D.C. http://www.mvd.usace.army.mil/About/MississippiRiverCommission(MRC)/Missis sippiRiverTributariesProject(MRT)/LeveeSystems.aspx.

—. 2017a. "1996 floodplain." Portland, OR. https://gispdx.opendata.arcgis.com/datasets/8ddf5441a64d4194a5fb68f3614ca874_93: City of Portland

Portland Maps.

—. 2017b. "The U.S. Army Corps of Engineers: A brief history: Improving transportation." Washington, D.C. http://www.usace.army.mil/About/History/Brief-History-of-theCorps/Improving-Transportation/.

—. 2017c. "The U.S. Army Corps of Engineers: Multipurpose waterway development." Washington, D.C. https://www.usace.army.mil/About/History/Brief-History-ofthe-Corps/Multipurpose-Waterway-Development/.

—. 2018. "National Levee Database." Washington, D.C. https://levees.sec.usace.army.mil/\#/.

U.S. Census Bureau. 1990. "1990 Census of population: General population characteristics: Oregon." Washington, D.C. http://www.census.gov/library/publications/1992/dec/cp-1.html.

- 2015. "2010 Census urban and rural classification and urban area criteria." Washington, D.C. https://www.census.gov/geo/reference/ua/urban-rural-2010.html.

—. 2016a. "American FactFinder: Community facts: 2012-2016 American Community Survey 5-Year Estimates." Washington, D.C. http://factfinder.census.gov/faces/nav/jsf/pages/index.xhtml.

—. 2016b. "American FactFinder: Community facts: Data from 2010 census and 2016 American Community Survey." Washington, D.C. http://factfinder.census.gov/faces/nav/jsf/pages/index.xhtml.

—. 2017. "U.S. gazetteer files." Washington, D.C. https://www.census.gov/geo/mapsdata/data/gazetteer2017.html.

—. 2018. "TIGER/Line with selected demographic and economic data." Washington, D.C. https://www.census.gov/geo/maps-data/data/tiger-data.html: U.S. Census Geography: Maps \& Data. 
U.S. Census Bureau and Federal Register. 2010. "Standards for delineating metropolitan and micropolitan statistical areas." Washington, D.C. Office of Management and Budget. https://www.census.gov/programs-surveys/metro-micro/about/ombstandards.html.

U.S. Environmental Protection Agency. 1993. "Constructed wetlands for wastewater treatment and wildlife habitat: Seventeen case studies." Washington, D.C. https://www.epa.gov/wetlands/constructed-wetlands-wastewater-treatment-andwildlife-habitat-17-case-studies.

—. 2000. "Low impact development (LID) literature review." Office of Water. Washington, D.C. https://nepis.epa.gov/Exe/ZyNET.exe/P1001B6V.TXT?ZyActionD=ZyDocumen $\underline{\mathrm{t} \& \text { Client }}=\mathrm{EPA} \&$ Index $=2000+$ Thru $+2005 \&$ Docs $=\&$ Query $=\&$ Time $=\&$ EndTime $=$ \&SearchMethod $=1 \&$ TocRestrict $=$ n $\&$ Toc $=\&$ TocEntry $=\& Q$ Field $=\& Q$ FieldYear $=\&$ QFieldMonth $=\& Q$ FieldDay $=\&$ IntQFieldOp $=0 \&$ ExtQFieldOp $=0 \& X m l$ Query $=\& F$ ile $=\mathrm{D} \% 3 \mathrm{~A} \% 5$ Czy files $\% 5$ CIndex $\% 20$ Data $\% 5$ C00thru $05 \% 5$ CTxt $\% 5$ C00000015\%5C $\underline{\mathrm{P} 1001 \mathrm{~B} 6 \mathrm{~V} \cdot \mathrm{txt} \& U \text { ser }=A N O N Y M O U S \& P a s s w o r d=\text { anonymous\&SortMethod }=\mathrm{h} \% 7}$ C-

\&MaximumDocuments $=1 \&$ FuzzyDegree $=0 \&$ ImageQuality $=\mathrm{r} 75 \mathrm{~g} 8 / \mathrm{r} 75 \mathrm{~g} 8 / \mathrm{x} 150 \mathrm{y} 15$ $0 \mathrm{~g} 16 / \mathrm{i} 425 \& D i s p l a y=$ hpfr\&DefSeekPage $=\mathrm{x} \&$ SearchBack $=$ ZyActionL\&Back $=$ ZyAct ionS\&BackDesc $=$ Results $\% 20$ page $\&$ MaximumPages $=1 \& Z y$ Entry $=1 \&$ SeekPage $=\mathrm{x} \&$ ZyPURL.

—. 2010. "Green infrastructure case studies: Municipal policies for managing stormwater with green infrastructure." Washington, D.C.: Office of Wetlands, Oceans and Watersheds. Report EPA-841-F-10-004. http://1.usa.gov/1weZVGJ.

—. 2016. "Understanding the Safe Drinking Water Act." Washington, D.C. https://www.epa.gov/sdwa/overview-safe-drinking-water-act.

—. 2017. "Integrating green infrastructure into federal regulatory programs." Washington, D.C. https://www.epa.gov/green-infrastructure/integrating-green-infrastructurefederal-regulatory-programs.

—. 2018a. "Green Infrastructure Collaborative." Washington, D.C. https://www.epa.gov/green-infrastructure/green-infrastructure-collaborative.

—. 2018b. "National Pollutant Discharge Elimination System (NPDES): Stormwater discharges from municipal sources." Washington, D.C. https://www.epa.gov/npdes/stormwater-discharges-municipal-sources.

U.S. Fish and Wildlife Service. 1991. "Urban refuge policy." FWS/RF/91-5368. U.S. Department of the Interior. Washington, D.C. 
—. 1997. "National Wildlife Refuge System Improvement Act: Mission and goals." Public Law 105-57. Washington, D.C.

https://www.fws.gov/refuges/policiesandbudget/HR1420 missionGoals.html.

—. 2006. "Tualatin River National Wildlife Refuge: Fact sheet." Washington, D.C. http://www.fws.gov/tualatinriver/pdf/FactSheet06-07.pdf.

—. 2015, September 16. "Friends and the urban standards of excellence: Webinar summary." Portland, OR.

http://www.fws.gov/urban/PDFs/Friends $\% 20$ Urban $\% 20$ Webinar $\% 20$ Summary u pdated.pdf.

U.S. Geological Survey. 2014. "The Christmas flood of 1964." Portland, OR. https://www.usgs.gov/news/christmas-flood-1964.

U.S. Geological Survey Water Data Support Team. 2016a. "National Water Information System: Web Interface. USGS 14211550 Johnson Creek at Milwaukie, OR." edited by United States Geological Survey. Washington, D.C. http://waterdata.usgs.gov/or/nwis/uv/?site no=14211550\&PARAmeter $\mathrm{cd}=0006$ $\underline{5,00060 .}$.

—. 2016b. "National Water Information System: Web Interface. USGS 14299800 Nehalem River near Vernonia, OR." edited by United States Geological Survey. Washington, D.C.

http://waterdata.usgs.gov/or/nwis/uv/?site no=14299800\&PARAmeter cd=0006 $\underline{5,00060 .}$.

University of Sheffield Social and Spatial Inequalities Group and Mark Newman. 2006. "Killed by floods." Sheffield, UK. http://www.worldmapper.org/posters/worldmapper map250 ver5.pdf.

Waananen, A.O., D.D. Harris, and R.C. Williams. 1971. "Floods of December 1964 and January 1965 in the far western states: Part 1: Description." U.S. Geological Survey. Washington, D.C. https://pubs.usgs.gov/wsp/1866a/report.pdf.

Walker, Jack L. 1969. "The diffusion of innovations among the American States." The American Political Science Review 63:880-899.

Walsh, Christopher J., Allison H. Roy, Jack W. Feminella, Peter D. Cottingham, Peter M. Groffman, and Raymond P. Morgan II. 2005. "The urban stream syndrome: current knowledge and the search for a cure." Journal of the North American Benthological Society 24:706-723.

Washington County Planning Commission. 1993. "Comprehensive Plan: Volume II: Comprehensive Framework Plan for the Urban Area." Hillsoboro, OR. 
Wenger, Caroline. 2015. "Better use and management of levees: Reducing flood risk in a changing climate." Environmental Reviews 23:240-255.

White, Stacey Swearingen and Michael R. Boswell. 2007. "Stormwater quality and local government innovation." Journal of the American Planning Association 73:185-193.

World Resources Institute. 2015. "Aqueduct global flood risk country rankings." Washington, D.C. : Aqueduct Global Flood Analyzer. http://www.wri.org/resources/data-sets/aqueduct-global-flood-risk-countryrankings.

Yi, Hongtao, Richard C. Feiock, and Frances S. Berry. 2017. "Overcoming collective action barriers to energy sustainability: A longitudinal study of climate protection accord adoption by local governments." Renewable and Sustainable Energy Reviews 79:339-346.

Yin, Robert K. 2014. Case Study Research: Design and Methods. Los Angeles, CA: SAGE Publications, Inc.

Zahran, Sammy, Samuel D. Brody, Wesley E. Highfield, and Arnold Vedlitz. 2010. "Nonlinear incentives, plan design, and flood mitigation: The case of the Federal Emergency Management Agency's community rating system." Journal of Environmental Planning \& Management 53:219-239.

Zedler, Joy B. and Suzanne Kercher. 2005. "Wetland resources: Status, trends, ecosystem services, and restorability." Annual Review of Environment \& Resources 30:39-74.

Zeileis, Achim, Christian Kleiber, and Simon Jackman. 2008. "Regression models for count data in R." Journal of Statistical Software 27:1-25. 


\section{Appendix A: Survey Summary Report}

\section{Executive Summary}

Flood hazard and floodplain management is a critical governance issue, as communities address increasing flood risks in many areas and attempt to meet numerous objectives in their decision making. The National Flood Insurance Program dictates many of these regulatory requirements, which are often balanced against goals for improved water quality, fish and wildlife habitat, economic development, and recreational opportunities.

Communities adopt policies and infrastructure that best help them meet these objectives.

To explore the decision making that goes into meeting these goals, we administered a survey to designated floodplain administrators throughout Oregon. This survey asked about the types of policy, planning, and infrastructures being used in communities, and what goals were being prioritized in decision making. As of January 2018, we received 107 complete responses, yielding a 48\% response rate. Most survey respondents were 50-64 years old and have a bachelor's or master's degree. The average amount of time in their current position was approximately six years, and the majority had no previous experience as a floodplain administrator.

There was a clear trend in many responses correlating with the size of the community, such as types of infrastructure used, prioritization of management objectives, and attitudes toward infrastructures. Fifty percent or more of all respondents said that green infrastructure is a necessary component of managing floodplains and flood hazard and will likely be used more in the future.

\section{Key Findings}

- Many communities reported having more federal flood disaster declarations than 100-year floods during their tenure.

- The use of both gray and green infrastructure increased with the size of the community, but the majority of communities rely more on green infrastructure for stormwater or floodplain management.

- The two most important benefits from flood hazard and floodplain management were flood control and water quality improvement.

- Fish and wildlife habitat was ranked higher than economic development as a potential benefit of flood hazard and floodplain management.

- Gray infrastructure ranks higher for effectively reducing flood risk.

- More communities, regardless of size, agreed that green infrastructure is more likely to be used in the future than gray infrastructure.

- Increased capacity and education were cited most as necessary for improved flood hazard and floodplain management (e.g., increased staff levels, updated Flood Insurance Rate Maps, and adoption of flood management plans). 


\section{“The question 'are you prepared for a 100-year flood' - I feel we are but I answered 'somewhat' because no flood is the same so there is always something new to understand and our floods are happening so rarely.... We are understaffed to manage this alone." \\ - Survey Respondent}

\section{Section One: Introduction}

Flooding is a concern for the entire state of Oregon. There has been substantial flooding every decade since the mid-1800s (Oregon Department of Land Conservation and Development 2015). Every county in Oregon has at least two flood-prone communities, with several counties_-Clackamas, Linn, Marion, and Washington-having fifteen or more flood-prone communities (Federal Emergency Management Agency 2018a).

Each of these communities is tasked with managing flood hazard and floodplains. As part of its land use planning, Oregon has adopted nineteen statewide planning goals; one of these, Goal 7, Areas Subject to Natural Hazards, requires that local governments adopt comprehensive plans to reduce the risk from natural hazards (Oregon Department of Land Conservation and Development 2001). At the federal level, the Clean Water Act regulates water quality and fill and discharge from floodplain areas. Moreover, for most people, flood insurance is available only through the National Flood Insurance Program (NFIP) administered by the Federal Emergency Management Agency (FEMA). To be a part of the NFIP, FEMA requires a community to meet several standards for management and development of the floodplain, making the NFIP one of the biggest drivers of flood hazard and floodplain management decisions in local government.

In a river and floodplain system, there are myriad assets and values that a community might be interested in protecting and enhancing: flood mitigation; water quality; economic development; recreation; transportation and navigation; open space, aesthetic, and natural heritage values; fish and wildlife habitat; and clean drinking water. These (potential) priorities and regulatory framework create numerous opportunities for a community to decide on its priorities and objectives, and how it is going to meet them.

This report is the result of a survey administered to designated floodplain administrators in flood-prone communities across the state (Figure 2). To be part of the NFIP, FEMA requires a community to have a 'designated floodplain administrator' to serve as the point of contact; frequently this role is part of the job duties of a planner, but it may be designated to anyone (e.g., another person or department in the local government, county government, or a contractor). We were interested in how communities prioritize objectives and adopt infrastructure and policy to both meet those objectives and meet regulatory requirements. 


\section{Section Two: Understanding This Report}

Oregon has 241 incorporated communities (Figure A-1); FEMA considers 223 of these communities prone to flooding, and 212 of those communities are part of the National Flood Insurance Program (NFIP) (Figure A-2). FEMA requires that a community have a point of contact, or designated floodplain administrator, to be part of the NFIP. We contacted these designated floodplain administrators, requesting that they take a floodplain infrastructure survey. We received 107 responses, which are summarized in this report (Figure A-3).

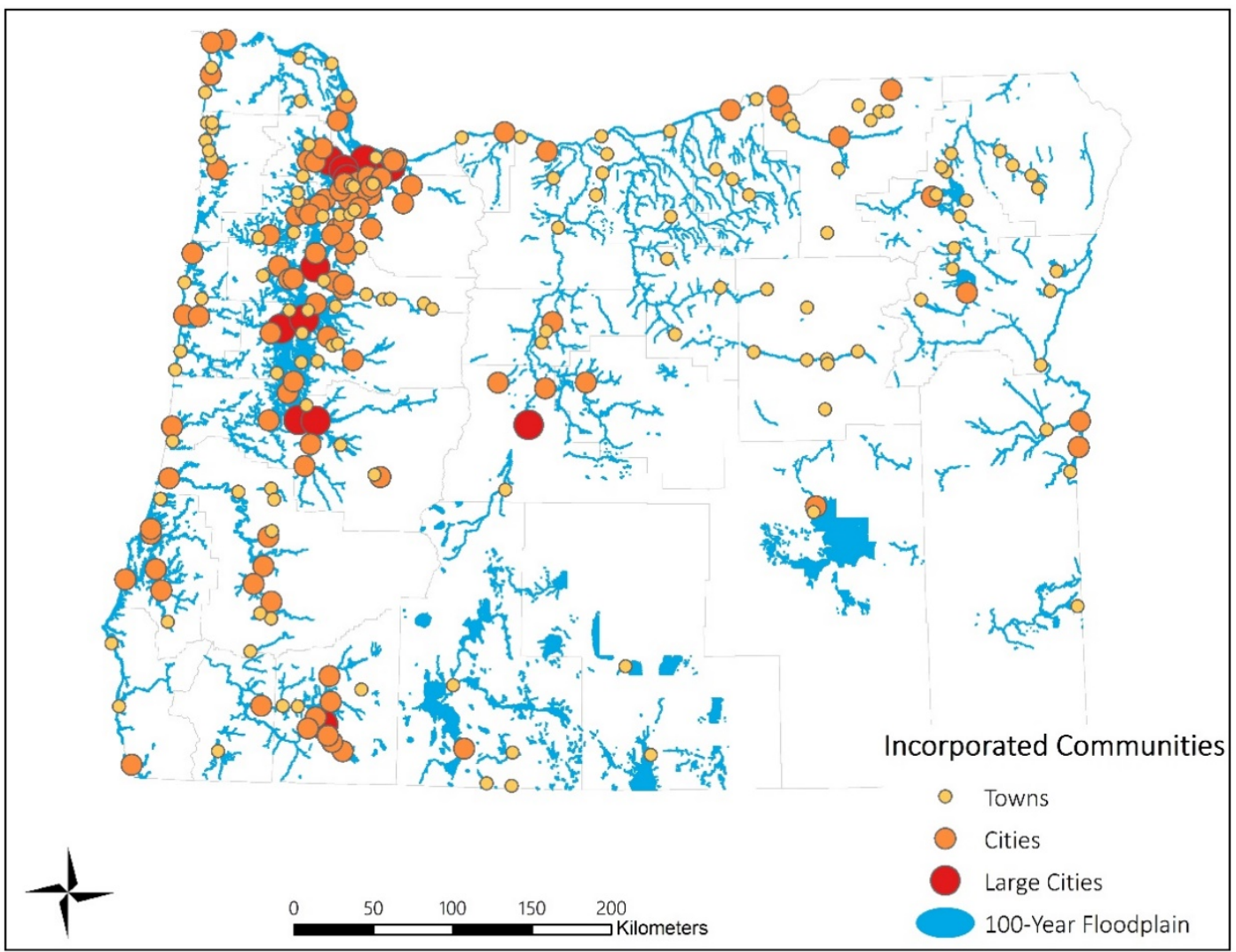

Figure A-1. Incorporated communities in Oregon, categorized population size into towns, cities, and large cities. 


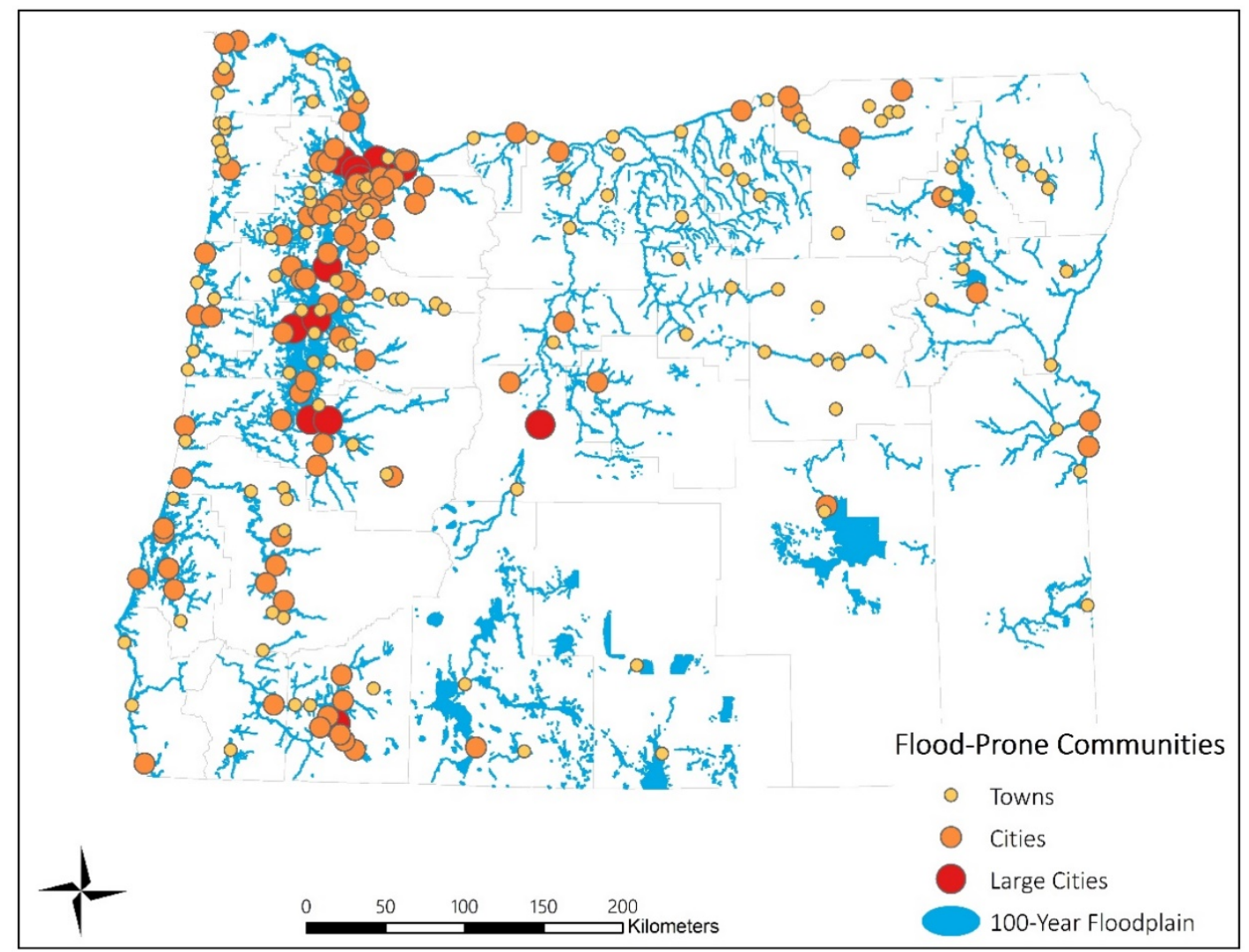

Figure A-2. Flood-prone incorporated communities in Oregon, categorized by population size into towns, cities, and large cities. 


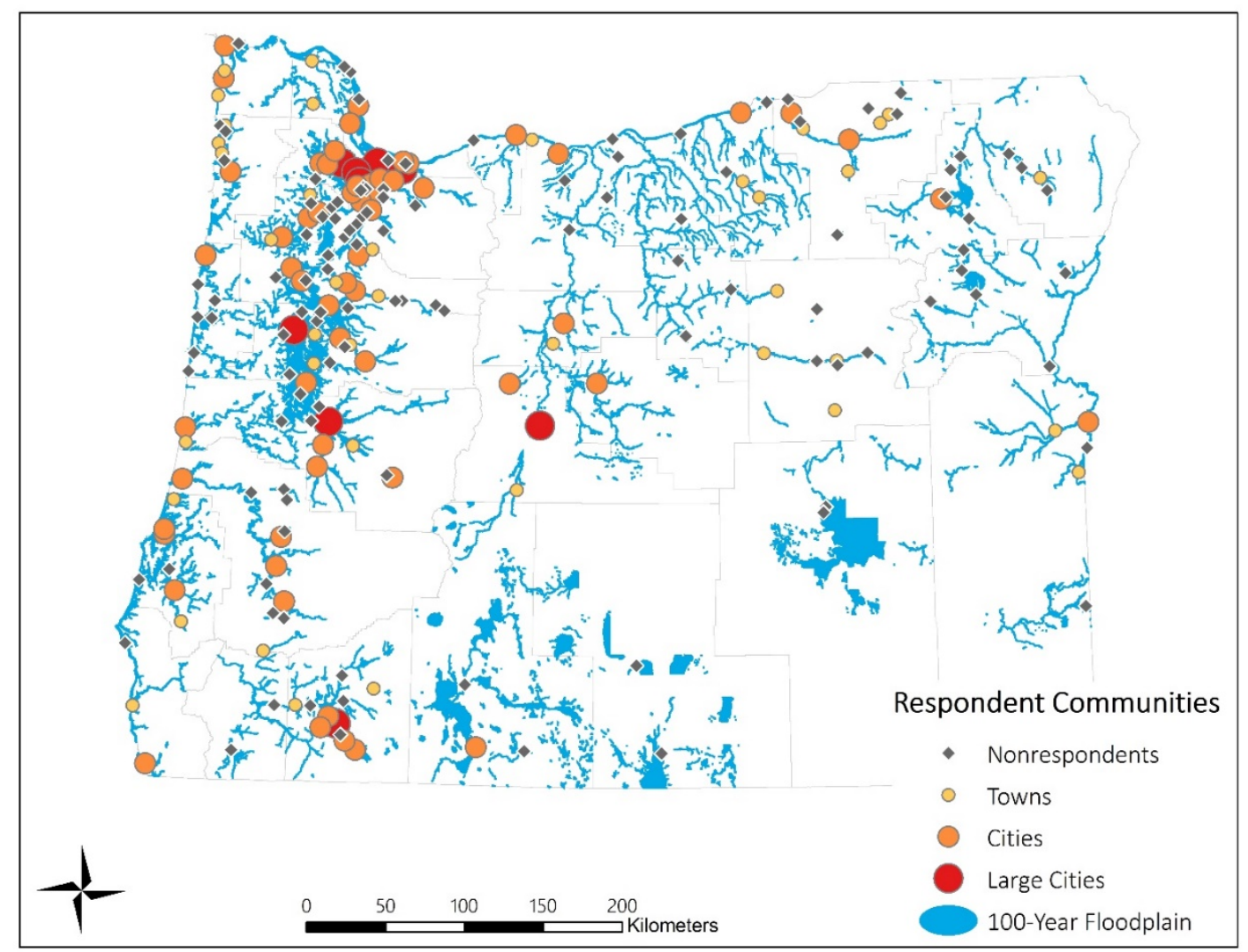

Figure A-3. Communities of survey respondents, categorized population size into towns, cities, and large cities.

For each question, the responses are separated into three groups based on the U.S. Census Bureau's definitions of urban and rural (2015):

1. Town: Communities with a population less than 2,500 people There are 39 towns represented in this report.

2. City: Communities with populations between 2,500 and 50,000 people There are 59 cities represented in this report.

3. Large City: Communities of 50,000 people or more

There are nine large cities represented in this report.

Comparing the number of respondents from these groups to the number of these communities in Oregon illustrates that the data are skewed toward larger communities (Figure A-4). 


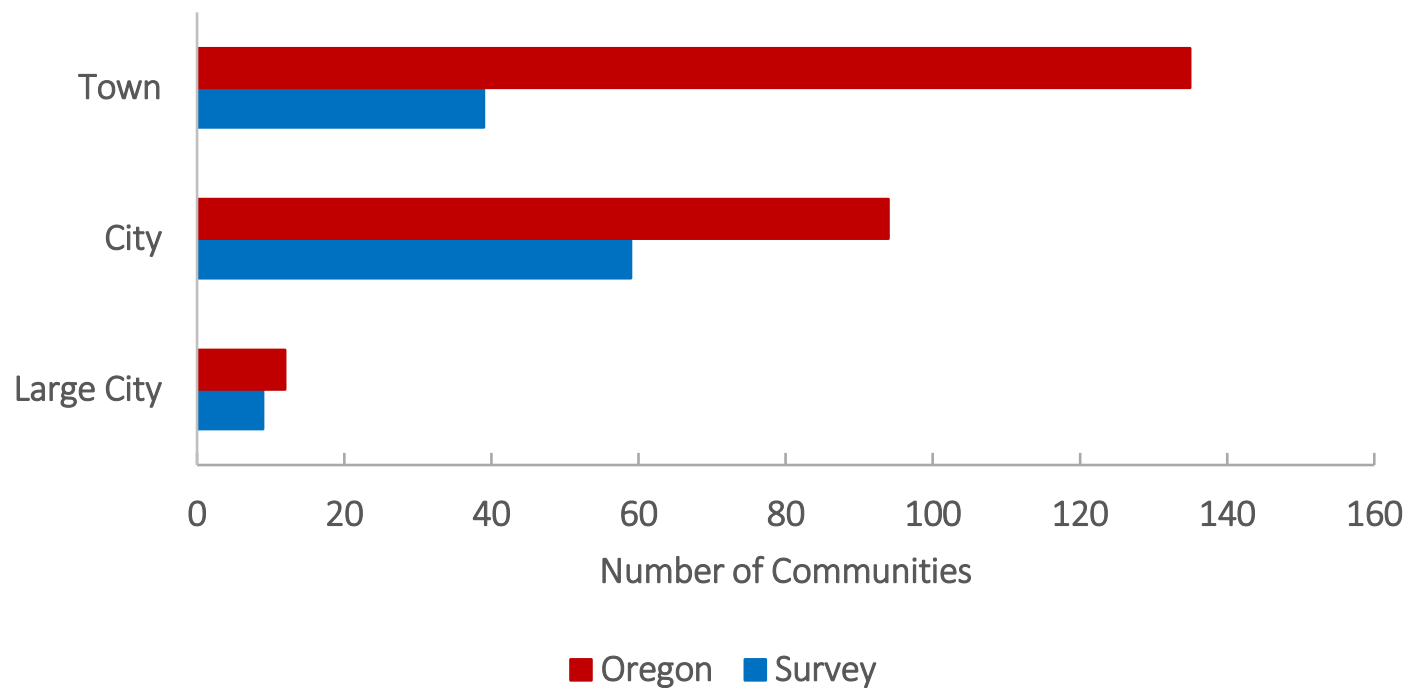

Figure A-4. The number of towns, cities, and large cities that responded to the survey compared to the total number of each in the state of Oregon. A higher proportion of cities and large cities replied to the survey than towns.

\section{Frequently Used Abbreviations}

\begin{tabular}{ll}
\hline Abbreviation & Meaning \\
\hline BiOp & $\begin{array}{l}\text { NOAA Biological Opinion on the Endangered Species Act and the National Flood } \\
\text { Insurance Program }\end{array}$ \\
\hline DLCD & Oregon Department of Land Conservation and Development \\
\hline FEMA & Federal Emergency Management Agency \\
\hline FIRM & Flood Insurance Rate Map \\
\hline NFIP & National Flood Insurance Program \\
\hline
\end{tabular}




\section{Section Three: Respondent Background}

This section summarizes some basic characteristics of survey respondents such as demographic information (e.g., level of education and age), professional memberships and certification, and experience with flood hazard and floodplain management.

\section{Position and Experience}

Designated Floodplain Administrator

To participate in the NFIP, FEMA requires a community to have a designated floodplain administrator to function as a point of contact. Across all community sizes, most respondents identified themselves as the designated floodplain administrator. ( $79 \%$ in towns, $81 \%$ in cities, and $67 \%$ in large Cities). ( $\mathrm{n}=106$, question 3 )

\section{Position Tenure}

The number of years in the current position ranged from less than a year to almost 40 years. For all communities, though, the average amount of time in the position was between six and seven years, and the median time was four years. $(n=99$, question 5$)$

\section{Experience}

A minority of respondents previously worked as a floodplain administrator in another community: $15 \%$ from a town, $32 \%$ from a city, and none from a large city. ( $\mathrm{n}=107$, question 6)

\section{Floodplain Manager Certification}

The primary professional organization for municipal floodplain managers, the Association of State Floodplain Managers, provides professional certification to floodplain managers that recognizes professional development and continuing education in floodplain management. Fifteen percent of respondents reported being certified floodplain managers, and as population size increases, so does floodplain management certification. (Question 7)

- Town: $\quad 8 \%(\mathrm{n}=38)$

- City: $\quad 18 \%(\mathrm{n}=57)$

- Large city: $33 \%(\mathrm{n}=9)$

Professional Membership

Like floodplain management certification, the likelihood of membership in a professional organization such as the Association of State Floodplain Managers or its regional branch, the Northwest Regional Floodplain Management Association, increased with the size of the city, with $21 \%$ of all respondents holding professional membership. (Question 8)

- Town: $\quad 15 \%(\mathrm{n}=39)$

- City: $\quad 22 \%(\mathrm{n}=59)$

- Large City: $44 \%(\mathrm{n}=9)$ 


\section{Education}

All respondents completed high school, with most respondents in larger communities possessing a bachelor's or master's degree (Table A-1). $(\mathrm{n}=107$, question 9)

Table A-1. Highest level of education attained by respondents.

\begin{tabular}{lllll}
\hline & $\begin{array}{l}\text { Town } \\
(\mathrm{n}=39)\end{array}$ & $\begin{array}{l}\text { City } \\
(\mathrm{n}=59)\end{array}$ & $\begin{array}{l}\text { Large City } \\
(\mathrm{n}=9)\end{array}$ & All \\
\hline High school diploma & $23 \%$ & $9 \%$ & $0 \%$ & $13 \%$ \\
\hline Associate degree & $28 \%$ & $2 \%$ & $0 \%$ & $11 \%$ \\
\hline Bachelor degree & $21 \%$ & $56 \%$ & $33 \%$ & $41 \%$ \\
\hline Master degree & $28 \%$ & $34 \%$ & $67 \%$ & $35 \%$ \\
\hline
\end{tabular}

$\underline{\text { Age }}$

Respondents range from 25 to over 65 years in age, with most in the smaller communities between 50-64 years old (Table A-2). ( $\mathrm{n}=107$, question 10)

Table A-2. Age ranges of respondents.

\begin{tabular}{lllll}
\hline Age & $\begin{array}{l}\text { Town } \\
(\mathbf{n}=39)\end{array}$ & $\begin{array}{l}\text { City } \\
(\mathrm{n}=59)\end{array}$ & $\begin{array}{l}\text { Large City } \\
(\mathrm{n}=9)\end{array}$ & All \\
\hline $25-34$ & $8 \%$ & $14 \%$ & $0 \%$ & $10 \%$ \\
\hline $35-49$ & $26 \%$ & $37 \%$ & $56 \%$ & $35 \%$ \\
\hline $50-64$ & $62 \%$ & $44 \%$ & $44 \%$ & $51 \%$ \\
\hline 65 or older & $5 \%$ & $5 \%$ & $0 \%$ & $5 \%$ \\
\hline
\end{tabular}

Political Tendency

Most respondents identified as politically moderate (41\%), with $21 \%$ identifying as conservative and 38\% identifying as liberal (Table A-3). ( $\mathrm{n}=95$, question 43)

Table A-3. Political tendency of respondents.

\begin{tabular}{lllll}
\hline $\begin{array}{l}\text { Political } \\
\text { Tendency }\end{array}$ & $\begin{array}{l}\text { Town } \\
(\mathrm{n}=\mathbf{2 9 )}\end{array}$ & $\begin{array}{l}\text { City } \\
(\mathrm{n}=57)\end{array}$ & $\begin{array}{l}\text { Large City } \\
(\mathrm{n}=9)\end{array}$ & All \\
\hline Liberal & $38 \%$ & $33 \%$ & $67 \%$ & $38 \%$ \\
\hline Moderate & $41 \%$ & $44 \%$ & $22 \%$ & $41 \%$ \\
\hline Conservative & $21 \%$ & $23 \%$ & $11 \%$ & $21 \%$ \\
\hline
\end{tabular}




\section{Participation and Knowledge}

Flood Hazard and Floodplain Management Activities

There are several activities a floodplain manager may participate in as part of their duties. There are several activities that the majority of respondents participated in (e.g., managing comprehensive planning, hazard mitigation or emergency management planning, and managing stormwater). Other activities respondents were more likely to participate in if they were in cities (e.g., preserving streams, wetlands, or floodplains), or large cities (e.g., (restoring streams, wetlands, or floodplains) (Table A-4, Figure A-5). (Question 11)

Table A-4. Flood hazard and floodplain management activities respondents have participated in. Number of responses, $\mathrm{n}$, is indicated in parentheses.

\begin{tabular}{|c|c|c|c|c|}
\hline Activities & $\begin{array}{l}\text { Town } \\
\left(n=33^{+}\right)\end{array}$ & $\begin{array}{l}\text { City } \\
(n=56)\end{array}$ & $\begin{array}{l}\text { Large City } \\
(n=9)\end{array}$ & All \\
\hline Manage comprehensive planning & $85 \%$ & $89 \%$ & $78 \%$ & $87 \%$ \\
\hline $\begin{array}{l}\text { Hazard mitigation or emergency } \\
\text { management planning }\end{array}$ & $76 \%$ & $75 \%$ & $89 \%$ & $77 \%$ \\
\hline $\begin{array}{l}\text { Preserving streams, wetlands, or } \\
\text { floodplains }\end{array}$ & $46 \%$ & $75 \%$ & $78 \%$ & $65 \%$ \\
\hline Managing stormwater & $53 \%$ & $61 \%$ & $89 \%$ & $61 \%$ \\
\hline $\begin{array}{l}\text { Restoring streams, wetlands, or } \\
\text { floodplains }\end{array}$ & $18 \%$ & $30 \%$ & $78 \%$ & $31 \%$ \\
\hline
\end{tabular}

${ } \mathrm{n}=34$ for managing stormwater.

Managing comprehensive planning

Hazard mitigation or emergency management planning

Preserving streams, wetlands, or floodplains

Managing stormwater

Restoring stream, wetlands, or floodplains
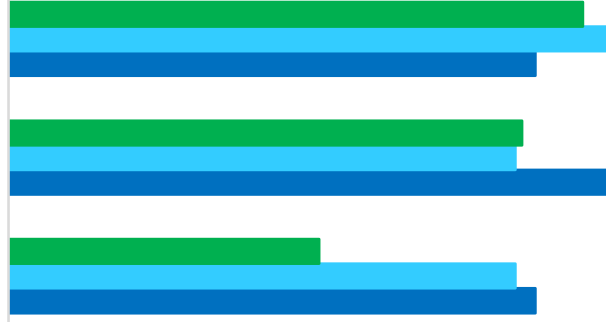

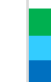
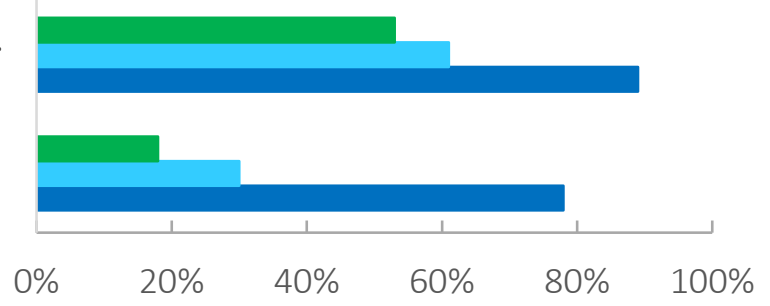

Town City $\square$ Large City

Figure A-5. The flood hazard and floodplain management activities respondents reported participating in. 
Flood Hazard and Floodplain Management Knowledge

Managing flood hazard and floodplains requires several areas of knowledge. The majority of respondents reported feeling very or extremely knowledgeable about zoning, but results for other aspects of flood hazard and floodplain management were extremely varied: respondents in towns and large cities were more knowledgeable about flood mitigation infrastructure and the NFIP biological opinion, while those from cities reported being more knowledgeable about the NFIP itself (Table A-5, Figure A-6). (Question 12)

Table A-5. The percentage of respondents who reported being very or extremely knowledgeable on several aspects of flood hazard and floodplain management.

\begin{tabular}{lllll}
\hline & $\begin{array}{l}\text { Town } \\
(\mathrm{n}=39)\end{array}$ & $\begin{array}{l}\text { City } \\
\left(\mathrm{n}=58^{+}\right)\end{array}$ & $\begin{array}{l}\text { Large City } \\
(\mathrm{n}=9)\end{array}$ & All \\
\hline Zoning & $67 \%$ & $90 \%$ & $78 \%$ & $80 \%$ \\
\hline $\begin{array}{l}\text { Flooding in your community } \\
\begin{array}{l}\text { National Flood Insurance Program } \\
\text { (NFIP) }\end{array}\end{array}$ & $46 \%$ & $74 \%$ & $78 \%$ & $64 \%$ \\
\hline $\begin{array}{l}\text { Flood mitigation infrastructure } \\
\text { NOAA Fisheries Biological Opinion on } \\
\text { the National Flood Insurance Program }\end{array}$ & $26 \%$ & $54 \%$ & $33 \%$ & $42 \%$ \\
\hline
\end{tabular}

${ }^{+} n=59$ for National Flood Insurance Program (NFIP) and Zoning.

Zoning

Flooding in your community

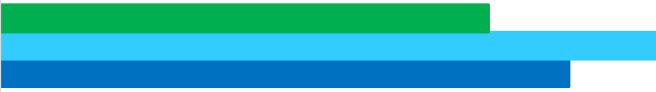

National Flood Insurance Program (NFIP)

Flood mitigation infrastructure
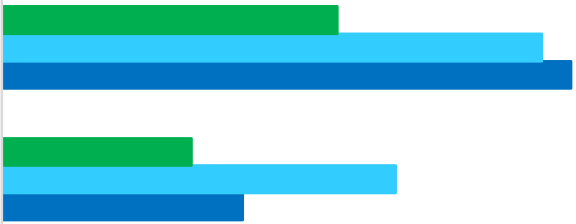

NOAA Fisheries Biological Opinion on the National Flood Insurance Program
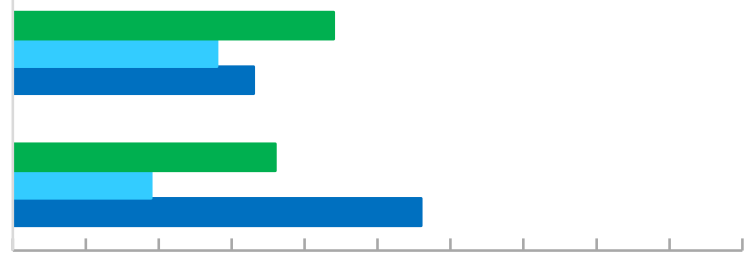

0\% 10\% 20\% 30\% 40\% 50\% 60\% 70\% 80\% 90\%100\% Town City $\square$ Large City

Figure A-6. Areas of flood hazard and floodplain management for which respondents reported being very or extremely knowledgeable. 


\section{Section Four: Community History and Experience with Flooding}

In this section, we asked people about their experience with flood events in their community: nuisance flooding, 100-year floods, and federal flood disaster declarations. Nuisance flooding is typically reported in a two-year period, and most often using water years, so we asked about the frequency of nuisance flooding between 2014 and 2016. The questions related to 100-year flood events and federal flood disaster declarations were asked in terms of the respondent's tenure in their current position to facilitate recall.

\section{Nuisance Flooding}

Nuisance flooding is defined as small events that cause road closures, overwhelmed storm drains, and infrastructure deterioration, such as seen on bridges or roads. Over a two-year period (October 2014 - September 2016), most communities reported a small number of events, but only cities reported have more than ten nuisance flood events (Table A-6, Figure A-7). (Question 14)

Table A-6. The number of nuisance floods communities reported over a two-year period.

\begin{tabular}{lllll}
\hline $\begin{array}{l}\text { Number of Nuisance Flood Events } \\
\text { (October 2014-September 2016) }\end{array}$ & $\begin{array}{l}\text { Town } \\
(\mathrm{n}=\mathbf{3 9})\end{array}$ & $\begin{array}{l}\text { City } \\
(\mathrm{n}=\mathbf{5 8})\end{array}$ & $\begin{array}{l}\text { Large City } \\
(\mathrm{n}=\mathbf{8})\end{array}$ & All \\
\hline 0 & $46 \%$ & $28 \%$ & $0 \%$ & $32 \%$ \\
\hline $1-5$ & $49 \%$ & $60 \%$ & $75 \%$ & $57 \%$ \\
\hline $6-10$ & $5 \%$ & $5 \%$ & $13 \%$ & $6 \%$ \\
\hline More than 10 & $0 \%$ & $7 \%$ & $13 \%$ & $5 \%$ \\
\hline
\end{tabular}

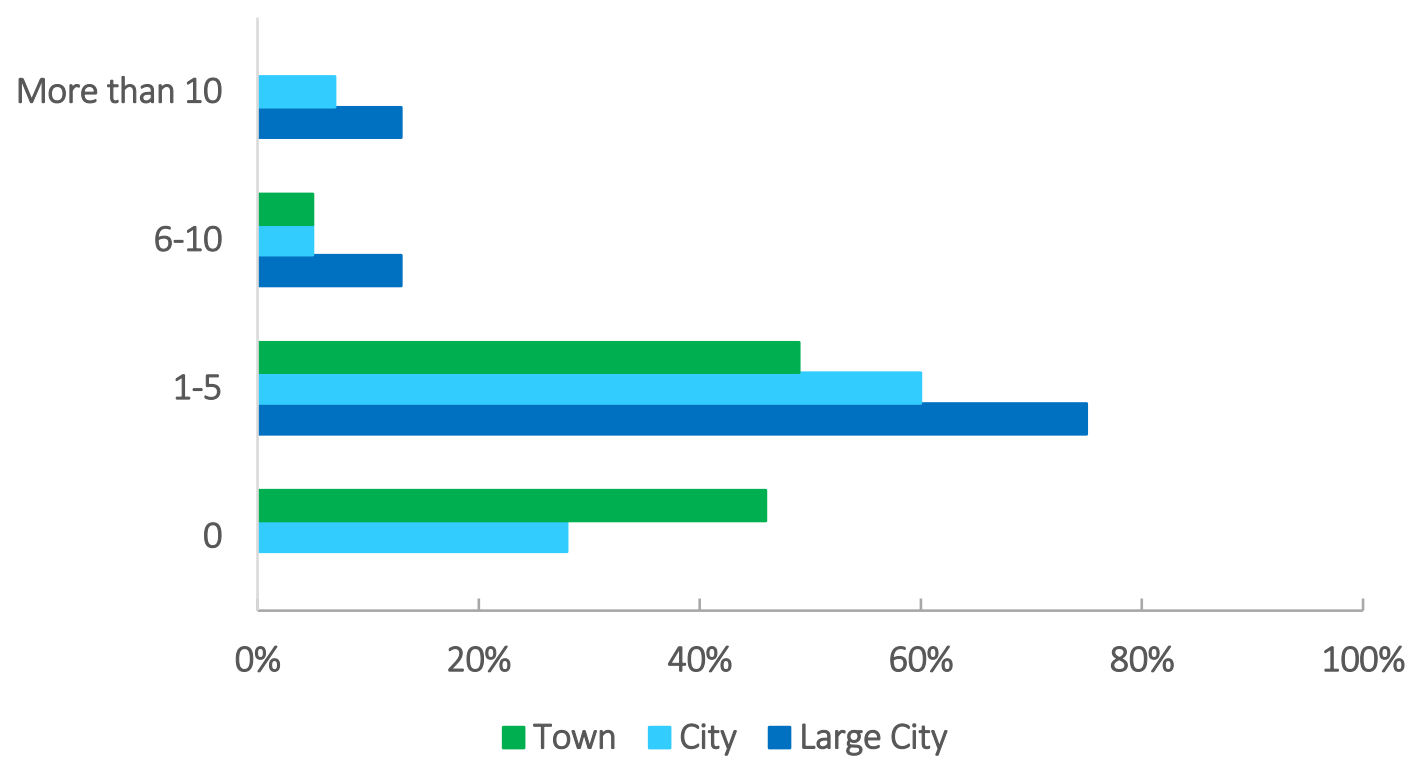

Figure A-7. The number of nuisance floods between October 2014 - September 2016 respondents reported.

100-Year Floods

A 100-year flood is a relatively rare flood event. It is also known as a base flood or a onepercent flood because it has a one percent chance of being equaled or exceeded during any 
given year; most flood hazard planning is based on the extent of the 100-year flood. The majority of respondents have not experienced a 100-year flood in their current position (Table A-7, Figure A-8). (Question 15)

Table A-7. The percentage of 100-year floods reported during the respondents' tenure as floodplain administrator for their community.

\begin{tabular}{lllll}
\hline Number of 100-Year Floods & $\begin{array}{l}\text { Town } \\
(\mathrm{n}=35)\end{array}$ & $\begin{array}{l}\text { City } \\
(\mathrm{n}=55)\end{array}$ & $\begin{array}{l}\text { Large City } \\
(\mathrm{n}=9)\end{array}$ & All \\
\hline 0 & $80 \%$ & $80 \%$ & $89 \%$ & $81 \%$ \\
1 & $11 \%$ & $9 \%$ & $11 \%$ & $10 \%$ \\
More than 1 & $9 \%$ & $11 \%$ & $0 \%$ & $9 \%$ \\
\hline
\end{tabular}

More than 1

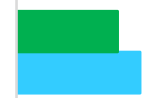

1

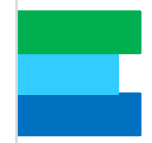

0

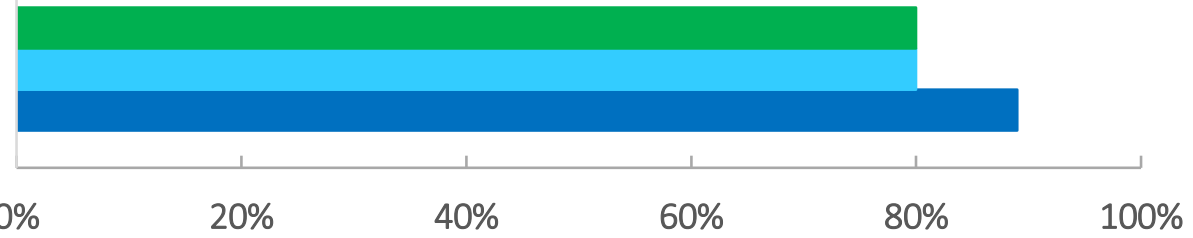

Town City $\quad$ Large City

Figure A-8. The number of 100-year floods respondents have experienced during their tenure.

For the respondents who have not experienced a 100-year flood during their tenure, we asked if they knew when the last one occurred; $40 \%$ of respondents from towns, $68 \%$ of respondents from cities, and $44 \%$ of respondents from large cities had an estimated year of the last occurrence. ( $\mathrm{n}=94$, question 16 )

Respondents then reported when the most recent 100-year flood occurred; responses ranged from the late 1800s to 2016, with two years, 1964 and 1996, being the most prevalent (Table A-8). $(n=50)$

- In December 1964, severe flooding across northern California, Oregon, and western Idaho killed almost 50 people, displaced thousands, and caused approximately $2014 \$ 4$ billion in damage (U.S. Geological Survey 2014).

- In 1996, there was extensive flooding in western Oregon: 26 rivers flooded and federal flood disasters were declared in eighteen counties. Eight people died and thousands were displaced (Rose February 5, 2016). 
Table A-8. The year of the most recent known 100-year flood, as reported by respondents.

\begin{tabular}{lllll}
\hline Years & $\begin{array}{l}\text { Town } \\
(\mathbf{n = 1 4 )}\end{array}$ & $\begin{array}{l}\text { City } \\
(\mathbf{n = 3 2})\end{array}$ & $\begin{array}{l}\text { Large City } \\
(\mathbf{n = 4 )}\end{array}$ & All \\
\hline$\sim 1880-1962$ & $29 \%$ & $6 \%$ & $0 \%$ & $12 \%$ \\
\hline 1964 & $14 \%$ & $19 \%$ & $25 \%$ & $18 \%$ \\
\hline $1965-1986$ & $14 \%$ & $9 \%$ & $0 \%$ & $10 \%$ \\
\hline 1996 & $29 \%$ & $53 \%$ & $50 \%$ & $46 \%$ \\
\hline $1997-2016$ & $14 \%$ & $13 \%$ & $25 \%$ & $14 \%$ \\
\hline
\end{tabular}

Federal Flood Disaster Declarations

A federal flood disaster is declared by the President following a request by a state governor. A flood is declared a federal disaster when its severity is beyond the combined capabilities of state and local governments to respond. A federal flood disaster declaration provides a wide range of federal assistance programs for individuals and public infrastructure, including funds for both emergency and permanent work. The majority of respondents have not had a federal flood disaster declared while in their position. However, the proportion of respondents from towns and large cities that reported having more federal flood disasters declared while in their position is higher than those who experienced a 100-year flood in the same time period, indicating that a disaster may be declared for less than a 100-year flood. Large cities have experienced more federal flood declarations than 100-year floods (Table A9, Figure A-9). ( $\mathrm{n}=98$, question 17)

Table 9. The percentage of federal flood disaster declarations reported during the respondents' tenure as floodplain administrator for their community.

\begin{tabular}{lllll}
\hline $\begin{array}{l}\text { Number of Federal Flood } \\
\text { Disaster Declarations }\end{array}$ & $\begin{array}{l}\text { Town } \\
(\mathrm{n}=34)\end{array}$ & $\begin{array}{l}\text { City } \\
(\mathrm{n}=56)\end{array}$ & $\begin{array}{l}\text { Large City } \\
(\mathrm{n}=9)\end{array}$ & All \\
\hline 0 & $77 \%$ & $89 \%$ & $67 \%$ & $83 \%$ \\
\hline 1 & $18 \%$ & $7 \%$ & $22 \%$ & $12 \%$ \\
\hline More than 1 & $6 \%$ & $4 \%$ & $11 \%$ & $5 \%$ \\
\hline
\end{tabular}


More than 1

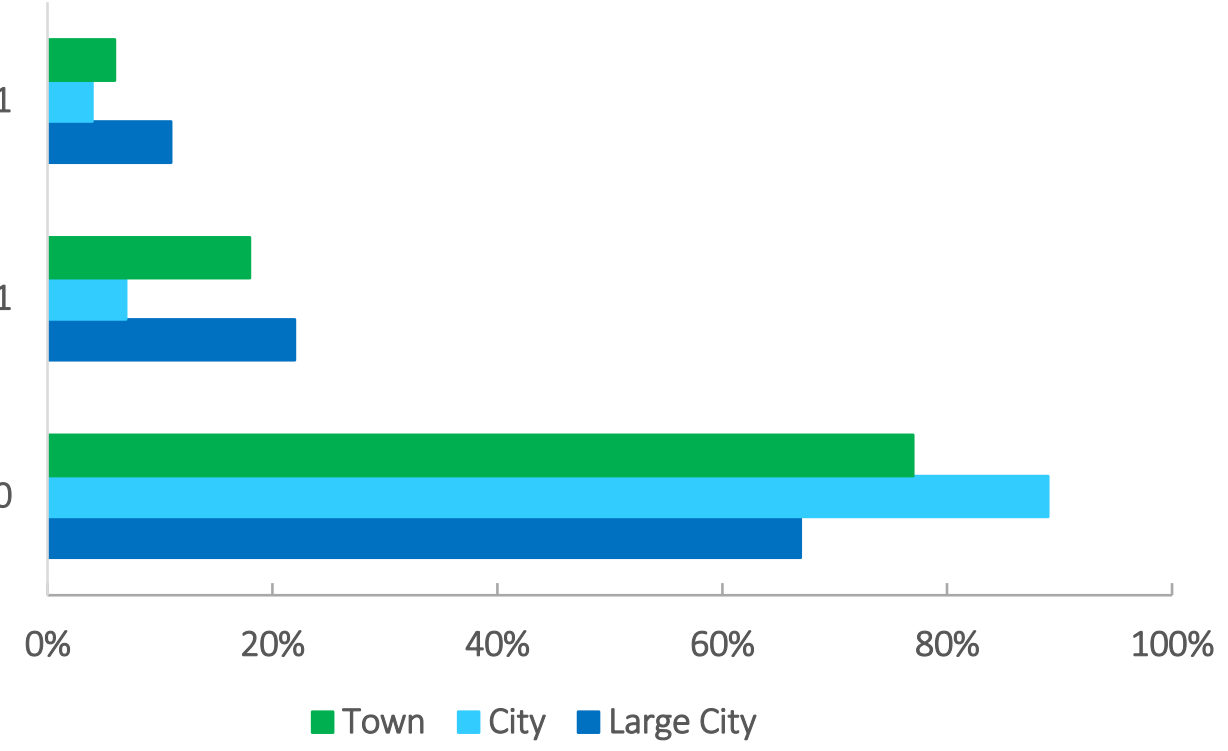

Figure A-9. The number of federal flood disaster declarations reported during respondents' tenure.

For the respondents who have not experienced a federal flood disaster declared during their tenure, we asked if they knew when the last one occurred; $29 \%$ of respondents from towns, $32 \%$ of respondents from cities, and $14 \%$ of respondents from large cities had an estimated year of the last occurrence (Table A-10). $(n=94)$

When asked what year the most recent federal flood disaster was declared, the years ranged from 1964 to 2015, with the most declarations occurring during 1996. $(\mathrm{n}=25)$

Table A-10. The year of the most recent federal flood declaration as reported by respondents.

\begin{tabular}{lllll}
\hline Years & $\begin{array}{l}\text { Town } \\
(\mathrm{n}=9)\end{array}$ & $\begin{array}{l}\text { City } \\
(\mathrm{n}=15)\end{array}$ & $\begin{array}{l}\text { Large City } \\
(\mathrm{n}=1)\end{array}$ & All \\
\hline $1964-1976$ & $11 \%$ & $20 \%$ & $0 \%$ & $16 \%$ \\
\hline 1996 & $33 \%$ & $33 \%$ & $0 \%$ & $32 \%$ \\
\hline $1997-2015$ & $56 \%$ & $47 \%$ & $100 \%$ & $52 \%$ \\
\hline
\end{tabular}




\section{Section Five: Community Flood Hazard and Floodplain Policy Development}

In this section we asked respondents about their sources of information for flood hazard and floodplain management, including the degree of interaction with other communities for information gathering or collaboration. Respondents in towns were slightly more likely to talk to representatives from other communities every few months than those from larger communities. However, respondents from large cities reported talking to other people three times as much as those from smaller communities. This may be correlated with the number of intergovernmental agreements (IGAs): large cities again reported having more than 1 IGA three times more often than smaller communities.

\section{Sources of Information}

The majority of communities, regardless of size, reference several pieces of information they rely on for flood hazard and floodplain management, with over half of small and large cities ( $71 \%$ and $78 \%$, respectively) naming three sources of information that are important. The most important sources of information listed include a document, an organization, and a person; to a lesser extent, other communities were also listed (Table A-11). (Question 20)

Table A-11. Number of sources communities cite as important in flood hazard and floodplain management.

\begin{tabular}{lllll}
\hline & $\begin{array}{l}\text { Town } \\
(\mathrm{n}=39)\end{array}$ & $\begin{array}{l}\text { City } \\
(\mathrm{n}=59)\end{array}$ & $\begin{array}{l}\text { Large City } \\
(\mathrm{n}=9)\end{array}$ & All \\
\hline Communities listing no sources & $26 \%$ & $10 \%$ & $26 \%$ & $14 \%$ \\
\hline Communities listing only one source & $8 \%$ & $7 \%$ & $14 \%$ & $8 \%$ \\
\hline Communities listing only two sources & $11 \%$ & $0 \%$ & $11 \%$ & $18 \%$ \\
\hline Communities listing three sources & $26 \%$ & $10 \%$ & $26 \%$ & $60 \%$ \\
\hline
\end{tabular}

There were four sources of information that were cited repeatedly as important to a community's management efforts:

- Flood Insurance Rate Maps

- Federal Emergency Management Agency

- Oregon Department of Land Conservation and Development

- National Flood Insurance Program Coordinator at Oregon Department of Land Conservation and Development

Flood Management Plans

Communities are not mandated to develop a flood management plan, but may choose to do so to improve management. Of those who responded to the question, smaller communities are more likely to have developed a flood management plan: Over half of towns have developed a plan $(59 \%, \mathrm{n}=27)$, but less than half of cities $(49 \%, \mathrm{n}=43)$ and large cities $(43 \%, n=7)$ have developed a flood management plan. The majority of these plans were written in the last ten years, but some plans were written in the early 1980s. (Question 23)

A small number of respondents reported reading other communities' flood management plans: eight percent of towns, $19 \%$ of cities, and 11\% of large cities. The flood management plans of Portland and Salem were named most by respondents (three times and twice, respectively). $(\mathrm{n}=106)$ 


\section{Talking to Other Communities}

Most respondents reported talking to representatives from other communities about their approach to flood hazard and floodplain management less than once a year. Respondents in large cities talk to others more often; these respondents reported talking to others at least one a month over three times as much as smaller communities (Table A-12, Figure A-10). (n $=100$, question 24)

Table A-12. The frequency respondents reported talking to representatives from other communities about their approach to flood hazard and floodplain management.

\begin{tabular}{lllll}
\hline Frequency & $\begin{array}{l}\text { Town } \\
(\mathrm{n}=34)\end{array}$ & $\begin{array}{l}\text { City } \\
(\mathrm{n}=57)\end{array}$ & $\begin{array}{l}\text { Large City } \\
(\mathrm{n}=9)\end{array}$ & All \\
\hline Less than once a year & $44 \%$ & $44 \%$ & $44 \%$ & $44 \%$ \\
\hline Once a year & $26 \%$ & $26 \%$ & $11 \%$ & $25 \%$ \\
\hline Every few months & $26 \%$ & $23 \%$ & $22 \%$ & $24 \%$ \\
\hline Once a month or more & $3 \%$ & $7 \%$ & $22 \%$ & $7 \%$ \\
\hline
\end{tabular}

Less than once a year

Once a year

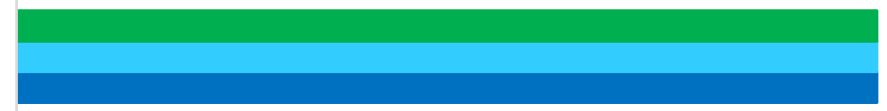

Once a year

Every few months

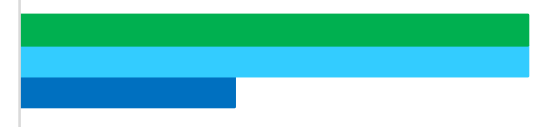

Once a month or more

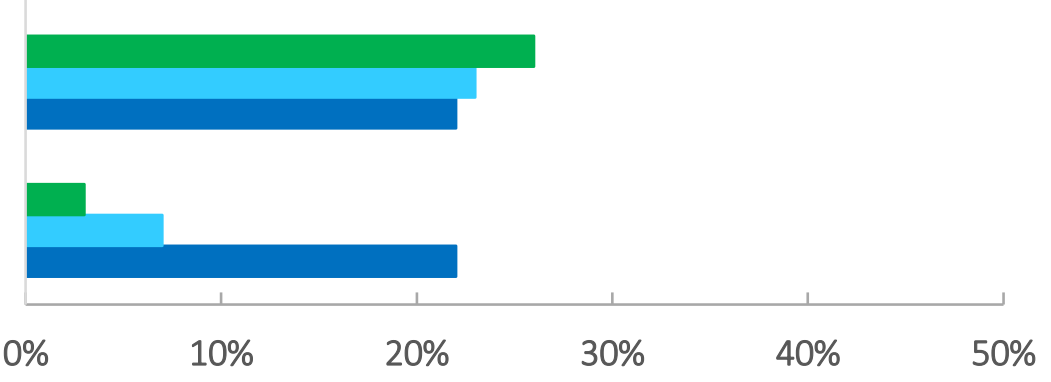

Town City $\quad$ Large City

Figure A-10. The frequency respondents reported talking to representatives from other communities about their approach to flood hazard and floodplain management.

\section{Intergovernmental Agreements}

Communities often have intergovernmental agreements (IGAs) with different entities such as private companies, neighboring communities, or government agencies to support mandated activities. IGAs related to flood hazard and floodplain management activities are most commonly to provide services such as emergency assistance and equipment. 
Approximately one-quarter of respondents $(27 \%)$ were unsure if their community had IGAs related to flood hazard and floodplain management. Of the remaining responses, the majority reported not having these types of IGAs; if they did have an IGA, though, it was most often only one IGA (Table A-13). ( $n=78$, question 25$)$

Table A-13. Number of IGAs respondents reported. Some numbers don't total $100 \%$ because some respondents reported having IGAs but didn't provide information about how many.

\begin{tabular}{lllll}
\hline Frequency & $\begin{array}{l}\text { Town } \\
(\mathrm{n}=27)\end{array}$ & $\begin{array}{l}\text { City } \\
(\mathrm{n}=43)\end{array}$ & $\begin{array}{l}\text { Large City } \\
(\mathrm{n}=8)\end{array}$ & All \\
\hline No IGAs & $56 \%$ & $72 \%$ & $50 \%$ & $64 \%$ \\
\hline Listed 1 IGA & $33 \%$ & $19 \%$ & $25 \%$ & $24 \%$ \\
\hline Listed more than 1 IGA & $7 \%$ & $5 \%$ & $25 \%$ & $8 \%$ \\
\hline
\end{tabular}

Respondents were asked what entities their intergovernmental agreements (IGAs) for flood hazard and floodplain management were with, and the primary focus of those agreements. Twenty-six respondents provided these details, which were then categorized.

IGAs are primarily held with:

- City government

- County government

- FEMA

- Local business

- Regional government

- State government

- U.S. Army Corps of Engineers

- Utility company

The purposes of these IGAs are:

- Emergency management

- Emergency response

- Mutual aid

- Planning

- Stormwater management 


\section{Decision Making}

There are numerous factors communities consider when making decisions about how to manage flood hazard and floodplains. Respondents reported the following factors as very or extremely important in decision making (Table A-14, Figure A-11). (Question 27)

Table A-14. The percentage of respondents who reported the following factors being very or extremely important in flood hazard and floodplain management decision making.

\begin{tabular}{lllll}
\hline & $\begin{array}{l}\text { Town } \\
(\mathrm{n}=\mathbf{3 4 - 3 6 )}\end{array}$ & $\begin{array}{l}\text { City } \\
(\mathrm{n}=55-57)\end{array}$ & $\begin{array}{l}\text { Large City } \\
(\mathrm{n}=9)\end{array}$ & All \\
\hline Risk reduction & $89 \%$ & $89 \%$ & $78 \%$ & $88 \%$ \\
\hline Effectiveness & $72 \%$ & $89 \%$ & $88 \%$ & $86 \%$ \\
\hline Cost effectiveness & $78 \%$ & $86 \%$ & $89 \%$ & $83 \%$ \\
\hline Meeting regulatory requirements & $72 \%$ & $79 \%$ & $100 \%$ & $78 \%$ \\
\hline $\begin{array}{l}\text { Maintenance requirements } \\
\text { Minimize potential exposure to flooding }\end{array}$ & $67 \%$ & $78 \%$ & $78 \%$ & $74 \%$ \\
$\begin{array}{l}\text { (e.g., through zoning) } \\
\text { Providing multiple benefits }\end{array}$ & $67 \%$ & $74 \%$ & $67 \%$ & $70 \%$ \\
\hline Project lifespan & $57 \%$ & $60 \%$ & $67 \%$ & $59 \%$ \\
\hline Meeting environmental goals & $60 \%$ & $57 \%$ & $44 \%$ & $57 \%$ \\
\hline
\end{tabular}

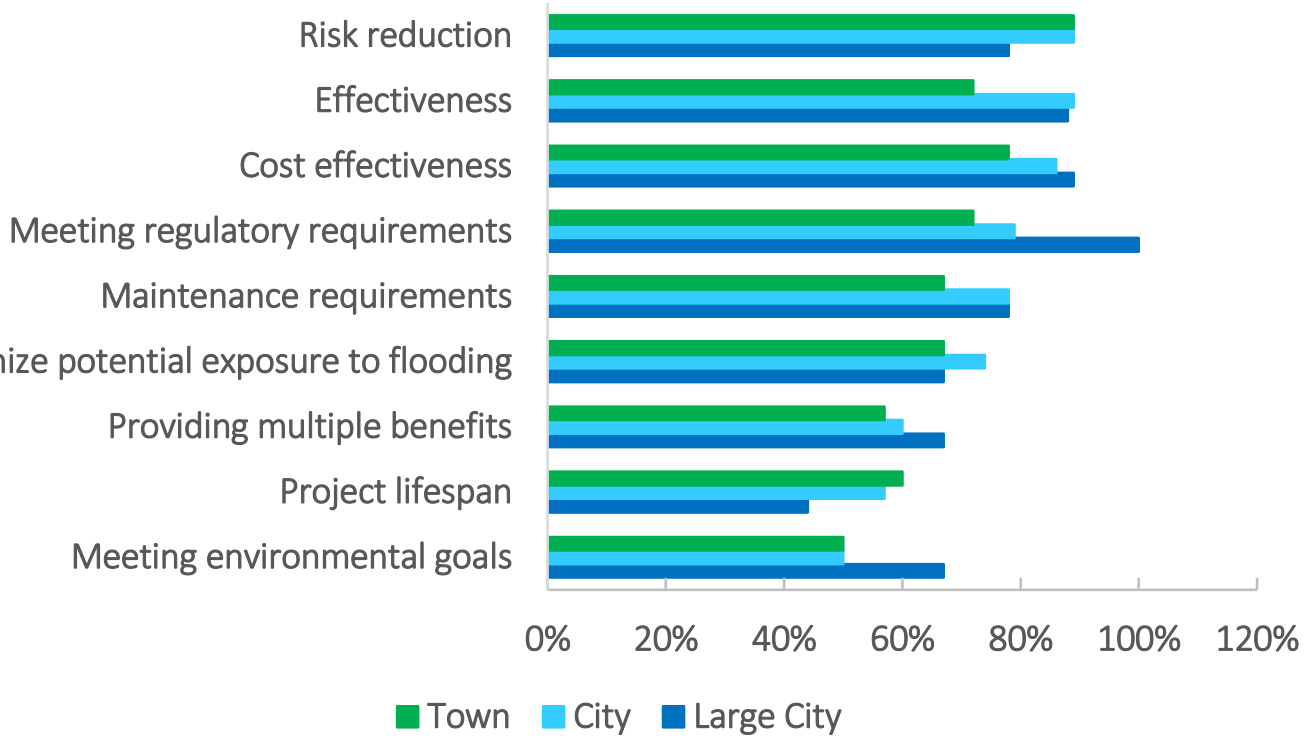

Figure A-11. The factors respondents reported as being very or extremely important in decision making. 


\section{Section Six: Community Infrastructure and Policy}

This section consists of community inventories related to flood hazard and floodplain management, including infrastructures and different governance activities, including those for improved planning and preparation, risk reduction, increased education and public awareness, and emergency management.

Many of the governance activities are suggested by FEMA as methods for improving flood hazard and floodplain management beyond the requirements of the NFIP. Specifically, these activities allow a community to get credit from FEMA to be part of the Community Rating System, a voluntary program that provides discounts on insurance rates for participating communities.

\section{Gray Infrastructure}

Communities may use different types of gray, or built, infrastructure to manage flood hazards and floodplains. Dams outside of the geographic boundary of the community are the most prevalent gray infrastructure communities are relying on (Table A-15, Figure A-12). (Question 30)

Table A-15. The types of gray infrastructure respondents reported their communities using for flood hazard and floodplain management.

\begin{tabular}{lllll}
\hline & $\begin{array}{l}\text { Town } \\
(\mathrm{n}=35-36)\end{array}$ & $\begin{array}{l}\text { City } \\
(\mathrm{n}=53-56)\end{array}$ & $\begin{array}{l}\text { Large City } \\
(\mathrm{n}=9)\end{array}$ & All \\
\hline $\begin{array}{l}\text { Dams outside the geographic } \\
\text { boundary of your community }\end{array}$ & $17 \%$ & $34 \%$ & $67 \%$ & $31 \%$ \\
\hline Levees & $14 \%$ & $20 \%$ & $33 \%$ & $19 \%$ \\
\hline Built flood control channels & $8 \%$ & $23 \%$ & $22 \%$ & $17 \%$ \\
\hline Weirs & $3 \%$ & $11 \%$ & $22 \%$ & $9 \%$ \\
\hline $\begin{array}{l}\text { Dams within the geographic boundary } \\
\text { of your community }\end{array}$ & $0 \%$ & $11 \%$ & $22 \%$ & $8 \%$ \\
\hline
\end{tabular}

\section{Green Infrastructure}

Communities may use a range of green infrastructure for stormwater or floodplain management. Large cities use more green infrastructure than towns or cities (Table A-16, Figure A-12). (Question 31)

Table A-16. The types of green infrastructure respondents reported their communities using for stormwater or floodplain management.

\begin{tabular}{lllll}
\hline & $\begin{array}{l}\text { Town } \\
(\mathrm{n}=\mathbf{2 8 - 3 3})\end{array}$ & $\begin{array}{l}\text { City } \\
(\mathrm{n}=4 \mathbf{7}-55)\end{array}$ & $\begin{array}{l}\text { Large City } \\
(\mathrm{n}=9)\end{array}$ & All \\
\hline Wetland or floodplain preservation & $58 \%$ & $79 \%$ & $100 \%$ & $74 \%$ \\
\hline Vegetated detention basins & $39 \%$ & $77 \%$ & $100 \%$ & $67 \%$ \\
\hline Vegetated bioswales & $46 \%$ & $71 \%$ & $100 \%$ & $65 \%$ \\
\hline Stream or floodplain restoration & $38 \%$ & $66 \%$ & $100 \%$ & $60 \%$ \\
\hline Natural flood control channels & $32 \%$ & $62 \%$ & $75 \%$ & $53 \%$ \\
\hline Wetland creation & $11 \%$ & $34 \%$ & $75 \%$ & $30 \%$ \\
\hline
\end{tabular}


$\underline{\text { Green and Gray Infrastructure }}$

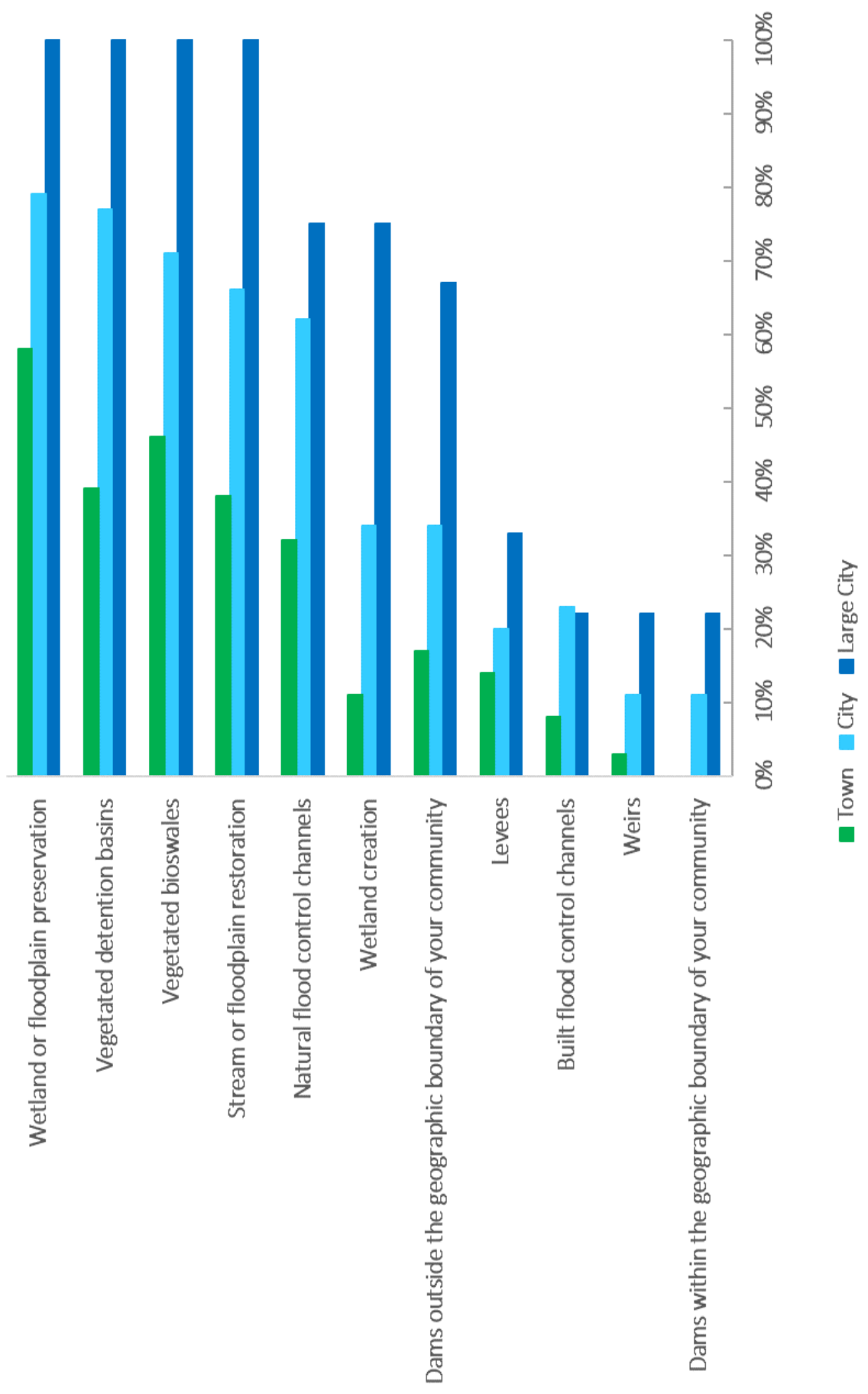

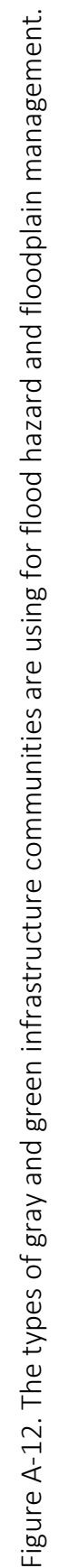


Green / Gray Infrastructure Index

Frequently a community uses a mix of green and gray infrastructure to meet its objectives. To easily compare the amount and types of infrastructures being used, we created a green/gray index from the previous inventories (Table A-17):

- If a respondent answered yes for an item, it was scored 1; if a respondent answered no to an item, it was scored 0

- The scores for both green and gray infrastructure were added together and a one was added to each to prevent issues of dividing by zero

- The mean for each was calculated by dividing the green infrastructure score by six and the gray infrastructure score by five

- To create a ratio, the mean for green infrastructure was divided by the mean for gray infrastructure, as reported below

Table A-17. The minimum, median, mean, and maximum values for the green / gray infrastructure index.

\begin{tabular}{lllll}
\hline Green / Gray Statistics & $\begin{array}{l}\text { Town } \\
(\mathrm{n}=\mathbf{3 6})\end{array}$ & $\begin{array}{l}\text { City } \\
(\mathrm{n}=\mathbf{5 8})\end{array}$ & $\begin{array}{l}\text { Large City } \\
(\mathrm{n}=9)\end{array}$ & All \\
\hline Minimum & 0.2 & 0.3 & 1.2 & 0.2 \\
\hline Median & 1.7 & 2.0 & 2.5 & 1.9 \\
\hline Mean & 2.0 & 2.4 & 2.4 & 2.3 \\
\hline Maximum & 5.0 & 5.8 & 4.2 & 5.8 \\
\hline
\end{tabular}




\section{Planning and Preparation}

There are numerous planning and preparation activities communities implement to manage flood hazards and floodplains. The most prevalent planning and preparation activities are the adoption of a stormwater management plan and maintaining elevation certificates for new construction in the floodplain (Table A-18, Figure A-13). (Question 32)

Table A-18. The planning activities respondents reported their communities using for flood hazard and floodplain management.

\begin{tabular}{|c|c|c|c|c|}
\hline & $\begin{array}{l}\text { Town } \\
(n=29-35)\end{array}$ & $\begin{array}{l}\text { City } \\
(n=50-59)\end{array}$ & $\begin{array}{l}\text { Large City } \\
(\mathrm{n}=8-9)\end{array}$ & All \\
\hline $\begin{array}{l}\text { Maintained elevation certificates for new } \\
\text { construction in the floodplain }\end{array}$ & $60 \%$ & $89 \%$ & $100 \%$ & $80 \%$ \\
\hline Adopted a stormwater management plan & $56 \%$ & $85 \%$ & $89 \%$ & $75 \%$ \\
\hline Adopted a floodplain management plan & $45 \%$ & $56 \%$ & $44 \%$ & $51 \%$ \\
\hline $\begin{array}{l}\text { Established a stream buffer code that } \\
\text { exceeds county requirements }\end{array}$ & $14 \%$ & $28 \%$ & $75 \%$ & $28 \%$ \\
\hline $\begin{array}{l}\text { Required that currently vacant floodplain } \\
\text { parcels will be kept free from development }\end{array}$ & $21 \%$ & $7 \%$ & $0 \%$ & $11 \%$ \\
\hline $\begin{array}{l}\text { Adopted a more restrictive mapping standard } \\
\text { than the National Flood Insurance Program } \\
\text { requirements }\end{array}$ & $3 \%$ & $15 \%$ & $11 \%$ & $10 \%$ \\
\hline
\end{tabular}

Adopted a stormwater management plan

Adopted a floodplain management plan

Established a stream buffer code that exceeds county requirements

Required that currently vacant floodplain parcels will be kept free from development

Adopted a more restrictive mapping standard than the National Flood Insurance Program...
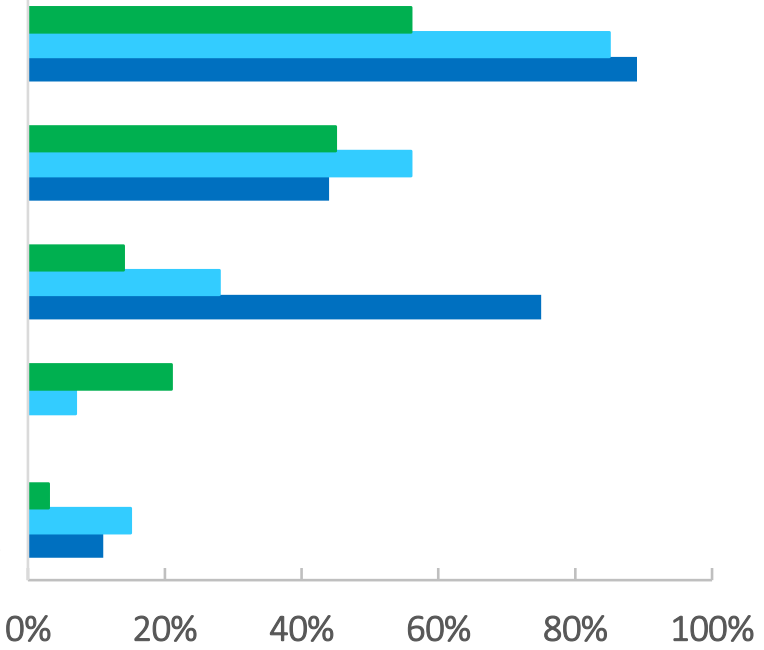

Town City $\square$ Large City

Figure A-13. The planning and preparation activities used by communities to address flood hazard and floodplain management. 


\section{$\underline{\text { Risk Reduction }}$}

There are several risk reduction activities a community may undertake. The majority of communities periodically remove debris from drainage systems and retentions basin, in addition to regulating new development for stormwater runoff and to minimize soil erosion and protect or improve water quality (Table A-19, Figure A-14). (Question 33)

Table A-19. The risk reduction activities respondents reported their communities using for flood hazard and floodplain management.

\begin{tabular}{|c|c|c|c|c|}
\hline & $\begin{array}{l}\text { Town } \\
(n=29-35)\end{array}$ & $\begin{array}{l}\text { City } \\
(n=48-55)\end{array}$ & $\begin{array}{l}\text { Large City } \\
(n=9)\end{array}$ & All \\
\hline $\begin{array}{l}\text { Regulated new development to ensure that } \\
\text { post-development stormwater runoff is no } \\
\text { worse than pre-development runoff }\end{array}$ & $59 \%$ & $94 \%$ & $100 \%$ & $82 \%$ \\
\hline $\begin{array}{l}\text { Regulated new construction to minimize soil } \\
\text { erosion and protect or improve water quality }\end{array}$ & $61 \%$ & $91 \%$ & $100 \%$ & $82 \%$ \\
\hline $\begin{array}{l}\text { Periodically removed debris from all drainage } \\
\text { systems and retention basins }\end{array}$ & $71 \%$ & $82 \%$ & $89 \%$ & $79 \%$ \\
\hline $\begin{array}{l}\text { Required compensatory storage in new } \\
\text { developments in the floodplain }\end{array}$ & $13 \%$ & $40 \%$ & $67 \%$ & $33 \%$ \\
\hline Prohibited any fill in the floodplain area & $21 \%$ & $22 \%$ & $11 \%$ & $20 \%$ \\
\hline $\begin{array}{l}\text { Acquired and/or relocated flood-prone } \\
\text { buildings out of the floodplain }\end{array}$ & $9 \%$ & $15 \%$ & $56 \%$ & $16 \%$ \\
\hline
\end{tabular}

Regulated new construction to minimize soil erosion and protect or improve water quality

Periodically removed debris from all drainage systems and retention basins

Required compensatory storage in new developments in the floodplain

Prohibited any fill in the floodplain area

Acquired and/or relocated flood-prone buildings out of the floodplain
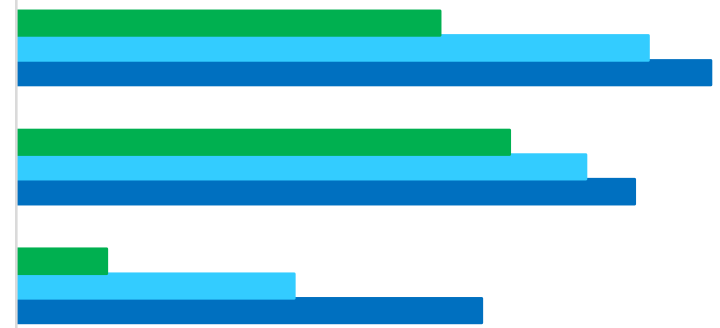

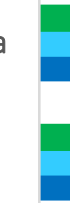

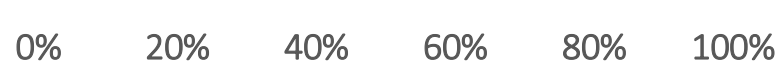

Town City $\quad$ Large City

Figure A-14. Activities communities are pursuing to reduce flood hazard risk. 


\section{Education and Public Awareness}

There are several things communities may do to increase education and public awareness about flood hazard and floodplain management. Most communities provide flood insurance rate maps to those who inquire and also communicate information to residents on flood hazard, flood insurance, or flood protection measures (Table A-20, Figure A-15). (Question 34)

Table A-20. Education and public awareness activities respondents reported their communities using for flood hazard and floodplain management.

\begin{tabular}{lllll}
\hline & $\begin{array}{l}\text { Town } \\
\text { (n=30-35) }\end{array}$ & $\begin{array}{l}\text { City } \\
(\mathrm{n}=49-58)\end{array}$ & $\begin{array}{l}\text { Large City } \\
(\mathrm{n}=9)\end{array}$ & All \\
\hline $\begin{array}{l}\text { Provide Flood Insurance Rate Maps (FIRMs) to } \\
\text { people who inquire }\end{array}$ & $70 \%$ & $95 \%$ & $100 \%$ & $87 \%$ \\
\hline $\begin{array}{l}\text { Communicate information on flood hazard, } \\
\text { flood insurance, or flood protection measures } \\
\text { to residents }\end{array}$ & $60 \%$ & $82 \%$ & $100 \%$ & $76 \%$ \\
\hline $\begin{array}{l}\text { Provide technical assistance on protecting } \\
\text { buildings to property owners who inquire }\end{array}$ & $40 \%$ & $76 \%$ & $78 \%$ & $63 \%$ \\
\hline $\begin{array}{l}\text { Communicate information on the natural and } \\
\text { beneficial function of floodplains to residents }\end{array}$ & $29 \%$ & $63 \%$ & $89 \%$ & $54 \%$ \\
\hline $\begin{array}{l}\text { Maintain current information on flood } \\
\text { insurance and flood protection on our website } \\
\text { or at the public library }\end{array}$ & & & & \\
\hline
\end{tabular}

\section{Communicate information on flood hazard, flood insurance, or flood protection measures to residents}

Provide technical assistance on protecting buildings to property owners who inquire

Communicate information on the natural and beneficial function of floodplains to residents

Maintain current information on flood insurance and flood protection on our website or at the public library
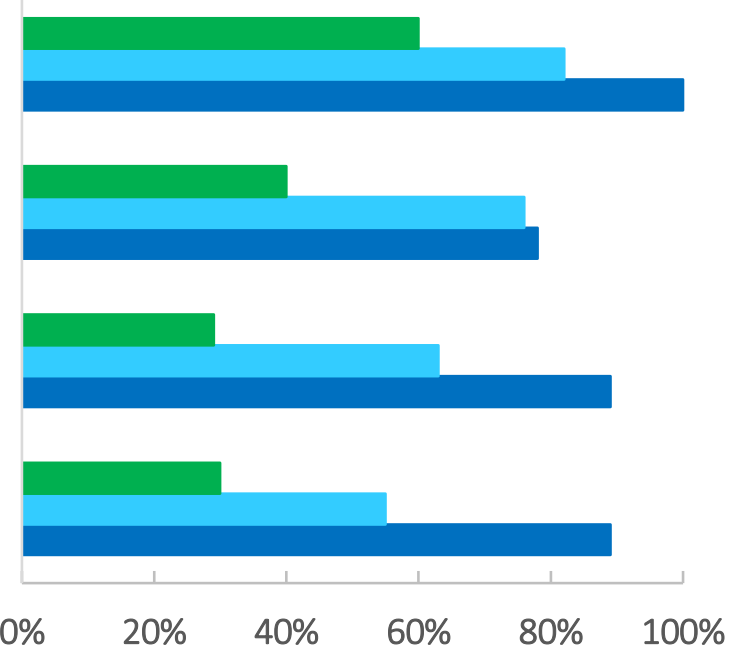

Town City Large City

Figure A-15. Activities to increase education and public awareness about flood hazard and floodplain management. 


\section{Emergency Management Improvements}

A community may implement several emergency management improvements for flood hazard. Providing early flood warning to the public was the most prevalent (Table A-21). (Question 35)

Table A-21. Emergency management improvements implemented for flood hazard.

\begin{tabular}{|c|c|c|c|c|}
\hline & $\begin{array}{l}\text { Town } \\
(n=34)\end{array}$ & $\begin{array}{l}\text { City } \\
(n=50,53)\end{array}$ & $\begin{array}{l}\text { Large City } \\
(n=6,7)\end{array}$ & All \\
\hline Provide early flood warning to the public & $27 \%$ & $52 \%$ & $50 \%$ & $42 \%$ \\
\hline Post signs in hazardous areas & $21 \%$ & $25 \%$ & $29 \%$ & $23 \%$ \\
\hline $\begin{array}{l}\text { Created a detailed flood response plan } \\
\text { keyed to flood crest predictions }\end{array}$ & $12 \%$ & $22 \%$ & $33 \%$ & $19 \%$ \\
\hline
\end{tabular}

\section{Preparedness}

Many respondents felt their community was moderately prepared for a 100-year flood, and only a few respondents in cities felt their community was extremely prepared for a 100 -year flood (Figure A-16). ( $\mathrm{n}=106$, question 36)

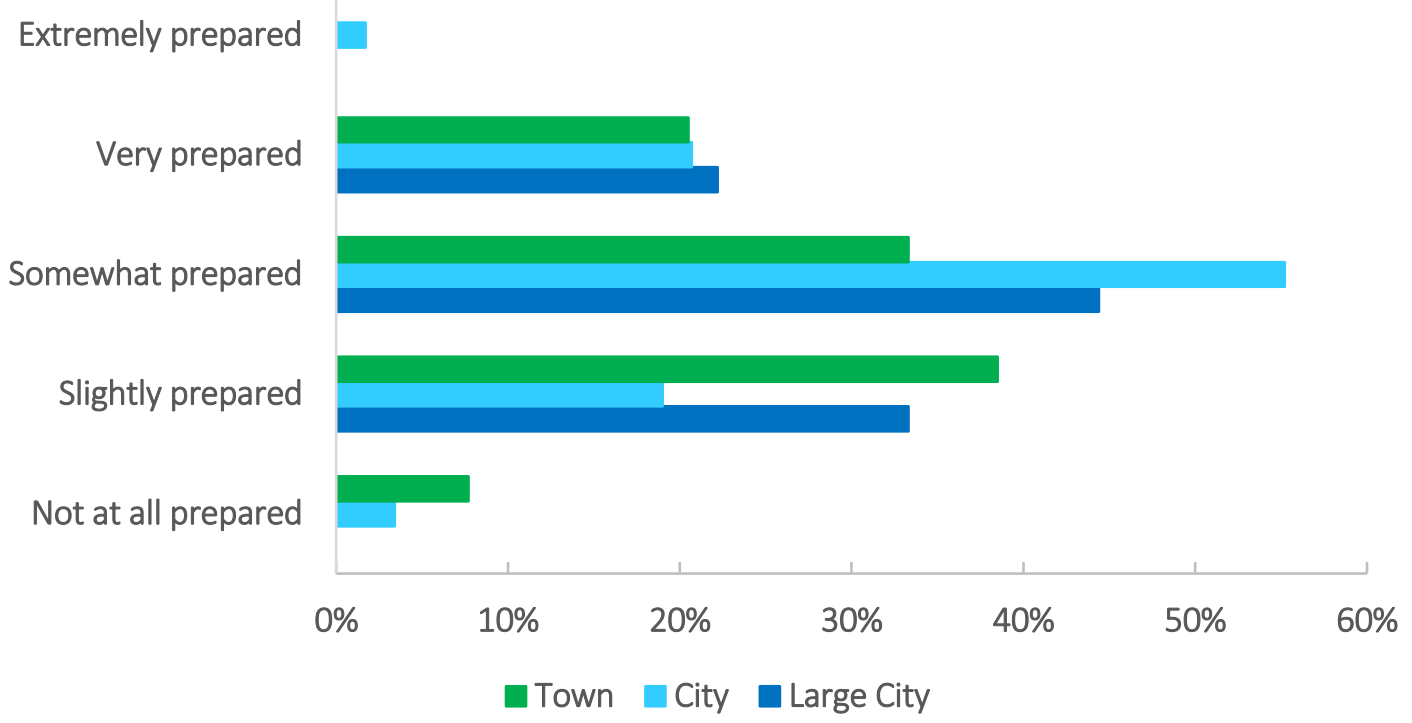

Figure A-16. How prepared for a 100-year flood respondents reported feeling.

When asked what improvements the respondent feels are necessary for their community to better manage flood hazard and floodplains, there were similarities in many responses; the most common were:

- Education for council members, staff, and residents

- Updated Flood Insurance Rate Maps

- Increased staff levels

- Infrastructure improvements or removal (e.g., too small culverts)

- Adoption of flood management plans 
Other responses included:

- "Move our town."

- "Personal responsibility and common sense.... It's frustrating when people KNOW they live in flood prone areas and still act surprised when the creeks rise during heavy rains."

- "Cooperative and informed developers/home builders. The architecture and home builder community [have] no clue and continuously perform a disservice to their clients (the homeowners). They fail to inform their clients of the hazards and additional regulations related to (re)development in the [Special Flood Hazard Area], allowing for projects to reach the permitting stage, only to find out the projects don't meet the regulatory requirements of floodplain development and must be redesigned. This creates a great financial burden upon the clients and make the community look heavy-handed and onerous." 


\section{Section Seven: Beliefs and Attitudes About Flood Hazard and Floodplain Management}

In this section, we asked respondents how they and their communities perceive the practices and consequences of flood hazard and floodplain management.

Flood Hazard and Floodplain Management Benefits

Respondents were asked to assign 100 total points to different benefits flood hazard and floodplain management can provide to a community. Respondents were able to assign as many or as few points as possible to each potential benefit, not to exceed 100 points overall. Overall, flood control and water quality improvement were scored the highest (Table A-22, Figure A-17). (Question 39)

Table A-22. The mean values of potential benefits as reported by respondents.

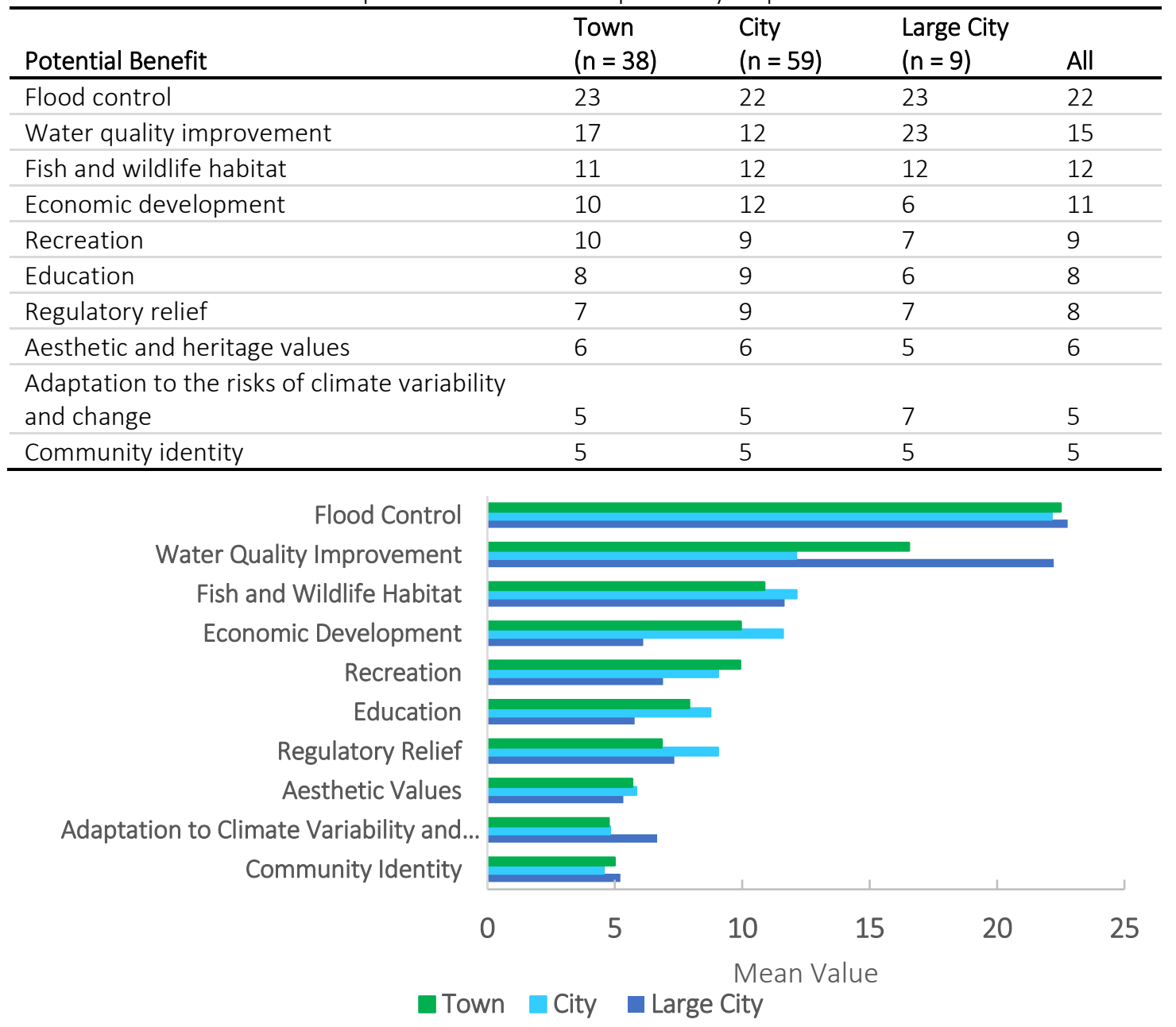

Figure A-17. Mean values for the potential benefits of flood hazard and floodplain management. Flood control, water quality improvement, and fish and wildlife habitat rank the highest for all three community sizes. 
Green Infrastructure Beliefs

There are many factors that contribute to the decision-making process on the types of infrastructure to use, from its perceived efficacy to community response to future goals. Within this context, respondents reported either somewhat or strongly agreeing that in their community, green infrastructure effectively reduces flood risk and is a necessary component of managing floodplains and flood hazard (Table A-23, Figure A-18). (Question 40)

Table A-23. The percentage of respondents who reported somewhat or strongly agreeing with the following dimensions of green infrastructure use in their community.

\begin{tabular}{|c|c|c|c|c|}
\hline & $\begin{array}{l}\text { Town } \\
(n=27-33)\end{array}$ & $\begin{array}{l}\text { City } \\
\left(n=56^{+}\right)\end{array}$ & $\begin{array}{l}\text { Large City } \\
(n=9)\end{array}$ & All \\
\hline provides multiple benefits & $45 \%$ & $84 \%$ & $100 \%$ & $72 \%$ \\
\hline will likely be used more in the future & $50 \%$ & $77 \%$ & $89 \%$ & $69 \%$ \\
\hline effectively manages stormwater & $45 \%$ & $79 \%$ & $89 \%$ & $68 \%$ \\
\hline is compatible with local environmental goals & $44 \%$ & $70 \%$ & $89 \%$ & $63 \%$ \\
\hline $\begin{array}{l}\text { is a necessary component of managing } \\
\text { floodplains and flood hazard }\end{array}$ & $50 \%$ & $63 \%$ & $100 \%$ & $62 \%$ \\
\hline effectively reduces flood risk & $52 \%$ & $64 \%$ & $89 \%$ & $62 \%$ \\
\hline $\begin{array}{l}\text { includes more than stormwater management } \\
\text { facilities }\end{array}$ & $45 \%$ & $63 \%$ & $78 \%$ & $58 \%$ \\
\hline $\begin{array}{l}\text { is an important strategy for adapting to the risks } \\
\text { of climate change and variability }\end{array}$ & $44 \%$ & $61 \%$ & $88 \%$ & $57 \%$ \\
\hline is affordable & $31 \%$ & $52 \%$ & $67 \%$ & $46 \%$ \\
\hline includes all vegetated spaces & $38 \%$ & $41 \%$ & $56 \%$ & $41 \%$ \\
\hline is the best way to meet regulatory requirements & $22 \%$ & $45 \%$ & $67 \%$ & $39 \%$ \\
\hline $\begin{array}{l}\text { is designed to benefit salmon and other native } \\
\text { fish }\end{array}$ & $22 \%$ & $44 \%$ & $67 \%$ & $39 \%$ \\
\hline is valued by residents & $38 \%$ & $30 \%$ & $56 \%$ & $35 \%$ \\
\hline is championed by local leaders & $22 \%$ & $34 \%$ & $56 \%$ & $32 \%$ \\
\hline is easily maintained & $19 \%$ & $39 \%$ & $11 \%$ & $30 \%$ \\
\hline
\end{tabular}

${ }^{+} n=48$ for green infrastructure is designed to benefit salmon and other native fish. 


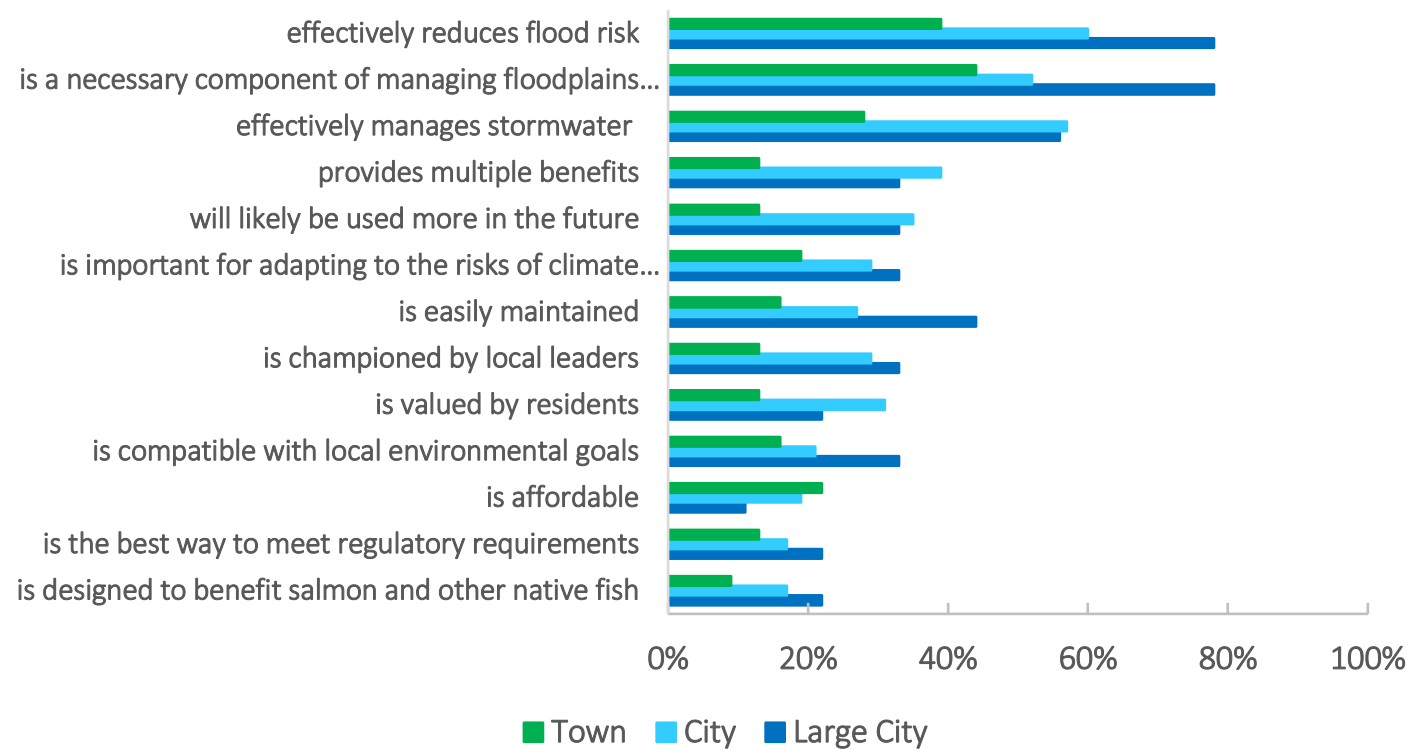

Figure A-18. The percentage of respondents reporting somewhat or strongly agreeing with statements about the use of green infrastructure in their community. 
Gray Infrastructure Beliefs

Many of the same factors contribute to the decision to use gray infrastructure. Overall, respondents favored the use of green rather than gray infrastructure for its efficacy in managing stormwater and flood risk, amongst other items. However, large cities in particular still see gray infrastructure as an effective way of reducing flood risk and managing flood hazard and floodplains, albeit not to the extent described with green infrastructure (Table A24, Figure A-19). (Question 41)

Table A-24. The percentage of respondents who reported somewhat or strongly agreeing with the following dimensions of gray infrastructure use in their community.

\begin{tabular}{|c|c|c|c|c|}
\hline & $\begin{array}{l}\text { Town } \\
(n=31-32)\end{array}$ & $\begin{array}{l}\text { City } \\
(n=51-52)\end{array}$ & $\begin{array}{l}\text { Large City } \\
(\mathrm{n}=9)\end{array}$ & All \\
\hline effectively reduces flood risk & $39 \%$ & $60 \%$ & $78 \%$ & $54 \%$ \\
\hline $\begin{array}{l}\text { is a necessary component of managing } \\
\text { floodplains and flood hazard }\end{array}$ & $44 \%$ & $52 \%$ & $78 \%$ & $52 \%$ \\
\hline effectively manages stormwater & $28 \%$ & $57 \%$ & $56 \%$ & $47 \%$ \\
\hline provides multiple benefits & $13 \%$ & $39 \%$ & $33 \%$ & $29 \%$ \\
\hline will likely be used more in the future & $13 \%$ & $35 \%$ & $33 \%$ & $27 \%$ \\
\hline $\begin{array}{l}\text { is an important strategy for adapting to the risks } \\
\text { of climate change and variability }\end{array}$ & $19 \%$ & $29 \%$ & $33 \%$ & $26 \%$ \\
\hline is easily maintained & $16 \%$ & $27 \%$ & $44 \%$ & $25 \%$ \\
\hline is championed by local leaders & $13 \%$ & $29 \%$ & $33 \%$ & $24 \%$ \\
\hline is valued by residents & $13 \%$ & $31 \%$ & $22 \%$ & $24 \%$ \\
\hline is compatible with local environmental goals & $16 \%$ & $21 \%$ & $33 \%$ & $21 \%$ \\
\hline is affordable & $22 \%$ & $19 \%$ & $11 \%$ & $19 \%$ \\
\hline is the best way to meet regulatory requirements & $13 \%$ & $17 \%$ & $22 \%$ & $16 \%$ \\
\hline $\begin{array}{l}\text { is designed to benefit salmon and other native } \\
\text { fish }\end{array}$ & $9 \%$ & $17 \%$ & $22 \%$ & $15 \%$ \\
\hline
\end{tabular}




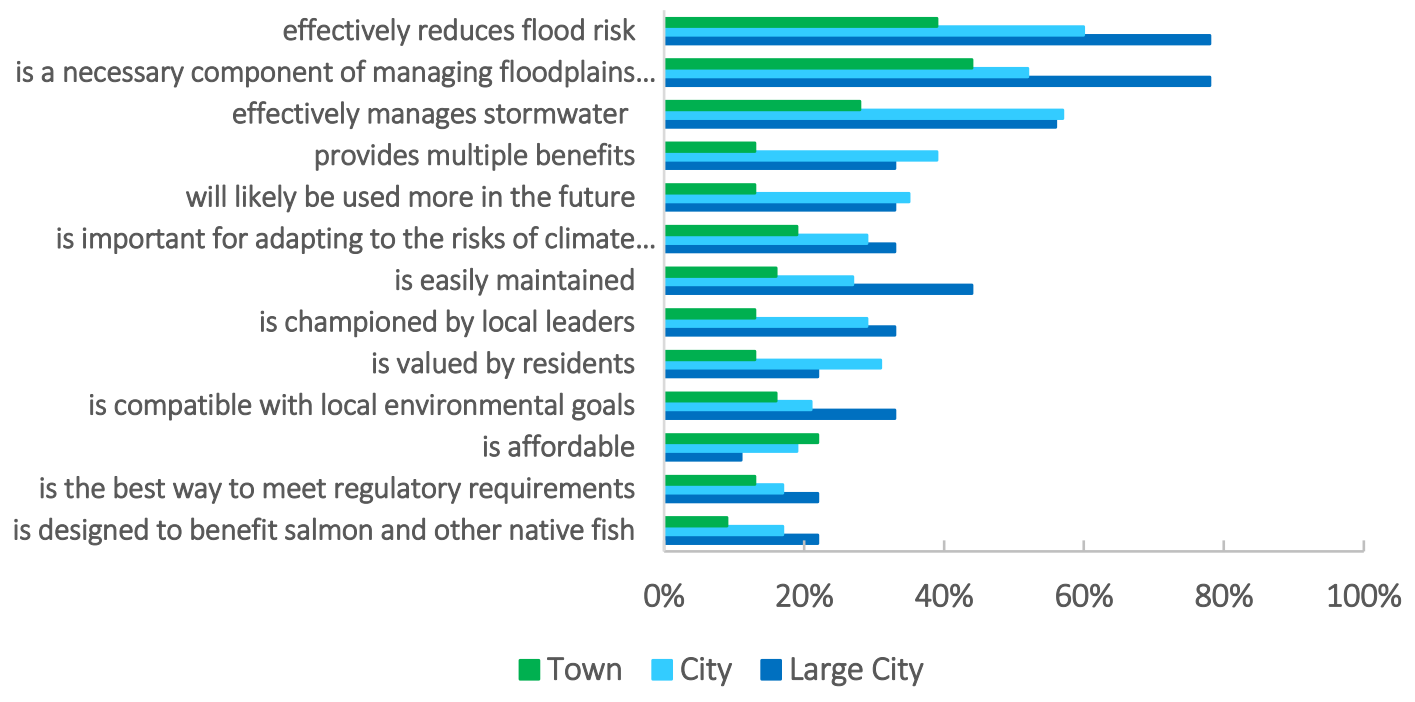

Figure A-19. The percentage of respondents reporting somewhat or strongly agreeing with statements about the use of gray infrastructure in their community. 


\section{Appendix B: Community Data}

We also accessed other data about each community to provide some context to the survey data, such as city finances and residents' income and education levels.

\section{General Fund}

City budgets consist of different funds, such as governmental or general funds. Most operating finances are collected in the general fund; these include revenues such as property taxes and licenses and permits and expenses such as general administration, emergency services, and parks and recreation (Table B-1). $(n=107$, Oregon Secretary of State 2018).

Table B-1. The mean general fund ending revenues, expenses, and balances for fiscal year 2016 (in dollars).

\begin{tabular}{lllll}
\hline & Town & City & Large City & All \\
\hline General fund revenues & 546,387 & $7,670,885$ & $108,023,167$ & $13,514,952$ \\
\hline General fund expenses & 539,585 & $8,141,445$ & $97,037,761$ & $12,847,934$ \\
\hline General fund ending balance & 249,116 & $3,060,981$ & $17,536,962$ & $3,253,701$ \\
\hline
\end{tabular}

\section{Income and Unemployment}

The U.S. Census (2016a) collects income data, including mean, median, and per capita income, as well as employment and unemployment data and poverty levels for a community. In general, each of these increases with the size of the community, with one exception: median income is higher in a smaller city than in a larger city (Table B-2). $(n=107)$

Table B-2. Mean values for median, mean, and per capita incomes for each city size (in dollars).

\begin{tabular}{lllll}
\hline & Town & City & Large City & All \\
\hline Median income & 44,816 & 49,955 & 48,499 & 47,959 \\
\hline Mean income & 56,855 & 61,585 & 63,434 & 60,017 \\
\hline Per capita income & 23,469 & 24,460 & 25,510 & 24,187 \\
\hline Unemployment rate & $5 \%$ & $6 \%$ & $5 \%$ & $5 \%$ \\
\hline Poverty rate & $16 \%$ & $17 \%$ & $18 \%$ & $17 \%$ \\
\hline Employees in public administration & $6 \%$ & $5 \%$ & $4 \%$ & $6 \%$ \\
\hline Government employees & $18 \%$ & $16 \%$ & $15 \%$ & $17 \%$ \\
\hline
\end{tabular}




\section{Education}

The U.S. Census also collects education data-the highest level of education attained by community members. People in larger communities were more likely to obtain a bachelor's or master's degree than those from smaller communities (Table B-3). Additionally, we compared community education levels with education levels of survey respondents and found that regardless of the size of the community, survey respondents were more likely to have at least a bachelor's or master's degree (Figure B-1). $(\mathrm{n}=107)$

Table B-3. Mean values of highest level of education attained within communities.

\begin{tabular}{lllll}
\hline & Town & City & Large City & All \\
\hline High school diploma & $32 \%$ & $28 \%$ & $20 \%$ & $29 \%$ \\
Associate degree & $9 \%$ & $9 \%$ & $9 \%$ & $9 \%$ \\
Bachelor degree & $13 \%$ & $14 \%$ & $19 \%$ & $14 \%$ \\
Graduate or professional degree & $7 \%$ & $9 \%$ & $11 \%$ & $8 \%$ \\
\hline
\end{tabular}




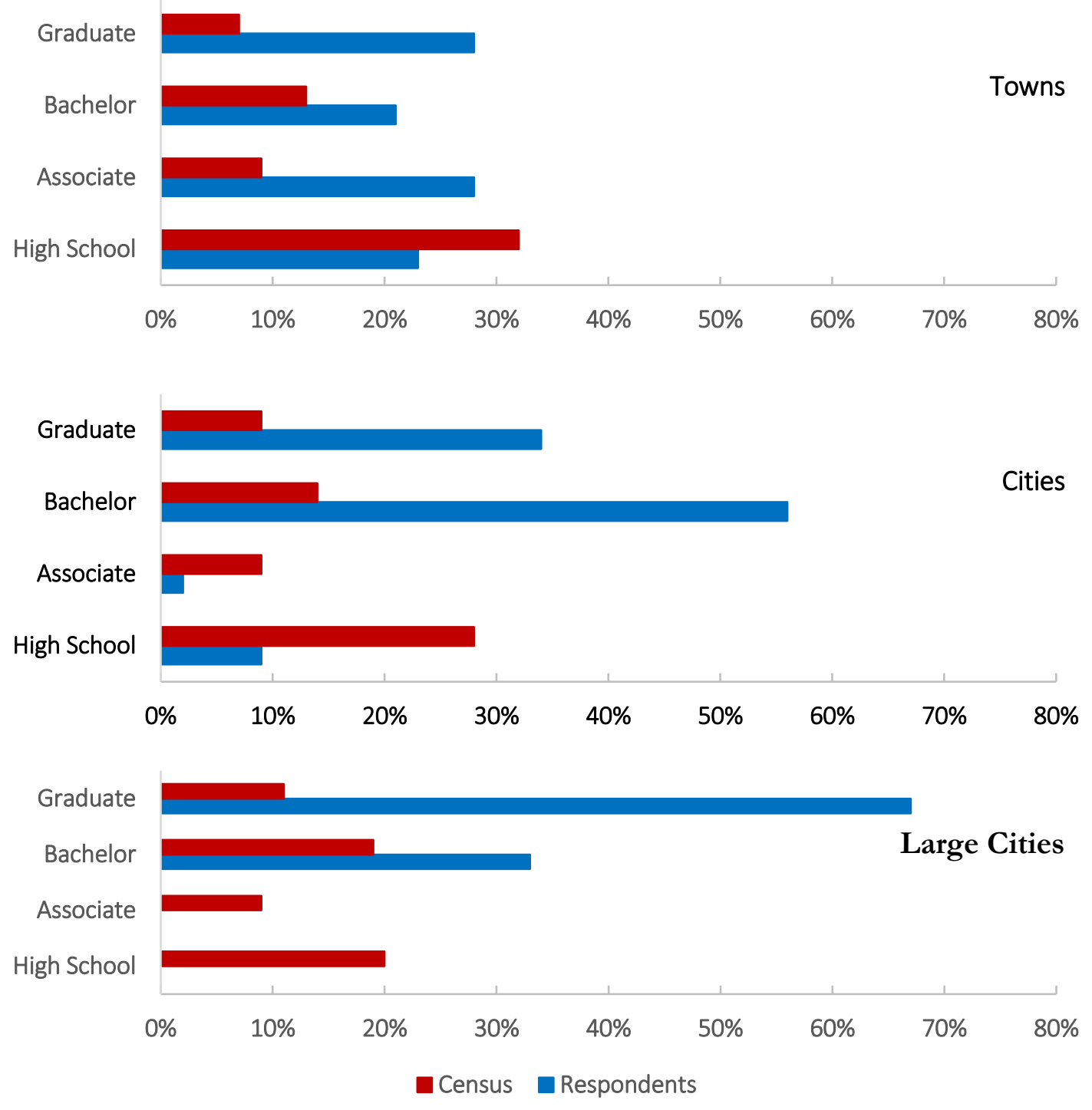

Figure B-1. A comparison of education levels from survey respondents and community members in towns (top), cities (center), and large cities (bottom). 


\section{Appendix C: Additional Survey Responses}

In several questions, respondents were given the opportunity to write in comments, providing the opportunity to expand on their answers. These supplementary responses are collected and categorized below.

\section{Flood Hazard and Floodplain Management Activities and Knowledge}

\section{Flood Hazard and Floodplain Management Activities}

Several respondents wrote in other flood hazard and floodplain management activities they have participated in. These activities are categorized and listed below. ( $\mathrm{n}=7$, question 11)

\section{City Code and Permitting}

- Permits and planning for the city in conjunction with contracted City Planner

- Code writing and updating

- Implementation of floodplain overlay district during development review

\section{FEMA Planning}

- Prepare and process map revisions through FEMA

- Community Rating System (CRS)

- Letter of Map Amendment (LOMA) analyst for FEMA

\section{Land use planning}

- Riparian ordinance adoption

Flood Hazard and Floodplain Management Knowledge

Similarly, several respondents wrote in other flood hazard and floodplain management topics for which they are very or extremely knowledgeable. These topics are categorized and listed below. ( $\mathrm{n}=3$, question 12 )

FEMA

- Flood mitigation codes

- Administration of FEMA mapping information and floodplain elevation certificates

\section{Building code and inspection}

- Building code and floodplain management; certified one and two family-plans examiner; building inspector 


\section{Communities Exemplifying Good Management}

Flood Management Plans

Respondents were asked to list the flood management plans from other communities that exemplify good flood hazard and floodplain management. Most of the communities listed were in western Oregon, with the exception of Prineville (in central Oregon) and Payette County, Idaho (Figure C-1). (Question 23)

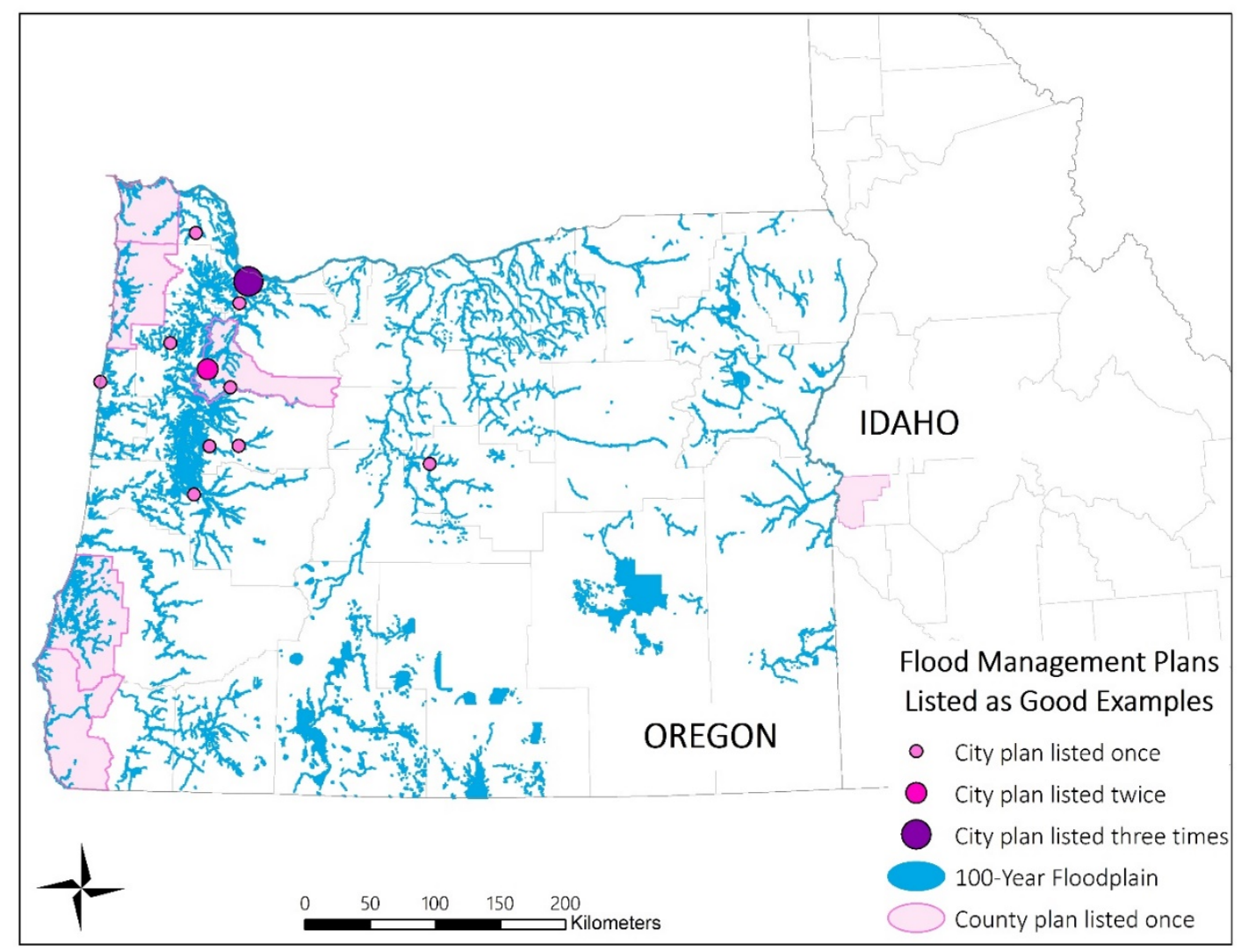

Figure C-1. Map of cities and counties listed by respondents as communities with flood management plans that exemplify good flood hazard and floodplain management. 


\section{$\underline{\text { Best Practices }}$}

Respondents were asked to list communities that are good examples of the best practices in flood hazard and floodplain management. In addition to naming several communities in Oregon, respondents also reported three out-of-state communities as being exemplars of best practices in flood hazard and floodplain management; these communities and respondents' descriptions, are reported below (Figure C-2, question 38):

- Skagit County, Washington: "Skagit County has an annual flood awareness week and 'flood fight teams' that train annually so that all staff are prepared when a flood occurs."

- Roseville, California: "[Rated 1] in the CRS." As described earlier, the Community Rating System, or CRS, is a voluntary FEMA program to incentivize flood hazard and floodplain management activities that surpass the NFIP requirements with discounts on flood insurance. Communities that join the CRS are rated from 1 (the highest rating) to ten (entry level); higher ratings indicate increased management activities and higher insurance discounts.

- North Carolina: "[North Carolina] has a great state floodplain mapping program. The state has taken over mapping from FEMA and have tons of data about vulnerability that can be used to automate and inform Hazus runs." Hazus is free spatial software available from FEMA that allows communities to model the estimated potential physical, economic, social, losses from floods, tsunamis, hurricanes, and other natural hazards. 


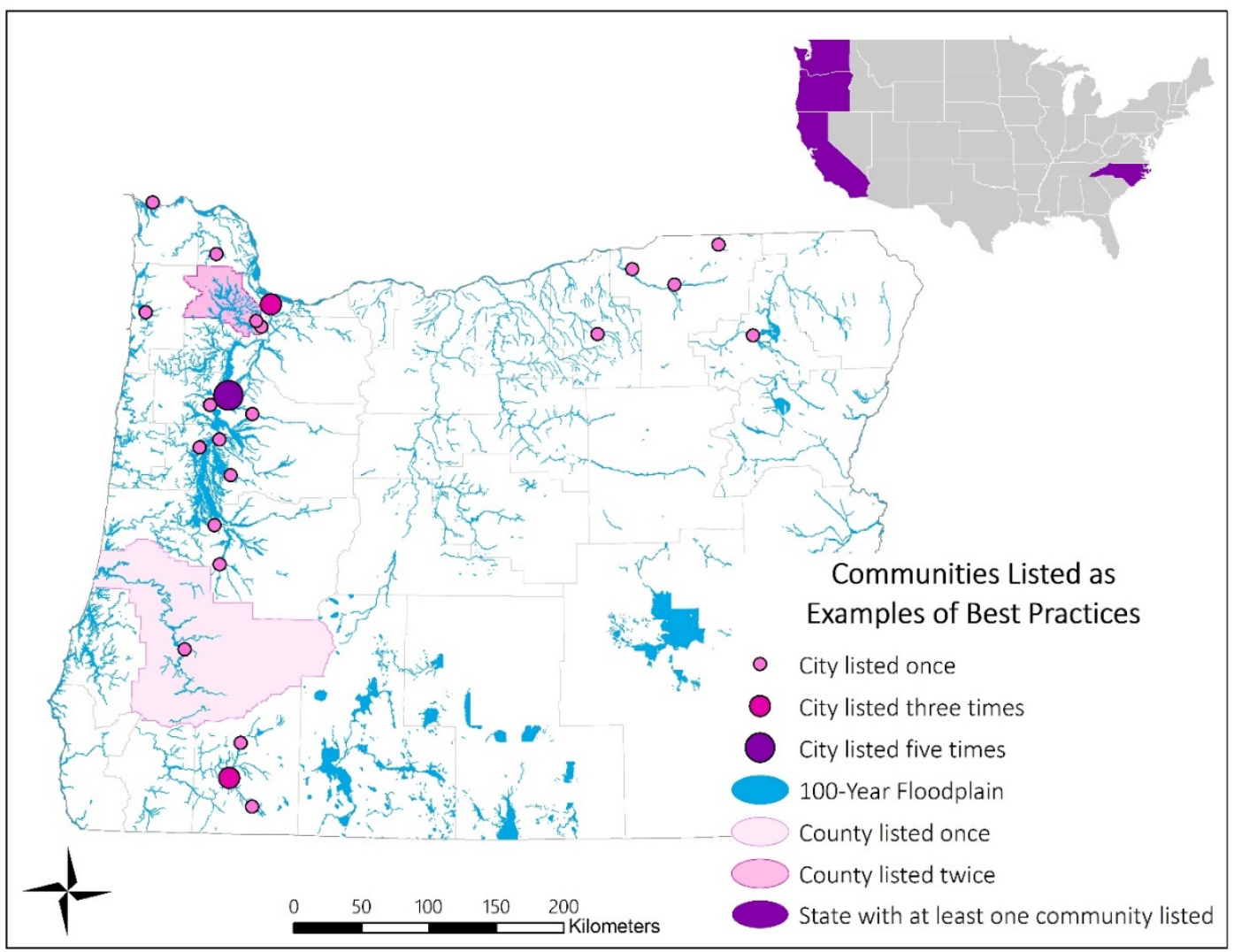

Figure C-2. Communities listed as exemplifying best practices in flood hazard and floodplain management, including communities in Oregon, Washington, California, and the state of North Carolina. 


\section{Management Priorities}

When asked about their community's priorities for flood hazard and floodplain management decision making, two respondents provided two other priorities: Education and outreach, and protecting property rights. (Question 27)

Respondents were asked how the priorities for this decision making have changed over time. Eleven respondents provided these details, which were then categorized. (Question 28)

\section{Improving Development and Zoning}

- "The community is completely built out and most local floodplains are constrained by residential development that predates the floodplain designation. Floodplain management efforts are almost entirely focused upon management of redevelopment (tear-down and rebuild) of older homes. In that sense, the new structures are built to current floodplain development standards and older structures in the floodplain are incrementally being replaced.

- "In the last [seven] years, the city has improved zoning related to flood protections in riparian areas and experienced a leadership change that values public investment in infrastructure projects, ... specifically on their own properties."

\section{Improving Stormwater Management}

- "Current city management has recognized city-wide benefits of hazard management. Supportive floodplain management program, as well as public works projects to improve floodplain natural and beneficial functions through construction of storm overflow areas."

- "Certainly, this is an important area that I look forward to addressing at some point. I've spoken with the major about the need to create a storm drainage fund in our budget - not just a line item in the general fund - and to start building funds there to increase the capacity of our storm drainage system. I'm interested in exploring bioswales and some of the other options that might be available to help us manage our stormwater safely. However, we have several pressing infrastructure projects and I wear many hats. This is most likely something we will have capacity to dig into within the next 3-4 years."

\section{Supporting Multiple Benefits}

- "With increasing concern about environmental issues (e.g., [NOAA] NFIP BiOp and [Clean Water Act Stormwater Management] Phase II requirements), there has been increasing emphasis on meeting multiple objectives through floodplain management in partnership with other program areas (e.g., stormwater, hazard mitigation planning, and zoning requirements)."

- 'We've started incorporating multiple purpose modeling into development of [capital improvement plans] so that we're ranking each project for its comparative benefits to the natural environment, public safety, infrastructure risk reduction, etc. We're working closely with DLCD and other Oregon jurisdictions in developing updated model floodplain ordinance language to bring code into compliance with 
NOAA BiOp performance standards. [We] may become [an] early adopter community (that's under discussion with DLCD, NOAA Fisheries, and FEMA)."

- "Provide multiple benefits has become more important."

- "More emphasis is being placed on projects that provide multiple benefits; e.g., flood mitigation, habitat restoration, ecological benefits, etc."

- "Meeting multiple benefits and cost effectiveness are guiding principles that include many of the other factors listed [in question 27] (effectiveness, project lifespan, meeting environmental goals, etc.). Priorities are always changing."

\section{Miscellaneous}

- "Priories change with regulation, experience, and known/experienced impacts."

- "Flood [sic] was a Goal 5 and [Goal] 7 issue for Oregon. Our regulations did not consider the close coordination needed with FEMA. FEMA changes in Biggert Waters [Flood Insurance Reform Act] and the recent [NOAA] Biological Opinion have caused impacts to insurance costs and changes in federal actions forcing changes in local activities. It is still evolving." 


\section{Green Infrastructure and Native Fish}

Respondents were asked about their perceptions of green and gray infrastructure. This included a question about whether green infrastructure is designed to benefit salmon and other native fish - and if so, what specific actions is the community taking. We broadly categorized these responses into seven groups, although there is substantial overlap in several answers ( $n=20 ; 13$ of 33 that responded somewhat or strongly agree to the question did not write in an answer, question 40).

$\underline{\text { Fish ladder }}$

- "Completing installation of a fish ladder in [a local creek]."

\section{Planning}

- "Our County has adopted [a] salmon recovery plan."

\section{Preservation}

- "Our City has purchased or [received] donated wetland areas in the past to hold in a protected state instead of them being potential development sites that would take them out of the green system."

- "We have a riparian corridor overlay along all stream banks which limits development within 50 feet of stream banks. We limit development within the 100year floodplain and require larger minimum lot sizes for any construction activities, which naturally deters development there."

- "Willing seller acquisition of structures in the floodplain, then restoration/reconnection, followed by designation as open space in perpetuity."

\section{$\underline{\text { Regulation }}$}

- "Recently, the City's design standards have been updated to require post construction BMPs [best management practices] for a development that disturbs more than $1,000 \mathrm{ft}^{2}$."

- "[Our City] continues to develop regulations and recommendations to ensure a healthy fish population."

- "Comprehensive update of sensitive lands' regulations."

\section{$\underline{\text { Restoration }}$}

- "I think the community has taken large strides in reducing pollution and lowering river temperatures by enhancing river banks and retention ponds."

- "Worked with ODOT on creek restoration projects."

- "Removing barriers, restoring habitat, wetlands."

\section{$\underline{\text { Riparian }}$}

- "Vegetated corridors and stormwater treatment."

- "Riparian zone is an adopted overlay where only native restoration activities and public uses such as trails [are] allowed." 
- "Code is in place to require water quality features on new stormwater systems and retain native vegetation buffers along riparian and wetland areas. Also partner with the [local] Watershed Council to provide native plants to owners of property along these natural features."

- "The primary action is to preserve and enhance riparian vegetation along stream corridors."

- "Required stream buffers and natural resource protections. LID [low impact development] approach to stormwater management is required per adopted

Stormwater Management Manual. Adopted and enforced tree protection code."

\section{Stormwater}

- "Our community requires new development to use green infrastructure to manage volume and water quality. This is vital to mitigating impacts from new development as it occurs. The City has also identified several green infrastructure CIP [capital improvement plan] projects that are part of the Stormwater Management Plan. These will improve water quality and start mitigating peak volume discharge during storm events."

- "Storm drainage improvements along [two local creeks] designed to benefit native fish [were] focus of [the] Capital Improvement Plan over [the] last eight years."

- "Stormwater does not enter river pathways."

- "Water quality monitoring is tied to discharges meeting criteria for salmonids. Stormwater [Management Department] works in partnership with Natural Resources [Department] to include stormwater retrofit opportunities in stream and wetland restoration planning." 


\section{Appendix D: Survey Instrument}

\section{\& Portland State}

1. Welcome to FINS, the Floodplain Infrastructure Survey!

Thank you for your interest in this research from Portland State University in Portland, Oregon. Your participation is very valuable to us as it helps ensure that we have a representative sample of communities throughout Oregon.

The questions we are asking have to do with community flood hazard and floodplain management. What we learn will be made available to floodplain managers, community leaders, planners, and policy makers.

Participation is completely voluntary. We estimate that the survey should take between 20 to 30 minutes of your time. The information you provide is completely confidential and we foresee no risk to you from participating in this study. Your responses will not be attributed to you in any reports or publications, but instead will be reported as statistical summaries.

To begin taking this survey, please enter your 4 digit access code below, then click on the button on the bottom right marked "Next" to indicate your consent to participate and start the survey. Thank you!

If you have questions about the study, please contact Samantha Hamlin at shamlin@pdx.edu or (971) 801-2636.

If you have concerns or questions about your participation in this study or about your rights as a research participant, please contact the Human Subjects Research Review Committee at:

Portland State University

Office of Research Integrity

1600 SW Fourth Ave., Market Center Building, Suite 620

Portland, OR 97201

(503) $725-2227$ or (877) $480-4400$

An access code was included in the email you received. Please enter this 4-digit access code below: 
2. For a community to be part of the National Flood Insurance Program (NFIP), the Federal Emergency Management Agency (FEMA) requires that the community has a designated floodplain administrator. While recognizing that there are other people in a community that play a role in flood hazard and floodplain management, we are specifically surveying floodplain administrators.

3. Are you the designated floodplain administrator for your community?

O Yes

O No. If no, can you provide the name and email address of the person who is?

4. What is your position title?

5. How many years have you been the floodplain administrator for your community?

6. Have you worked as a floodplain administrator in another community?

O No

Yes; how many years: 


$$
\begin{aligned}
& \text { 7. Are you a Certified Floodplain Manager? } \\
& \text { O Yes } \\
& \text { O No }
\end{aligned}
$$

8. Are you now, or have you ever been, a member of a floodplain management association?

For example, the Northwest Regional Floodplain Management Association (NORFMA), the Association of State Floodplain Managers (ASFPM), or the Floodplain Management Association (FMA)

O Yes

O No

9. What is the highest level of formal education you have completed?

O Less than high school diploma

O High school diploma

O Associate degree

O Four-year college degree (e.g., BA, BS)

O Master's degree (e.g., MS, MPA, MBA)

O Doctorate degree (e.g., JD, PhD, or equivalent)

10. What is your age?
O 24 or younger
O $25-34$
O $35-49$
O $50-64$
O 65 or older 


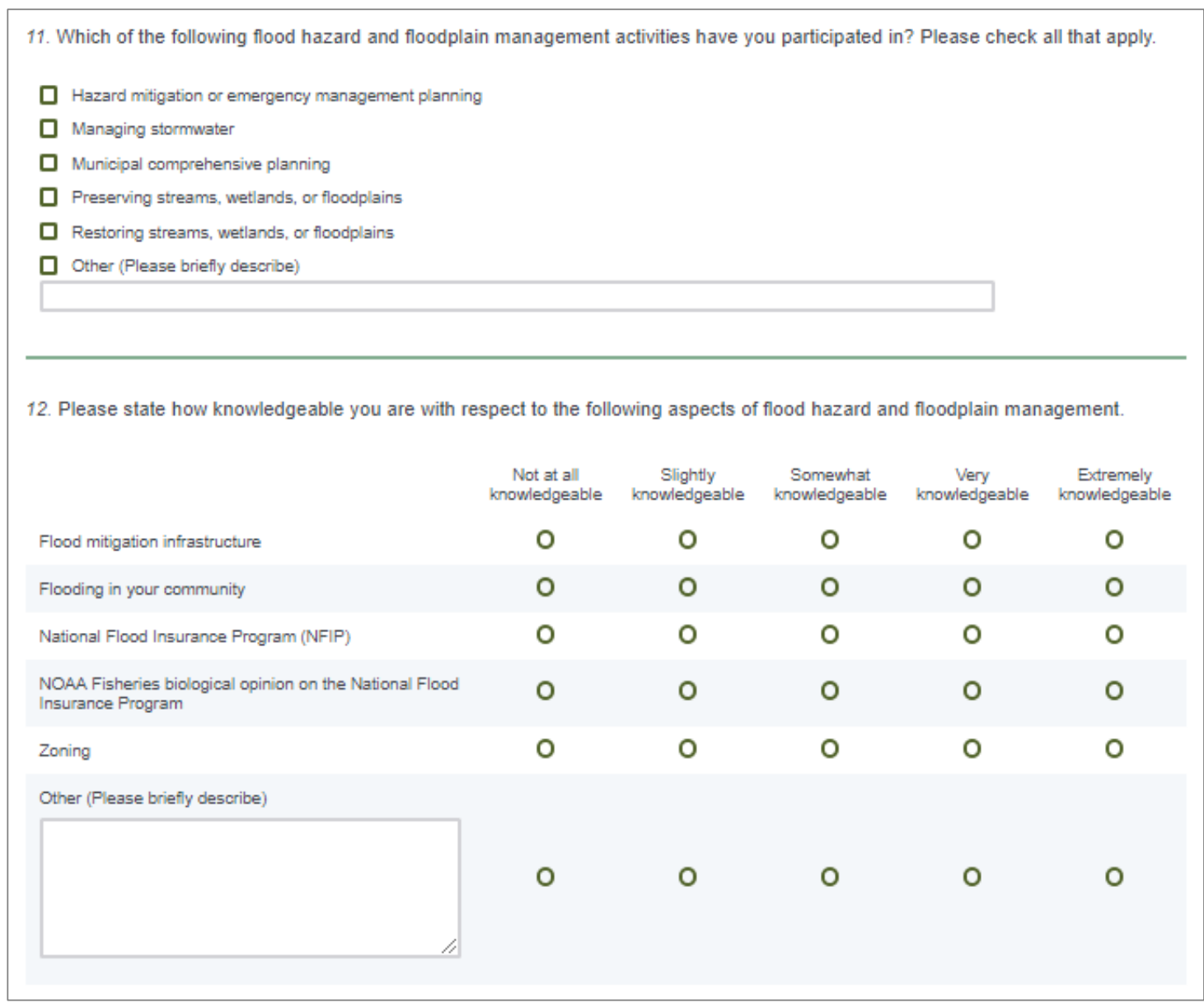


13. In this section, we're going to ask you about your community's experience with flooding. Here are three definitions for questions we ask you:

- Nuisance flooding is defined as small events that cause road closures, overvhelmed storm drains, and infrastructure deterioration, such as seen on bridges or roads.

- A 100-year flood is a relatively rare flood event. It is also known as a base flood or a one-percent flood because it has a one percent chance of being equaled or exceeded during any given year.

- A federal flood disaster is declared by the President following a request by a state governor. A flood is declared a federal disaster when its severity is beyond the combined capabilities of state and local governments to respond. A federal flood disaster declaration provides a wide range of federal assistance programs for individuals and public infrastructure, including funds for both emergency and permanent work.

14. Please estimate how many nuisance flood events your community has experienced over the previous two water years (from October 2014 to September 2016).
0
O $1-5$
O $6-10$
O More than 10
O Don't know

15. During your tenure as the floodplain administrator, how many 100 -year floods have there been in your community?
0
O 1
02
O $3-5$
O More than 5
O Don't know

16. If there haven't been any during your tenure, do you know when the last 100 -year flood happened in your community?

O Yes (If yes, please provide year, if known)

O No 
17. During your tenure as the floodplain administrator, how many federal flood disaster declarations have there been in your community?
00
O 1
O 2
O $3-5$
O More than 5
O Don't know

18. If there haven't been any during your tenure, do you know when the last federal flood disaster declaration occurred in your community?

Yes (If yes, please provide year, if known)

O No

19. In this section, we're going to ask about shared information or collaborations your community might have with other communities.

20. What are the three most important sources of information for you in flood hazard and floodplain management? For example, this may include (but aren't limited to):

- A person (please include name, job title, and organization)

- A document (please include title)

- An organization (please include organization name)

- Another community (please include community name)

Information source:

Information source:

Information source:

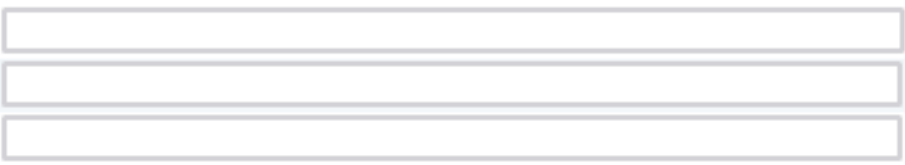


21. Does your community have a flood management plan?

O Yes. If yes, what year was it written?

O No

O Don't know

22. Have you read other communities' flood management plans?

O Yes

O Maybe

O No

23. If yes, please list up to five flood management plans from other communities that you think exemplify good flood hazard and floodplain management.
Plan 1
Plan 2
Plan 3
Plan 4
Plan 5

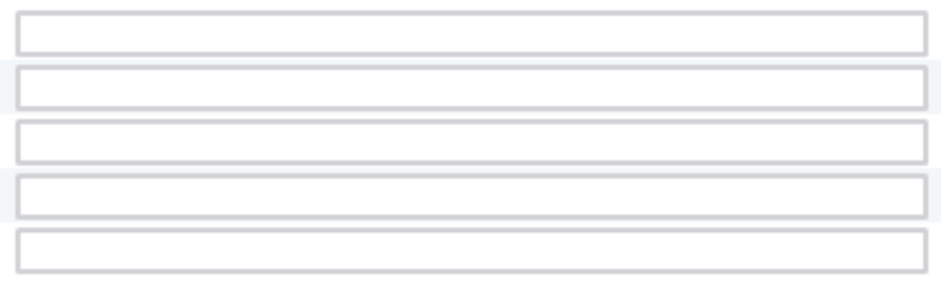


24. How often do you talk to representatives from other communities about their approach to flood hazard and floodplain management?
More than once a week
Ot least weekly
At least monthly
Every few months
O At least once a year
O Less than once a year
O Not sure

25. Does your community have intergovernmental agreements related to flood hazard or floodplain management (for example, with a neighboring community or state agency)?
O Yes
No
Don't know

26. If you answered yes to the previous question, please list up to the five most important agreements. Include the name of the entity and 1-2 sentences describing the purpose of the agreement.

Agreement 2




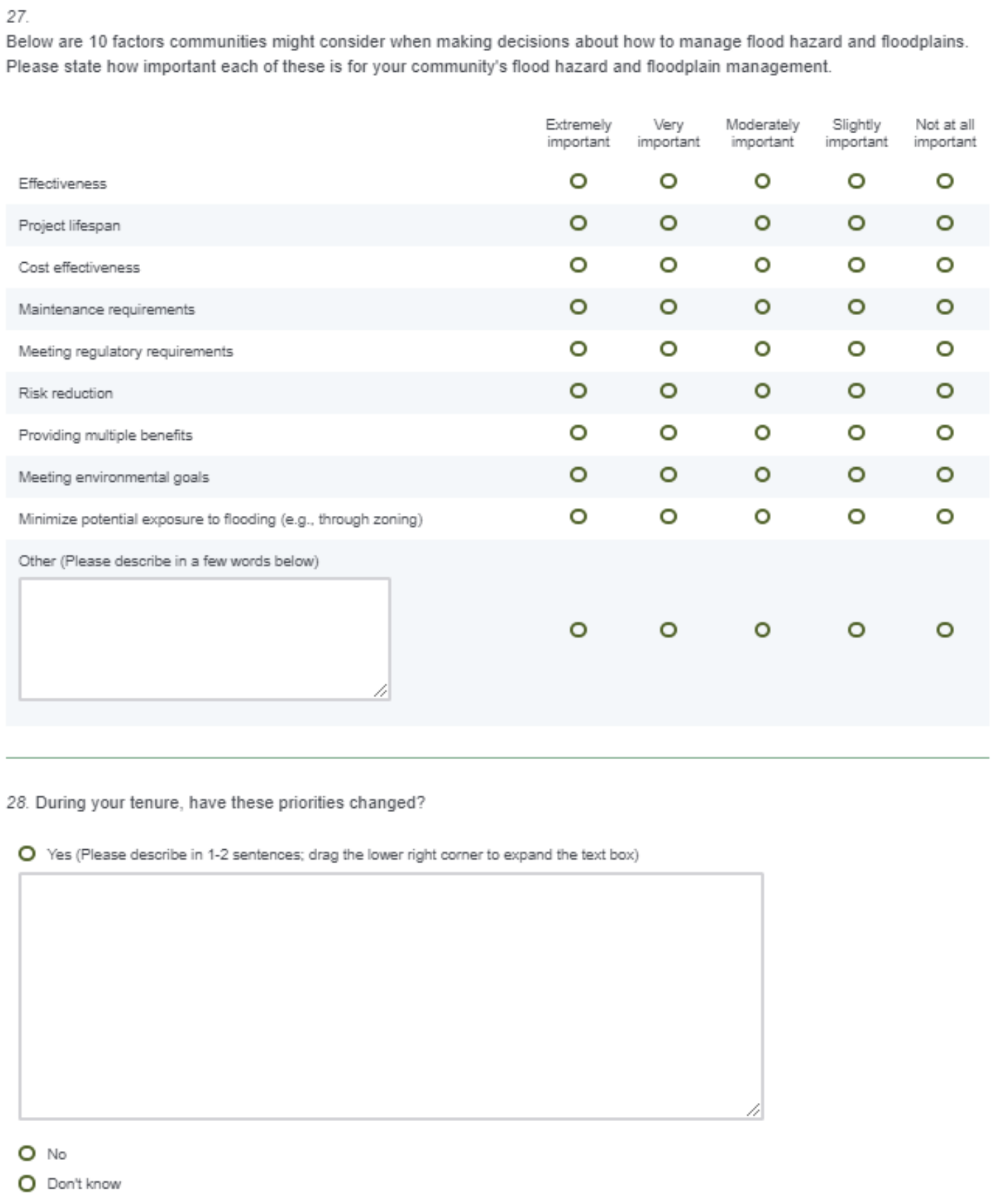


29. In this section, we're going to ask you about actions or approaches your community has taken for flood hazard and floodplain management. This includes actions related to stormwater management, which can affect the frequency of nuisance flooding.

30. Does your community rely on any of the following types of gray infrastructure for flood hazard mitigation?

$\begin{array}{llll} & \text { Yes } & \text { No } & \text { Don't Know } \\ \text { Built flood control channels } & 0 & 0 & 0 \\ \text { Weirs } & 0 & 0 & 0 \\ \text { Levees } & 0 & 0 & 0 \\ \text { Dams within the geographic boundary of your community } & 0 & 0 & 0 \\ \text { Dams outside of the geographic boundary of your community } & 0 & 0 & \\ \end{array}$

31. Does your community rely on any of the following types of green infrastructure for stormwater and floodplain management?

\begin{tabular}{llll} 
& Yes & No & Don't know \\
Vegetated bioswales & 0 & 0 & 0 \\
Vegetated detention basins & 0 & 0 & 0 \\
Natural flood control channels & 0 & 0 & 0 \\
Stream or floodplain restoration & 0 & 0 & 0 \\
Wetland or floodplain preservation & 0 & 0 & 0 \\
Wetland creation & 0 & 0 & 0 \\
\hline
\end{tabular}


32. Has your community undertaken any of the following planning and preparation activities?

$\begin{array}{llll}\text { Adopted a stormwater management plan } & \text { Yes } & \text { No } & \text { Don't know } \\ \text { Adopted a floodplain management plan } & 0 & 0 & 0 \\ \begin{array}{l}\text { Adopted a more restrictive mapping standard than the National } \\ \text { Flood Insurance Program requirements }\end{array} & 0 & 0 & 0 \\ \begin{array}{l}\text { Required that currently vacant floodplain parcels vill be kept free } \\ \text { from development }\end{array} & 0 & 0 & 0 \\ \begin{array}{l}\text { Established a stream buffer code that exceeds county requirements } \\ \begin{array}{l}\text { Maintained elevation certificates for new construction in the } \\ \text { floodplain }\end{array}\end{array} & 0 & 0 & 0\end{array}$

33. Has your community implemented any of the following flood risk reduction activities?

Prohibited any fill in the floodplain area
$\begin{aligned} & \text { Aoquired and/or relocated flood-prone buildings out of the } \\ & \text { floodplain }\end{aligned}$
$\begin{aligned} & \text { Periodically removed debris from all drainage systems and } \\ & \text { retention basins }\end{aligned}$




\begin{tabular}{|c|c|c|c|}
\hline \multicolumn{4}{|c|}{ 34. Does your community conduct any of the following education and public awareness activities? } \\
\hline & Yes & No & Don't know \\
\hline $\begin{array}{l}\text { Provide Flood Insurance Rate Maps (FIRMs) to people who } \\
\text { inquire }\end{array}$ & 0 & 0 & O \\
\hline $\begin{array}{l}\text { Communicate information on flood hazard, flood insurance, or } \\
\text { flood protection measures to residents }\end{array}$ & 0 & 0 & O \\
\hline $\begin{array}{l}\text { Communicate information on the natural and beneficial functions } \\
\text { of floodplains to residents }\end{array}$ & $\mathrm{O}$ & O & O \\
\hline $\begin{array}{l}\text { Maintain current information on flood insurance and flood } \\
\text { protection on our website or at the public library }\end{array}$ & 0 & $\mathrm{O}$ & $\mathrm{O}$ \\
\hline $\begin{array}{l}\text { Provide technical assistance on protecting buildings to property } \\
\text { owners who inquire }\end{array}$ & 0 & $\mathrm{O}$ & O \\
\hline \multicolumn{4}{|c|}{$\begin{array}{l}\text { 35. Has your community established or improved any of the following emergency management improvements for } \\
\text { flood hazard? }\end{array}$} \\
\hline & Yes & No & Don't know \\
\hline Provide early flood warning to the public & O & 0 & O \\
\hline $\begin{array}{l}\text { Created a detailed flood response plan keyed to flood crest } \\
\text { predictions }\end{array}$ & 0 & 0 & o \\
\hline Post signs in hazardous areas & O & O & O \\
\hline
\end{tabular}


36. How prepared do you believe your community is for a 100 -year flood?

O Not at all prepared

O Slightly prepared

O Somewhat prepared

O Very prepared

O Extremely prepared

37. What improvements do you believe are necessary for your community to better manage flood hazard and floodplains?

38. Please list up to 5 communities you think are good examples of the best practices in flood hazard and floodplain management. Provide a 1-3 sentence description for each community.

\begin{tabular}{l|l|l|l|l|}
\hline & $\begin{array}{c}\text { Community Name, } \\
\text { State }\end{array}$ \\
\hline Community 2 & $\begin{array}{c}\text { Brief description of what makes this community a good example of best } \\
\text { practices in flood hazard and floodplain management }\end{array}$ \\
\hline Community 3 & & \\
\hline
\end{tabular}


39. Flood hazard and floodplain management can often provide multiple benefits to a community. Please assign 100 total points to reflect which benefits are provided by your community's approach to flood hazard and floodplain management.

Listed below are 10 potential benefits your community's approach to flood hazard and floodplain management may provide. You may assign as little as 0 points or as many as 100 points to a benefit if that is the only benefit you view as important to your community. If all benefits are valued equally, please assign 10 points to each.

Flood control

Economic development

Community identity

Aesthetic and heritage values

Adaptation to the risks of a climate variability and change

Education

Recreation

Fish and wildlife habitat

Water quality improvement

Regulatory relief

Total 


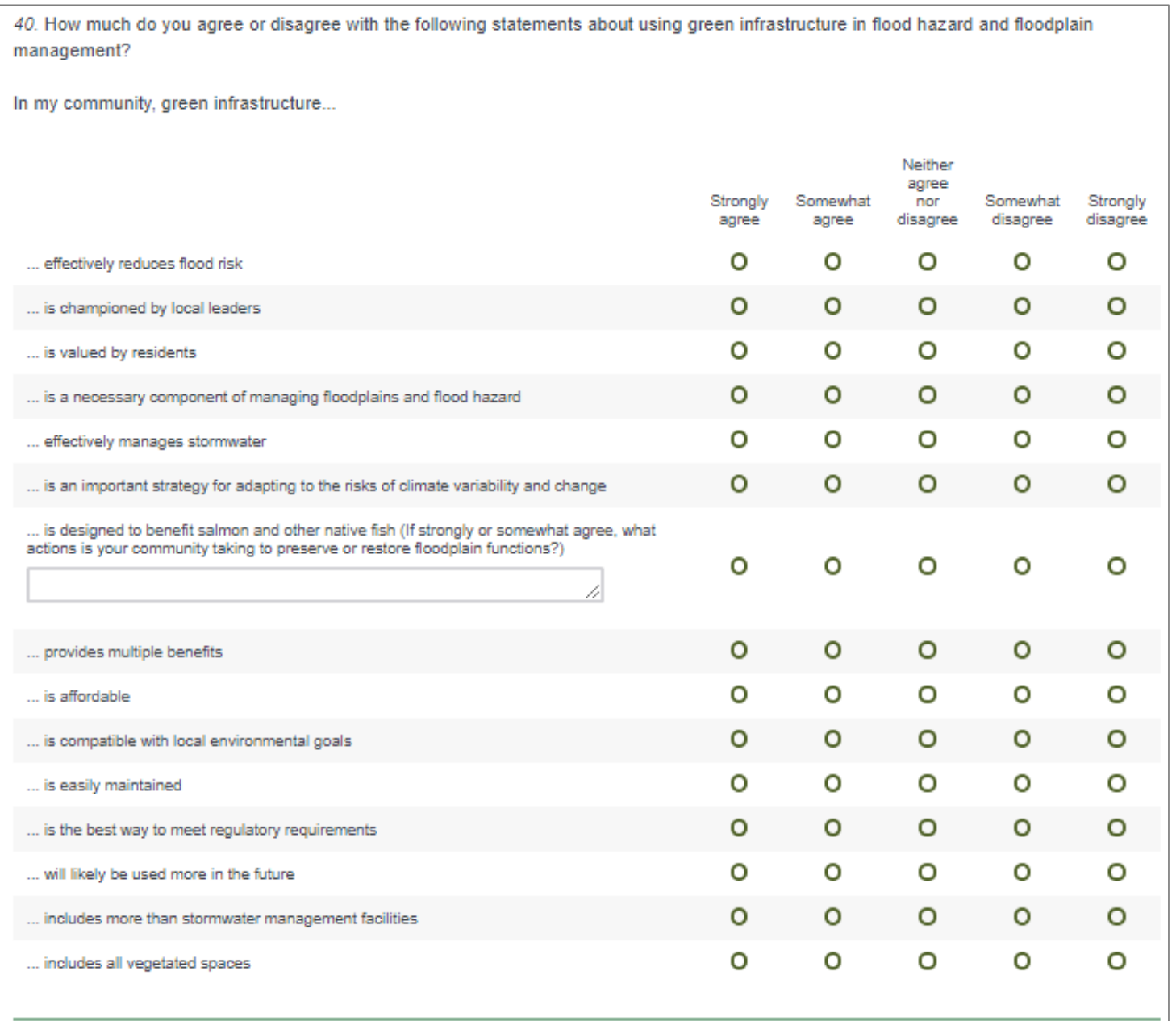




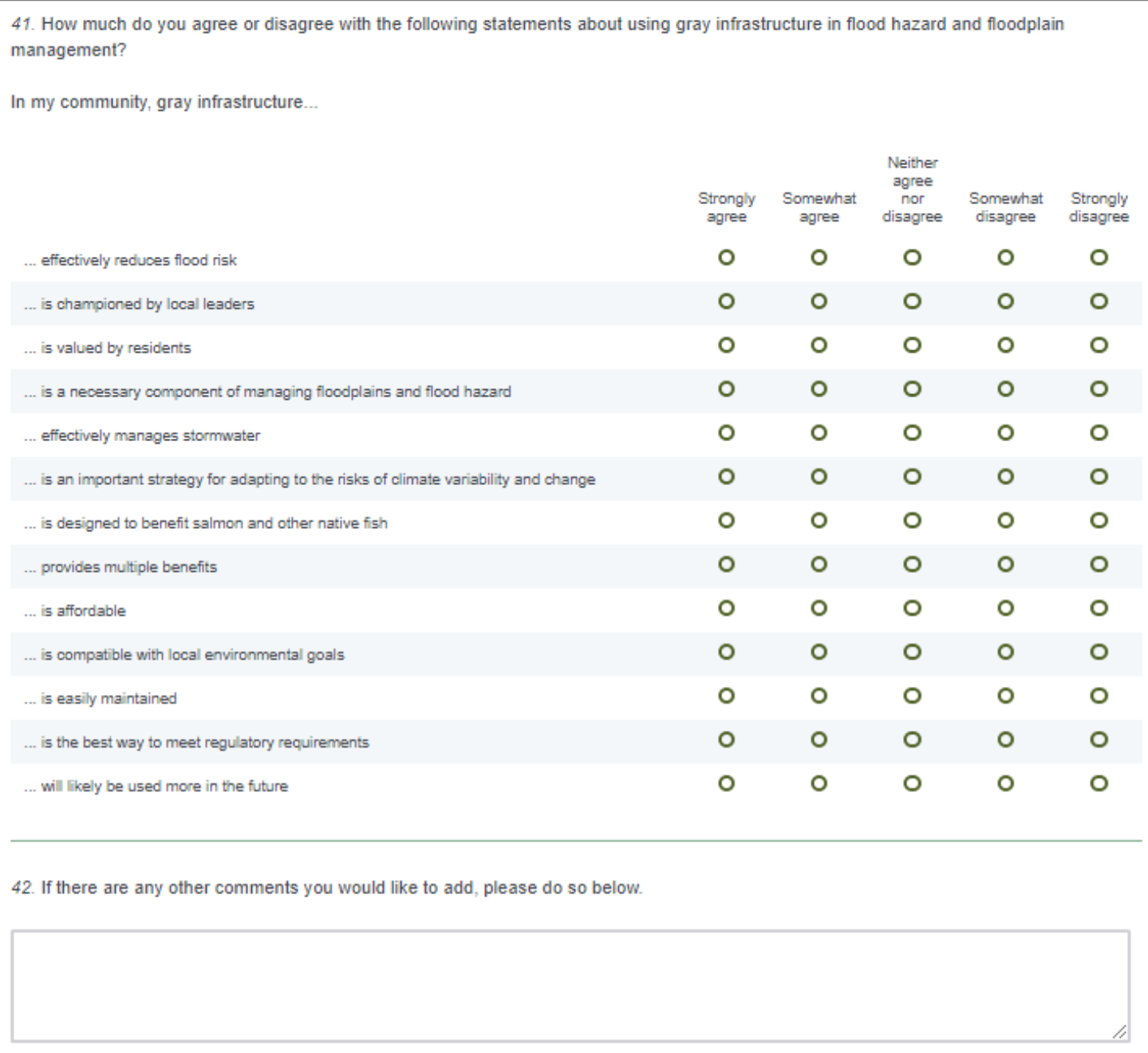


43. What is your political tendency?

O Very liberal

O Somewhat liberal

O Moderate

O Somewhat conservative

O Very conservative

44. I am compiling a list of people that would like to learn more about our results from this survey of flood-prone communities in Oregon. Would you like to be added to this list?

O Yes (Please enter email address)

№

45. Thank you for your time. We really appreciate your contribution to this project. 